\title{
Reliability Analysis of Containment Isolation Systems
}

Manuscript Completed: March 1985

Date Published: June 1985

Prepared by

P. J. Pelto, K. R. Ames, R. H. Gallucci

Pacific Northwest Laboratory

Richland, WA 99352

\section{Prepared for}

Division of Systems Integration

Office of Nuclear Reactor Regulation

U.S. Nuclear Regulatory Commission

Washington, D.C. 20555

NRC FIN B2526 


\section{DISCLAIMER}

This report was prepared as an account of work sponsored by an agency of the United States Government. Neither the United States Government nor any agency Thereof, nor any of their employees, makes any warranty, express or implied, or assumes any legal liability or responsibility for the accuracy, completeness, or usefulness of any information, apparatus, product, or process disclosed, or represents that its use would not infringe privately owned rights. Reference herein to any specific commercial product, process, or service by trade name, trademark, manufacturer, or otherwise does not necessarily constitute or imply its endorsement, recommendation, or favoring by the United States Government or any agency thereof. The views and opinions of authors expressed herein do not necessarily state or reflect those of the United States Government or any agency thereof. 


\section{DISCLAIMER}

Portions of this document may be illegible in electronic image products. Images are produced from the best available original document. 


\section{ABSTRACI}

This report summarizes the results of the Rellability Analysis of Containment Isolation System Project. Work was performed in five basic areas: design review, operating experlence revlew, related research revlew, generic analysis and plant speciflc analysls. Licensee Event Reports (LERs) and Integrated Leak Rate Test (ILRT) reports provided the major sources of contalnment performance information used in this study. Data extracted from LERs were assembled into a computer data base. Qual itative and quantitative Information developed for containment performance under normal operating conditions and design basis accidents indicate that there is room for improvement. A rough estimate of overall contal nment unavallability for relatively small leaks which violate plant technical specifications is 0.3 . An estimate of containment unavallabllity due to large leakage evets is in the range of 0.001 to 0.01 . These estimates are dependent on several assumptions (particularly on event duration times) which are documented in the report. 


\section{STUDY CONTRIBUTORS}

NRC Preject Manager

Y. Huang(a)

PNL Project Manager

P. J. Pelto

Desion Review

K. R. Ames

C. H. Henager

M. A. McL ean

R. J. Shippell

Operating Experience Review

C. A. Counts

R. H. Gallucci

J. C. Lavender

T. B. Powers

M. T. Smith

Related Research Review

M. R. Garnich

Generic Analys is

P. J. Pelto

Plant Specifle Analysis

P. J. Pelto

Plant Specific Analys is

P. J. Pelto

Collections and Rev lew of Additional Data

S. H. Bian

J. C. Lavender

P. J. Pelto

LER Computer Data Base and User Manual

K. R. Ames

R. H. Gal I ucci

(a) U.S. Nuclear Regulatory Commission

$$
v / v i
$$




\section{CONTENTS}

1.0 SUMMARY . . . . . . . . . . . . . . . . . . . 1.1

2.0 INTRODUCTION . . . . . . . . . . . . . . . . . . 2.1

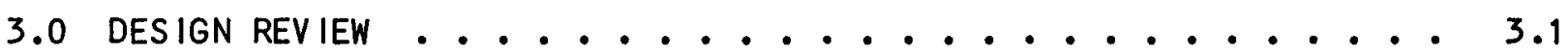

4.0 OPERATING EXPERIENCE REVIEW . . . . . . . . . . . . . 4.1

4.1 TRENDS OBSERVED IN REVIEW ING LER ABSTRACTS . . . . . . . . 4.1

4.1.1 Fallure Trends for Isolation Valves . . . . . . 4.1

4.1.2 Fallure Trends for Penetrations . . . . . . . . 4.2

4.1.3 Fallure Trends in BWRs............. 4.2

4.1.4 Fallure Trends in PWRs . . . . . . . . . . . . 4.2

4.1.5 Trends in Operator/Personnel-Induced Failures . . . 4.3

4.1.6 General Reporting Trends in LERs ............ 4.3

4.1.7 Fallures Resulting In High Leak Rates . . . . . . 4.4

4.2 RESULTS OF SURVEY OF NRC INSPECTORS AND OTHER EXPERTS . . . 4.5

4.2.1 NRC Inspectors ................ 4.5

4.2.2 Amer Ican Nuclear Insurers ........... 4.7

4.3 POTENTIAL USES OF INTEGRATED LEAK RATE TEST (ILRT) DATA • • • 4.8

4.3.1 General Description of ILRT Data Relevant to RACISP - 4.9

4.3.2 Information Available In ILRT Reports . . . . . . 4.10

5.0 RELATED RESEARCH REVIEW . . . . . . . . . . . . 5.1

6.0 GENERIC ANALYSIS . . . . . . . . . . . . . . . . 6.1

6.1 TECHNICAL SPECIFICATION VIOLATIONS . . . . . . . . 6.1

6.2 LARGE LEAKAGE EVENTS . . . . . . . . . . . . . . 6.2

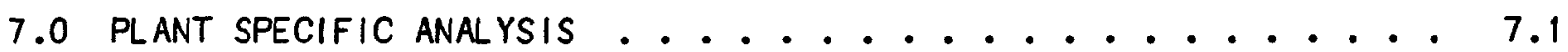

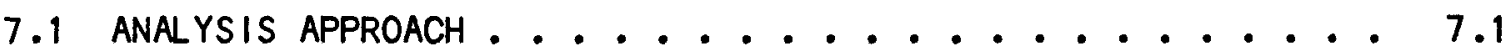

7.2 PEACH BOTTOM 2 EXAMPLE ................. 7.2

7.3 ST. LUCIE 2 EXAMPLE ................ 7.3

8.0 COLLECTION AND REVIEW OF ADDITIONAL DATA . . . . . . . . . 8.1

8.1 ADDITIONAL LER DATA . . . . . . . . . . . . 8.1

8.2 REVIEW OF ILRT REPORTS ................. . . . 8.1

9.0 CONCLUSIONS AND RECOMMENDATIONS . . . . . . . . . . . . 9.1 
REFERENCES . . . . . . . . . . . . . . . . . . . R R

APPENDIX A. USER MANUAL AND LISTING FOR LER COMPUTER DATA BASE • • • . A.1

APPENDIX B. STRUCTURE OF LER DATA BASE . . . . . . . . . . . . B. 1

APPENDIX C. LISTING OF PENETRATIONS AND VALVES . . . . . . . . . . c.1 


\section{IABLES}

1 Summary Results for Containment Unavallabllity . . . . . . . 1.2

2 ILRT fallures of Interest .................. 8.3

3 Leak Rate/Leak Area Calculation Method . . . . . . . . 8.4

$4 \quad$ ILRT Leak Area Data . . . . . . . . . . . . . . . . 8.5 


\subsection{SUMMARY}

Contalnment structures and their isolation systems are designed to reduce the radiological consequences and risk to the public from varlous postulated design basis accident conditions. In the context of probabilistic risk assessments, questions have been raised concerning the avallability and rel lability of containment i solation systems when they are called upon to function under various accident conditions. To assist in providing answers to these questions, the Containment Systems Branch of the U.S. Nucl ear Regulatory Commission (NRC) contracted with the Pacific Northwest Laboratory (PN) to perform the Reliability Analysis of Containment I solation Systems Project (RACISP). The results of this study will be used by the NRC in the resolution of Generic Issue II.E.4.3, in evaluations of the consequences of potential containment leakage and in assessments of the adequacy of containment isolation system designs and leak detection programs. The results will al so be useful in the NRC staff's severe accident evaluation program where quantitative specifications are needed for containment integrity at the onset of various postulated accident scenarios.

RACISP was initiated in July 1983. The primary sources of information used in conducting the study were Licensee Event Reports (LERs) and Contalnment Integrated Leak Rate Test (CILRT) reports. LERs from 1965 through 1984 were reviewed, and 1858 containment related fallure events were identified. Data extracted from the LERs were assembled into a computer data base. In addition, avallable CILRT reports were reviewed and 109 reports documenting potential containment related fallure were identified.

Table 1 summarizes the prel iminary estimates of contal nment unavallability resulting from this study. Containment unavallability is defined as the probabllity that the containment will not perform its function successfully at any given time during plant life. The information contained in the LERs and CILRT reports was not always presented in sufficient detall to permit an accurate characterization of potential breaches of containment integrity. Consequently, the resulting estimates of containment unavallability have a substantial measure of uncertainty.

As seen from Table 1, a preliminary estimate obtalned from the LER data base of containment unavailability due to large leakage events (holes in the containment liner or open containment isolation valves) is in the range of .001 to .01. Containment unavailability for relatively small leaks which violate plant technical speciflcations is estimated to be 0.3 . The estimated containment unavallabllity from simultaneously opened alrlocks is $5 \mathrm{E}-05$. Estimates of containment unavallability as a function of leak area were obtalned using CILRT data. For pressurized water reactors (PWRs) contal nment unavallability ranges from 0.05 for a leak area of 0.006 square inches to 0.075 for a leak area of 0.6 square inches. The total unavallability for PWRs is estimated to be 0.25 . For boll ing water reactors (BWRs) containment unavallabllity ranges from 0.161 for a leak area of 0.006 square inches to 0.036 for a leak area of 0.6 square inches. The total unavallability for BWRs is estimated to be 0.34 . These results can be combined to obtain a prel iminary est Imate of IIght water reactor (LWR) contalnment unavallability of 0.29 . 
It should be noted that these results are often based upon incomplete and imprecise information and caution must be exercised in any use of the results. The estimates of contal nment unavallabilities and assoclated leak areas are dependent upon several assumptions which are documented in the report. Recommendations for obtaining additional data and performing more detalled containment system rel labllity analyses are provided.

IABLE 1e Summary Results for Containment Unavallabil ity

\section{Containment Unavallabllity Leak Area or Rate}

LER Data Base

Tech Spec Violations

\section{3}

Airlocks

Large Leaks

CILRT Data Base

PWR

BWR
0.05

0.125

0.075

0.25 Total

0.161

0.143

0.036

0.34 Total

0.29
$1-10 \times$ al lowable

leak rate $(a)$

$5000 \mathrm{sq}$ inches

28 sq inches

Overall LWR

$0.006 \mathrm{sq}$ inches

0.06 " "

$0.60 "$ "

$0.006 \mathrm{sq}$ inches

0.06 " "

$0.60 " 11$

(a) Allowable leak rate is defined as the containment leak rate that will satisfy 10 CFR Part 100. 


\subsection{INTRODUCTION}

Since the TMI Accident, questions have been raised by the Nuclear Regulatory Commission (NRC) staff, the pub/lc, and the nuclear industry concerning the rellability of contalnment isolation systems (CIS) if called upon to function in the event of an accident. In order to respond to such questions, certain information and operating data on containment performance must be developed to be used in evaluating the effectiveness of containment isolation systems.

In July 1983, the Pacific Nor thwest Laboratory (PNL) commenced a project in which avallable contal nment performance data was collected and consol idated. The overall objective was to use this data to perform rellability analyses of containment isolation systems. More specifically, the goal was to quantify the probabllity of pre-existing contalnment boundary leak areas.

The primary sources of information Identified for use in generating the data base were Licensee Event Reports (LERs) and Containment Integrated Leak Rate Test (CILRT) reports. A computer data base of reported breaches of contalnment integrity was created. This data base can be updated as additional containment performance data becomes avallable. Sections 3,4 and 5, and Appendices $A$ and $B$ of thls report descrlbe the data collected, how the data are stored in the computer data base, and how data can be retrleved from the data base. It should be noted that the information in the data base is not always in sufficient detall to permit an accurate characterization of a potential breach of contalnment integrity. This lack of detall is primarily due to the fact that reporting requirements were not originally developed with the present study objectives in mind.

Even though any use of the data developed may result in a substantial measure of uncertainty. Sections 6 and 7 demonstrate how the data can be used in estimating the reliability of containment isolation systems. Such estimates were made for different classes of plants as well as for specific plant types. Section 8 shows that additional data from LERs and CILRT reports wlll have only a small effect on the reliability estimates.

The implications of the results and the necessary qualifications and assumption that must be made in using the results are discussed in Section 9. There is no information presented in this report that pertains to containment behavior under severe accident conditions. Nevertheless, the results could possibly be used in ongoing severe accident evaluation programs to more accurately deplct the status of containment integrity at the onset of a severe accident. 


\subsection{DESIGN REYIEW}

As noted by Blejwas (1982), there are at least 11 different combinations of containments using different combinations of reinforced concrete, steel and tendons in a varlety of geometric configurations. The use of such design options as ice condenser, subatmospherlc, and inerted containments further increases the number of different containment types. A brief review of the different types of containment designs was performed as one of the initial steps of this project. A review of guidelines and standards related to Cls design and performance was al so conducted. The basic objectives of this design revlew were to identify major differences in containment isolation system design; to develop potential groupings of containment types; and to develop information to assist in developing a data classification scheme for use in the subsequent operating experience review.

Seven containment types were selected as representative of the main types of ClS design. These include: large dry, ice condenser, dual, subatmospheric, Mark I, Mark II, and Mark III. Of these seven, FSARs were revlewed for the following plants:

$\begin{array}{ll}\text { Plant } & \text { Contalnment Type } \\ \text { Pal isades (PWR) } & \text { Large Dry } \\ \text { Sequoyah } 1 \text { (PWR) } & \text { Ice Condenser } \\ \text { St. Lucie 2 (PWR) } & \text { Dual } \\ \text { Surry I (PWR) } & \text { Subatmospher ic } \\ \text { Peach Bottom 2 (BWR) } & \text { Mark I }\end{array}$

Avallable information on valve and penetration size, type, and normal, shutdown and accident status (e.g., open or closed) was cataloged. Information from this review was used to develop the LER data classification scheme outlined in Appendix B.

This design review indicated that similarities exist for the penetrations and valve designs for the contalnment types identifled above. For example, they all contain large penetrations and valves such as equipment hatches, personnel air locks, and purge/vent valves. However, many differences are noted, particularly, between PWR and BWR designs.

The simplest grouping of containment design is a PWR category and a BWR category. This grouping may be useful for general rellability comparisons. More speciflc rellability comparisons and consideration of potential 
improvements (e.g., continuous containment pressure monitoring system) would require more containment-type-specific and even plant-specific analyses. The Detalled Revlew and Analysis Task further investigates differences in performance of the different contalnment designs.

In support of this design review, applicable standards and guidel ines related to CIS design and performance were identifled and reviewed to provide background information for the operating experience review. 


\subsection{OPERATING EXPERIENCE REYIEW}

This section summarlzes the results of a review of operating experience with containment isolation systems. The prime sources of operating experience information were Licensee Event Reports (LERs). Additional information was gathered from NRC inspectors, containment leakage testing reports, and the technical literature. The Nuclear Safety Information Center (NSIC) data base was screened for failures of containment isolation valves and penetrations as recorded in the Licensee Event Reports. For a time period ongoing from April 1965 to May 1983, approximately 3000 entries that could be of potential interest were identified. LER abstracts were reviewed for these incidents and a classification scheme was developed using the results of the design review discussed in Section 3.0. Appendix B provides detalls on the classification system used and information contained in the data base. A summary and a detalled listing of the data base have been prepared and are available upon request from the NRC project manager. Section 4.1 discusses general findings from the LER reviews. Results from a survey of selected NRC inspectors and other eyperts are given in Section 4.2. Section 4.3 discusses the avallability and potential uses of integrated leak rate test (ILRT) data.

\subsection{IRENDS OBSERVED IN REVIEW ING LER ABSTRACTS}

Of the LER (and Abnormal Occurrence Report) abstracts reviewed for fall ures related to CISSs, approximately 2000 were found to be applicable, that is relating to fallures to isolate and/or excessive leakage. Since some LERs describe multiple fallure incidents, the total number of applicable Cls failure incidents extracted from these abstracts was approximately 3000. Thus, for every three LERs classified as CIS-related in the Nuclear Safety Information Center data base, one can expect two to address CIS failures-to-isolate and/or excessive leakage. However, al though one of every three so classifled LERs does not address these types of CIS fallure, roughly a one-to-one correspondence exists between the number of LERs and the number of ClS failure incidents addressing isolation failure and/or excessive leakage.

\subsubsection{Eallure Trends for Isolation Valves}

Valve failures accounted for approximately 70 percent of all applicable $\mathrm{ClS}$ failures. Leakage was observed to be the most frequent type of isolation valve fail ure in the LER Review. Most often, seat damage due to foreign material was the cause of the leakage. Seat corrosion, general seat wear, and packing leakage were other frequently observed failure causes. Failures of isolation valves to close were usually found to be caused by the following:

- valve operator failure/problems

- packings (generally too tight, thereby causing torque switches to kick out before full closure)

- interruption of valve operator power/air supply 
The valve operator problems accounted for approximately 40 percent of the fallures to close, with air solenoids and I imitorque operators comprising the majority of these. In the case of air-operated solenoid valves, the solenold fall ure was often caused by contaminated alr. In several incidents, less clean service air was bled into the cleaner instrument air supply. Some solenoids have shown a tendency to stick due to baking of oll contained in the air supply. The Zion plants have been especially susceptible to these air-operated solenoid valve problems.

\subsubsection{Fallure Irends for Penetrations}

Penetration fallures accounted for approximately 30 percent of all $\mathrm{ClS}$ fallures. Approximately 90 percent of the penetration fallures in the LER Review were attributable to personnel air lock (PAL) problems. Primary fallure causes were as follows:

- leakage past door seal gaskets

- leakage due to foreign materlal on seals

- failures to close due to interlock mechanism fallures or mal adjustment

PAL fallures accounted for the majority of failures to isolate (as opposed to excessive (eakage).

\subsubsection{Eailure Trends in BWRs}

Primary containment fallure/problems for BWRs are most often related to valve fallures-to-close or excessive leakage. Leakage past MSIVs was especially frequent (much more than in PWRs), often involving as many as 15 valves leaking in excess of technical specifications. MSIV failures to isolate were rarely reported.

Fallures-to-close were most often attributable to valve operator problems, closing on foreign materials, and separation of the valve disk from the valve stem (a mechanical control parts fallure). Other BWR valves experiencing problems include vacuum breaker valves, containment vent valves, and traversing in-core probe valves.

\subsubsection{Eallure Trends in PWRs}

PAL leakage dominated the CIS failures in PWRs and accounted for approximately half of the LERs for PWRs. PAL seal problems were caused primarily by dirt, aging, and forelgn materlal damage. Failures of one or both of the PAL doors to close and latch were al so reported frequently. Often, one of the doors would not latch. When the operator opened the other door, the pressure differential would cause the unlatched door to swing open. This type of fallure was almost always caused by problems with the interlock mechanism. However, many of the incidents involving simultaneous opening of PAL doors were attributed to "operator error." Al so noteworthy is that PAL fail ures often occurred whlle the plant was at or near full power. 
Remalning problems in PWRs involved valve leakage and/or fall ures to close. Excessive leakage through large purge isolation valves was another prevalent type of valve fallure at the PWRs. Degradation of the valve seat because of the operating environment was often responsible for leakage.

\subsubsection{Irends in Operator/Personnel-InducediFallures}

Both BWRs and PWRs experlenced CIS fall ures attributed to plant personnel. Personnel-induced fallures occurred relatively uniformly at both plant types. Common incidents involved the following:

- operators forgetting to close valves after testing or power transitions

- maintenance personnel incorrectly wiring or installing valves

- construction personnel damaging valves and penetrations during plant modifications or repairs

Incidents such as the above were often traceable to procedural deficlencies. Incidents were also reported where holes were drllled through containment and left unsealed until discovered during an ILRT. These fallure were attributed to personnel error.

\subsubsection{General ReportingiTrends in LERs}

With reference to the information extracted from the LER abstracts for the LER Coding Form, the fol lowing data were found to usually be reported $(>2 / 3$ of the time):

- component identifier

- system (in which located)

- fallure mode and causes

- discovery mode

- corrective actions

The foll ow ing data were sometimes reported $(1 / 3-2 / 3$ of the time):

- component type, location (relative to contalnment), and manufacturer

- related LERs 
Remaining problems in PWRs involved valve leakage and/or fallures to close. Excessive leakage through large purge isolation valves was another prevalent type of valve fall ure at the PWRs. Degradation of the valve seat because of the operating environment was often responsible for leakage.

\subsubsection{Irends in Operator/Personnel-Induced_Fallures}

Both BWRs and PWRs experienced CIS fall ures attributed to plant personnel. Personnel-Induced fallures occurred relatively uniformly at both plant types. Common incidents involved the following:

- operators forgetting to close valves after testing or power transitions

- maintenance personnel incorrectly wiring or installing valves

- construction personnel damaging valves and penetrations during plant modifications or repairs

Incidents such as the above were often traceable to procedural deficlencies. Incidents were al so reported where holes were drllled through containment and left unsealed until discovered during an ILRT. These fallure were attrlbuted to personnel error.

\subsubsection{General Reporting Trends In LERs}

With reference to the information extracted from the LER abstracts for the LER Coding Form, the following data were found to usually be reported $(>2 / 3$ of the time):

- component identifier

- system (in which located)

- fail ure mode and causes

- discovery mode

- corrective actions

The following data were sometimes reported $(1 / 3-2 / 3$ of the time):

- component type, location (relative to containment), and manufacturer

- related LERs

The following data were usually not reported ( $1 / 3$ of the time):

- fallure duration

- whether or not containment was isolated

- leak rates 
LER abstracts on valve leakage tended to provide the least information, primarlly due to a tendency to address several leak rate test fallures in a single LER.

As noted earl ler, LER (and Abnormal Occurrence Report) abstracts from Apr II 1965 through May 1983 were reviewed. From 1965 through mid-1977, the abstracts contained only general information about incidents. Little of the specific information sought for the LER Coding Forms was provided and no definite numbering system for the incldent reports was evident. Event dates and reactor power levels were reported inconsistently. The event descriptions provided in the abstracts were general, providing little speclfic information such as leak rates and valve types, locations, sizes, and manufacturers.

From mid-1977 through 1981, the qual ity of the abstracts improved. More detalled incident descriptions were provided, and more of the specific information sought for the LER Coding Forms was found. However, some relapse in the reporting qual ity seems to have occurred with the most recent LER abstracts (1982-1983). Sufficient Information was stlll provided to permit completion of most of the items on the LER Coding Forms; however, this information was less complete than that found in the mid-1977 through 1981 LER abstracts

\subsubsection{Eallures Resulting in Hilah Leak Rates}

In review Ing the LER data base several incldents were noted which had the potential for very high leakage rates. Since IImited Information was provided on leak rates or leak areas, a brlef review was performed of fallures involving valves and penetrations with a large leak potentlal. Three types of events are of interest: large penetration fail ures (e.g., airlocks); large valve fallures (e.g., purge/vent valves); and direct breach of contalnment (e.g., drilled holes).

Many instances of fallure of one airlock door or seal appear in the data base. A smaller number of fallures of both doors or instances of leaving both doors open were noted. The following incident is a typical example:

\section{Date Reactor Exent Lype Leak Rate}

12/18/78 Arkansas Nuclear 1 Large Dry Emergency hatch Leak rate function
outer and Inner of hatch area but
doors left open corrective actlon
taken in seconds

Although the potentlal leak area is large for these type of events, airlock or similar penetration failures may not be of major concern due to the short fallure duration and a frequent testing interval. The large number of fallures do indicate some design problems which should be investigated. 
Fallures of large valves have resulted in large leak rates. The data base contains a large number of single valve fallures but fallure of two valves is required for a large leak rate. Purge valves and vent valves are of interest because of their size and fallure rates. Selected incidents are described below:

\begin{tabular}{|c|c|c|c|c|}
\hline Date & Reactor & $\begin{array}{c}\text { Containment } \\
\text { Type } \\
\end{array}$ & Event & Leak Rate \\
\hline 1973 & Oconee 1 & Large Dry & $\begin{array}{l}3 \text { I solation valves } \\
\text { open }\end{array}$ & No information \\
\hline $9 / 14 / 79$ & Pal isades & Large Dry & $\begin{array}{l}2 \text { containment exhaust } 3 \\
\text { by-pass valves } \\
\text { left open }\end{array}$ & 3 inch valves \\
\hline
\end{tabular}

Based upon this cursory revlew, the occurrence of several valve fallures with potentially large leak rates were identifled. The LER data base describes the fail ure mechanism but gives little or no information on the leak rates. Section 4.3 discusses Integrated Leak Rate Test (ILRT) reports, another source of leak rate information.

A quick search of the data base revealed few events in which containment was directly penetrated by events such as inadvertent dr Illing. Two such instances have been documented (San Onofre 1 in 1977 and Surry 2 in 1980).

\subsection{RESULTS OF SURVEY OF NRC INSPECTORS AND OTHER EXPERTS}

Selected NRC Senior Inspectors for containment systems were contacted and asked to relate their experlence with contalnment isolation system performance. In addition, American Nuclear Insurers was contacted regarding their reports of contalnment isolation system performance related work (Weinstein 1980).

\subsubsection{NRC Inspectors}

All the inspectors pointed out problems with leakage in BWR MSIVs and PWR large purge isolation valves. One inspector mentioned a problem with the testing conditions for MSIVs--whether to test them during "hot" or "cold" conditions. He favored hot testing since this more readily simulates potential accident conditions. Seat deformation was specifled as the main cause of leakage during testing of PWR large purge isolation valves (butterfly type). One inspector indicated that, if the valve were left open for a few hours prior to its test, the seat would deform sufficiently so that, upon closure and immediate testing, excessive leakage would take place. Often, about an hour in the closed position would be required before the valve seat would return to its normal configuration and subsequently pass the leakage test. 
All the inspectors mentioned that reported leakage rates often do not represent true leakage rates. Utilities are generally allowed to perform some minor repair on a valve prior to recording its "as-found" condition for a leakage test. Similarly, major repair (such as completely rebullding a valve) is permitted prior to recording a valve's "as-left" condition at the end of its leakage test. One inspector indicated that Types $B$ and $C$ tests are performed before Type A, enabling repairs to be made so that the Type A test can be passed easily.

Each inspector had additional comments, the highlights of which are summarized below.

Inspector 1

Inspector 1 noted that PWR outboard isolation check valves, especially ones in the reactor coolant pump seal and letdown I Ines, have falled to pass l eakage tests because of a weak spring that normally assists valve closure. Instrument penetrations which form an extension of the containment boundary sometimes become disrupted during maintenance activities. When returned to service, the leakage test may be ignored. Thus, the penetrations are callibrated only for normal operating rather than design basis pressures. When tested at design basis pressures, they fall. He pointed out that PWR fuel transfer tube drain valves are often not identified as isolation valves and are therefore left open during leakage testing, causing excessive leakage untll closed. He al so brought attention to a concern over the proper fluid medium for use during isolation valve leakage testing, i.e., whether the normal working fluid should be employed rather than exclusively testing with air.

\section{Inspector 2}

Inspector 2 listed some of the more common causes of isolation valve leakage: seating problems, dirt/debris, and packing problems. He al so mentioned that valve designs and configurations sometimes make proper performance of Types $B$ and $C$ tests impossible. Valves may be tested in the "wrong" direction, i.e., opposite to the normal flow direction. However, this difficulty does not ar ise during the Type A test.

\section{Inspector 3}

Inspector 3 noted fallures to pass Type $\mathrm{C}$ tests by BWR isol ation check valves in the feedwater, reactor core isolation cooling, and high pressure coolant injection systems. He made a special point of stating that leakage tests are often performed too quickly after pressurization of the line. Readings are often taken before equllibrium conditions have been established. Test results can vary significantly depending upon the time of testing. He recommended spreading the readings out over at least one-half hour after pressurization.

\section{Inspector 4}

Inspector 4 stated that most problems encountered during Type A tests were due to human errors, primarily in failing to follow test procedures. He felt that these outwelghed hardware-related problems that might be encountered. 
Inspector 5 mentioned that maintenance procedures on isolation valves are not always followed and that isolation valve and penetration inspections are sometimes performed at irregular intervals. San Onofre experienced a Type A test fallure when its containment was breached by drilling during the test.

\subsubsection{American Nuclear Insurers}

In addition to the NRC inspector contacts, M. B. Weinstein of the American Nuclear Insurers was contacted regarding his containment related work reported in the technical literature (Weinstein 1980).

Weinstein indicated that, in screening events (from LERs and ILRT reports) for inclusion in a data base on containment integrity failures, he retained only those incidents where a definite leakage path was established through the contalnment. This approach was taken to minimize questions concerning whether or not certain failures constituted losses of contalnment integrity. Since his goal was to estimate an upper bound on the availability of containment integrity (a lower bound on the unavailability), this approach was reasonable. As a consequence of this limiting assumption, the following types of containment integrity "failures" were excluded from his data base:

- failures of components where containment integrity was maintalned by a functioning, redundant component

- failures where a potential leak path could, but was highly unlikely to, exist. Included in this category were the following:

- isolation valve fallures in liquid-filled systems

- isolation valve failures in systems pressurized above the containment design basis pressure

- as a result of this assumption, isolation valve fallures in engineered safety feature (ESF) systems, air supply systems, and BWR feedwater systems were disregarded.

- Fallures which occurred during outages and were corrected prior to restart. Such failures were deemed not to compromise contalnment integrity since the plant was not in a state where contalnment integrity was essential, so long as the breach was corrected prior to restart.

Weinstein noted numerous fall ures of check valves in BWR feedwater and ESF systems. However, he questioned whether such fallures constituted a breach of containment integrity. The presence of pressurized water within the system should effectively prevent escape of radionuclicies during a potential accident. Certain classes of large valves were of particular interest: purge valves, vent valves, and MSIVs. These often fall in pairs, enabling leakage to exceed the maximum value allowed by technical specifications. 
Personnel air lock (PAL) fallures (both doors simultaneously), though common, usually constitute only a small percentage of the total unavailability of contalnment integrity when compared to that attributable to failures of large valves. Although the potentlal leak area through a PAL is I arge, the duration of such fallures is sufficiently short to amount to a small portion of the total unavall ability.

Welnstein explained that approximately one-half of his estimates for fallure durations were obtained from utllity sources. He felt that utilities were a useful source of such information for major contalnment fallures. However, they would be of little value for small fallures, such as for certain Individual valves. ILRT reports sometimes contain information on durations of larger failures and were a better source than LERs for such information.

The results of the RACISP can be compared with Weinstein's results (1980). Containment unavallabll ities obtained in RACISP are typically higher due to several reasons: a lack of detall in the data base, the conservative assumptions made on the leak duration times and whether the reported fallure events actually represented a direct leak path from contalnment. In addition RACISP performed a more detalled review of ILRT reports and defined ILRT fallures more stringently. As discussed earlier in this section, Weinstein (1980) screened out several categorles of events since his goal was to estimate an upper bound on the avallabllity of contalnment integrity (lower bound on the unavailability). The RACISP did not perform this detailed screening and its results may be more representative of an upper bound on the unavallability.

\subsection{POTENTIAL USES OF INTEGRATED LEAK RATE TEST (ILRT) DATA}

A review of reports resulting from ILRTs conducted at elghteen nuclear power plants during the period 1973 through 1983 was undertaken to determine the potential of these type reports as sources of data for use in the detailed review and analysis task. ILRT reports for the following nuclear power plants were reviewed. The reactor and containment types and the year during which the ILRT was conducted are presented in parenthesis.

- Millstone 1 (BWR, Steel Mark-1, 1973)

- Prairie Island 1 (PWR, Steel Double, 1973)

- Arkansas Nuclear 1 (PWR, Prestressed Concrete, 1974)

- Brunswick 2 (BWR, Reinforced Concrete Mark-1, 1974)

- Calvert Cliffs 1 (PWR, Prestressed Concrete, 1974)

- Brunswick 1 (BWR, Rel inforced Concrete Mark-1, 1976)

- Kewaunee (PWR, Steel Double, 1976)

- Donald C. Cook 1 (PWR, Reinforced Concrete lce Condenser, 1978)

- McGulre 1 (PWR, Steel Ice Condenser, 1979)

- Donald C. Cook 2 (PWR, Reinforced Concrete Ice Condenser, 1981)

- Sequoyah 2 (PWR, Steel lce Condenser, 1981)

- Surry 1 (PWR, Reinforced Concrete Subatmospheric, 1981)

- Surry 2 (PWR, Relnforced Concrete Subatmospheric, 1981) 
- Calvert Cliffs 2 (PWR, Prestressed Concrete, 1982)

- Maine Yankee (PWR, Reinforced Concrete, 1982)

- St. Lucle 1 (PWR, Steel Double, 1983)

- Crystal River 3 (PWR, Rel nforced Concrete, 1983)

- Fort Cal houn 1 (PWR, Reinforced Concrete, 1983)

The focus of these reviews was to develop an understanding of the type of information contained in the ILRT reports and ideas about how the information could be used in the process of evaluating containment performance under various accident conditions.

\subsubsection{General Description of ILRT Data Relevant to RACISP}

The purpose of ILRTs is to demonstrate that leakage through primary reactor containment and systems and components penetrating the primary containment is less than the allowable leakage rates specified in the plant's technical specifications. Demonstration of containment integrity is accomplished by performance of local leak rate tests and the integrated leak rate test of the primary containment.

Local leak rate tests are performed individually on components which seal or penetrate the primary contalnment (Type B tests) plus all primary containment isolation valves (Type C tests). The integrated primary containment leak rate test (Type A test) is performed by pressurizing the entire containment structure and measuring the overall integrated leakage rate.

Generally, the ILRT reports reviewed contained some information about results of the Type A, B and C tests; however, the degree of detall avallable varled considerably. Narrative summaries describing the conduct of the Type A tests (including descriptions of test equipment, instrumentation used and analytical techniques used to compute leakage rates), initial plant conditions, a chronology of events occurring during the test (including the discovery of leaks), analysis of the Type A test data and a statement about successful completion of the tests were generally included in all the reports reviewed. Detalled numerical data about the Type A test were generally included in the reports in varlous forms (i.e., tabular and/or graphically).

Data from the Type $B$ and $C$ tests varled considerably in the degree and form in which it was reported. The report resulting from an ILRT conducted at Maine Yankee in 1982 contained data from Type B and C tests conducted in 1980 and 1981. This data was presented in two tables making it easy to compare leakage rates found for given system or component during that two-year time period. A similar reporting format was used in the St. Lucie 1 ILRT Report. Other reports provided some data from previously conducted Type B and C tests but in less convenient formats, while others provided only limited data from tests conducted in conjunction with the ILRT being reported. In some reports the system or component tested was identified by title; while in other reports, system or component identification was by a code or number which would require referring to the plant FSAR for further specification. 
Varlous other types of information such as system drawings, procedure change descriptions, test checklists, computer code descriptions, and measuring equipment calibration certifications were also included in the ILRT reports reviewed.

\subsubsection{Information Avallable in ILRT Reports}

Baslcally the Information contalned in ILRT reports that may be useful to RACISP appears to be the narrative descriptions of the Type A tests and the numerical data resulting from the Type $A, B$ and $C$ tests.

The narrative descriptions provide information concerning leaks that are discovered during pressurization of primary containment. Discovery of a leak during pressurization for the ILRT was reported in many of the reports revlewed. In every case pressurization was halted while the source of leakage was identifled and el ther repaired or isolated. After repair or Isolation, pressurization continued and the ILRT proceeded untll it successfully concluded. In some cases the leakage rate and the leaking system or component are specifically identified in the narrative.

The numerical data resulting from the Type $A, B$ and $C$ tests described in the ILRT Reports can provide useful information on the overall condition of containment integrity. As indlcated in Section 4.1 the LER data base contalns Ilittle information on leak rates and duration times. Information from the over 300 ILRT reports which have been generated can supplement the LER data base and provide essential information on leakage areas. Several organizations have performed report reviews of ILRT reports. ORNL (Dougan 1984) reviewed selected ILRTs in support of the Appendix J revision. Quadrex (Rowley et al. 1983) reviewed a large amount of Type A tests to study testing time reduction. Stone and Webster (Frank et al. 1982) reviewed selected ILRTs and assisted in developing improved test procedures. However, none of these reviews have examined the ILRTs to extract leakage rate data. The results of a more detalled review of ILRTs are described in Section 8.0 . 


\subsection{RELATED RESEARCH REVIEW}

A search was conducted for information on current projects and documents from completed projects whlch were directly related to the RACISP. Brlef descriptions of each of the projects were prepared. The projects were summarlzed under two headings: Current Projects and Comoleted Projects . Each project description includes, where avallable: project title, performing organization, project manager, objectives, major activities, and comments. Major pertinent documents al ready published in the project are included. In some cases an item represents only a published article or report as indicated.

The search identifled eight current and 13 completed projects or studies, and 25 published documents. Of the current work being performed, the large scale effort Involving three programs at Sandia National Laboratories (SN) is the most significant. These include the Electrical Penetration Assemblies Program, the Integrity of Contal nment Penetrations under Severe Accident Loads, and the Containment Integrity Program. Prior to this effort, the Containment Systems Experiment performed by PNL was perhaps the most significant study of contalnment isolation to date. Overall, these projects, along with the other summarized in this report, indicate a shift in emphasis in containment-related research from studies of the potential for gross structural failures to studies of leakage rates, pathways, and human factors which influence the rellability of containment systems.

Some additional studles with particular relevance to RACISP include: the ORNL review of ILRT reports in support of the Appendix J revision (Dougan 1984); the Quadrex revlew of type A test results in support of ILRT testing time reduction (Rowley et al. 1983); the Stone and Webster review of selected ILRTs to assist in developing improved test procedures (Frank et al. 1982); and the Hanford Engineering Development Laboratory review of ILRT reports in support of Fast FI ux Test Facil ity ILRT requirements (Irw In and Conrads 1984). 


\subsection{GENERIC ANALYSIS}

The LER data base contains a large number of single valve and penetration fallures but typically an additional fallure of a redundant component is required for a large leakage rate to result. The data base al so identifles incidents where containment integrity was directly breached. These are the types of incidents of primary interest to this project. These incidents can range from relatively minor violations of technical specification limits to large breaches in containment.

Two major areas are of interest in any rellabllity analysis: rellability and avallability. Rellability is defined as the probability that a component will perform successfully for a given mission time. Avallabllity is defined as the probabllity that a component will perform successfully at a given instant of time. Unrellability and unavailability are the complements of these terms (i.e., component will fall). Typically for on-line components rellability is the measure of interest while avallability is used to describe the status of standby components. Unavailability is useful in describing containment isolation system fallures and can be defined as the total duration of containment failure divided by the total time contalnment is required.

A possible approach for quantifying the unavallabllity of containment isolation systems is to estimate the fallure duration of the complete set of incidents which result in a direct breach of containment along with their leakage rates or leak areas. The failure duration can be divided by the total reactor years represented by the data base (approximately 740 reactor years for the period of the data base covering the time period from April 1965 to May 1983). Several problems were encountered in implementing this approach. As noted in earlier. sections of this report, the LER data base is based upon LER abstracts which often provide only partial information on the fallure events. In particular, the leak rate and the leak duration were seldom given. The complete LER with accompanying letter or contact with the specific utility involved in preparing the report may be required to obtain the necessary detalled information. An additional problem is the incompleteness of the LER data base in including the results of ILRT tests. Several ILRT fallure incidents have been documented. Information on these fallures is often not included in the LER data base and when they are, minimal details are provided.

Recognizing the above problems, a simple analysis of containment unavailability was performed using the LER data base. Two classes of events were examined: those that were known to violate plant technical specification on leak rates and those that were known to result in large leaks.

\subsection{TECHNICAL SPECIEICATION VIOLATIONS}

The LER data base contains 1838 reported events. Valve fall ure (valve falls to close or is improperly opened) or leakage accounts for 1414 reported events while penetration fail ure or leakage accounts for 424 events. A majority of the events reported involve the fallure of one component while a redundant 
component is still functional. These events represent a violation of the plant technical specifications but do not necessarily result in a direct leak path from containment.

Valve and penetration leakage data were examined to obtain an estimate of the unavailability of containment. A majority of events involving leaking valves or penetrations were identified in type $B$ and $C$ local leak rate tests. A total of 534 events were identified which violated the technical specifications on leakage for valves and penetrations other than airlocks. A total of 302 events were identified which violated technical specifications on airlocks. Again, these violations of technical specifications do not necessarily result in a direct leak path from containment. They include such events as one valve leaking above a specified upper limit with an intacct redundant valve in series so that an actual leak path from containment did not exist, and one airlock door leaking but backed up by a leaktight second door.

The events described above were reviewed to develop a subset of events more realistically representing actual leak paths from containment. Many events were identified which violated the Type B and C technical specifications for "as found" leakage (greater than 60 percent of allowable leakage, $L_{a}$ ). Some judgment in reviewing the LER abstracts was necessary but approximately 40 percent, or 215 of the reported valve leakage events appeared to $f$ it this category. Type $B$ and $C$ tests for valves and penetrations other than airlocks are typically performed at least every two years. Conservatively assuming a one-year fallure duration for these types of events and 740 reactor years, an estimated unavailability of containment is 0.3 for leakage from valves and penetrations. These technical specification violations are assumed to result in a leak rate from one to ten times the allowable limit.

\subsection{LARGE LEAKAGE EVENTS}

The LER data base was reviewed to identify events which result in large direct breaches of containment. As discussed in Section 4.1.7, these fallures involve valves and penetrations with a large leak potential. Three types of events were identified: large penetration fallures (e.g., airlocks); large valve fallures (e.g., purge/vent valves); and direct breach of containment (e.g., drilling holes).

Of the 302 events identifled for airlocks, 75 events involved both doors of an airlock being simultaneously opened. These events result in a large leak area but have a very short duration time. The duration times reported range from seconds to a few hours. Conservatively assuming a 4-hour event duration for these types of events and 740 reactor years, the estimated unavailability for containment is 5.0E-05 for leakage from simultaneously opened airlock doors. The doors of typical airlock are assumed to represent an area of approximately 5000 square inches. 
In reviewing the data base, four events were identifled to be of interest in estimating large leakage potential:

\begin{tabular}{lll} 
Reactor & Year & \multicolumn{1}{c}{ Event } \\
\cline { 3 - 3 } Oconee 1 & 1973 & I sol at I on Valves Open \\
San Onofre 1 & 1977 & Hol es In Containment \\
Pal Isades & 1979 & By-pass Val ves Open \\
Surry 1 & 1980 & Hol es in Containment
\end{tabular}

These events all involved a direct breach of contalnment resulting from a procedural breakdown/operator error. Thelr frequency is belleved to be typical of large leakage events. Using 740 reactor years, a frequency of 5E-03 per year is obtained. The LER data base contains no Information on event duration. Based on engineering judgment, an average event duration of one year is assumed. This results in an unavallabli ity of 5E-03. This estimate is very prel iminary and a range of .01 to .001 for the unavallabllity of contal nment from large leakage events is suggested as a prel Iminary estimate. The actual leak area/rate for these events ranged from small drilled holes to an open six inch valve. A leak area equivalent to a six inch open penetration is assumed to obtain a conservative estimate. 


\subsection{PLANT SPECIEIC ANALYSIS}

The information presented in Section 6.0 ignored potential differences due to reactor type and contalnment type. In this section a reference BWR and a reference PWR are examined and a simple rellability analyses of selected containment isolation system components are performed. Appl Icable methods are discussed and data needs are identifled.

\subsection{ANALYSIS APPROACH}

If sufficient containment isolation systems fallure experience exists for the plant of Interest, rellability estimates can be made directly. An approach simllar to that described in Section 6.0 could be appl led to a specific plant. However, such detalled data is seldom avallable and predictive model ing must be used to develop estimates.

A plant specific contalnment reliabllity analysis consists of the following steps:

1. Obtain system description information.

2. Bound the problem.

3. Prepare loglc models (e.g., fault trees) or directly Identify containment leak paths.

4. Obtain fallure rate data, fallure detection data, and leak area data.

5. Calculate unavallability and associated leak area for contalnment leak paths.

6. Develop distributions of unavallability versus leak area.

A key factor in this analysis is the type and qual ity of avallable data. A containment system design consists of varlous mechanical and electrical components for which general fallure data is avallable (e.g., WASH-1400 data base). The LER data base provides information on the number fall ures of varlous containment components over a set time perlod. To be useful in a rellability assessment, this Information must be converted to operating and demand fallure rates. To perform this conversion the number of valves and penetrations for each reactor in the data base is required along with information on the testing frequency. This involves a substantlal effort and work in this area was not performed in this project. The utility of a more detalled LER data base versus the cost to develop such a data base needs o be examined.

In addition to fallure rate data, assoclated leak area estimates are required for a contalnment rellabllity analysls. As discussed in earlier sections, the LER data base provides minimal leak area information. A spectrum of leak areas exist 
for containment components. For example, a valve will leak a small amount at a relatively high probability and will fall completely at a much smaller probabllity. This spectrum of fallures problem is one of the more difficult encountered in safety/rellabllity analysis and no simple solution has been developed. The analyst typically has to resort to engineer ing judgment.

The following sections provide simple examples of a rellability analysis for two reference plants: Peach Bottom 2 and St. Lucle 2.

\subsection{PEACH BOTTOM-2 EXAMPLE}

Peach Bottom 2 is a BWR with a Mark I contalnment. Primary containment consists of a drywell and a pressure-suppression chamber connected by vent tubes. The primary containment is inerted with nitrogen to maintain the oxygen level to less than 4 percent and is surrounded by a secondary containment bullding. As this example will show, the inerting system offers some plant-speclific capability for detecting pre-existing leaks.

Two areas are of interest when examining the response of containment isolation systems to design basis accidents: 1) the potential for pre-existing leaks; 2) fallure at the time of the accident or shortly thereafter (Including fallure to isolate). This project is focused on containment leakage and not gross structural fallure. Also, degradation due to severe accident conditions was not considered.

Appendix $C$ presents a partial listing of the penetrations and valves for Peach Bottom 2. Key valves include: steam line, drywell purge, suppression chamber purge, and suppression chamber vacuum breaker. Major penetrations include: drywell head, drywell head access, equipment access Iatch, and personnel access hatch. A rigorous reliabli ity analysis would examine these and other valves and penetrations to estimate the potential for pre-existing leak and its corresponding size.

For purposes of this example, a failure of the drywell head and a fallure of the suppression chamber vacuum breaker valves were examined. The drywell head is a 32-foot diameter cover with a double gasket seal. The suppression chamber vacuum breaker system consists of two 20-inch IInes with two valves in series. Both valves are located outside of primary containment. One valve is air operated and is opened when a differential pressure switch de-energizes a dc solenoid valve to release air from the air operator. This valve falls open upon loss of air supply and may be opened from the control room. The other valve in each line is a self-operating vacuum breaker simllar to a simple check valve.

The Reactor Safety Study (NRC 1975) gives a failure rate for double gaskets of 3E-09 per hour. Assuming gasket fallure results in a leak area $1 / 16$ inch times the circumference of the gasket, a leak area of 75 square inches is estimated. The reference BWR has an inerted containment which allows for detection of unacceptable leaks. A three-day detection and correction time is assumed resulting in an unavailability of 2E-07 for a 75 square inch leak area for this event. 
The Reactor Safety Study (NRC 1975) gives a fallure rate of large piping of 1E-10 per hour. Assuming this represents a complete break, a leak area of 300 square inches is estimated. Similarly to above a three-day detection and correction time is assumed. An unavallabllity of 7.2E-09 is estimated for a 300 square inch leak area. Using valve fallure rate data in the Reactor Safety Study, an unavallability estimate of two valves falling open or remaining open is 1.3E-07. This estimate assumes a six-month detection and correction time for each component. Using this six-month value, a fallure rate for two valves remaining open of 3E-11 per hour is obtalned. Again assuming a three-day detection time for two valve fallures, an unavallability of $2.2 \mathrm{E}-09$ is estimated for a leak area of 300 square inches.

A detalled reliability analysis would examine each major penetration and valve and obtain estimates of the unavallabllity and leak area simllar to the above analysis. In addition to pre-existing leaks, the fallure of containment isolation components at the time of the accident or shortly thereafter are of interest. The Reactor Safety Study (NRC 1975) used Peach Bottom 2 as a reference plant and obtained a value of 3.1E-04 for a leak area of 1 to 13 square inches (a common mode contribution of 5E-03 was identifled in the study but was conservatively calculated and significant for large LOCA only) and a value of 1.7E-04 for a leak area greater than 28 square inches. These values are substantially larger than those presented above. As an upper bound comparison, the large leak frequency developed in Section 6.0 (5E-03 per year) is applied to the reference BWR. Again a three-day detection and correction time is used. This results in an estimated unavallability 4.1E-05 for large leaks. Based upon the leak detection capabllities of BWRs with inerted containments, the impact from large pre-existing leaks on BWRs should not be of major concern assuming proper action is taken to identify and correct them.

\subsection{ST. LUCIE-2 EXAMPLE}

St. Lucie 2 is a PWR with dual contalnment. Primary containment is a steel contalnment vessel. This vessel is surrounded by a reinforced concrete shield building and the two structures are separated by an annular space.

Appendix $C$ presents a partial listing of the penetrations and valves for St. Lucie 2. Key valves include: contalnment purge, hydrogen purge, and containment vacuum rel lef. Major penetrations include personnel access airlocks, the equipment access hatch, piping and duct penetration sleeves and electrical penetration sleeves. A rigorous rellability analysis would examine these and other valves and penetrations to estimate the potential for pre-existing leak and its corresponding size.

For purposes of this example, a fallure of the equipment access hatch and a fallure of the contalnment vacuum rel lef system were selected. These systems roughly correspond with those selected for Peach Bottom 2. The equipment access hatch is a 28-foot diameter plate with a double gasket seal. The containment vacuum consists of a 24-inch line with two valves in serles. A check valve is inside containment and a butterfly valve outside the containment. 
The Reactor Safety Study (NRC 1975) gives a fallure rate for double gaskets of 3E-09 per hour. Assuming gasket fallure results in a leak area of $1 / 16$ inch times the clrcumference of the gasket, a leak area of 66 square inches is est Imated. Unl Ike Peach Bottom 2, St. Lucle 2 does not have any continuous leakage detection capabllity. A one-year detection and correction time is assumed based upon Type B leak testing at 2-year intervals and I imited use of the hatch. An unavailability of $2.6 \mathrm{E}-05$ for a 66 square inch leak area is est imated.

Since the inner valve is located inside contalnment, failure of the plping in the vacuum rel ief systems is not of major Interest. Using valve fallure rate data in the Reactor Safety Study and a six-month detection and correction time, an unavailability estimate of 1.3E-07 was calculated for two valves falling or remaining open. No common mode effects were considered. Thus an unavallability of 1.3E-07 for a 450 square inch leak area is estimated.

A detalled rel labllity analysis would examine each major penetration and valve and obtain estimates of the unavallabllity and leak area similar to the above analysis. In addition to pre-existing leaks, the fallures of containment isolation systems components at the time of the accident or shortly thereafter are of interest. The Reactor Safety Study (NRC 1975) analysis of the Surry plant (PWR, subatmospheric) resulted in a value of 8.6E-04 for a leak area greater than 13 square inches. A more recent study (Carlson 1981) of Sequoyah (PWR, ice condenser) obtal ned a value of 1.2E-04. These values are assumed to bound those of St. Lucle 1. These values are somewhat larger than those presented above. As an upper bound comparison, these values should be compared with the unavallability of contalnment due to large leaks of 5E-03 (see Section 6.0). Thls comparison indicates that pre-existing leaks should be more carefully examined for PWRs similar to St. Lucle which have no continuous or short-term leak detection capabllities. 


\subsection{COLLECTION AND REYIEW OF ADDITIONAL DATA}

The Collection and Review of Additional Data Task updated the LER data base to May 1984 and repeated the generic analysis presented in Section 6.0. The generic analysis was expanded to include a more detalled revlew of ILRT reports. The results of Type A, Type B and Type C tests were used to obtain a prel iminary estimate of containment unavallability.

\subsection{ADDITIONAL LER DATA}

Fol lowing the approach outl ined in Section 6.1, valve and penetration leakage data were examined to obtain an estimate of the unavallabllity of containment. The total reactor years for the perlod of the LER data base (April 1965 to May 1984) is approximately 815 ( 473 PWR and 342 BWR). A total of 232 leakage events were identified to be of interest. An estimated containment unavailability of 0.3 is obtained and is the same as the previous estimate.

The updated LER data base identifled 86 simultaneously opened airlock events. Conservatively assuming a 4-hour event duration time for these types of events and 815 reactor years, the estimated unavallabllity of containment is 5.0E-05. This is the same as the prevlous estimate.

A review of the updated LER data base identifled no additional events involving large valve fallures or direct breaches of contalnment. Using the four events described in Section 6.2 and 815 reactor years, an unavallabllity of 5E-03 is obtained. This is the same as the previous estimate.

The above results indicate that the unavallability estimates for technical specification violations and large leakages are not sensitive to one more year of additional data. It does not appear necessary to update the data base annually and a two or three year interval may be approprlate.

\subsection{REVIEW OF ILRT REPORTS}

Integrated Leak Rate Test (ILRT) reports provide a data base of potential use in the RACISP. A recent study by the Hanford Engineering Development Laboratory (Irw in and Conrads 1984) was used to obtain Information on integrated leak rate test (ILRT) fallures. This report provides data on the majority of ILRT tests conducted to date for the U.S. LWR Industry. Actual and potential ILRT fallures are documented and where avallable estlmates of the leakage rate is given. A total of 231 ILRTs were revlewed to Identify specific instances in which a contalnment falled to meet the required integrity as found during the ILRT. An ILRT was considered a falled test under the following conditions: evidence of structural deterloration; an identified leak path is isolated to meet the test acceptance criterla; the contalnment boundary is altered so that the ILRT is affected; the test sequence is aborted to repair identified leak paths; and test conditions change which result in underpredicting the leak rate. of the 231 ILRTs, 69 were preoperational ILRTs which serve to identify design and construction failures and are not of direct interest to RACISP. 
The Rellability Analysis of Containment Systems Project is primarily interested in identifled leak paths which were isolated and/or repaired. Sixty ILRT fallures were identifled to be of direct value in estimating containment unavallabllity (see Table 2). Of these sixty ILRT fallures, 35 were for BWRs and 25 were for PWRs. Fallures of pre-operational ILRTs, ILRTs which falled due to ILRT instrumentation problems, and ILRTs whlch falled due to leaks Into PWR secondary systems were not considered. The 231 ILRT reports revlewed represent a total operating period of 571 years from the pre-operational ILRT to the most recent ILRT for the reactors considered. PWRs represent 329 years and BWRs represent 242 years. Assuming a typlcal three year test interval for an ILRT and an average fallure duration of one-hal $f$ of this period, the estimated unvallability of containment is 0.16 for LWRs. PWR unavallabllity is 0.11 and BWR unavailabllity is 0.22 .

The ILRT data base contains l imited information of the leakage rates assoclated with the above contalnment unavallabilities. Leakage rate data is provided for 29 of the 60 ILRT fallures. This data is typically given in terms of percent per day or a factor of al lowable leakage. The isentropic flow model was used to obtain estimated leak areas for the ILRT data. Table 3 provides the detalls of the model used. Table 4 gives the avallable leakage rate data and the calculated leak areas. The calculated leak areas ranged from approximately 0.007 square inches to 0.65 square inches. The fraction of ILRT fallures falling into subsets of this range was calculated for PWRs and BWRs. It was assumed that the range of leak rates reported al so applled to ILRT tests where no leak rate information was provided. The results of this analysis are summarized below:

PWR Containment Unavailabllity ys, Leak Area

\begin{tabular}{cc} 
Unavallability & Leak Area, sq. inches \\
0.022 & 0.006 \\
0.055 & 0.06 \\
0.033 & 0.60 \\
\hline 0.11 total &
\end{tabular}

BWR Containment Unavallabllity vs. Leak Area

\begin{tabular}{cc} 
Unavallability & Leak Area, sq. inches \\
0.104 & 0.006 \\
0.093 & 0.06 \\
0.023 & 0.60 \\
\hline 0.22 total &
\end{tabular}

The above results indicate that al though BWRs have a higher containment unvallabllity, the fallures are assoclated with a smaller leak area than PWRs. On an expected leak area basis (unavallabllity times leak area) fallures with the larger leak areas dominate the results. The expected leak area of a PWR is higher than that of a BWR. 
TABLE 2. ILRT Failures of interest

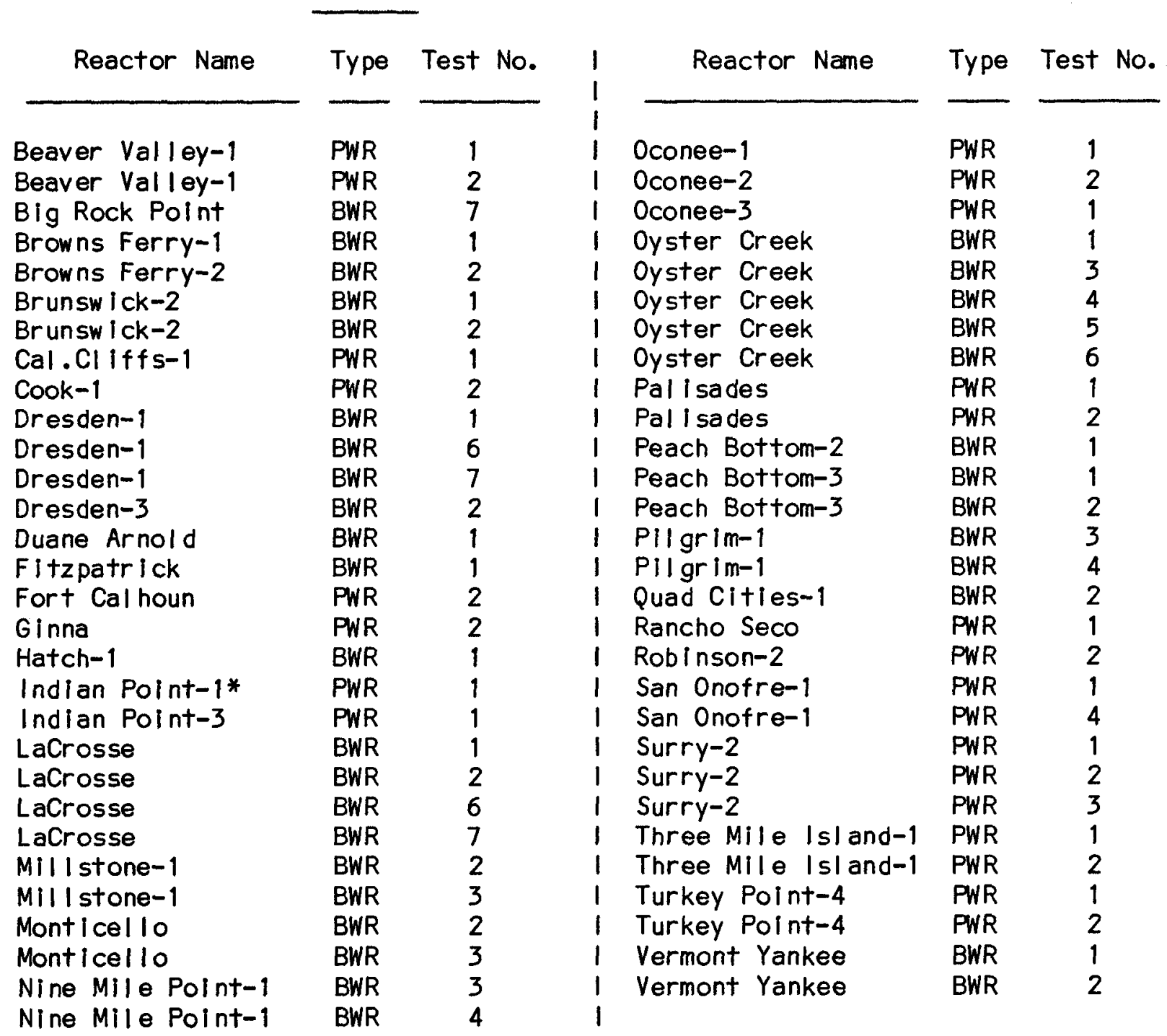

* Note two falled ILRTs reported so count twice 
IABLE 3. Leak Rate/Leak Area Calculation Method

Use Isentropic flow model. Assume choked flow and properties of air:

$$
A=1.88 \frac{\dot{m} \sqrt{I}}{P}
$$

where:

$$
\begin{aligned}
& A=\text { area, sq. } f t . \\
& \dot{m}=\text { flow rate, } I b_{m} \text { per second } \\
& T=\text { temperature, }{ }^{\circ} R \\
& P=\text { pressure, } I b_{f}
\end{aligned}
$$

The flow rate can be written in terms of the welght percent leakage per day and the welght of air in contal nment:

$$
\dot{\mathrm{m}}=(1.16 \mathrm{E}-07) \mathrm{Lm}
$$

where:

$\dot{m}=$ flow rate, $I b$ per sec.

$L=$ leakage, wt. percent per day

$m=$ welght of air, $1 b_{m}$

Assuming an air temperature of $530^{\circ} \mathrm{R}$ and the ideal gas law:

$$
P V=m R T
$$

where:

$$
\begin{aligned}
& P=\text { pressure, } I b_{f} \\
& m=\text { welght of alr, } I b_{m} \\
& R=\text { gas constant for air }=53.3 \mathrm{ft}-1 b_{f} \text { per } I b_{m}{ }^{\circ} R \\
& T=\text { temperature }=530^{\circ} R
\end{aligned}
$$

Combining equations (1), (2), and (3) and converting area to square inches, results in Equation (4).

$$
A=(2.55 E-8) L V
$$

where:

$A=$ leak area, sq. in.

$L=$ leakage, wt. percent per day

$V=$ containment volume, cubic ft. 
TABLE 4. ILRT Leak Area Data

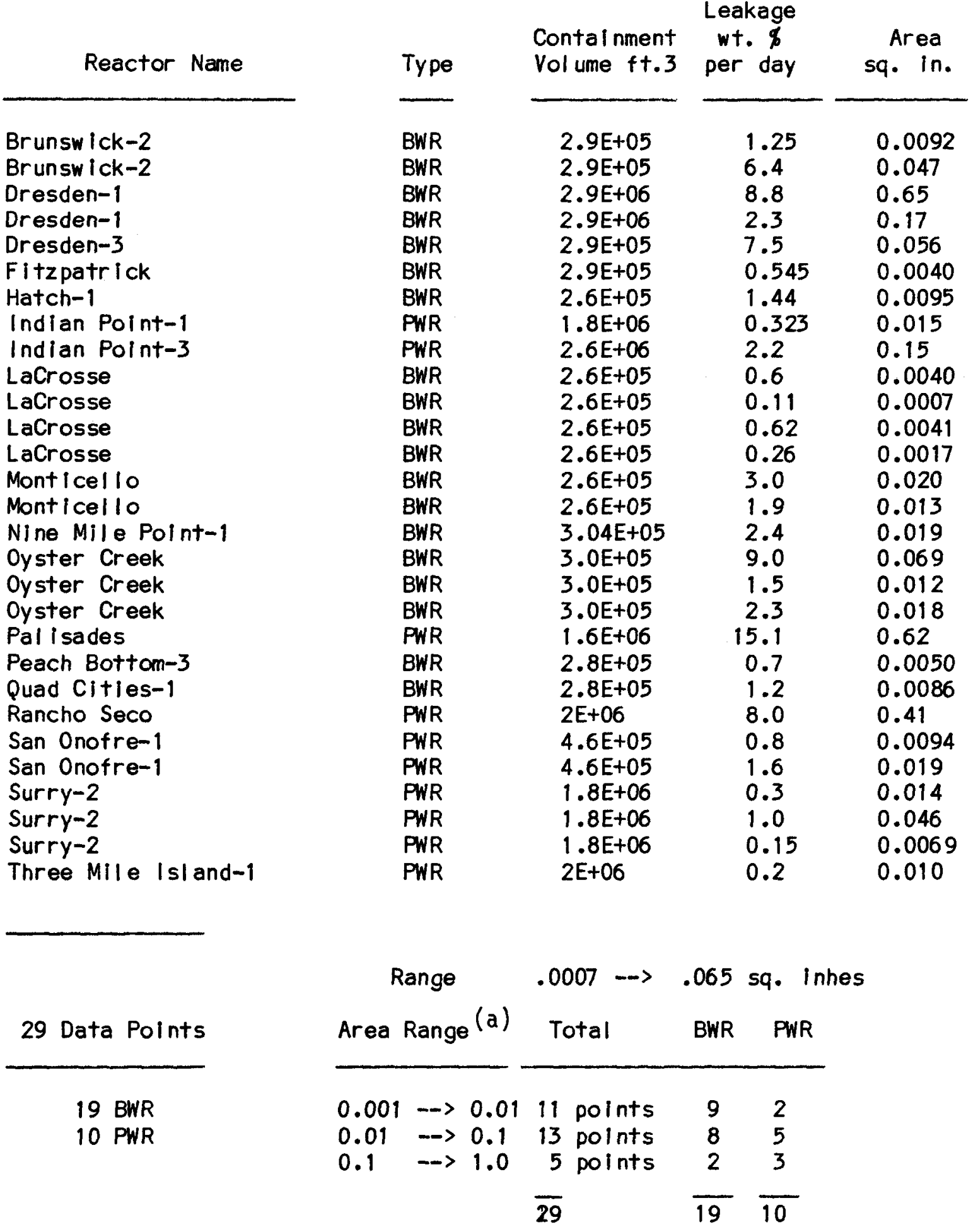

(a) Use mid-range values for area estimmates 
The above analysis is very prel iminary and based upon rather sketchy data. Several major assumptions were necessary. The assumption of the fallure duration is probably conservative but may be offset by using I imited leak rate data. Also it should be remembered that Type B and C tests are typically performed before an ILRT. This implies that the leak rates noted in an ILRT are smaller than the actual case. An additional revlew of "as found" leakages from Type $B$ and Type $C$ tests was performed as discussed below.

To improve upon the above results, 136 ILRT reports were obtained and revlewed to examine Type B and Type C test results. A total of 49 ILRT reports were Identifled for which the Type A test did not fall but with the consideration of type $B$ and $C$ "as found" leakage would be classified as a fallure. Of these 49 reports, 29 were for PWRs and 20 were for BWRs.

To simplify the analysis these 49 fallures are added directly to the results presented above. Thus a total of 109 ILRT fallures are identified. Of these fall ures, 55 were for BWRs and 54 were for PWRs. Using the same assumptions as before, the estimated unavallability of containment is 0.29 for LWRs. PWR unavallabil ity of contalnment is 0.25 and BWR unavallability is 0.34 . Containment unavallability versus leak area estimates are obtained using the same assumptions as before. The results of this analysis are summarlzed below:

PWR Containment Unavallabllity vse Leak Area

$\begin{array}{cc}\text { Unavallability } & \text { Leak Area, sq. inches } \\ 0.05 & 0.006 \\ 0.125 & 0.06 \\ 0.075 & 0.60 \\ \overline{0.25} \text { total } & \end{array}$

BWR Containment Unavallability vs, Leak Area

Unavallability

0.161

0.143

0.036

0.34
Leak Area, sq. Inches

0.006

0.06

0.60 


\subsection{CONCLUSLONS AND RECOMMENDATIONS}

This report has summarized the results of the Rellability Analysis of Containment Isol ation System Project. Qual itative and quantitative information developed for containment isolation system performance under normal operating conditions and design basis accidents indicate that there is room for improvement in contalnment performance. Table 1 presents some summary results. A rough estimate for overall containment unavallability for relatively small leaks whlch violate plant technical specifications is 0.3 . An estimate of contal nment unavallabil ity due to large leakage events ranges from .001 to 0.01 . These estimates are dependent on several assumptions (particularly on event duration times) which are documented in this report.

Example plant speclfic rellabllity analyses indicate that contalnment design details are important and a wide range of containment unavailability versus leak area estimates can result. Only selected containment penetrations and valves were examined. The BWR plant had an estimated unavallabllity of approximately two orders of magnitude lower than that of the PWR for similar penetrations and valves. The principal difference is due to the leak detection capabllities of the inerted BWR containment. In comparing pre-existing leak unavailabilities with estimates of containment component failures at the time of an accident (e.g. fallure to isolate), one notes that the values calculated for the BWR for pre-existing leaks are much lower. Large pre-existing leak areas in inerted BWRs may not be of much concern assuming proper action is taken to identify and correct them. A more complete analysis of pre-existing contalnment breaches in PWRs is recommended. Based on the simple comparisons in this report, the potential for pre-existing leaks should be more carefully examined for PWRs which have no continuous or short term leak detection capabilities.

This study identifled several areas where improved or additional data is required to perform containment rel labllity analyses. The LER data base contains $11+t+l e$ information on leak areas/rates and duration times. As discussed in the report, another potential source of information are the ILRT reports. ILRTs were revlewed to obtain additional information on contal nment failures and the data to quantify them. The estimated unavallabllity of contalnment is 0.29 for LWRs. BWRs have a larger unavallabllity than PWRs but the fallures are assoclated with a smaller leak area.

The LER data base was used in this report to support the generic analysis. As discussed in the main text, this data base can be used to generate operating and demand fallure rates for containment isol ation components. A rigorous analysis of this data requires substantial cost and time. Component fallure data are avallable from other data bases and were used in the prelliminary analyses given in Section 7.0. Based upon time and cost constraints, we recommend that the LER data base be examined for information on key containment components and that a rigorous analysis of all the information reported not be performed. Such key components include large purge and vent valves, airlocks and equipment hatches for which existing data bases provide little specific information. Section 6.2 presents a prel iminary analysis of airlock fallures. 
The results of thls study can be compared with those of Weinstein (1980). Containment unavall abllitles obtained in RACISP are typically larger for several reasons. Due to a lack of detall in the data base, conservative assumptions were made on the leak duration times and whether the reported fall ure events actually represent a direct leak path from containment. In addition, RACISP performed a more detalled revlew of ILRT reports and defined ILRT fallures more stringently. Weinstein (1980) screened out several categor les of events since his goal was to estimate an upper bound on the avallabll ity of contalnment (lower bound on the unavallabllity). The RACISP did not perform this detalled screening. Recognizing the prelliminary nature of the results, the estimates reported in this study may be more representative of an upper bound on containment unavallability. 


\section{REFERENCES}

Blejwas, T. E., et al. 1982. Backoround Study and Preliminary Plans In a Pregram on the Safety Margins of Containments. NUREG/CR-2549M Sandia National Laboratories, Albuquerque, New Mexico.

Carlson, D. D., et al. 1981. Reacter Safety Study Methodelogy Applications Program: Sequoyah 11 PWR Power Plant. NUREG/CR-1659, Sandla National Laboratories, Albuquerque, New Mexico.

Dougan, J. R. 1984. Evaluatlon of Contalnment Leak Rate Testing Criteria, NUREG/CR-3549, Oak Ridge National Laboratory, Oak RIdge, Tennessee.

Irwin, J. J. and T. J. Conrads. 1984. Ihe Fast Flux Test Facillty Integrated Leak Rate Test Requirements Re-evaluation. HEDL-TC-2484. Hanford Engineer ing Development Laboratory, Richland, Washington.

Frank, S., B. C. Kueckler, and H. J. Kunkel. 1982. Contalnment Integrated Leak-Rate Testino Imprevements. EPRI NP-2726, Stone and Webster EnglneerIng Corporation, Boston, Massachusetts.

NRC. 1975. Reactor Safety Study: An Assessment of Accident RIsks in U.S. Commercial Nuclear Power Plantse WASH-1400, U.S. Nucl ear Regulatory Commission, Washington, D.C.

Rowley, C. W., T. E. Renton, and K. Martin. 1983. Criterla for Determinlne the Duration of Integrated Leakage Tests of Reactor Containmentse EPRI NP-3400, Quadrex Corporation, Tul sa, Okl ahoma.

Weinstein, M. B. 1980. "Primary Contalnment Leakage Integrity: Avallabllity and Review of Fallure Experience." Nuclear Safety. 21(5): 618-632. 
APPENDIX A

USER MANUAL AND LISTING FOR LER COMPUTER DATA BASE PROGRAM 


\section{APPENDIX A}

\section{USER MANUAL AND LISTING FOR LER COMPUTER DATA BASE PROGRAM}

This appendix contains the user manual and a listing for an interactive computer program to search, edit and generate reports from the containment isolation system LER data base. This computer program utilizes the dBase III data base management software package. Appendix $B$ provides additional detalls on the structure of the LER data base. 
TABLE OF CONTENTS

A. 1 USER MANUAL ..................... A. 1 SYSTEM REQUIREMENTS ... . . . . . . . . . A.5 INTRODUCTION ........................ A.7 FIELD GLOSSARY FOR LER DATABASE . . . . . . . . . A.9 GETTING STARTED . . . . . . . . . . . . . A.13 ACCESSING THE ON-LINE GLOSSARY . . . . . . . . A.15 SIMPLE SEARCHES ................... A.17 REPORT FORMATTING WITH OPTION "C" . . . . . . . . A.21

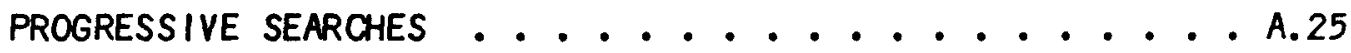
UPDATING OR EDITING THE DATABASE . . . . . . . . A.29 ERASING SEARCH FILES FROM YOUR DISK ......... A.33 CHANG ING THE SETTINGS FOR COLORS, DEFAULT DISK, ETC. • . A.34 A.2 LISTING ..................... A. . . . . . . . . . TECHNICAL ASSISTANCE ................... A. 148 


\section{SYSTEM REQUIREMENTS}

IBM Personal Computer, XT, or compatible with at least 256K Bytes of Memory. DOS version 2.0 or higher.

One floppy disk drive and a hard disk drive. (Software will run with two floppy disk drives, but since only about 100 records can be accessed this way, we do not recommend trying to use the software with two floppy drives and no hard disk.)

A printer with at least 80 column capacity.

dBASE III database management software package.

A color monitor is not required, but the program is designed to use color to make operation easler. 
INTRODUCTION

This reporting system is designed so that you can find out what is in the Containment Isolation System LER (Licensee Event Report) database, whether you know anything about dBASE II I or not. There are, however, a few basic ideas you need to understand first. One database we're all familiar with is the telephone directory. Let's look at a sample line from an imaginary phone book:

\section{Jones Sally K 43 Uptown Pike Notown.....234-5678}

This 7 ine is one RECORD in the database. Since you know how phone books are organized, you know that Jones is the last name of a person. Sally is her first name, $K$ her middle initial, 43 Uptown Pike is her street address, Notown is the city where she lives, and her telephone number is 234-5678. Each one of these pieces of information is called a FIELD. If you used dBASE III to set up a telephone directory (which you could), the RECORDS you'd see as you entered the information would look something like this:

LNAME : Jones :
FNAME : Sally
INITIAL :K:
ADORESS : 43 Uptown Pike
CITY : Notown

PHONE : 234-5678:

Each 1 ine is a FIELD and in order for dBASE II I to file and retrieve the information, we've had to give each field a name; LNAME. FNAME. INITIAL, etc. dBASE III will let us use up to 10 characters for each field name, but no spaces, so we sometimes have to abbreviate the name of the type of information that a field will hold.

The advantage of having information in a computer database is the ease with which we can retrieve or analyze it. For instance. suppose you were Sally Jones and actually had a directory database for a 11 the people in Notown. You could find out very quickly the names and telephone numbers of all the people who live on Uptown Pike. If there were a lot of them, you could find out who lives on Uptown Pike between street number 1 and street number 100, or for that matter, just who lives across the street and next door. If you got a lot of wrong numbers, you could find out who has phone numbers almost like yours (try doing that with your phone book!).

The database you're about to use has 29 FIELDs in each RECORD. Of those fields, we have selected 14 FIELDs that we were able to get good information for to be used in normal use. Starting on the next page is a glossary which explains the contents of each of the 14 fields and the codes, if any, needed to interpret the information. In the reference section of this manual, there is a list of the remaining fields and descriptions of the information they are intended to contain. 


\section{FIELD GLOSSARY FOR LER DATABASE}

Field Name

Definition

DATABNUM Unique four-digit number assigned to each record by PNL. Think of it is as a serial number.

LERNUM Number assigned to the Licensee Event Report (LER) by the NRC. The first two digits are the year of the LER.

TYPEMAIN $V$ indicates a valve failure, $P$ a penetration failure

TYPESUB 1

For a valve:

$A=$ electric motor operated (AC)

$R=$ relief or safety

$B=$ electric motor operated (DC)

C = hydraulic operated

$D=$ pneumatic diaphragm/cylinder operated

$E$ = solenoid operated (AC)

$F=$ solenoid operated (DC)

$G$ = float operated

$H=$ explosive squib operated

$J$ = mechanically operated

$K=$ electric motor operated (unspecified)

$S=$ check

$X=$ other

$L$ = solenoid operated (unspecified)

$M=$ manually operated

$N=$ remotely operated

$P$ = damper

$Q$ - vacuum breaker

TYPESUB1

For a penetration:

$A=$ personal access

$B=$ fuel handling

$C=$ equipment access

$D=$ electrical

$E$ = instrument line

$F$ - process piping

$G=$ access (unspecified)

$X=$ other

\section{REACNAME}

CODE

$\begin{array}{ll}\frac{1}{2} & \text { CIS CLASS } \\ \frac{1}{2} & \frac{1}{2} \text { REACTOR NAME } \\ \frac{1}{2} & \frac{1}{2} \frac{1}{2}\end{array}$

AR1,2 1 Ark Nuc. One 1,2

BF1-3 5 Browns Ferry 1-3

BP1 8 Big Rock Point

BR1,2 5 Brunswick 1,2

BVI 2 Beaver Valley 1

CC1,2 1 Calvert Cif 1,2

$\mathrm{CO} 15$ Cooper Station

CR3 1 Crystal River 3

DA1 5 Duane Arnold

DB1 3 Davis-Besse

DC1.2 4 D.C. Cook 1,2

D01,2 I Diablo Canyon 1,2

OR1 8 Dresden 1

DR2, 35 Oresden 2,3

EF2 5 Enrico Fermi 2

EN1, 25 E.I. Hatch 1,2

$\mathrm{FCl} 1$ Fort Calhoun
FP1

FV1

GG1

$\mathrm{HB3}$

HN1 I Haddam Neck

5 J.A. Fitzpatrick

8 Fort St. Vrain

7 Grand Gulf 1

IP2, 3 I Indian Point 2.3

JFI.2 1 J.M. Farley 1.2

KEI 3 Kewaunee

LB1 8 LaCrosse BWR

LS1, 26 LaSalle 1,2

MG1.2 4 McGuire 1,2

MI1 5 Millstone 1

MI2 1 Millstone 2

MO1 5 Monticello

MY1 1 Maine Yankee

NA1, 22 North Anna 1,2

NMT 5 Nine Mile Pt. 1

OC1 5 Oyster Creek 1

OE 1-3 I Oconee 1-3

PAT 1 Palisades

PB2, 35 Peach Bottom 2,3

PI1 5 Pilgrim 1

PR1, 23 Prairie Is. 1,2

Newer reactors continued on next page...
PT1.2 1 Point Beach 1.2 PV1 1 Palo Verde 1

QC1,2 5 Quad Cities 1,2

RG1 1 R.E. Ginna

RO2 1 H.B. Robinson 2

RS1 1 Rancho Seco

SA1,2 1 Salem 1,2

SET,2 4 Sequoyah 1,2

SL1, 23 St. Lucie 1,2

SM1 6 Shoreham

SO1 8 San Onofre 1

SO2.3 1 San Onofre 2.3

SST. 26 Susquehanna 1.2

SU1.2 2 Surry 1,2

TI1,2 1 Three Mi. Is. 1,2

TR1 1 Trojan

TU3,4 1 Turkey Point 3,4

VS1 i V.C. Summer

VY1 5 Vermont Yankee

WF 33 Waterford 3

WP2 6 WNP 2

YR1 8 Yankee Rowe

ZI1.2 1 Zion 1.2 
Field Name

REACNAME, cont'd

BL1,2 Bellefonte 1.2 CL1 Clinton 1 SH1 Shearon Harris

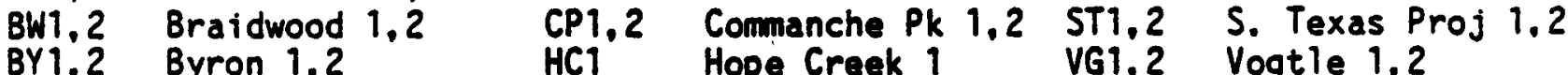

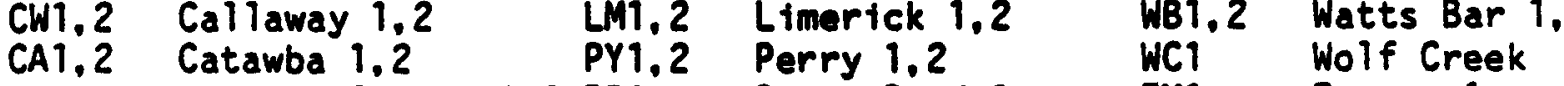

CT1,2 Carroll County 1,2 RB1 River Bend 1 ZM1 Zimmer 1

REACTYPE One of the following: $B=$ BWR

$H=H T G R$ (Fort St. Vrain)

P = PWR

CISCLASS Class of Containment Isolation System (CIS)

Class 1. PWR - Large Dry Containment

Class 2. PWR - Subatmospheric Containment

Class 3. PWR - Dual (Double) Containment

Class 4. PWR - Ice Condenser Containment

Class 5. BWR - Mark I Containment

Class 6. BWR - Mark II Containment

Class 7. BWR - Mark III Containment

Class 8. Other CIS

SYSPRIMA Primary system involved in failure.

Designations are different for PWR's and BWR's.

List of SYSPRIMA codes for PWR's

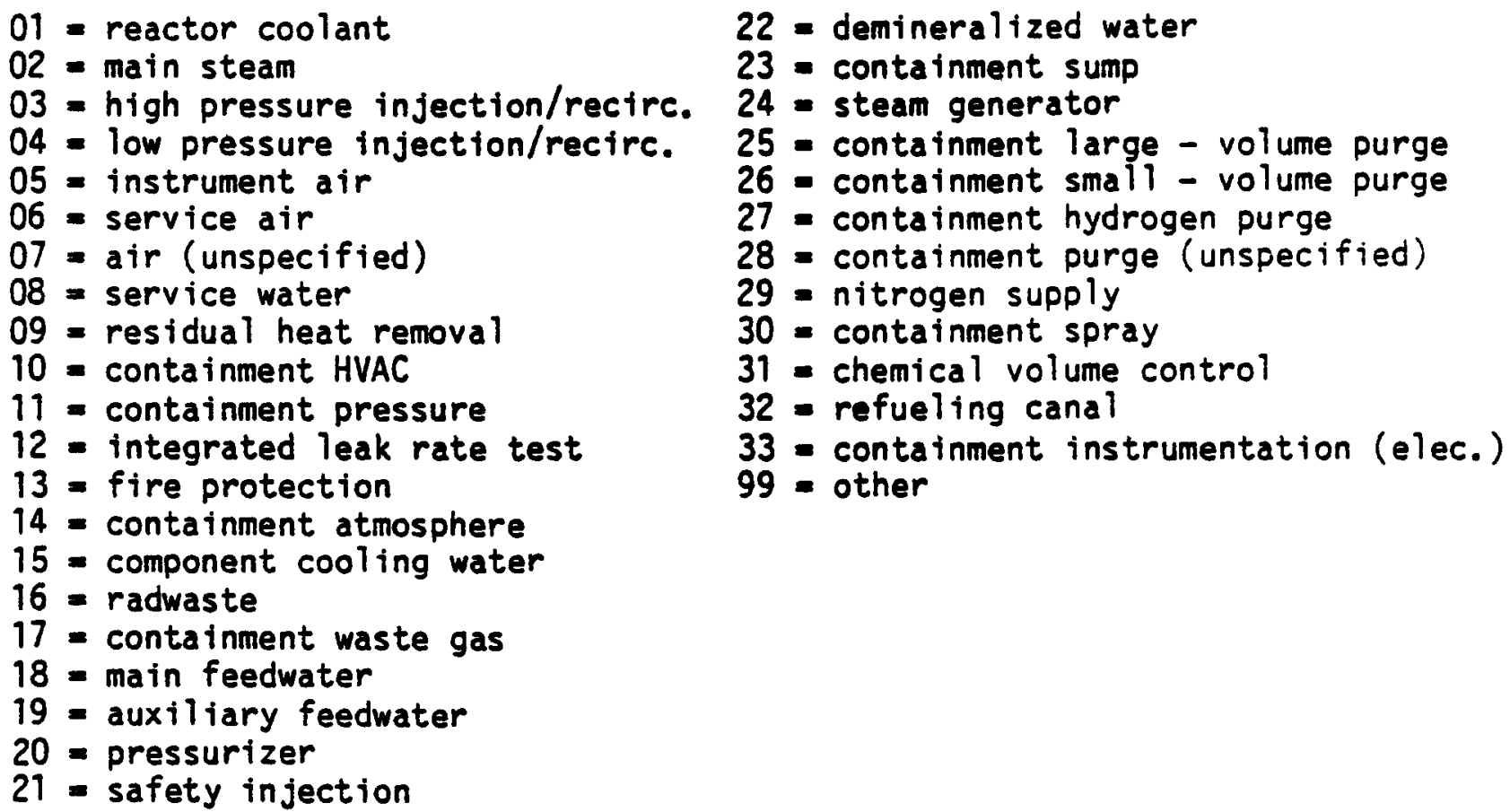


Field Name

SYSPRIMA

List of SYSPRIMA codes for BWR's

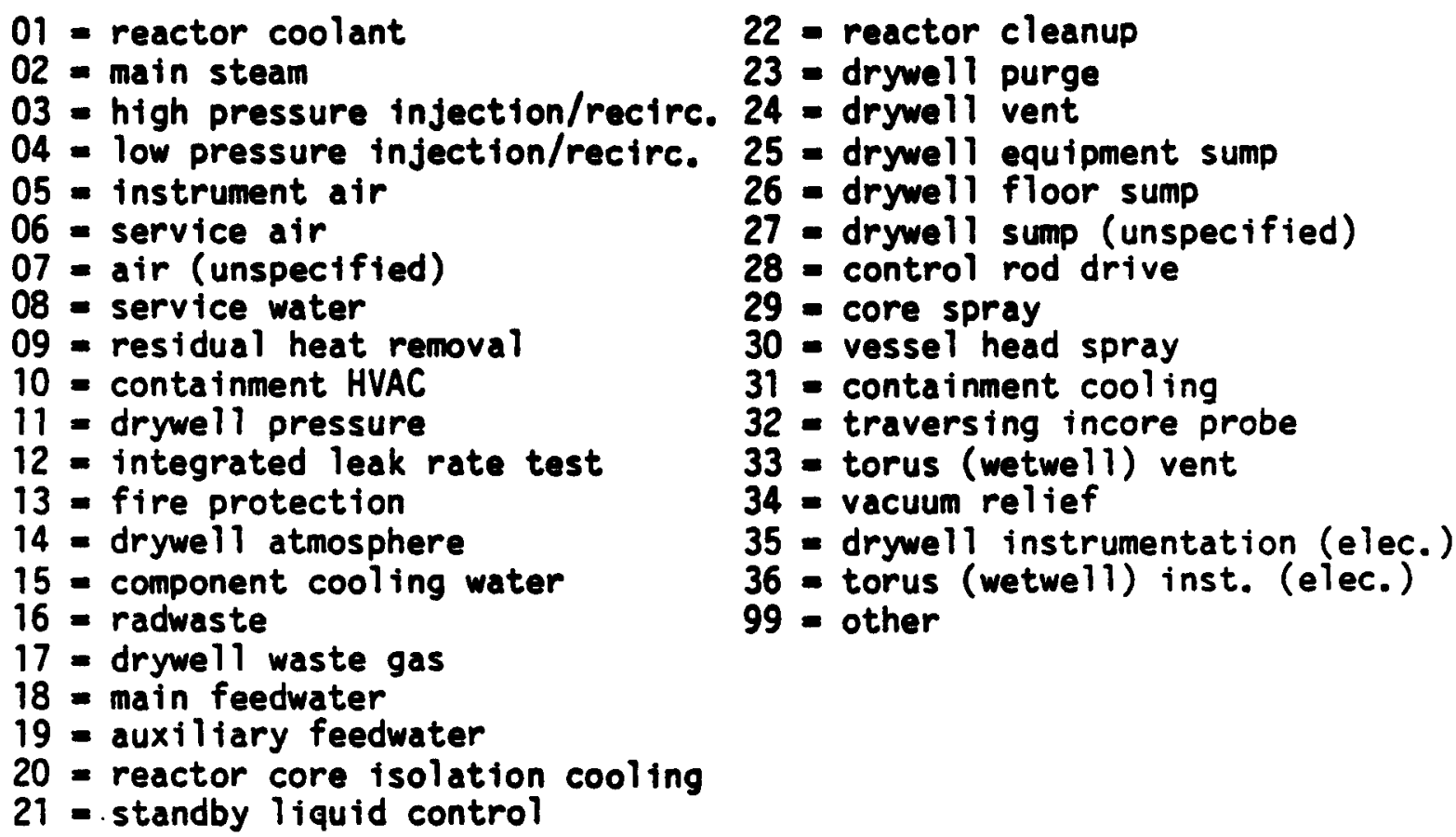

NUMFAILS Number of failures reported in the LER, 1 unless specified

DATE Date of failure event in six-digit code, e.g.. 830812 - August 12. 1983.

MODE One of the following fallure modes:

$A$ = leakage (fail to seal)

$B=$ fail to close

$C=$ unplanned opening (fail to remain closed)

Failure mode $B$ also refers to failures in which the component does not close within a reasonable time limit, thereby constituting a potential failure to isolate containment. 


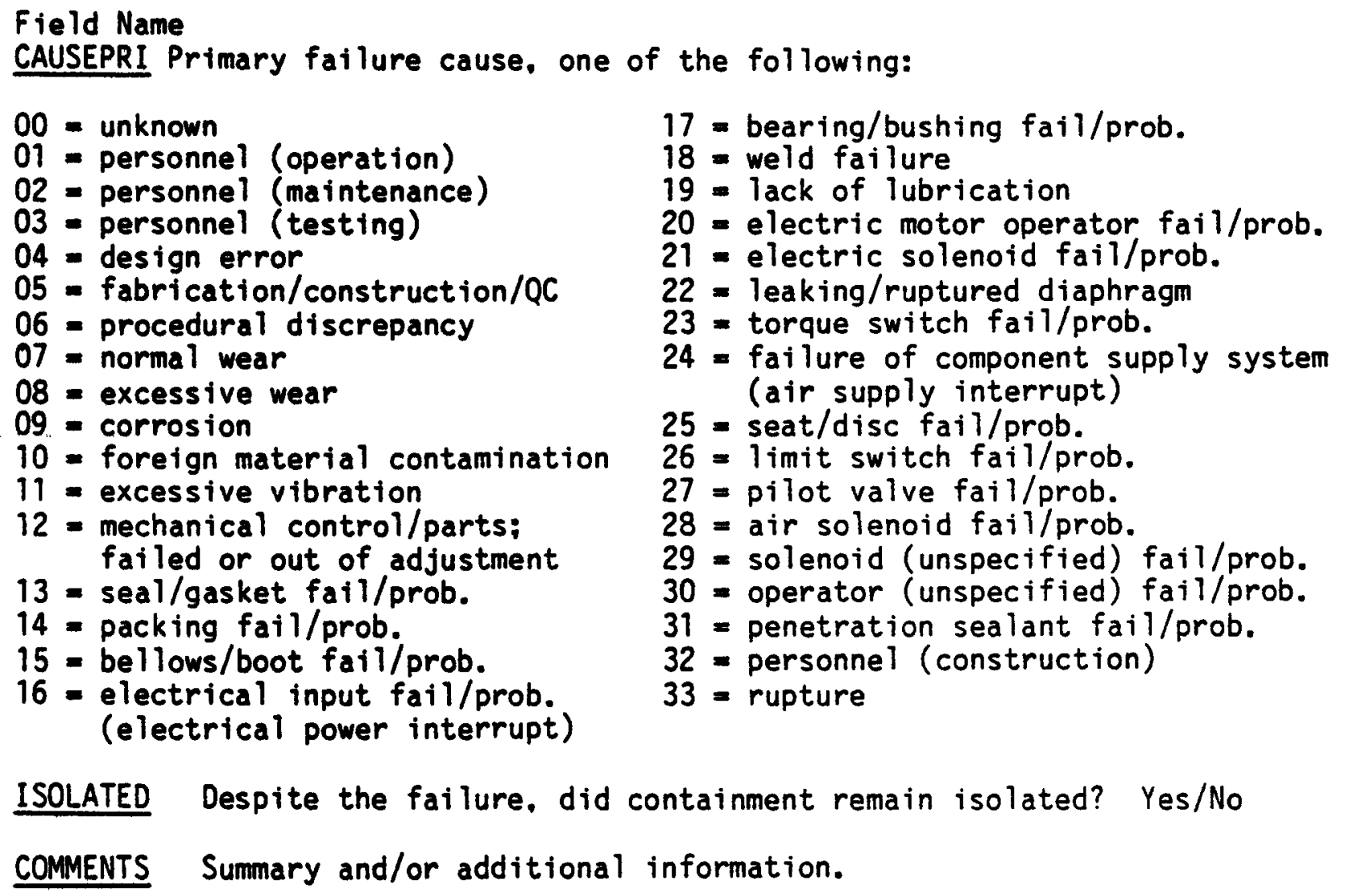




\section{GETTING STARTED}

There are some fairly complicated steps to go through to install the database and reporting program on your computer. These instructions assume that your computer has been configured for the program and that the program has been configured for your computer. If the program doesn't work as this manual says it will. call the person listed at the end of the manual for technical assistance.

If the computer is off when you sit down to work. slide the master boot disk into drive $A$, close the disk drive door, and turn the computer on. Enter the date and time when and if you are asked. If the computer is already on and the $A>$ prompt is showing on the screen, check to make sure that the time and date are set correctly. Just type 'date' and enter; if the date is incorrect. enter the right one, otherwise, just enter again and type ' $t$ ime' and do the same thing. The program will work even if you don't do this, but if the date and time are always set. you can go back to a file later and see when it was created or last modified. Especially in database work, it can be very valuable to tell which is the latest version of a file or be able to go back weeks or months later and reconstruct what was done on a particular day.

Once you have the A> prompt, put the dBASE III disk marked 'RACISP Reporting' in drive $A$ and type 'RACISP' and enter. That will activate a customized instruction program which will tell you how to proceed.

The rest of the job is easy, because there are explanatory messages on the screen and a 17 you have to do in most places is choose items from a menu. We have done our best to make this manual unnecessary.

Below is the first message you will see on the screen. The numbers in parentheses are the page numbers in this manual to turn to for more explanation.

Welcome to the reporting system for the Containment Isolation System (CIS) LER database. This database contains information extracted from LER's related to CIS. If you are unfamiliar with the database, you should start by reading the glossary which explains the contents of the database. If you elect to continue, you will have opportunities to look at the glossary when you are called on to enter field names. Numbers in parentheses refer to page numbers in the user's manual.

$G$ Look at glossary of field names.

C Columnar lists of selected fields on screen or printed.

D Display entire record(s) on screen.

$L$ List all or selected records on printer.

E Edit recordís) on screen.

$P$ Purge unwanted searches from disk.

$R$ Reset program defaults.

$X$ Exit back to dBASE III.

"Enter your choice" 
ACCESSING THE ON-LINE GLOSSARY

If you enter ' $G$ ', you will get the first screen of the online glossary.

\begin{aligned} \hline DATABNUM Unique four-digit number assigned to each record by PNL. Think of \\ it is as a serial number. \end{aligned}

Simply enter the key for the option you want at the bottom of the screen. It is your choice whether to use the on-line glossary or to refer to the one printed in this manual. You might want to make a copy of the one in the manual for planning or interpreting searches while you're not on the computer. 


$$
\text { • }
$$




\section{SIMPLE SEARCHES}

When you enter any of the options for simple searches, you will first get a message asking whether you sant to work with the whole database or only selected records.

Unless you just want to look at records for a while or are intending to make a printed 1 isting of one or more FIELDS for the whole database, you should choose the 'S', or Selected option. Even if you choose the 'All' option, you can terminate the process by entering ' $X$ ' on a display screen or pressing Esc if the printer is trying to print the whole database and you don't want it to. (If you do press Esc while the printer is running, it probably won't stop immediately, and may go on for quite a while since many printers have a buffer that stores data to be printed so the computer can be doing other things.)

When you choose the ' $S$ ' option, this is what you' 11 see.

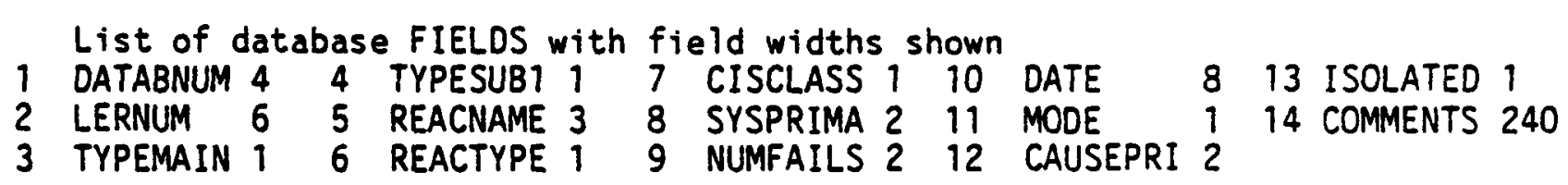

Would you like to look at a glossary of FIELD names? : :

This is your opportunity to refresh your memory of the field definitions before you set the conditions for the search. It is optional. If you answer ' $N$ ' or when you exit from the glossary subroutine, this is what you'll see:

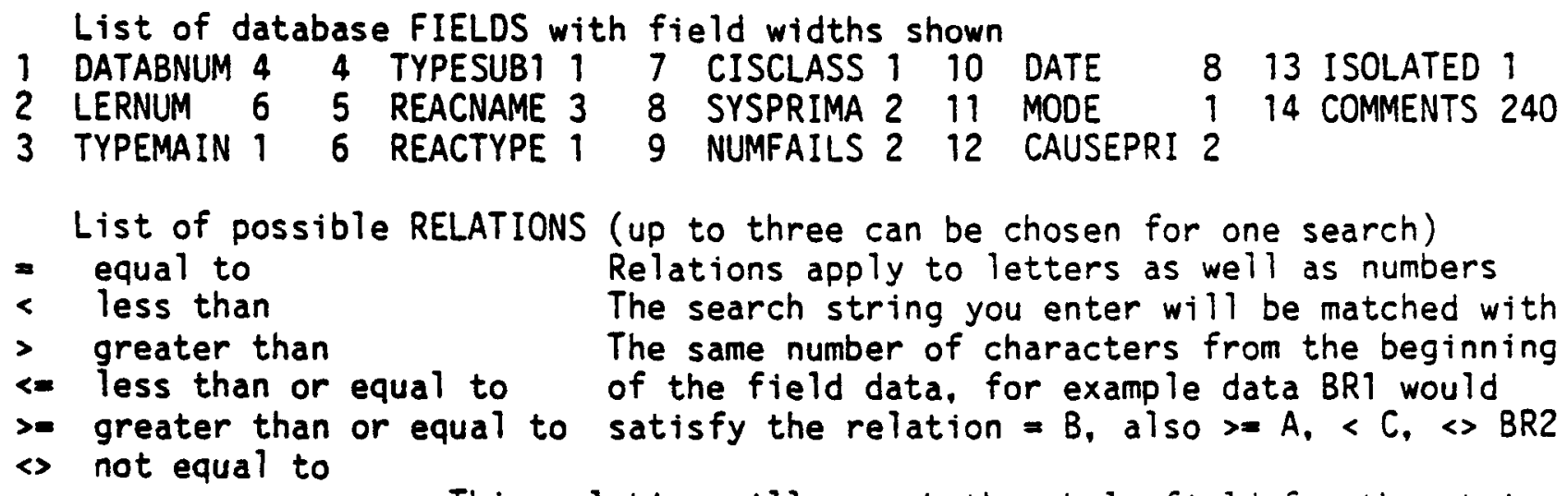

HAS

This relation will search the whole field for the string you specify. i.e. abcdefghij HAS def. If you enter in ALL CAPS, case will be ignored. i.e. abcdefghi HAS FGH.

$\begin{array}{llll}\text { FIELD NUMBER: } & \text { : RELATION : } & \text { : VALUE : } & : \text { :AND: } \\ \text { FIELD NUMBER: } & : \text { RELATION : } & : \text { VALUE : } & \text { :AND: } \\ \text { FIELD NUMBER: } & : \text { RELATION : } & : \text { VALUE : } & \text { : AND: }\end{array}$

For less than three conditions, just <RETURN> without entering anything Note: you can change the AND's connecting the conditions to OR's or NOT's 
All you have to do to select the conditions you want to search for is fill in the blanks. You don't have to type the field names, just the numbers next to them in the field list at the top of the screen. If you make a typing error and you don't notice it until you've gone on to the next blank, just use the backspace key to get back to the error and type over it.

For RELATION, you can choose any one of the seven listed on the screen. For character data, the relations are evaluated alphabetically, i.e. $A<B, R<=$ $U, Y \ll N$. HPCI < HPSI, etc.

The HAS relation is a shorthand way for you to use dBASE III's substring search feature. The field whose number you enter will be searched from beginning to end for the characters you enter after VALUE. A special feature al lows you to find all occurrances of a word or other character string whether it was capitalized when entered into the database or not. Any values you enter in ALL CAPS will cause the program to ignore the case of any characters in the field.

For instance, if you specified that you wanted to see all records where the COMMENTS HAS OPERATOR, you would find the records with operator, Operator, or OPERATOR (or any non-standard way of capitalizing). If, on the other hand. you specified COMMENTS HAS Operator, you would on ly find the occurances where the first letter is capitalized and the rest are lower case.

Notice that among the other pieces of information is the width of each field. This is a reminder so you won't enter too many characters. In the case of the SYSPRIMA, CAUSEPRI, and some other fields not included in the basic 14, the codes are numbers, but these numbers are entered as string values. What this means is that if the code you are looking for is '03', you will not find a match by entering just a ' 3 '. Instead you would find a 11 the values between ' 30 ' and ' 39 '. Except in the case of the HAS relation, the first character you enter will be compared with the first character in the field, the second with the second, etc.

If you want less than three conditions, just press the return key, leaving the blanks empty until you have exited the last one. Then wait; if you're searching the whole database, the search will take some time, probably more than enough for some sips of coffee, but not enough to go make a phone call.

What you'1 1 see next depends on what you're doing. If you're using Option $C$, you'l 1 get messages asking you to make choices about the content and formatting of your output. For more instructions on option $C$ see page (13). 
If you're using option $D$, you'll get a message asking you to wait followed by the time and date and some information about the number of hits the search found and an opportunity to print that information out on the printer. After that, you' 11 see the first record in the database which satisfies your conditions. The menu at the botton of the page will give you your options on $v$ iewing the rest. A sample record is shown below.

Identification Information for Record \#

Database Number: 0401 LER Number: 82-008

Component Information

Type: Pneumatic diaphragm/cylinder operated Valve

Reactor Name: Ark Nuc. One 1 Reactor Type: PWR

CIS Class 1: PWR - Large Dry Containment

Primary System involved: 10, Containment HVAC

Failure Information:

Date: 820329 Number of Failures 1

Fatlure Mode: Mode B. Failure to close within a reasonable time, constituting a potential failure to isolate containment.

Primary Cause of Failure: 24, failure of component supply system (air supply $i$ nterrupt)

Containment was isolated

Comments: Containment cooler isolation valve fails to close. Valve CV-6202 wou Id not close due to air relay problem.

$N$ - Next, P - Previous, F - First, L - Last, S - Specify \#, X-exit : :

If you're using option L, you'll have an opportunity to type in a line of notes to be printed as part of the first page heading and after a minute your printer will start the 1 isting, three records to a page. If you're printing very many records, it could take quite a while.

If you decide it's just too much to print, you can push the Esc key and the printer will stop (maybe not right away). dBASE III will ask you if you want to end the program and you' 11 want to enter ' $y$ ' if you really do want to quit. As soon as you get back the. on the left edge of the screen, you can type in DO REPORT if you want to get back into the program. No data will be lost by doing this and any temporary search files you might have created up to that point will be intact. 


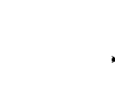




\section{REPORT FORMATTING WITH OPTION 'C'}

If you've entered Option $C$ on a simple search, you'll first be given an opportunity to select conditions for the records you want to see as explained above in SIMPLE SEARCHES. Below is the massage:

Do you want to list all the records in the database or would you

like to list only selected records? A - All S - Selected : :

If you choose 'S', you'll see

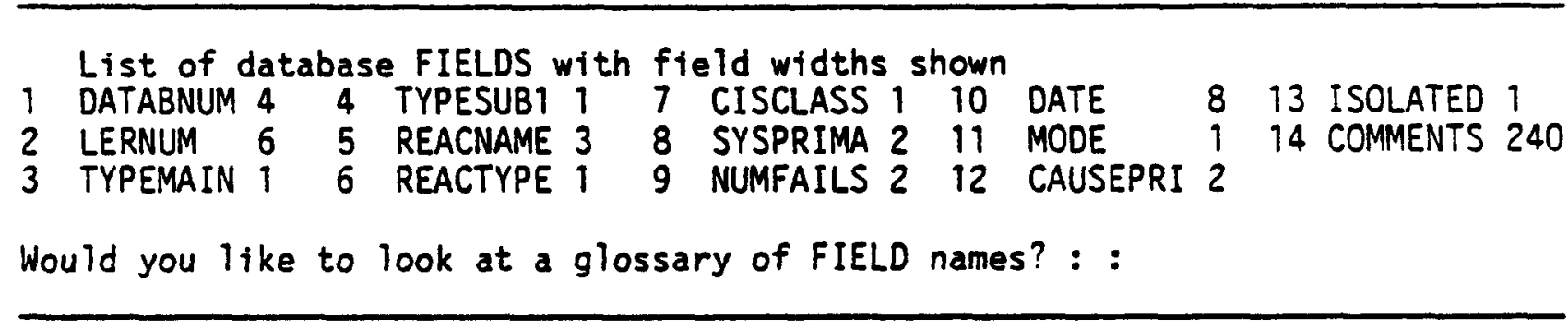

If you choose 'Y', you'll go into the On-Line Glossary. If you choose ' $N$ ', or after you exti the glossary, you'll see:

This subroutine allows you to print or display columns of data from the database. There are three preset formats which you can choose or you can easily create your own combination of fields to list.

1 - Format 1, All 14 fields.

2 - Format 2, DATABNUM, LERNUM, REACNAME, TYPEMAIN, TYPESUB1, SYSPRIMA, CAUSEPRI, MODE, \& ISOLATED.

3 - Format 3, Just Print or Display number of Hits and Failures along with Selection Parameters. (Note: you'll be returned to this menu)

C - Custom Report format.

$X$ - Exit back to previous menu.

Your Choice : :

If you choose the custom report format, you'll see:

Most computer screens will display 80 characters on one line. Computer printers, by using 12, 15 or more characters to the inch or wide paper. can often print many more characters per line. Please enter right margin you want to use (left margin is 4). If you start any new columns after the 75th, you will not be able to customize headings.

Right margin to use : 80 : 
If 80 is OK just press enter. Next, you' 11 get the field name listing:

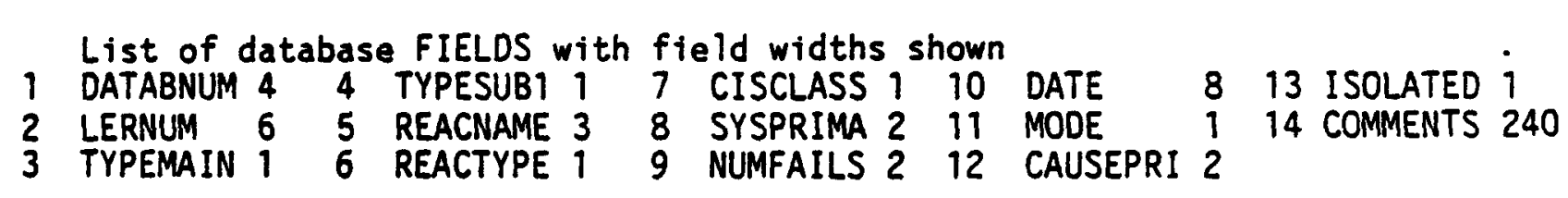

Would you like to look at a glossary of FIELD names? : :

As you can see, we're not about to let you miss any chance you might want to look at the glossary. After you say ' $N$ ' or exit, you'll see:

This subroutine lets you make custom formats for onscreen or printed reports. In this subprogram, just enter the numbers of the fields you want to see and enter a blank for the last one (unless you get the 'Page Full' message first). If COMMENTS is one of the fields you want, please enter the number for it last. since it will use up any remaining page width.

Width of remaining space on page : 80:

Number of FIELD for Column \# 01 <RETURN> to end : :

As soon as you enter a number for the first field you want reported, you'll see a new number for the width of the remaining space on the page and a chance to enter another field number. If you enter the number for the COMMENTS field, that will be the last field and at the bottom of the screen you'll see:

Enter $A$ to see All of COMMENTS, $T$ to truncate to one line : :

If you choose 'T', you'll on ly get the number of characters from COMMENTS which will fit on the remainder of the line. Normally, this will be enough. Next, you'll have an opportunity to customize your column headings:

Here are your standard column headings

DATABNUM LERNUM REACNAME TYPEMAIN TYPESUB1 COMMENTS (for example)

Are these headings OK?, if not, you can enter new ones.

$Y$ - Headings are OK $N$ - Not OK, Make make new ones : :

This shows an example of the headings the program will choose for your report assuming you decide to 1 ist the fields shown in that order. The program has two different sets of headings; if you choose on ly a few fields, the headings will be just the field names. If there isn't room for them, the program has some narrower headings it will give you. 
If you choose to customize your headings, you' 11 see a message like this:

The space shown for your heading is the widest space you can use without making the report too wide to fit on the page. The underlined part of the area shows the field width. Any spaces you use beyond the underline are subtracted from the extra space that will be available for the next column's heading, so use the extra space judiciously.

\begin{tabular}{lc}
$\begin{array}{l}\text { Field Number } \\
\text { OATABNUM }\end{array}$ & Field Width \\
:DATABNUM & 4 \\
$:$ & $:$ \\
\hline
\end{tabular}

The cursor will be at the first letter of the 'canned' heading. If you want to change the heading, just type over what is displayed. Notice that your heading can take up to three 1 ines, but if you only type on one or two 1 ines, the resulting blank lines will not show in the report.

If you want to keep the 'canned' heading for a field, just press return three times and the program will display the 'canned' heading for the next field unless it was the last field.

Once you have finished customizing your headings, you'll get a message asking you whether you want printed output or just screen output. If you choose printed output, you'll also have the opportunity to type in a line of notes to appear on the first page heading. You can choose a screen report and later choose to print it or vice versa. When the screen listing or printer listing is complete you'll be given an opportunity to rerun the report on either the screen or the printer. 

$\because$ 


\section{PROGRESSIVE SEARCHES}

The progressive search feature al lows you to interactively select groups of RECORDs by a large number of conditions. For instance. suppose you wanted to get information relating to a particular reactor subsystem, let's say the high pressure safety injection system on PWRs. To find those records, you would SPec ify SYSPRIMA = 03 AND REACTYPE = P. However, you might find that this search would yield too many 'hits' to study easily and you might want to further subcategorize. If you did a simp le search, you'd have to start over and you could add only one more condition. But if you made that search the first of a series of progressive searches, you could try different things to narrow the search to a more manageable (or more pertinent) selection of records. For instance, maybe what you're really interested in is on ly those PWR's with large dry containment and only those LER's filed before 1981. You could easily make that a subsearch of your first search and see how many records you find. You might find that there are still too many, or you might find very few or no records at a 11 . Too many records still would suggest another subsearch while too few or no records would indicate you need to back up and broaden you categories a little. The point is that the progressive search feature lets you adapt your search as you go.

Now, let's see how it works. If you enter ' $S$ ', the next message you get will be the foll lowing:

This part of the program displays a catalog of the searches of the database which have been performed up to now. The searches are organized into Series. Each Series begins with a search of the whole database. Subsequent searches search only the records picked out by the search listed immediately above them. Up to 99 different Series are possible (assuming your disk has that much room) and each series can have up to 99 searches in it. If you want a report on one of the searches you see listed in the catalog, simply enter its series number and search number. You may also choose any of the listed searches as a place to start your own series of inquiries. If you choose a search before the end of the series and make additional searches from it, you will erase subsearches previously made. To CANCEL further appearances of this message, enter ' $C$ '. If don't want to search the database now, enter ' $X$ '. Press any other key to just continue.

If you are using the program for the first time, or if all previous searches have been erased, you will not get any catalog listing, but will go directly to the menu which lets you choose parameters for the first search. If you do get a catalog, first you will get a message asking you if you want to print it out on the printer. After you choose that, the next thing you'll see on screen will be a display something like this: 
\# HITS \#FL SELECTION PARAMETERS

SERIES 01

014552 ISOLATED $=N$ AND COMMENTS HAS BUILOING AND REACTYPE $=B$

\# HITS \#FL SELECTION PARAMETERS

019501023 REACTYPE $=P$ AND CAUSEPRI $\longleftrightarrow 05$ AND CAUSEPRI $\gg 31$

SERIES 02

02542559 DATE $>82$

\# HITS \#FL SELECTION PARAMETERS

01128145 CAUSEPRI $=01$ AND MODE $=A$ AND ISOLATED $=\mathrm{N}$

SERIES 03

021313 REACNAME $=8 R$

Enter number of series you want to use or continue.: :

To start a new search of the whole database, enter a new number

You can enter ' $X$ ' now if you don' $t$ want to continue

If you want a series less than 10, the use of the leading zero is optional. Entering ' 02 ' is just the same as entering ' 2 ' or ' 2 '. As soon as you enter a series number and press the enter key, the message at the bottom of the screen will be replaced by:

Enter number of the search you want to use or continue. : :

If you continue from any but the last one, each continuation

will erase one previous subsearch.

The number under the heading '\#' is number of the search. The series number appears near the right hand edge of the screen.

The number under the heading 'HITS' is the number of records the search found.

The number under the heading '\#FL' is the number of failures the search found. Some LER's report on multiple failures, indicated in the database field NUMFAILS. This number, which is the sum of NUMFAILS for the records the search found, should always be greater than or equal to the number of HITS.

Under the heading 'SELECTION PARAMETERS', is an expression of the conditions a record had to satisfy to be found by the search. Each selection parameter can have up to three conditions. Each condition consists of a FIELD name, a REALTION, and a VALUE. If the information in the named FIELD of a RECORD satisfies the RELATION to the VALUE, that RECORD will be found by the search. We've already discussed FIELD names, and the rest is simple. Let's look at some examples: 
ISOLATED $=N$ AND COMMENTS HAS BUILDING AND REACTYPE $=8$

Translation:

ISOLATED $=N$

The field ISOLATED has an $N$ as its first character;

AND COMMENTS HAS BUILOING

AND the character string BUILDING appears somewhere in the COMMENTS field;

(When all the letters in the VALUE, which is BUILOING here, are uppercase, the search will find any occurrance of the word building, whether any letters are captalized or not.)

ANO REACTYPE $=B$

AND the field REACTYPE has $B$ as its first character.

Notice that these conditions are cumulative, as indicated by the AND's. A11 three conditions must be met for a record to be found. Other combinations are also possible, as in the example below:

COMMENTS HAS isolated OR ISOLATED $=\mathrm{N}$

Translation:

COMMENTS HAS isolated

The word 'isolated' appears somewhere in the COMMENTS FIELD. Note that this will not accept 'Isolated' or 'ISOLATED' because it is not entered in uppercase.

OR ISOLATED $=\mathrm{N}$

Or the first character of the FIELO named ISOLATED is ' $N$ '.

Since the two conditions are joined by an OR, records which satisfy either condition will be found. 
Once you have entered the numbers of a series and a search, different things can happen, depending on whether you picked a pre-existing search to report on or search from. If you picked a new search, the next step is the same as choosing the conditions for a simple search, covered on page 10. After you've completed selecting the conditions you want, or if you've selected an existing search, you'll get a screen like the example shown below (possibly after a message telling you that a temporary file is being created). Notice that the current file is highlighted, but previous conditions are shown, too.

\section{SERIES 01 \\ \# HITS \#FL SELECTION PARAMETERS" \\ 019501023 REACTYPE $=$ P AND CAUSEPRI 205 AND CAUSEPRI 31 \\ 02542559 DATE > 82}

\section{REPORT OPTIONS}

A - CHANGE Selection Parameters or use a different Search.

$L$ - LOOK at Entire Records on Screen, one at a time.

P - PRINT Entire Records in Input Format.

C - COLUMNS of Selected Data Fields On Screen or to Print. Or only listing of selection parameters \& vital statistics

R - RESET Program defaults.

$X$ - EXIT To lst Menu in Report program.

Your Choice? : :

Numbers in parentheses refer to page numbers in the user's manual.

Most of these options are identical to the Options presented on the first menu. Options $C$ and $R$ haven't changed and Option $P$ is the same as Option $L$ on the first menu. Option $L$ is the same as Option $D$ was on the first menu and Option $X$ is self explanatory. Only Option $A$ is new. so let's look at how it works. When you choose Option $A$, the next message you see is:

\section{OPTIONS}

A - Save the search you're currently working with and use it as the basis for a new one with different selection parameters.

B - Replace the current search with one that has different selection parameters.

C - Save your current search and look at the list of searches available on the disk with the option to choose one of them or start a new search. (Note: your current search will be on the list)

Your Choice : :

Any one of these options leads back to screens we've already covered. 
When you enter 'E' to edit the database, the first message you will get will be:

WARNING, This command will alter the database ENTER PASSWORD : :

This is to prevent any casual or absentminded users from changing the information in the database. Naturally, you will keep a backup copy of the database and PNL will have a backup copy too, but unauthorized modifications to the database without your knowledge could yield erroneous reports when you access the database. If you really want to edit the database. the password to use is 'ADEPT'. Simply type it in and you will enter the database editing program and see the message below.

$$
\begin{aligned}
& \text { E - Edit any record in the database } \\
& \text { S - Select certain records to edit } \\
& \text { A - Add new records to the database } \\
& \text { Your Choice : : }
\end{aligned}
$$

(explanation below)

Choosing option E will bring up the first record in the format shown in the example below.

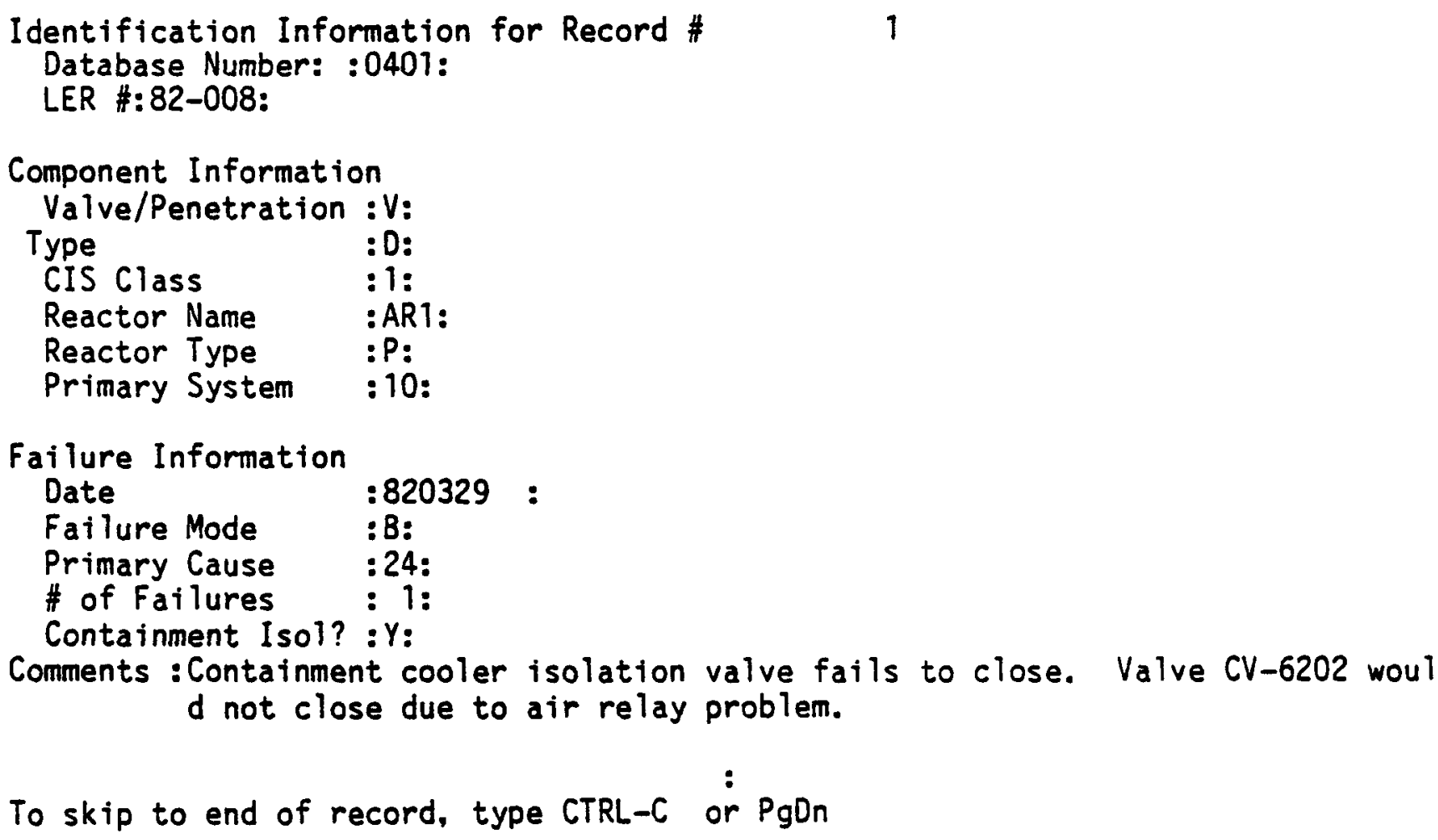

The cursor will be under the first character in Database Number. To make 
changes, just type over the data which is there. If record \# 1 is not one of the records you want to edit, press CTRL-C or PgDn and you' 11 get the option line:

N Next, P Previous, F First, L Last, S Specify \#, D Delete, X - eXit : :

Unless you know the record numbers of the records you want and can reach them with the $S$ option, it could prove very time consuming to find the records you want to edit. Note that the number you specify with Option $S$ is not the contents of the field DATABNUM, but the dBASE III record number, which can change if the database if sorted or updated.

If you want to use DATABNUM to find the records you want to edit. choose the $S$ Option from the opening edit menu shown on the previous page.

Option S for Editing Selected Records

After choosing the S Option from the opening Edit Menu, the next message you'll see is:

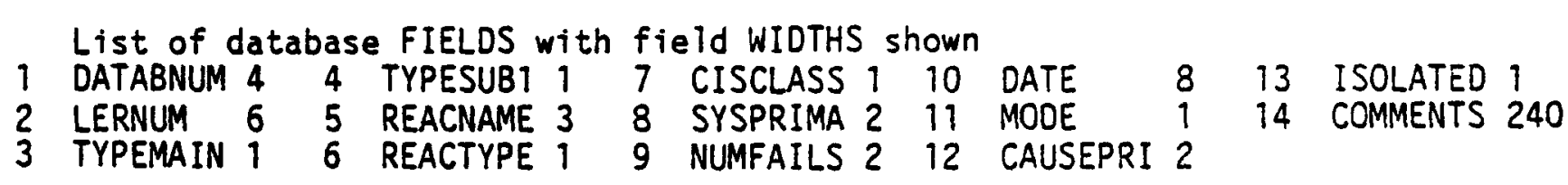

Would you like to look at a glossary of FIELO names? : :

After you enter ' $N$ ' or exit the glossary, th following will be added:

List of possible RELATIONS

= equal to

< less than

$>$ greater than

$<=$ less than or equal to

$>$ greater than or equal to satisfy the relation $=B$, also $>=A,<C$, $<>B R 2$

(s) not equal to

HAS

This relation will search the whole field for the string you specify. i.e. abcdefghij HAS def. If you enter in ALL CAPS, case will be ignored. i.e. abcdefghi HAS FGH.

FIELD NUMBER : : RELATION : : VALUE :

FIELD NUMBER : : RELATION : : VALUE :

$$
\begin{aligned}
& \text { : }: \text { AND: } \\
& \text { : :AND: } \\
& \text { : }
\end{aligned}
$$

For less than three conditions, just <RETURN> without entering anything

This works exactly the same way as the simple search, detailed on page (10). 
One thing to stress, however is what to do if you're editing specific records which you have the value of DATABNUM for. You will enter ' 9 ' for FIELD NUMBER, ' $=$ ' for RELATION, and the $v a l u E(s)$ you want for VALUE, remembering to include any leading zeros (' 401 ' is not the same as ' 0401 ' here). If you're looking for more than one specific record, you must change the ANDs 1 ink ing the conditions to ORs. Simply type over the ANDs when the cursor goes to them.

Next, you'11 get a message like the one below:

02/21/85 09: 58:45

REACNAME $=A$

HITS= 99 TOTAL NUMFAILS $=99$

Do you want this information printed on the printer? : :

After you've chosen whether to print or not, you'll see:

Press $X$ to Exit back to previous menu or any other key to continue : :

Assuming you've decided to continue, you will next see the first record which satisfies your conditions in the format like the sample below:

Identification Information for Record \# 1 Database Number: :0401:

LER \#: 82-008:

Component Information

Valve/Penetration : V:

Type

:D:

CIS Class

$1:$

Reactor Name :ART:

Reactor Type :P:

Primary System :10:

Failure Information

Date

Failure Mode

:820329:

Primary Cause :24:

\# of Failures : 1:

Containment Isol? : Y:

Comments : Containment cooler isolation valve fails to close. Valve CV-6202 woul d not close due to air relay problem.

To skip to end of record, type CTRL-C or PgDn

After you've typed or down arrowed through the whole record, you'll hve the 
following options for what to do next:

N - Next, P - Previous, F - First, D - Delete, X - eXit : :

If you choose to delete the record, it will come back on the screen in dimmer colors (so you'll know it's fading) and after getting to the end of the record, you'll get a bright message saying:

Record marked for deletion, $U$ to Undelete, RETURN to leave as is. $d$ :

If you choose to leave the record deleted. it will still be in the database, but you won't see it. To really get rid of $i t$, you'll have to use the dBASE III command PACK. See your dBASE III manual for an explanation of this.

Option A for Adding New Records

If you choose Option A from the opening edit menu, you'l I see a blank record like the one below:

Identification Information for Record \#

183

Database Number: : :

LER \#: :

Component Information

Valve/Penetration : :

Type

CIS Class

$::$

Reactor Name

Reactor Type

$:$ :

Primary System : :

$: \quad:$

$:$

Failure Information

Date

Failure Mode

Primary Cause

\# of Failures : :

Containment Isol? : :

Comments :

To skip to end of record, type CTRL-C or PgDn

After you've finished typing in the data for the new record, you' 11 get the following message:

A - Add another record, D - Delete this record, $X$ - eXit : : 
After you've used the progressive search feature for a while, you may decide that you have more temporary search files on your disk than you want ( or have room for). Option $P$ is designed to take care of the problem. An example of the first message you'll see is:

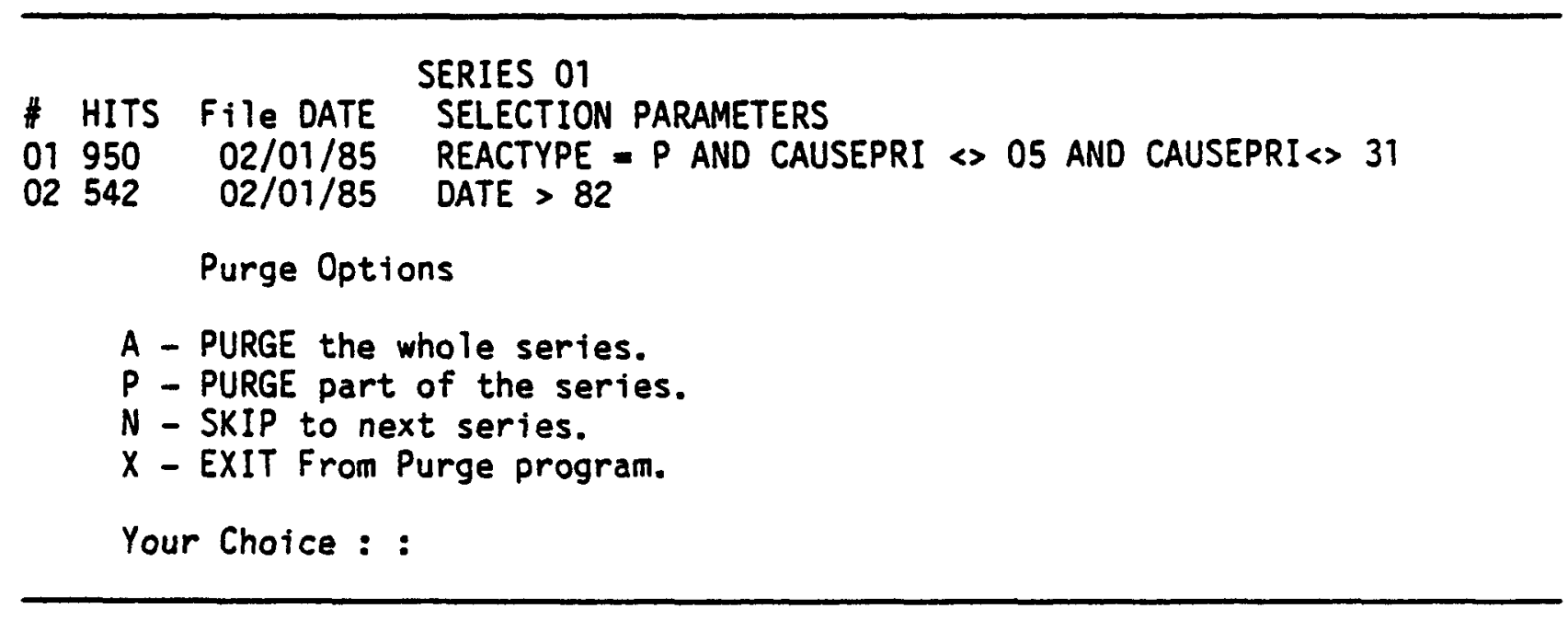

If you choose option $A$, you'll get one additional message:

Number of first search in series to purge? : :

Please note that this does not in any way affect the original database, but it does erase temporary databases you've created while using the progressive search options. Note that the date when each temporary file was created appears with it so you can see how long ago a particular search was made. 


\section{CHANGING THE SETTINGS FOR COLORS, DEFAULT DISK, ETC.}

When you choose Option $R$, you'll see the following screen:

Type over any program default setting you want to change

Just press the RETURN for any you want unchanged

Do you want to work with all 29 fields or only 14 : 14:

You can have the program act as soon as you enter the commands, or you can have the computer wait for a confirming RETURN

Do you want to confirm? :N:

Will you be using a color screen? : Y:

What is the designation of the disk and subdirectory (if any)

where your database files will be? :C: :

What is the name of your Master File? :NLER1:

If you choose to work with only 14 fields, in the cases where the program displays entire records on the screen or outputs them to the printer, the program will decode the coded fields, such as the type of component, the name of the reactor, the name of the system which the failure occured in, and the primary cause of the failure.

If you choose any number other than 14 or 29 for number of fields. the program will not work. All options we'vediscussed for the 14 field database work similarly for the 29 field database, but some of the messages are a little different and the field list shows 29 fields. If you're working with 29 fields, the on-line glossary will show all 29 fields.

While learning to use the program, you should probably choose to confirm each action with the return key. Otherwise, you may not realize you've entered the wrong option for what you're trying to do until the program is doing something else.

Don't try using the color screen option if you're using a monochrome screen. The results will be illegible.

You shouldn't need to change the values for disk and subdirectory or Master File. If you do, you need to know a little about DOS. If you mess up (or change on purpose) the values currently in these blanks, the program will revert to the beginning values the next time it is started. If new starting values are needed, contact the technical assistance person named at the end of the manual. 


\section{A.2. LISTING}

* REPORT.PRG 5-02-85 KRA

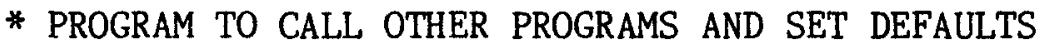

* VERSION WHICH STORES DECODING DATA IN MEMORY

* VERSION FOR PETE PELTO haRd DISK AND COLOR SCREEN

* PUBLIC VARIABLES CREATED

* CF

* CF1

* $\mathrm{CF} 2$

* COLl - 5 Color control variables.

* CONF Toggle variable for CONFIRM

* DBD Drive and subdirectory where permanent \& temporary database files are.

* GCV Glossary control Variable, controls entry/exit to/from Glossary

* HITS Count of records in temporary file, stored as FHITS in \&DBD \pm R3TFCAT.

* ID MSERIES+TFNUM for temporary reference file.

* MCV Master Control Variable, 14 or 29 depending on number of fields in use.

* MCV2 BASE if main file is in use, TEMP if temporary files are used.

* MF Name of Master File, i.e. NLER1.

* MN

* MSERIES Temporary file series, used in listing catalog.

* N Counter.

* NF Sum of NUMFAILS for temporary file, stored as FNF in \&DBD \pm R3TFCAT.

* NID MSERIES+TFNUM for the temporary file being created or reported.

* OPT Primary option variable used to select menu items.

* $\mathrm{PH}$

* PH2 Page heading, column headings for columnar printouts.

* PN Page number, used in print routines.

* PRF

* SCV Logic variable that tells whether memory variables are stored.

* SP Selection parameter, dbase III format

* SPU. Selection parameter, user format, stored as UPARAM in \&DBD \pm R3TFCAT.

* TFNUM Temporary file number, sometimes used as a counter

* YN Y/N variable reused, often from one file to the next.

* 31 Public variables created

* PRIVATE VARIaBLES CREATED

* PSWD

RELEASE ALL

SET CONFIRM OFF

SET DELETED ON

SET DELIMITER ON

SET TALK OFF

SET BELL OFF

SET DEVICE TO SCREEN

PUBLIC SCV

IF .NOT. SCV

PUBLIC OPT, YN, TFNUM, SP , SPU, PH2, PH, PN , HITS, CF1, CF2, CF , N , NF , PRF , GCV , MF , ICV3

PUBLIC CONF, DBD, MSERIES, ID , NID, GCV , COL1 , COL 2, COL 3, COL4, MCV , MCV2, MN , COL5

STORE ' $N$ ' TO CONF

ENDIF

IF .NOT. FILE('RNCODE.MEM')

CLEAR

@ 10,10 SAY 'Storing memory variables, please wait'

DO R1MI

ENDIF

STORE .T. TO SCV 
* SETTING DEFAULTS

STORE ' ' TO YN,MN

STORE 14 TO MCV

STORE 'NLER4' TO MF

STORE 'D: \pm RACISP' TO DBD

STORE ' $6+/ 1,3+/ 1,1$ ' TO COL1

STORE ' $3+/ 1,6+/ 1,1$ ' TO COL2

STORE ' $7+/ 4,3+/ 1,1$ ' TO COL3

STORE $' 6 / 1,3 / 1,1 ;$ TO COL 4

STORE ' $2+/ 1,6+/ 1,1$ ' TO COL5

ENDIF

STORE ' ' TO OPT

DO WHILE UPPER(OPT) \langle\rangle$^{\prime} X 1^{\prime}$

SET COLOR TO \&COL1

CLEAR

STORE ' ' TO OPT

STORE 'BASE' TO MCV2

TEXT

Welcome to the reporting system for the Containment Isolation System (CIS) LER database. This database contains information extracted from LER's related to CIS. If you are unfamiliar with the database, you should start by reading the glossary which explains the contents of the database. If you elect to continue, you will have opportunities to look at the glossary when you are called on to enter field names.

ENDTEXT

$G$ Look at glossary of field names.

$S$ Search the database, make onscreen or printed reports.

C Columnar lists of selected fields on screen or printed.

D Display entire record(s) on screen.

L List all or selected records on printer.

E Edit record(s) on screen.

$P$ Purge unwanted searches from disk.

$R$ Reset program defaults.

$X$ Exit back to dBASE III.

@ 18,11 SAY "Enter your choice"

@ 18,30 GET OPT

READ

IF UPPER(OPT) $=$ ' $X$ '

STORE ' $X 1$ ' TO OPT

LOOP

ENDIF

IF UPPER(OPT) $=$ ' $L$ '

DO RIPRINT

STORE ' ' TO OPT, YN

ENDIF

IF UPPER(OPT) $=$ ' ${ }^{\prime}$ 
DO RIGLOS

ENDIF

IF UPPER(OPT) \langle\rangle$^{\prime} X '$. AND.UPPER(OPT) \langle\rangle$^{\prime} R^{\prime}$. AND.UPPER(OPT) \langle\rangle$^{\prime} P^{\prime}$

IF .NOT. FILE( ' $\& D B D \pm \& M F$.DBF')

SET COLOR TO \&COL3

@ 20,0 SAY 'You must reset Master File name or drive designation before proceeding.' (a 21,0 SAY 'The one currently set, '+DBD+' \pm ' $+\mathrm{MF}+$ ' does not exist'

SET COLOR TO \&COL1

STORE 'RF' TO OPT

ENDIF

ENDIF

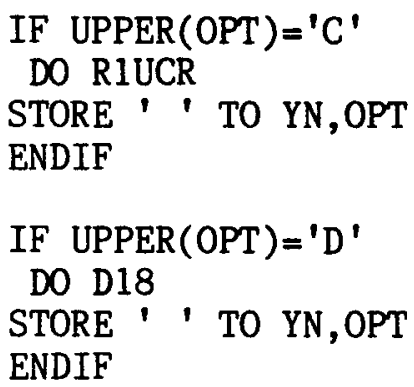

IF UPPER(OPT) $=$ ' $\mathrm{C}$ '

DO RIUCR

STORE ' ' TO YN,OPT

ENDIF 
ENDDO

ENDIF

IF UPPER(OPT $)={ }^{\prime} R^{\prime}$

DO RISET

ENDIF

ENDDO

CLEAR

SET CONFIRM OFF

SET TALK ON

RETURN

A. 38 


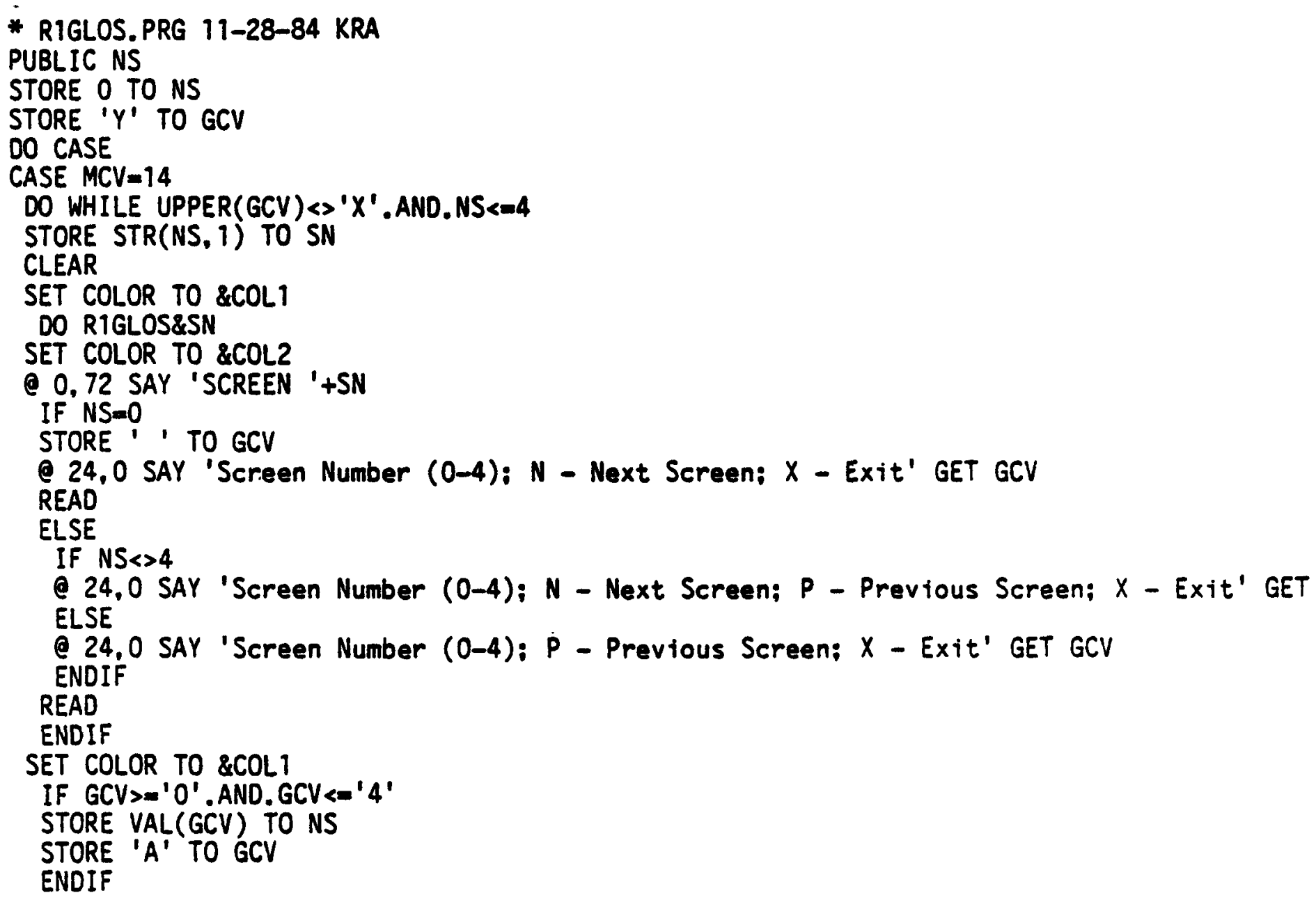


STORE ' ' TO GCV

e 24,0 SAY 'Screen Number (0-9); $N$ - Next Screen; $X$ - Exit' GET GCV

READ

ELSE

IF $N S<>9$

e 24,0 SAY 'Screen Number (0-9); $N$ - Next Screen; $P$ - Previous Screen; $X$ - Exit' GET

ELSE

e 24,0 SAY 'Screen Number (0-9); $P$ - Previous Screen; $X$ - Exit' GET GCV ENDIF

READ

ENDIF

SET COLOR TO \&COLI

If GCV $>={ }^{\prime} O^{\prime}$. AND. GCV $<=$ ' 9 '

STORE VAL(GCV) TO NS

STORE 'A' TO GCV

ENDIF

IF NS>1. AND. UPPER(GCV $)=' P$ '

STORE NS-1 TO NS

ENDIF

IF UPPER(GCV) $=$ ' $N$ '

STORE NS+1 TO NS

ENDIF

IF UPPER(GCV)<> 'A' AND. UPPER(GCV)<>'P'. AND. UPPER(GCV) $<>^{\prime} N$ '

STORE ' $X$ ' TO GCV

ENDIF

ENDDO

ENDCASE

RETURN 
* RTGLOSO.PRG 11-9-84 KRA

* SCREEN NUMBER 0

TEXT

DATABNUM Unique four-digit serial number assigned to each record by PNL.

LERNUM Number assigned to the Licensee Event Report (LER) by the NRC. The first two digits are the year of the LER.

TYPEMAIN $V$ indicates a valve failure, $P$ a penetration failure

TYPESUB 1

For a valve:

$A=$ electric motor operated (AC)

$B=$ electric motor operated (DC)

$C=$ hydraulic operated

$D=$ pneumatic diaphragm/cylinder operated

$E$ = solenoid operated (AC)

$F=$ solenoid operated (DC)

$G=$ float operated

$H=$ explosive squib operated

$\mathrm{J}=$ mechanically operated

$K=$ electric motor operated (unspecified)

$L=$ solenoid operated (unspecified)

$M=$ manually operated

$N=$ remotely operated

$P=$ damper

ENDTEXT

RETURN

$Q=$ vacuum breaker

$R=$ relief or safety

$S=$ check

$x=$ other

\section{TYPESUB 1}

For a penetration:

$A=$ personal access

$B=$ fuel handling

$C=$ equipment access

$D=$ electrical

$E=$ instrument line

$F=$ process piping

$G=$ access (unspecified)

$X=$ other 


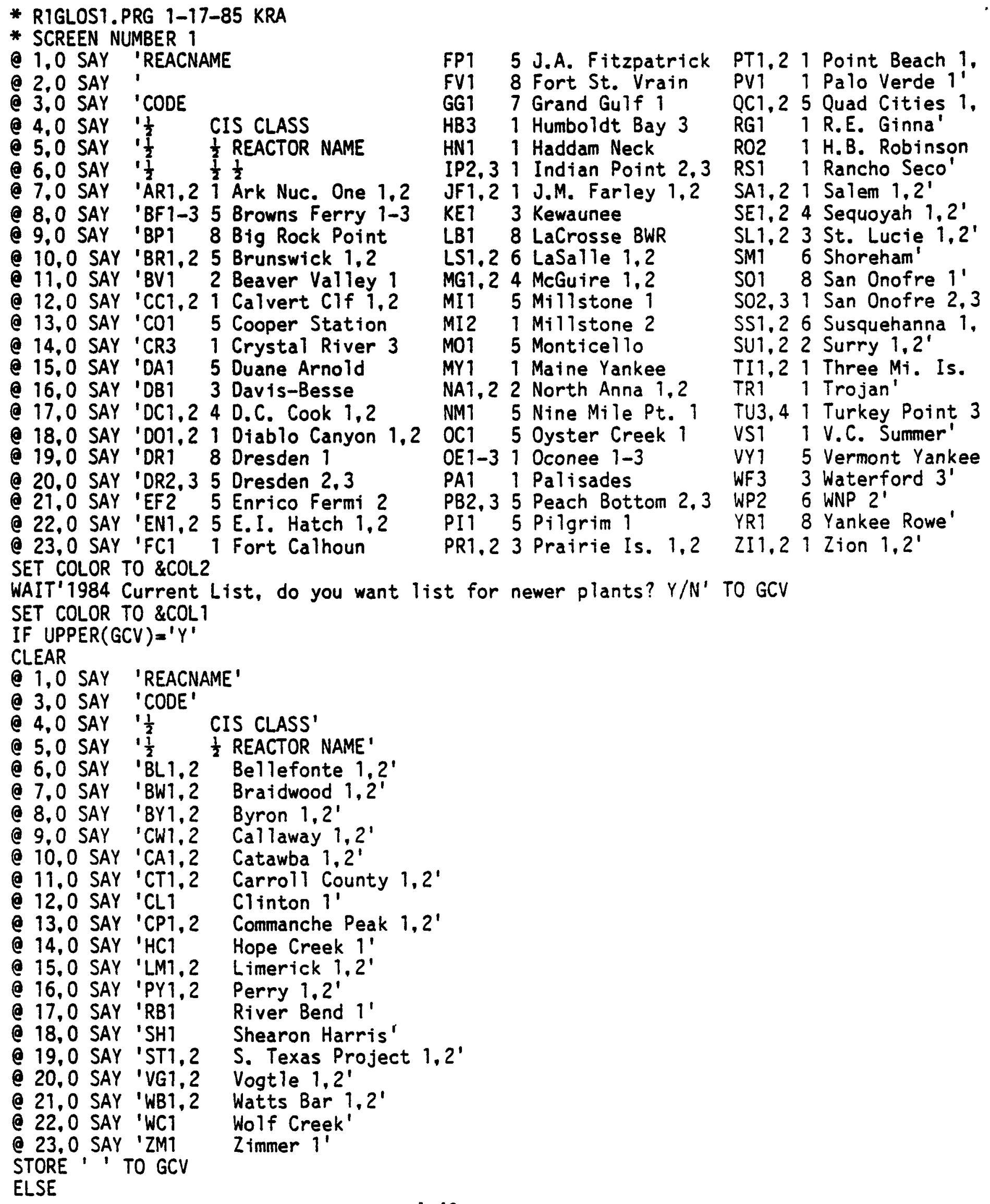




\section{STORE ' I TO GCV}

RETURN

ENDIF 
* R1GLOS2.PRG 11-9-84 KRA

* SCREEN NUMBER 2A

STORE ' ' TO NNS

TEXT

REACTYPE One of the following: $B=B W R$

$\mathrm{H}=\mathrm{HTGR}$ (Fort St. Vrain)

$\mathrm{P}=\mathrm{PWR}$

CISCLASS Class of Containment Isolation System (CIS)

Class 1. PWR - Large Dry Containment

Class 2. PWR - Subatmospheric Containment

Class 3. PWR - Dual (Double) Containment

Class 4. PWR - Ice Condenser Containment

Class 5. BWR - Mark I Containment

Class 6. BWR - Mark II Containment

Class 7. BWR - Mark III Containment

Class 8. Other CIS

SYSPRIMA Primary system involved in failure.

ENDTEXT

Designations are different for PWR's and BWR's.

@ ROW( )+1,8 SAY 'To see PWR list type $\mathrm{P}$ or to see BWR list type B. 'GET NNS

READ

CLEAR

IF UPPER(NNS) $=$ ' $\mathrm{P}$ '

* SCREEN NUMBER 2B

TEXT

SYSPRIMA Primary system involved in failure. For a PWR:

01 = reactor coolant

22 = demineralized water

02 = main steam

23 = containment sump

03 = high pressure injection/recirc. 24 = steam generator

04 = low pressure injection/recirc. 25 = containment large - volume purge

05 = instrument air

06 = service air

07 = air (unspecified)

26 = containment small - volume purge

27 = containment hydrogen purge

28 = containment purge (unspecified)

08 = service water

09 = residual heat removal

29 = nitrogen supply

30 = containment spray

10 = containment HVAC

31 = chemical volume control

11 = containment pressure

32 = refueling canal

12 = integrated leak rate test

33 = containment instrumentation (elec.)

13 = fire protection

99 = other

14 = containment atmosphere

15 = component cooling water

16 = radwaste

17 = containment waste gas

18 = main feedwater

19 = auxiliary feedwater

20 = pressurizer

21 = safety injection

ENDTEXT

ELSE

* sCREen NUMBER 2C

TEXT 
SYSPRIMA Primary system involved in failure. For a BWR:

$01=$ reactor coolant

22 = reactor cleanup

02 = main steam

$23=$ drywell purge

03 = high pressure injection/recirc.

24 = drywell vent

04 = low pressure in jection $/ \mathrm{recirc}$.

05 = instrument air

25 = drywell equipment sump

06 = service air

07 = air (unspecified)

$26=$ drywell floor sump

08 = service water

$27=$ drywell sump (unspecified)

09 = residual heat removal

28 = control rod drive

10 = containment HVAC

11 = drywel1 pressure

12 = integrated leak rate test

$29=$ core spray

$30=$ vessel head spray

13 = fire protection

14 = drywell atmosphere

$15=$ component cooling water

31 = containment cooling

32 = traversing incore probe

33 = torus (wetwel1) vent

34 = vacuum relief

35 = drywell instrumentation (elec.)

16 = radwaste

17 = drywel1 waste gas

36 = torus (wetwell) inst. (elec.)

$37=$ nitrogen supply

18 = main feedwater

38 = torus (wetwe11) purge

$99=$ other

19 = auxiliary feedwater

20 = reactor core isolation cooling

21 = standby liquid control

ENDTEXT

ENDIF

RETURN 
* RTGLOS3.PRG 1-17-85 KRA

* SCREEN NUMBER 3

TEXT

NUMFAILS Number of fallures reported in the LER, 1 unless specified

DATE Date of failure event in six-digit code, e.g.. 830812 = August 12. 1983.

MODE One of the following failure modes:

$A=$ leakage (fail to seal)

$B=$ fail to close

$C=$ unplanned opening (fail to remain closed)

Failure mode $B$ refers to failures in which the component does not close within a reasonable time limit, thereby constituting a potential failure to isolate containment.

ENDTEXT

RETURN 
* R1GLOS4.PRG 11-9-84 KRA

* SCREEN NUMBER 4

TEXT

CAUSEPRI Primary cause, one of the following:

$00=$ unknown

$01=$ personnel (operation)

17 = bearing/bushing fail/prob.

02 = personnel (maintenance)

18 = weld failure

03 = personnel (testing)

19 = 1ack of lubrication

04 = design error

05 = fabrication/construction $/ Q C$

20 = electric motor operator fail/prob.

21 = electric solenoid fail/prob.

06 = procedural discrepancy

$07=$ normal wear

08 = excessive wear

$09=$ corrosion

22 = leaking/ruptured diaphragm

23 = torque switch fail/prob.

24 = failure of component supply system (air supp1y interrupt).

10 = foreign material contamination

11 = excessive vibration

12 = mechanical control/parts; failed or out of adjustment

13 = seal/gasket fail/prob.

14 = packing fail/prob.

15 = bellows/boot fail/prob.

16 = electrical input fail/prob.

25 = seat/disc fail/prob.

26 = limit switch fail/prob.

27 = pilot valve fail/prob.

28 = air solenoid fail/prob.

29 = solenoid (unspecified) fail/prob.

30 = operator (unspecified) fail/prob.

31 = penetration sealant fail/prob.

32 = personnel (construction)

33 = rupture

34 = equalizing valve (on air lock)

35 = hydraulic operator fail/prob.

ISOLATED Despite the failure, did containment remain isolated? Yes/No

COMMENTS Summary and/or additional information.

ENDTEXT

RETURN 
* R3CAT1.PRG 5-03-85 KRA

* Program segment to show list of previously created temporary files at the

* beginning of the R3PORT program.

* variables created:

* TFNUM( $n$ ) a temporary counter of temporary files

* L(n) a temporary counter of lines

* YN(c) a temporary decision variable

* files called: R1SEL

SET DEVICE TO SCREEN

STORE ' ' TO YN, ICV3

IF OPT $=$ ' $A$ '.OR .OPT $=$ ' $a$ '

* IF this is not the first time through

IF UPPER(SUBSTR(OPT , 2,1)) $=^{\prime} \mathrm{A}$ '

* IF the current search is being continued

* find the next number for ID

STORE NID TO ID

STORE '\&DBD \pm R3T\&ID' TO PRF

STORE VAL(NID)+1 TO IDN

STORE STR(IDN,4) TO NID

IF VAL(NID) $<1000$

IF SUBSTR(NID $, 1,1)\langle\rangle^{\prime} 0^{\prime}$

STORE ' $0^{\prime}+$ SUBSTR(NID, 2,3) TO NID

ENDIF

ENDIF

* IF THERE'S ALREAdY a R3T\&NId FILE EXISTING, WE NEED TO ERASE IT

STORE DBD+'R3T'+NID+'.DBF' TO FN

IF FILE (' $\left.\& F N^{\prime}\right)=. T$.

ERASE \&FN

ENDIF

STORE SUBSTR(NID, 1,2) TO MSERIES

STORE SUBSTR(NID, 3,3) TO TFNUM

RETURN

* jump out and select parameters for new temporary file, \&DBD \pm R3T\&ID.DBF

ENDIF

IF UPPER(SUBSTR(OPT , 2,1)) $=^{\prime} \mathrm{B}$ '

* IF the current temporary file is being overwritten

* Need to wipe out current record in \&DBD $\pm R 3 T F C A T$ since the file is being changed STORE DBD+'R3T'+NID+'.DBF' TO FN

ERASE \&FN

RETURN

* jump out and select new parameters, using the same ID

ENDIF 
ENDIF

STORE 'R' TO ICV

IF UPPER(MN) \langle\rangle$^{\prime} \mathrm{C}$ '

CLEAR

TEXT

This part of the program displays a catalog of the searches of the database which have been performed up to now. The searches are organized into Series. Each Series begins with a search of the whole database. Subsequent searches search only the records picked out by the search listed immediately above them. Up to 99 different Series are possible (assuming your disk has that much room) and each series can have up to 99 searches in it. If you want a report on one of the searches you see listed in the catalog, simply enter its series number and search number. You may also choose any of the listed searches as a place to start your own series of inquiries. If you choose a search before the end of the series and make additional searches from it, you will erase subsearches previously made. To CANCEL further appearances of this message, enter ' $C$ '. If don' $t$ want to search the database now, enter ' $X$ '. Press any other key to just continue.

ENDTEXT

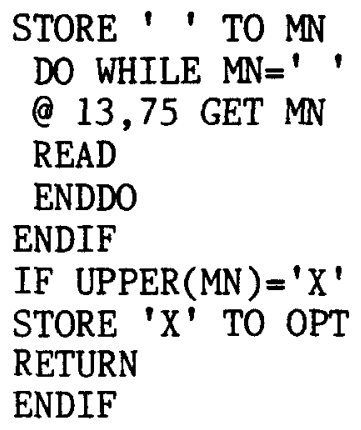

IF .NOT.FILE( '\&DBD \pm R3TFCAT.DBF')

USE RICAT

COPY STRU TO \&DBD \pm R3TFCAT

ENDIF

USE \&DBD $\pm R 3 T F C A T$

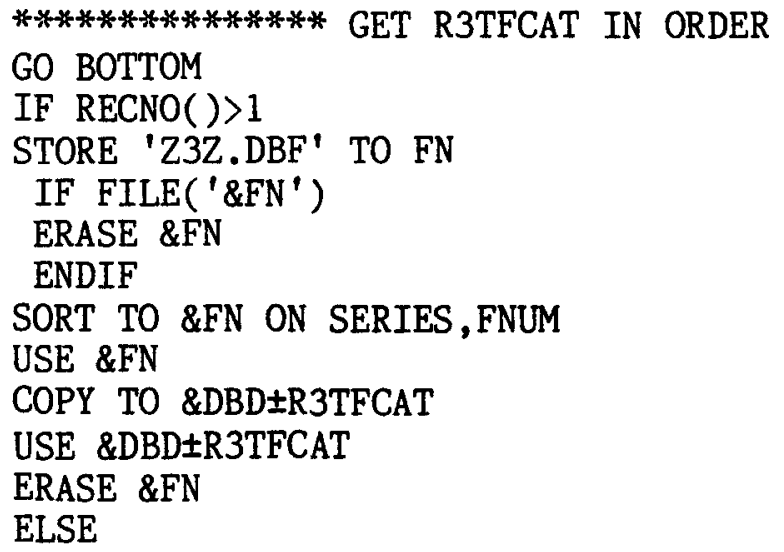


STORE ' ' TO ICV2

* subroutine to identify missing files in catalog database

DO WHILE .NOT. EOF()

STORE SERIES+FNUM TO A

IF FILE ('\&DBD $\left.\pm R 3 T \& A . D B F^{\prime}\right)=. T$.

STORE ' $Y$ ' TO ICV2

SKIP

ELSE

DELETE

SKIP

ENDIF

ENDDO

PACK

DO WHILE UPPER(ICV) $=$ ' $R$ '

GO TOP

IF $\operatorname{EOF}()=. T$.

STORE ' $\mathrm{X}$ ' TO ICV

ELSE

SET COLOR TO \&COL3

STORE ' ' TO ICV3, LV

(a) 20,0 SAY 'Ready to list search files on screen, do you want printed list too?'

@ 20,70 SAY 'Y/N' GET ICV3

READ

SET COLOR TO \&COL1

ENDIF

STORE 1 TO L

GO TOP

CLEAR

DO WHILE .NOT. EOF()

SET COLOR TO \&COL2

@ L, 70 SAY "SERIES "+SERIES

SET COLOR TO \&COLl

@ L,0 SAY "\# HITS \#FL SELECTION PARAMETERS"

* display header for catalog

STORE L+1 TO L

STORE VAL(SERIES) TO S

STORE SERIES TO MSERIES

DO WHILE (.NOT. EOF( )).AND.VAL(SERIES) $=\mathrm{S}$

@ L,O SAY FNUM PICTURE '99'

@ L,3 SAY FHITS PICTURE ' $9999^{\prime}$

@ L,8 SAY FNF PICTURE '9999'

STORE TRIM(UPARAM) TO SPU

(e) L,14 SAY SUBSTR(SPU, 1,65) 
IF LEN(SPU) $>65$

STORE L+1 TO L

(a) L,14 SAY SUBSTR(SPU,66,49)

ENDIF

STORE L+1 TO L

SKIP

IF L>23.AND. ( .NOT.EOF())

WAIT 'Too many searches for one screen, press any key to continue' CLEAR

GO TOP

STORE ' $X X$ ' TO LV

STORE 1 TO L

ENDIF

ENDDO

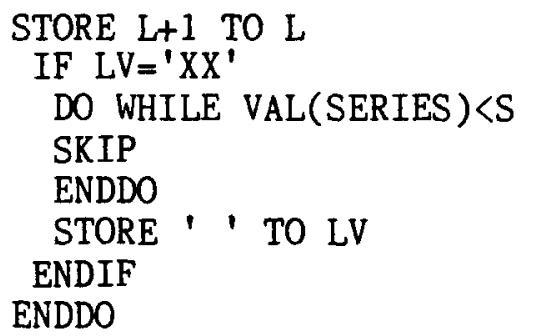

IF $\operatorname{ROW}()>21$

WAIT 'List complete, press any key to continue'

ENDIF

IF UPPER(ICV3) $=$ ' $Y$ '

GO TOP

STORE 5 TO L

SET DEVICE TO PRINT

SET MARGIN TO 4

ENDIF

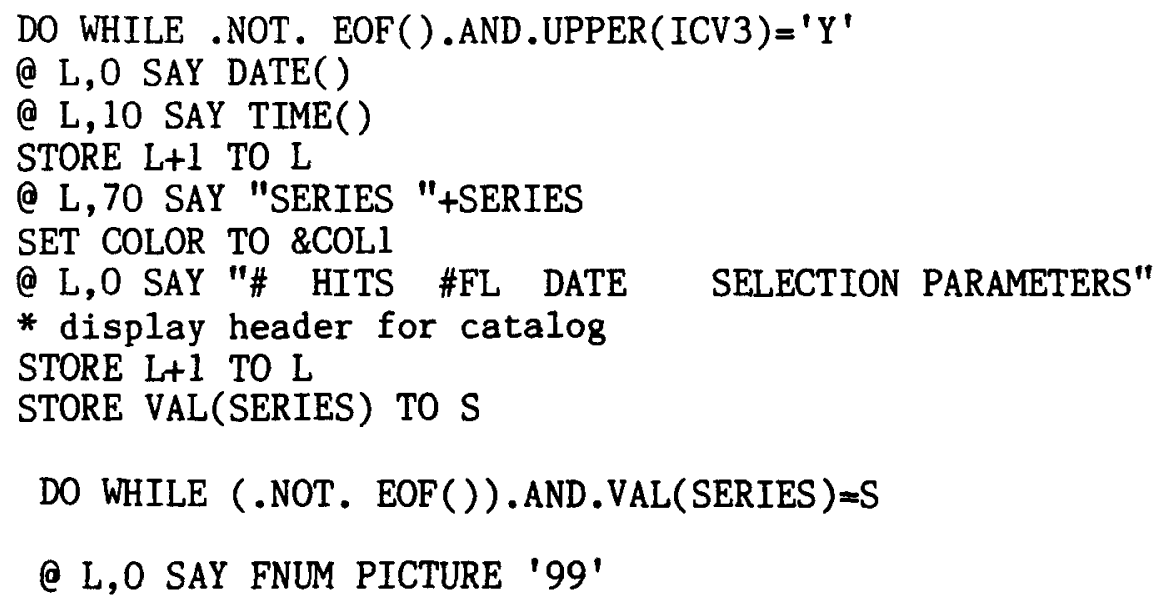

DO WHILE (.NOT. EOF()). AND.VAL(SERIES) $=S$

@ L,0 SAY FNUM PICTURE '99' 


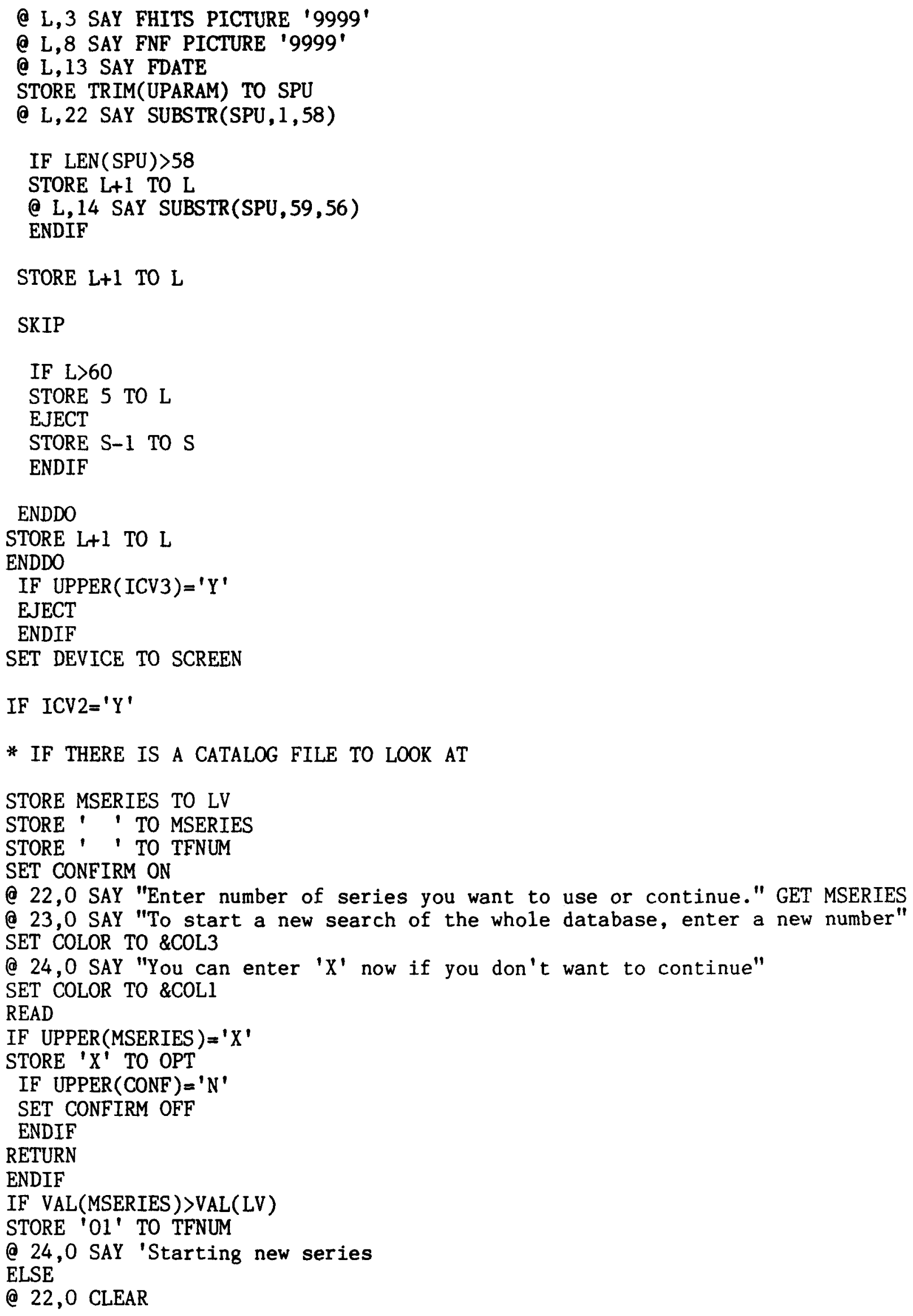


(a 22,0 SAY "Enter number of the search you want to use or continue." GET TFNUM

(a 23,0 SAY "If you continue from any but the last one, each continuation"

@ 24,0 SAY "will erase one previous subsearch."

READ

ENDIF

IF UPPER(CONF) $=$ ' $N$ '

SET CONFIRM OFF

ENDIF

* MAKE SURE MSERIES AND TFNUM ARE IN THE RIGHT FORMAT

IF VAL(MSERIES) $<10$

STORE 'O'+STR(VAL(MSERIES), 1) TO MSERIES

ENDIF

IF VAL(TFNUM) $<10$

STORE ' 0 '+STR(VAL(TFNUM), 1) TO TFNUM

ENDIF

* SET UP THE VARIABLE ID, for IDentification

-STORE MSERIES+TFNUM TO ID

* SET UP THE VARIABLE RID, FOR Reference IDentification

STORE VAL(ID)-1 TO IDR

STORE STR(IDR,4) TO RID

IF VAL(RID) $<1000$

IF SUBSTR(RID $, 1,1)\langle>$ ' 0 '

STORE ' 0 '+SUBSTR(RID, 2,3) TO RID

ENDIF

ENDIF

* AT THIS POINT, THERE ARE FOUR POSSIBILITIES

* 1. AN EXISTING FILE haS BEEN CHOSEN

* 2. THE NEXT NUMBER IN AN EXISTING SERIES HAS BEEN CHOSEN

* 3. A NEW SERIES WITH TFNUM $=$ '01' HAS BEEN CHOSEN

* 4. NONE OF THE ABOVE HAS BEEN CHOSEN

* THE CASES WILl BE haNDLEd ONE AT a TIME

* CASE 1 AN EXISTING FILE haS BEEN CHOSEN

GO TOP

DO WHILE SERIES+FNUM 〈 ID.AND. (.NOT.EOF( ))

SKIP

ENDDO

IF SERIES+FNUM=ID

STORE ' $N$ ' TO YN

STORE ID TO NID

IF $\operatorname{SUBSTR}(I D, 3,2)={ }^{\prime} 01^{\prime}$

STORE ' $\& D B D \pm \& M F$ ' TO PRF

ELSE

STORE '\&DBD $\pm R 3 T \& R I D$ ' TO PRF

ENDIF 
STORE ' $X$ ' TO ICV

ENDIF

* CASE 2 The NEXT NUMBER IN AN EXISTINg SERIES haS BEen ChOSEn

IF ICV $<>$ ' $X '$

GO TOP

DO WHILE SERIES+ENUM 〈 RID.AND. (.NOT.EOF())

SKIP

ENDDO

IF SERIES+FNUM=RID

STORE ID TO NID

STORE RID TO ID

STORE '\&DBD \pm R3T\&ID' TO PRF

STORE ' $\mathrm{X}$ ' TO ICV

ENDIF

ENDIF

* CASE 3 a NEW SERIES WITH TFNUM $=$ '01' HAS BEEN CHOSEN

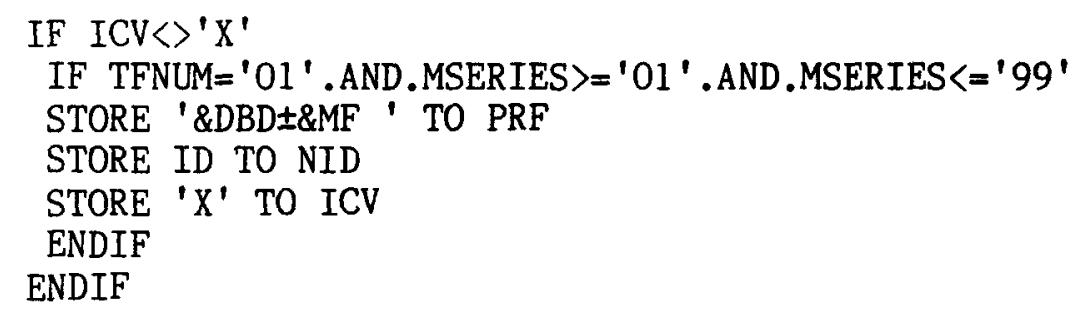

* CASE 4 NONE OF THE abOVE haS BEen CHOSEN

IF ICV $<>^{\prime} X^{\prime}$

@ 21,0 CLEAR

@ 21,0 SAY 'The number you entered is not a currently available search.'

@ 22,0 SAY 'Press " $R$ " to look at the catalog again or press " $S$ " to start'

@ 23,0 SAY 'a new series' GET ICV

READ

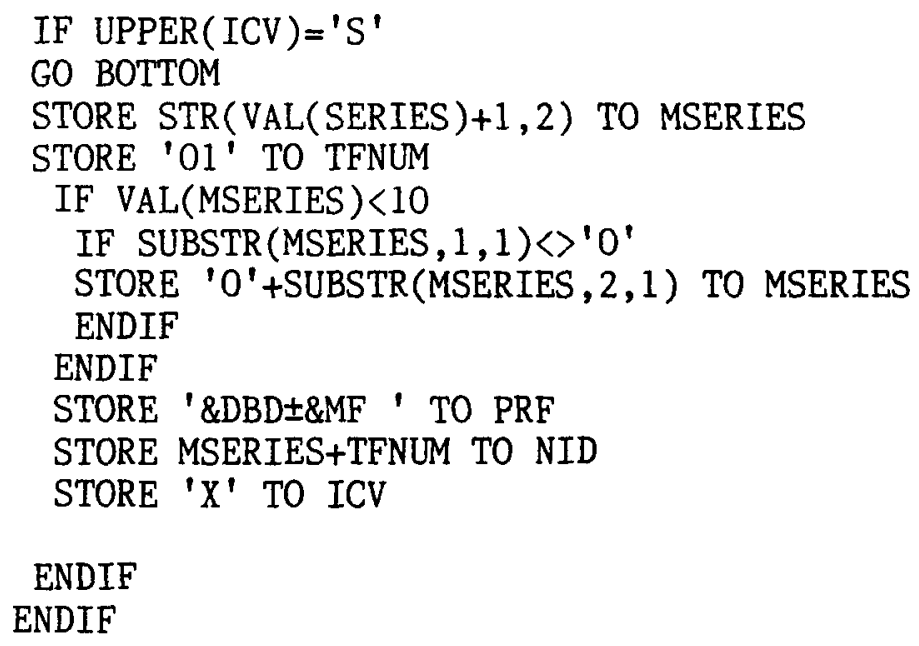

ELSE 
* this is the CaSe where the catalog file was found to be empTy

\section{STORE 'O1' TO MSERIES, TFNUM}

STORE '0101' TO NID

STORE '\&DBD $\pm \& M F$ ' TO PRF

ENDIF

\section{ENDDO}

\section{CLEAR}

* at THIS POINT, ID, IF ANy, MATChes PRF

* NID MATCHES THE NEXT FILE TO BE CREATED, MSERIES AND TFNUM MATCH NID

* IF aN EXISTING fIle haS BEEN CHOSEN, YN $=$ ' $N$ ' AND NID MATCHES THE EXISTING

* FILE. THAT WAY, IF OPTION AB IS CHOSEN IN R3OPT, THE EXISTING FILE WILl BE

* ERASED AND RECREATED.

RETURN 
* R1S.PRG 5-02-85 Ken Ames

STORE ' ' TO ICV

PUBLIC IV1,IV2,IV3

TEXT

List of possible RELATIONS

= equal to

$<$ less than

$>$ greater than

$<$ less than or equal to

Relations apply to letters as well as numbers The search string you enter will be matched with The same number of characters from the beginning of the field data, for example data BR1 would

\rangle$=$ greater than or equal to satisfy the relation $=\mathrm{B}$, also $\rangle=\mathrm{A},\langle\mathrm{C},\langle\rangle \mathrm{BR} 2$

$\longleftrightarrow$ not equal to

HAS

This relation will search the whole field for the string you specify. i.e. abcdefghij HAS def. If you enter in ALL CAPS, case will be ignored. i.e. abcdefghi HAS FGH.

ENDTEXT

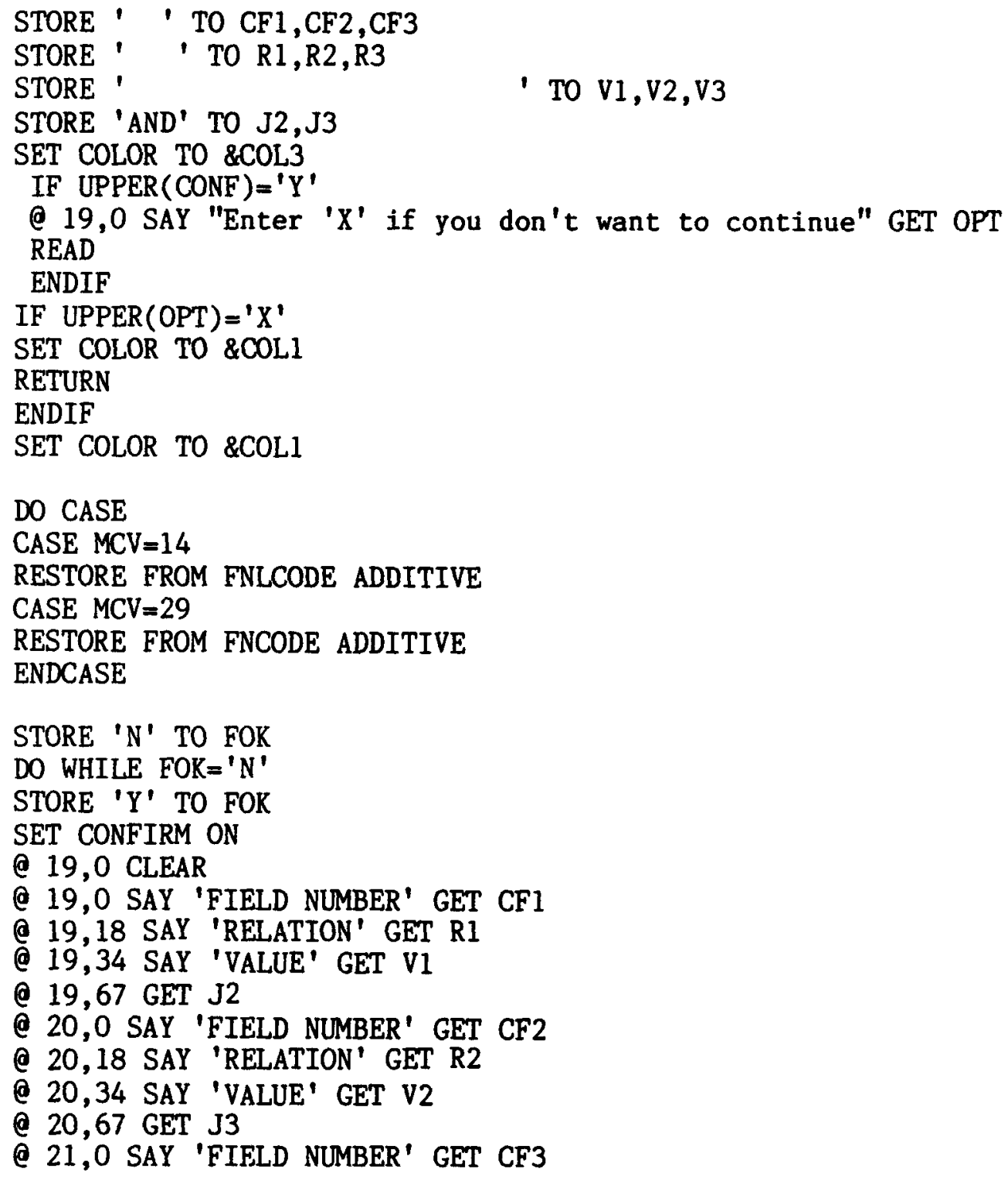




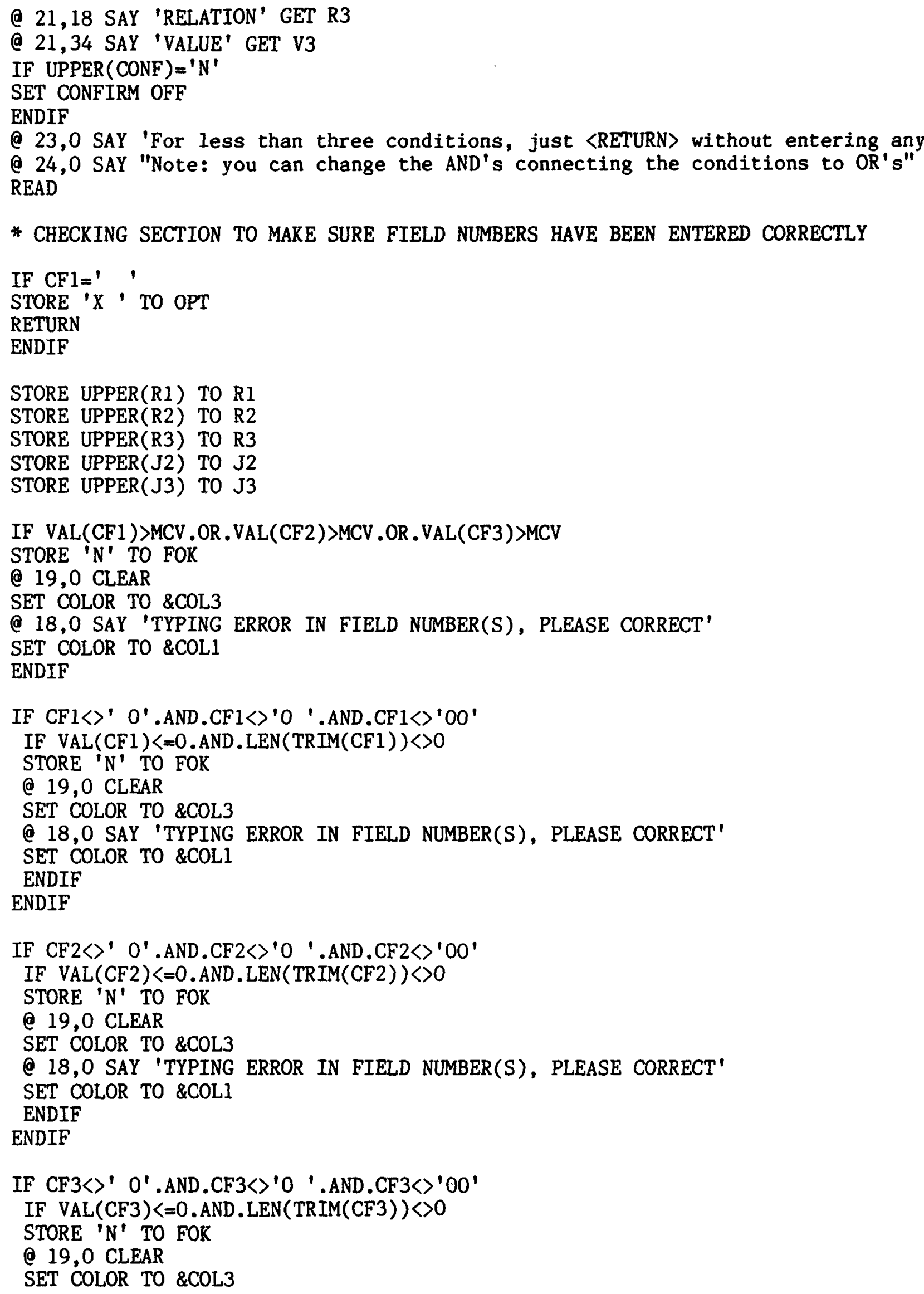


( 18,0 SAY 'TYPING ERROR IN FIELD NUMBER(S), PLEASE CORRECT'

SET COLOR TO \&COL1

ENDIF

ENDIF

IF FOK $=$ ' $N$ '

STORE ' $N$ ' TO FOK2

ENDIF

IF $\mathrm{R} 1\langle\rangle^{\prime}=$ '

IF $R I<\rangle^{\prime}<$,

IF $\left.R I\langle\rangle^{\prime}\right\rangle$ '

IF $\mathrm{RI}\langle\rangle^{\prime}\langle=$ '

IF $\left.R 1\langle\rangle^{\prime}\right\rangle=$ '

IF $R I\langle\rangle^{\prime}\langle\rangle^{\prime}$

IF $R 1<>$ 'HAS'

STORE ' $N$ ' TO FOK

(a) 19,0 CLEAR

SET COLOR TO \&COL3

IF FOK2=' $N$ '

( 18,0 SAY 'TYPING ERROR IN FIELD NUMBER(S) AND RELATIONS, PLEASE CORRECT' ELSE

@ 18,0 SAY 'TYPING ERROR IN RELATIONS, PLEASE CORRECT'

ENDIF

SET COLOR TO \&COL1

ENDIF

ENDIF

ENDIF

ENDIF

ENDIF

ENDIF

ENDIF

IF $\mathrm{CF} 2\langle\rangle^{\prime}$

IF $R 2\langle\rangle^{\prime}=$ '

IF $R 2\langle\rangle^{\prime}<$ '

IF $\left.\mathrm{R} 2\langle\rangle^{\prime}\right\rangle$,

IF $\mathrm{R} 2\langle\rangle^{\prime}<=$ '

IF $\left.\mathrm{R} 2\langle\rangle^{\prime}\right\rangle=$ '

IF $R 2\langle\rangle^{\prime}\langle\rangle^{\prime}$

IF $\mathrm{R} 2\langle\rangle^{\prime} \mathrm{HAS}$ '

STORE ' $N$ ' TO FOK

(a) 19,0 CLEAR

SET COLOR TO \&COL3

IF FOK2=' $N$ '

@ 18,0 SAY 'TYPING ERROR IN FIELD NUMBER(S) AND RELATIONS, PLEASE CORRECT' ELSE

@ 18,0 SAY 'TYPING ERROR IN RELATIONS, PLEASE CORRECT' ENDIF

SET COLOR TO \&COL1

ENDIF

ENDIF

ENDIF

ENDIF

ENDIF

ENDIF 


\section{ENDIF}

ENDIF

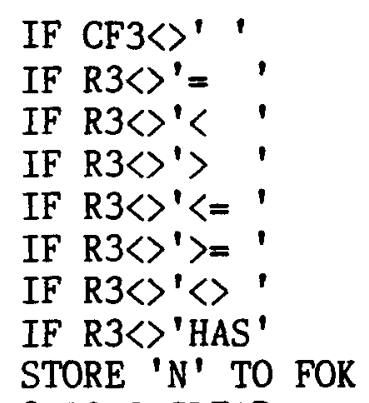

ENDDO

IF $\operatorname{VAL}(\mathrm{CF} 1)<10$

STORE 'O'+STR(VAL(CF1), 1) TO CF1 ENDIF

IF VAL(CF2)<10.AND.CF2 $<\rangle^{\prime}$ '

STORE 'O'+STR(VAL(CF2), 1) TO CF2

ENDIF

IF VAL(CF3)<10.AND.CF3 $>>'$,

STORE 'O'+STR(VAL(CF3), 1) TO CF3

ENDIF

\section{STORE FN\&CF1 TO CF1 \\ IF $C F 2\langle\rangle^{\prime}$ '}

STORE FN\&CF2 TO CF2

ENDIF

IF $\mathrm{CF} 3\langle\rangle \mid$ '

STORE FN\&CF3 TO CF3

ENDIF

STORE TRIM(R1) TO R1

STORE TRIM(R2) TO R2

STORE TRIM(R3) TO R3 


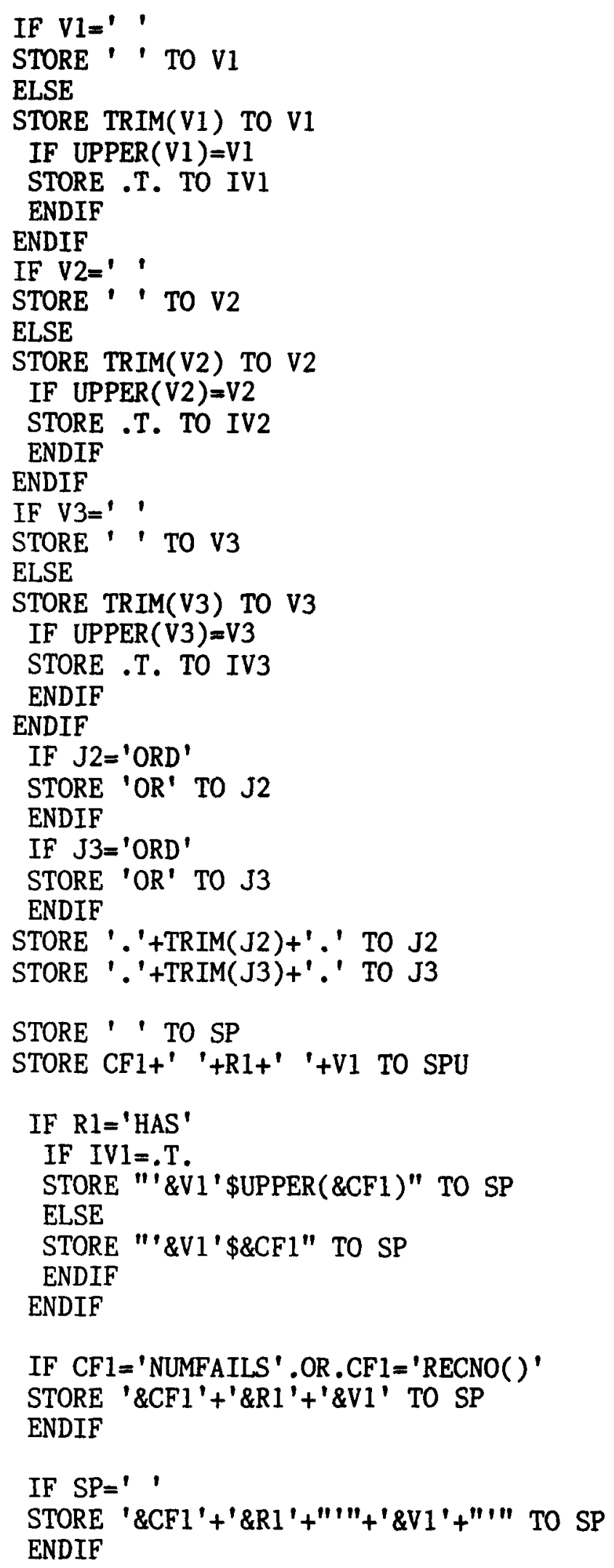


STORE SPUt' '+SUBSTR $(J 2,2, \operatorname{LEN}(\mathrm{J} 2)-2)+$ ' '+CF2+' '+R2t' '+V2 TO SPU

STORE SP + J2 TO SP

IF R2='HAS'

IF IV2 $=$.T.

STORE SP+"'\&V2' \$UPPER(\&CF2)" TO SP

ELSE

STORE SP+"'\&V2'\$\&CF2" TO SP

ENDIF

STORE 1 TO ICV

ENDIF

IF CF2 = 'NUMFAILS' .OR.CF $2=$ 'RECNO( )'

STORE SP + '\&CF2'+'\&R2'+'\&V2' TO SP

STORE 1 TO ICV

ENDIF

IF ICV $<>1$

STORE SP + '\&CF2'+'\&R2'+"'"'+'\&V2'+"'" TO SP

ENDIF

STORE O TO ICV

IF $\mathrm{CF} 3\langle\rangle$ ' '

STORE SPUt' '+SUBSTR(J3,2, LEN $(J 3)-2)+'$ '+CF3+' '+R3+' '+V3 TO SPU

STORE SP + J3 TO SP

IF R3=' $H A S^{\prime}$

IF IV $3=$. T.

STORE SP+"'\&V3' \$UPPER(\&CF3)" TO SP

ELSE

STORE SP+"'\&V3'\$\&CF3" TO SP

ENDIF

STORE 1 TO ICV

ENDIF

IF $C F 3=$ 'NUMFAILS'.$O R$.CF $3=$ 'RECNO()'

STORE SP + '\&CF3'+'\&R3'+'\&V3' TO SP

STORE 1 TO ICV

ENDIF

IF ICV $<>1$

STORE SP + '\&CF3'+'\&R3'+"'"'+'\&V3'+"'" TO SP

ENDIF

ENDIF

ENDIF

RETURN 


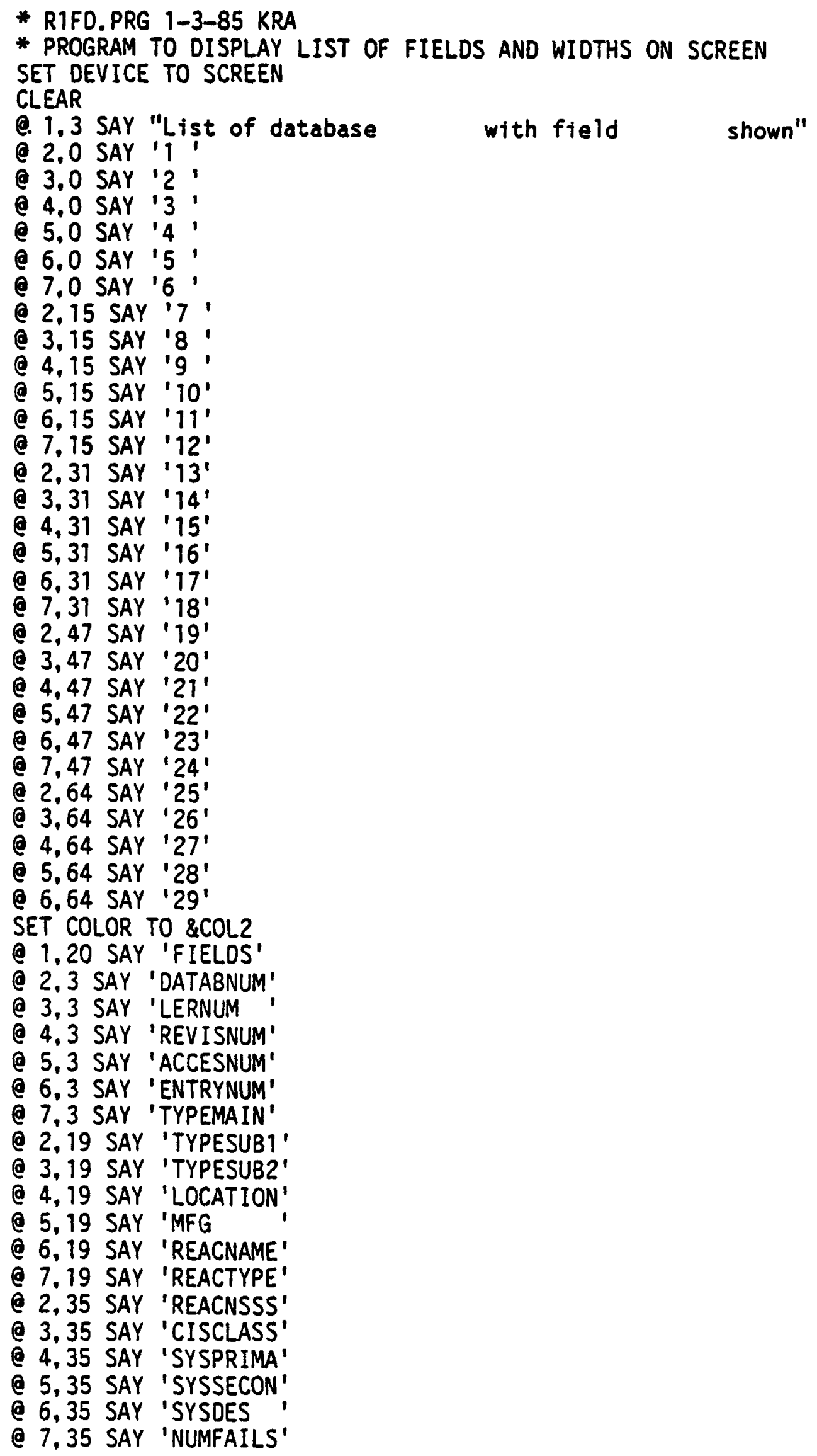




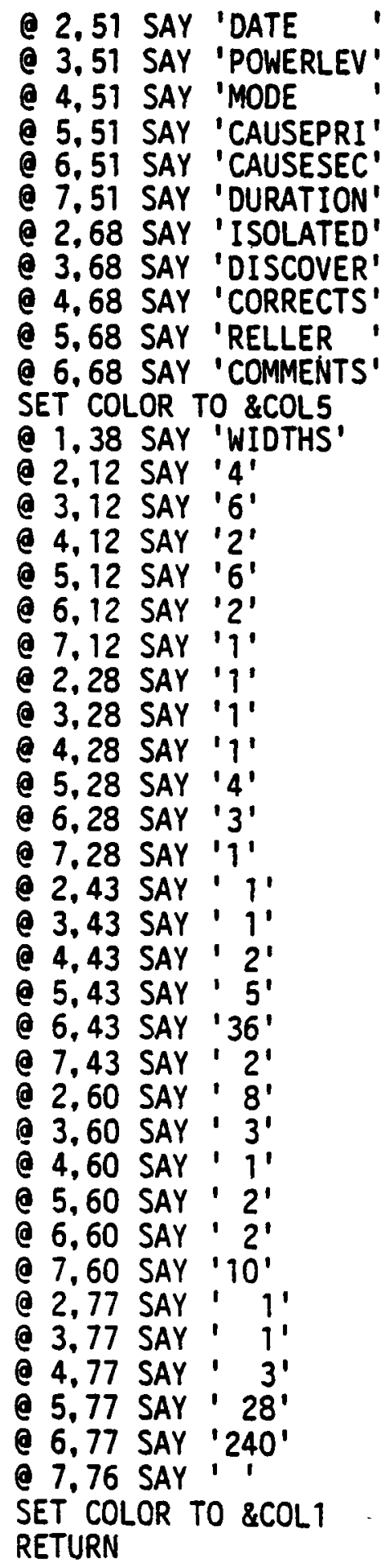


* R1FOL.PRG 1-17-85 KRA

* PROgRam to oISPLAY LIST OF 14 fIELDS AND WIDTHS ON SCREEN SET DEVICE TO SCREEN

CLEAR

e 1.3 SAY "List of database

e 2,0 SAY ' 1 '

e 3,0 SAY ' 2 '

e 4,0 SAY ' 3 '

อ 2,16 SAY ' 4 '

e 3.16 SAY ' 5 '

e 4,16 SAY ' 6 '

e 2,32 SAY ' 7 '

e 3,32 SAY ' 8 '

e 4,32 SAY ' 9 '

e 2,47 SAY ' 10 '

อ 3,47 SAY ' 11 '

อ 4,47 SAY ' 12 '

e 2,64 SAY ' 13 '

e 3,64 SAY ' 14 '

SET COLOR TO \&COL2

e 1,20 SAY 'FIELDS'

e 2,3 SAY 'DATABNUM'

e 3,3 SAY 'LERNUM

e 4,3 SAY 'TYPEMAIN'

a 2,19 SAY 'TYPESUBI'

e 3,19 SAY 'REACNAME'

e 4,19 SAY 'REACTYPE'

e 2,35 SAY 'CISCLASS'

e 3,35 SAY 'SYSPRIMA'

e 4,35 SAY 'NUMFAILS',

e 2,51 SAY 'DATE

e 3,51 SAY 'MODE

e 4,51 SAY 'CAUSEPRI'

e 2,68 SAY 'ISOLATED'

e 3,68 SAY 'COMMENTS'

SET COLOR TO \&COL5

e 1,38 SAY 'WIOTHS'

e 2,12 SAY ' 4 '

e 3,12 SAY ' 6 '

e 4,12 SAY ' 1 '

e 2,28 SAY ' 1 '

e 3,28 SAY ' 3 '

e 4,28 SAY ' 1 '

e 2,44 SAY ' 1 '

อ 3,44 SAY ' 2 '

e 4,44 SAY ' 2 '

อ 2,60 SAY ' 8 '

e 3,60 SAY ' 1 '

@ 4,60 SAY ' 2 '

e 2,77 SAY ' 1 '

อ 3.77 SAY ' 240 '

e 4,77 SAY

SET COLOR TO \&COL?

RETURN

with field shown" 


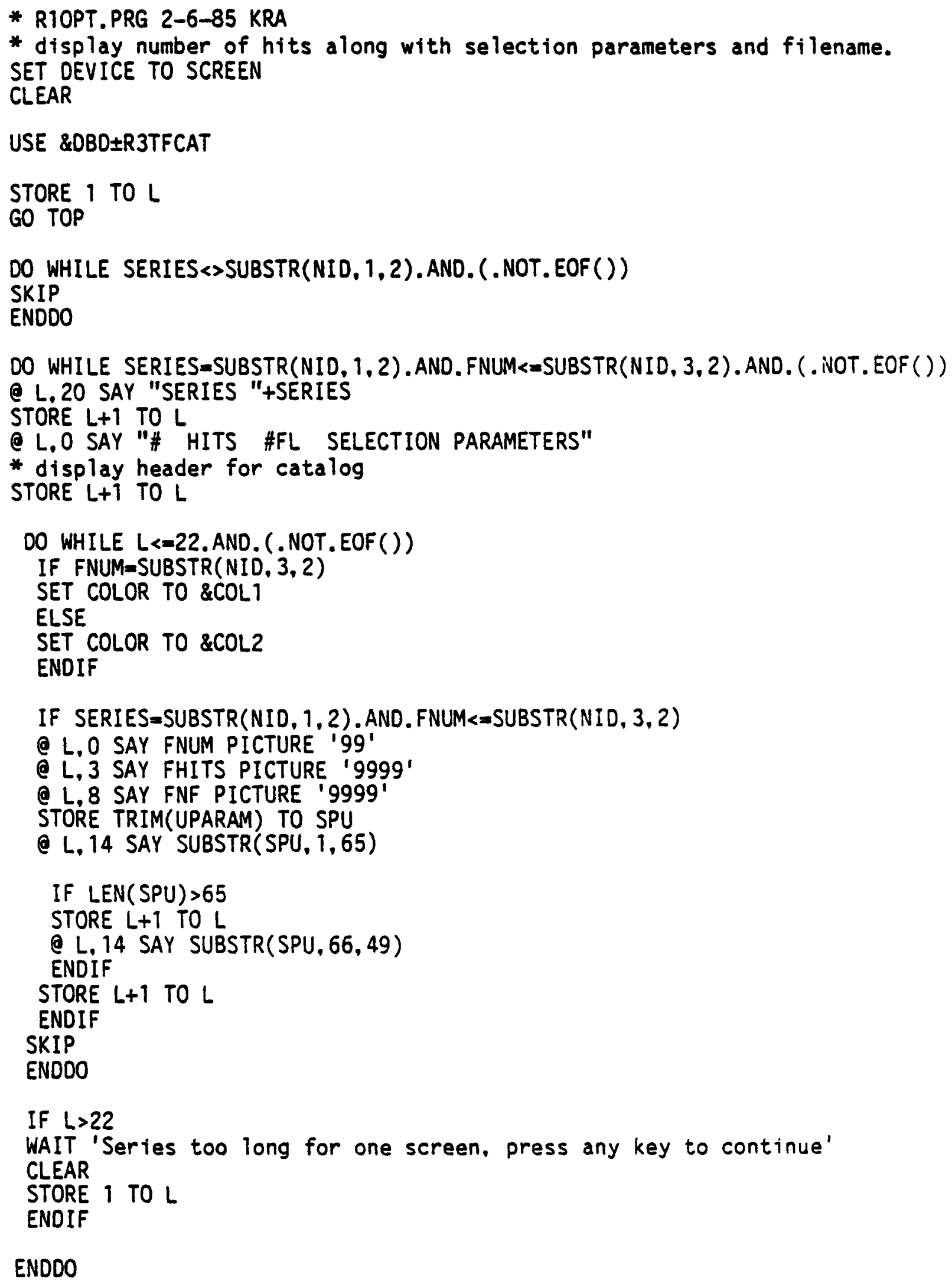

ENDDO

SET COLOR TO \&COL1 
STORE ' ' TO OPT

STORE 'TEMP' TO MCV2

* Present options to exit, print, display, or change selection parameters. @ L +1.0 CLEAR

TEXT

REPORT OPTIONS

A - CHANGE Selection Parameters or use a different Search.

$L$ - LOOK at Entire Records on Screen, one at a time.

$P$ - PRINT Entire Records in Input Format.

C - COLUMNS of Selected Data Fields On Screen or to Print. or print only search vital statistics.

R - RESET Program defaults.

$X$ - EXIT To 1st Menu in Report program.

ENDTEXT

WAIT " Your Choice?" TO OPT

REAO

IF UPPER(OPT) $=$ ' $X$ '

RETURN

ENDIF

IF UPPER(OPT) $=$ "P"

DO RIPRINT

RETURN

ENOIF

IF UPPER(OPT) $=$ ' $L$ '

DO D18

RETURN

ENDIF

IF UPPER(OPT) $=$ ' $\mathrm{C}$

DO RTUCR

RETURN

ENDIF

IF UPPER(OPT) $=$ ' $A$ '

STORE ' $'$ TO SUBOPT

CLEAR

TEXT

\section{OPTIONS}

A - Save the search you're currently working with and use it as the basis for a new one with different selection parameters.

B - Replace the current search with one that has different selection parameters.

C - Save your current search and look at the list of searches available on the disk with the option to choose one of them or start a new search.

ENDTEXT

(Note: your current search will be on the list) 


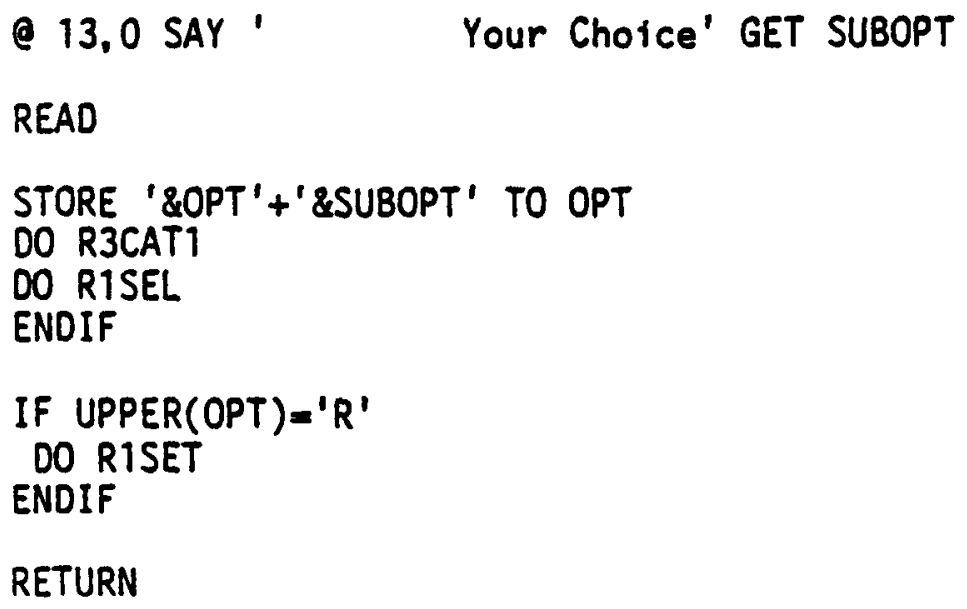


* R1UCR.PRG 5-02-85 Ken Ames

* U1timate custom report program for RACISP database

* Maximizes both speed and flexibility for onscreen or printed reports

* Choose between default and custom report formats

PUBLIC LCVO,LCV 2, LCV3

STORE ' ' TO LCV2, LCVO,LCV3,ICV3

CLEAR

IF $M C V 2=$ 'BASE'

DO WHILE ICV3=',

e 1,0 SAY 'Do you want to list all the records in the database or would you'

e 2,0 SAY 'like to list only selected records? A - A11 S - Selected' GET ICV3 IF UPPER(ICV3) \langle\rangle$^{\prime} A^{\prime}$. AND.UPPER(ICV3) \langle\rangle$^{\prime} S^{\prime}$

STORE ' 'TO ICV3

ENDIF

READ

ENDDO

IF UPPER(ICV3) $=$ 'S'

* IF THE 'SELECTED' OPTION IS CHOSEN, PRESENT MENUS LIKE REPORT PROGRAM

STORE ' ' TO GCV

DO WHILE UPPER(GCV) \langle\rangle$^{\prime} \mathrm{X} 1^{\prime}$

CLEAR

DO CASE

CASE $M C V=14$

DO RIFDL

IF UPPER(GCV) \langle\rangle$^{\prime} X$ '

@ 6,0 SAY 'Would you like to look at a glossary of FIELD names?' GET GCV READ

(a) 6,0 CLEAR

ENDIF

CASE $M C V=29$

DO RIFD

IF UPPER(GCV) \langle\rangle$^{\prime} X '$

@ 8,0 SAY 'Would you like to look at a glossary of FIELD names?' GET GCV READ

@ 8,0 CLEAR

ENDIF

ENDCASE

IF UPPER $(G C V)=' X ' . O R$.UPPER $(G C V)={ }^{\prime} N$ '

STORE ' $X 1$ ' TO GCV

ENDIF

\author{
IF UPPER(GCV) $=$ ' $Y$ ' \\ DO R1GLOS \\ ENDIF \\ ENDDO \\ DO RIS \\ IF UPPER(OPT) $={ }^{\prime} X$ '
}


RETURN

ENDIF

ENDIF

ENDIF

CLEAR

STORE ' 3 ' TO LCVO

DO WHILE LCVO $=$ ' 3 '

STORE ' ' TO LCVO

DO CASE

CASE $M C V=14$

TEXT

This subroutine allows you to print or display columns of data from the database. There are three preset formats which you can choose or you can easily create your own combination of fields to list.

1 - Format 1, Al1 14 fields.

2 - Format 2, DATABNUM, LERNUM, REACNAME, TYPEMAIN, TYPESUB1, SYSPRIMA, CAUSEPRI, MODE, \& ISOLATED.

3 - Format 3, Just Print or Display number of Hits and Failures along with Selection Parameters. (Note: you'll be returned to this menu)

C - Custom Report format.

$X$ - Exit back to previous menu.

ENDTEXT

STORE ' ' TO LCVO

DO WHILE LCVO=' '

@ 17,0 SAY 'Your Choice' GET LCVO

READ

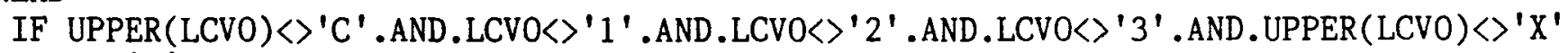
STORE ' TO LCVO

ENDIF

ENDDO

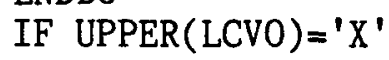

RETURN

ENDIF

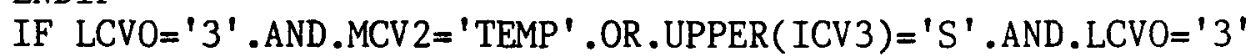

STORE ' 'TO LCV3

(a 19,0 SAY 'P - Print, S - Screen, B - Both' GET LCV3

READ

IF UPPER(LCV3) $=$ ' $\mathrm{P}$ '.OR .UPPER (LCV3) $=$ ' $\mathrm{B}$ '

(a) 21,0 SAY "You can type in below any notes you'd like printed in the heading" STORE SPACE(78) TO PH2

@ 22,0 GET PH2

READ

SET DEVICE TO PRINT

SET MARGIN TO 4

* Print condition headings

STORE 4 TO L 


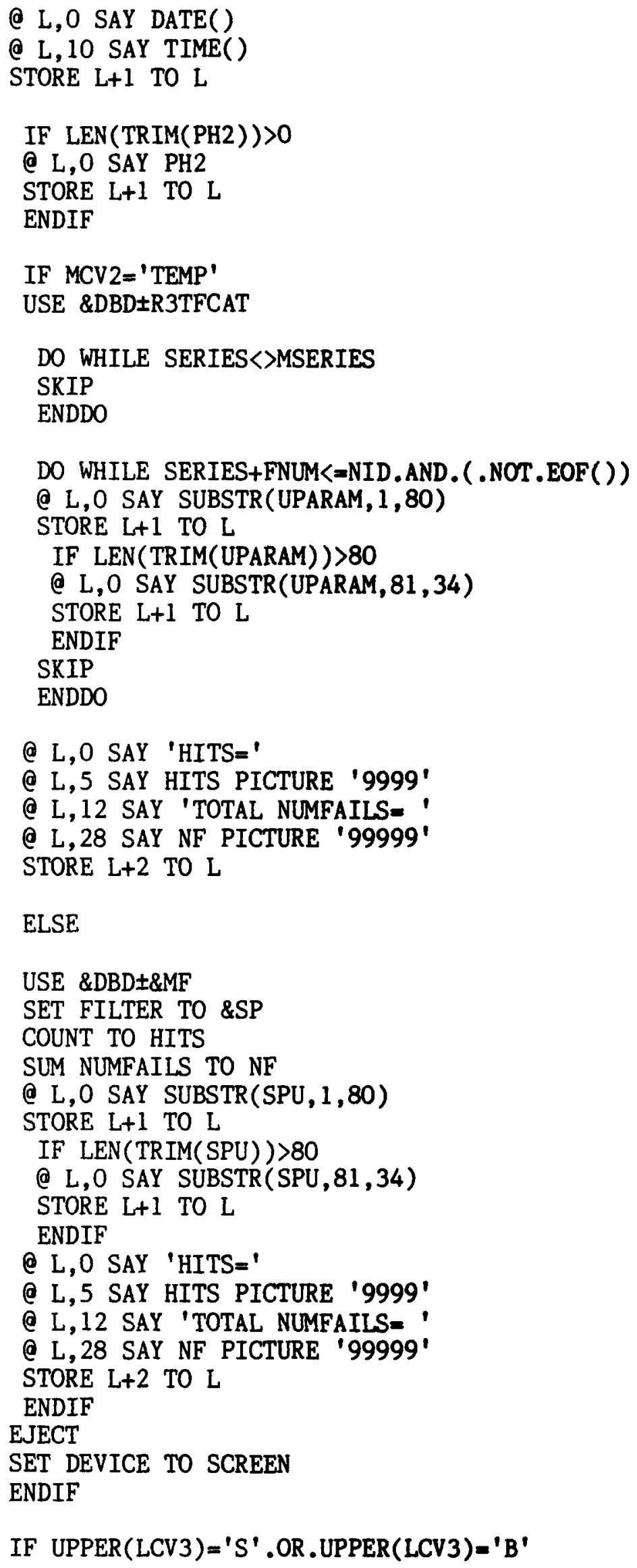




\section{CLEAR}

STORE 1 TO L

(e L,0 SAY DATE()

e L, 10 SAY TIME()

STORE L+1 TO L

IF MCV2='TEMP'

USE \&DBD \pm R3TFCAT

DO WHILE SERIES $>>M S E R I E S$

SKIP

ENDDO

DO WHILE SERIES+FNUM<=NID.AND. (.NOT.EOF())

(e L,0 SAY SUBSTR(UPARAM, 1,80)

STORE L+1 TO L

IF LEN(TRIM(UPARAM)) $>80$

e L,0 SAY SUBSTR(UPARAM, 81,34)

STORE L+1 TO L

ENDIF

SKIP

ENDDO

a L,O SAY 'HITS='

e L,5 SAY HITS PICTURE '9999'

e L,12 SAY 'TOTAL NUMFAILS='

@ L, 28 SAY NF PICTURE '99999'

STORE L+2 TO L

ELSE

IF UPPER(LCV3) $<>$ 'B'

USE \&DBD \pm MF

SET FILTER TO \&SP

COUNT TO HITS

SUM NUMFAILS TO NF

ENDIF

e L,0 SAY SUBSTR(SPU, 1,80)

STORE L+1 TO L

IF LEN(TRIM(SPU)) $>80$

(e L, 0 SAY SUBSTR(SPU, 81,34)

STORE L+1 TO L

ENDIF

e L,O SAY 'HITS='

e L,5 SAY HITS PICTURE '9999'

e L,12 SAY 'TOTAL NUMFAILS='

e L,28 SAY NF PICTURE '99999'

STORE L+2 TO L

ENDIF

ENDIF

CLOSE DATABASES

WAIT

CLEAR

ENDIF

CASE $M C V=29$ 
TEXT

This subroutine allows you to print or display columns of data from the database. There are three preset formats which you can choose or you can easily create your own combination of fields to list.

1 - Format 1, All 14 fields used in the abbreviated database:

DATABNUM, LERNUM, TYPEMAIN, TYPESUB1, REACNAME, REACTYPE, CISCLASS, SYSPRIMA, NUMFAILS, DATE, MODE, CAUSEPRI, ISOLATED, \& COMMENTS.

2 - Format 2, DATABNUM, LERNUM, REACNAME, TYPEMAIN, TYPESUB1, SYSPRIMA, CAUSEPRI, MODE, \& ISOLATED.

3 - Format 3, Just Print or Display number of Hits and Failures along with Selection Parameters. (Note: you'11 be returned to this menu)

C - Custom Report format.

$X$ - Exit back to previous menu.

ENDTEXT

STORE ' ' TO LCVO

DO WHILE LCVO=' '

@ 17,0 SAY 'Your Choice' GET LCVO

READ

IF UPPER(LCVO) \langle\rangle$^{\prime} C^{\prime}$. AND. LCVO \langle\rangle$^{\prime} 1{ }^{\prime}$. AND. LCVO \langle\rangle$^{\prime} 2{ }^{\prime}$. AND . LCVO $\left.<\right\rangle^{\prime} 3{ }^{\prime}$

IF UPPER(LCVO) \langle\rangle$^{\prime} X$ '

STORE ' $'$ TO LCVO

ENDIF

ENDIF

ENDDO

IF UPPER $\left(\right.$ LCVO) ${ }^{\prime}$ ' $\mathrm{I}$ '

RETURN

ENDIF

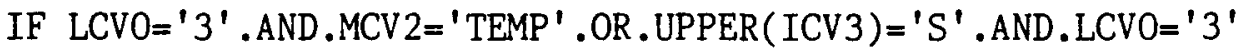

STORE ' ' TO LCV3

(a 19,0 SAY 'P - Print, S - Screen, B - Both' GET LCV3

READ

IF UPPER(LCV3) $={ }^{\prime} \mathrm{P}^{\prime}$.OR .UPPER(LCV3) $={ }^{\prime} \mathrm{B}^{\prime}$

@ 21,0 SAY "You can type in below any notes you'd like printed in the heading" STORE SPACE(78) TO PH2

(a 22,0 GET PH2

READ

SET DEVICE TO PRINT

SET MARGIN TO 4

* Print condition headings

STORE 4 TO L

(e) L, 4 SAY DATE()

(e) L, 14 SAY TIME()

STORE L+1 TO L

IF $\operatorname{LEN}(\operatorname{TRIM}(\mathrm{PH} 2))>0$

(a) L,0 SAY PH2

STORE L+1 TO L 
ENDIF

IF MCV2= 'TEMP'

USE \&DBD $\pm R 3 T F C A T$

DO WHILE SERIES $>M S E R I E S$

SKIP

ENDDO

DO WHILE SERIES+FNUM $=$ NID .AND . ( . NOT .EOF())

@ L,0 SAY SUBSTR(UPARAM, 1,80)

STORE L+1 TO L

IF LEN(TRIM(UPARAM)) $>80$

@ L,0 SAY SUBSTR(UPARAM, 81, 34)

STORE L+1 TO L

ENDIF

SKIP

ENDDO

\begin{abstract}
@ L,O SAY 'HITS='
@ L,5 SAY HITS PICTURE '9999'

@ L, 12 SAY 'TOTAL NUMFAILS $=$ '

@ L,28 SAY NF PICTURE '99999'

STORE L+2 TO L
\end{abstract}

ELSE

USE \&DBD $\pm \& M F$

SET FILTER TO \&SP

COUNT TO HITS

SUM NUMFAILS TO NF

(a L,0 SAY SUBSTR(SPU, 1,80)

STORE L+1 TO L

IF LEN(TRIM(SPU) ) $>80$

@ L,0 SAY SUBSTR(SPU, 81,34)

STORE L+1 TO L

ENDIF

(a) L,O SAY 'HITS $=$ '

a L,5 SAY HITS PICTURE '9999'

@ L, 12 SAY 'TOTAL NUMFAILS= '

@ L,28 SAY NF PICTURE '99999'

STORE L+2 TO L

ENDIF

EJECT

SET DEVICE TO SCREEN

ENDIF

IF UPPER (LCV3) = 'S' .OR .UPPER $($ LCV3 $)={ }^{\prime} \mathrm{B}^{\prime}$

CLEAR

STORE 1 TO L

(a L,O SAY DATE()

(a L,10 SAY TIME()

(a) L,51 SAY "Page"

@ L,56 SAY PN

STORE L+1 TO L 


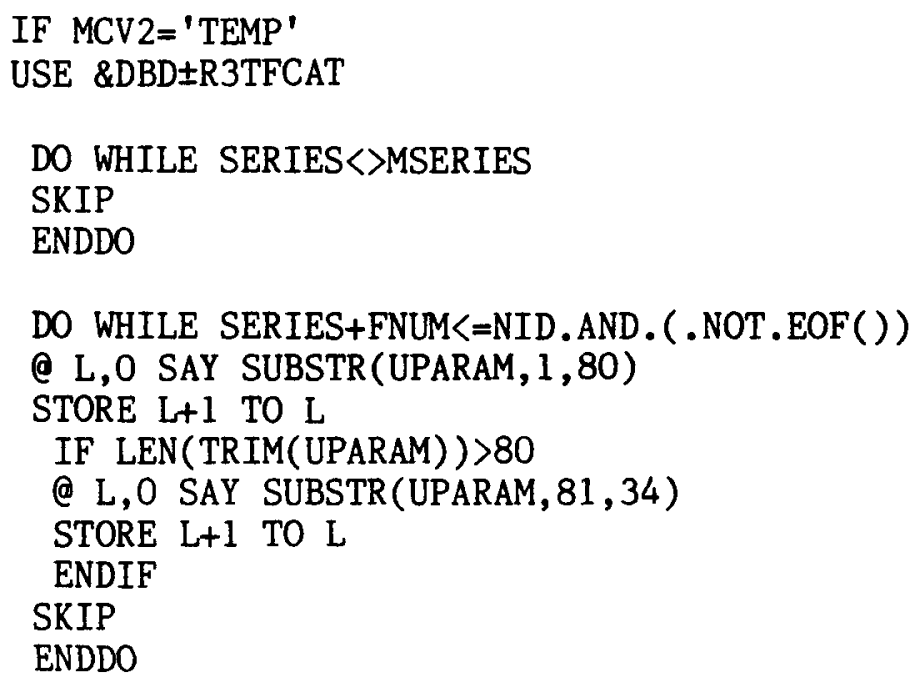


* Choose the report width

CLEAR

STORE ' 80 ' TO PW

TEXT

Most computer screens will display 80 characters on one line. Computer printers, by using 12,15 or more characters to the inch or wide paper, can often print many more characters per line. Please enter right margin you want to use (left margin is 4). If you start any new columns after the $75 \mathrm{th}$, you will not be able to customize headings.

ENDTEXT

@ 6,0 SAY 'Right margin to use' GET PW

READ

* Choose the database fields to be used in the report

STORE ' $N$ ' TO GCV

CLEAR

DO WHILE UPPER(GCV) $<>$ ' $X$ '

DO CASE

CASE MCV $=14$

DO RIFDL

IF UPPER(GCV) \langle\rangle$^{\prime} X '$

@ 6,0 SAY 'Would you like to look at a glossary of FIELD names?' GET GCV READ

@ 5,0 CLEAR

$\begin{array}{lllll}\text { STORE "4 } & \text { DB \# } & \text { DATABNUM" } & \text { TO FNO1 } \\ \text { STORE "6 } & \text { LER \# } & \text { LERNUM" } & \text { TO FNO2 } \\ \text { STORE "1 } & \text { TYPE } & \text { MAINTYPEMAIN" } & \text { TO FNO3 } \\ \text { STORE "1 } & \text { TYPE } & \text { SUBITYPESUB1" } & \text { TO FNO4 } \\ \text { STORE "3 } & \text { REAC } & \text { NAMEREACNAME" } & \text { TO FNO5 } \\ \text { STORE "1 } & \text { REAC } & \text { TYPEREACTYPE" } & \text { TO FN06 } \\ \text { STORE "1 } & \text { CIS } & \text { CLS CISCLASS" } & \text { TO FNO7 } \\ \text { STORE "2 } & \text { SYS } & \text { PRI SYSPRIMA" } & \text { TO FN08 } \\ \text { STORE "2 } & \text { NUM } & \text { FLS NUMFAILS" } & \text { TO FN09 } \\ \text { STORE "8 } & \text { DATE } & \text { DATE" } & \text { TO FN10 } \\ \text { STORE "1 } & \text { MODE } & \text { MODE" } & \text { TO FN11 } \\ \text { STORE "2 } & \text { CAU } & \text { PRI CAUSEPRI" } & \text { TO FN12 } \\ \text { STORE "1 } & \text { ISOL } & \text { ISOLATED" } & \text { TO FN13 } \\ \text { STORE "240COMMENTS } & \text { COMMENTS" } & \text { TO FN14 }\end{array}$

ENDIF

\section{CASE $M C V=29$}

DO R1FD

IF UPPER(GCV) \langle\rangle$^{\prime} X$ '

@ 8,0 SAY 'Would you like to look at a glossary of FIELD names?' GET GCV READ

@ 8,0 CLEAR

$\begin{array}{llll}\text { STORE "4 } & \text { DB \# } & & \text { DATABNUM" } \\ \text { STORE "6 } & \text { LER \# } & & \text { LERNUM" } \\ \text { STORE "2 } & \text { RV } & \text { TO FNO2 } \\ \text { STORE "6 } & \text { ACCESS } & \text { REVISNUM" } & \text { TO FNO3 } \\ \text { STORE "2 } & \text { EN } & \text { ACESNUM" } & \text { TO FNO4 } \\ \text { ENTRYNUM" } & \text { TO FNO5 }\end{array}$




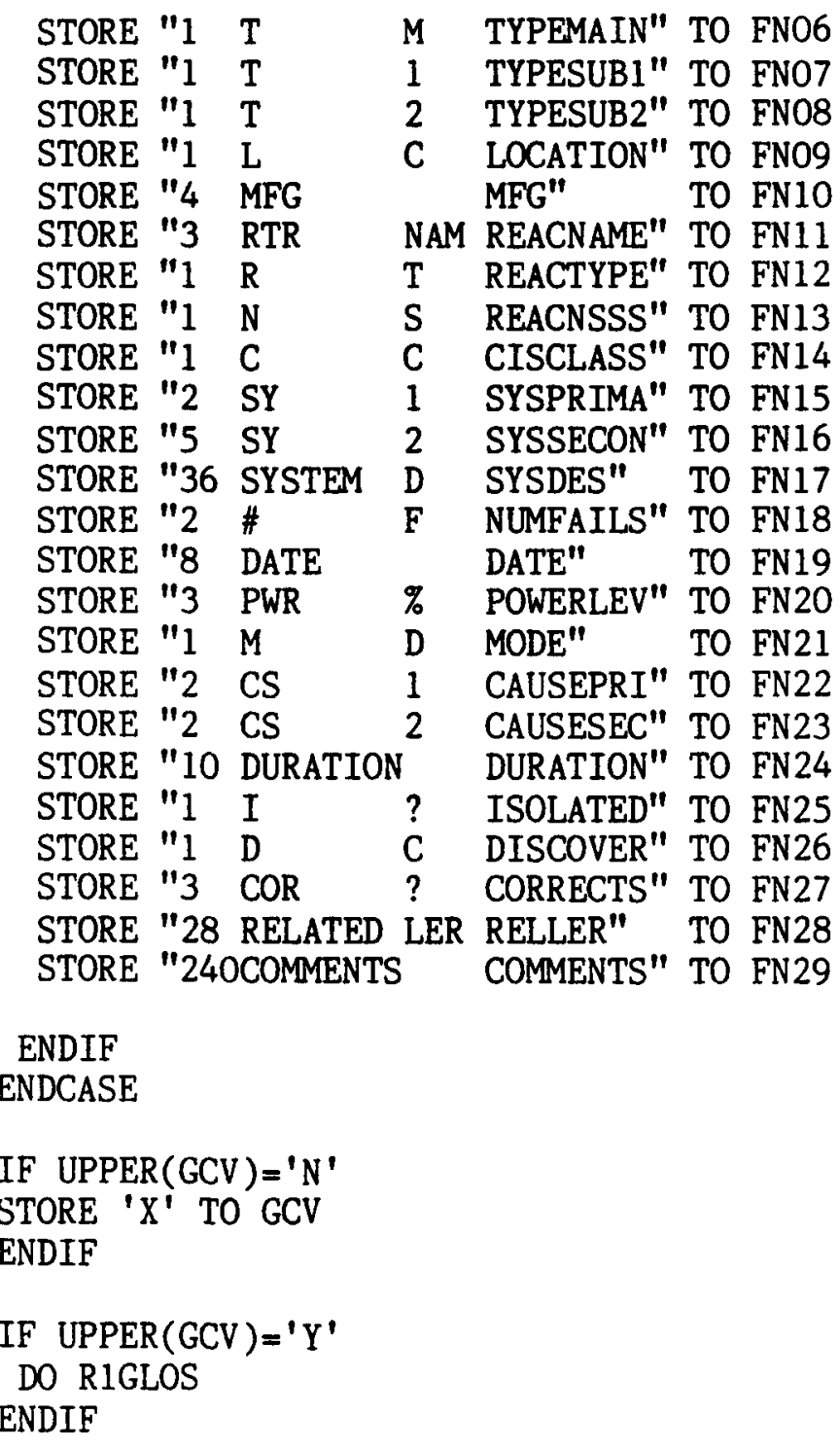

ENDDO

TEXT

This subroutine lets you make custom formats for onscreen or printed reports. In this subprogram, just enter the numbers of the fields you want to see and enter a blank for the last one (unless you get the 'Page Full' message first). If COMMENTS is one of the fields you want, please enter the number for it last, since it will use up any remaining page width. ENDTEXT

IF UPPER(CONF) $=$ ' $N '$
SET CONFIRM ON
ENDIF
IF MCV $=29$
$@ 14,0$ CLEAR
ELSE
$@ 12,0$ CLEAR
ENDIF
STORE VAL(PW) TO CRPW 
STORE 1 TO NN

SET COLOR TO \&COL2

STORE ' ' TO LCV2, LCV4

STORE ' $Y$ ' TO LCV

SET COLOR TO \&COL1

STORE "' TO CRDEL

STORE $O$ TO CRAPW

DO WHILE LCV $<>$ ' $X$ '

IF $\mathrm{NN}<10$

STORE STR(NN,1) TO N

STORE ' 0 ' $+\mathrm{N}$ TO $\mathrm{N}$

ELSE

STORE $\operatorname{STR}(\mathrm{NN}, 2)$ TO N

ENDIF

STORE ' ' TO FN

SET COLOR TO \&COL2

IF $M C V=14$

@ 12,15 SAY 'Width of remaining space on page: ' SET COLOR TO \&COL1

@ 12,49 SAY STR(CRPW-CRAPW, 3)

ELSE

@ 14,15 SAY 'Width of remaining space on page: '

SET COLOR TO \&COLl

@ 14,49 SAY STR(CRPW-CRAPW,3)

ENDIF

SET COLOR TO \&COL2

IF $\operatorname{ROW}()+\mathrm{NN}<=22$

( $\mathrm{ROW}()+\mathrm{NN}, 0$ SAY 'Number of FIELD for Column \#'+N+' 〈RETURN> to end' GET FN ELSE

@ 22,0 SAY 'Number of FIELD for Column \#'+N+' 〈RETURN> to end' GET FN

ENDIF

READ

IF $F N=$ ' '

STORE NF-1 TO NF

EXIT

ENDIF

STORE NN+1 TO NN

STORE NN TO NF

STORE TRIM(FN) TO FN

IF $\operatorname{VAL}(F N)<10$

STORE 'O'+FN TO FN

ENDIF

STORE FN TO FNO\&N

IF SUBSTR(FN\&FN , 16, 8) = 'COMMENTS'

STORE ' $X$ ' TO LCV

IF UPPER(CONF) $=$ ' $\mathrm{N}$ '

SET CONFIRM OFF

ENDIF

SET COLOR TO \&COL1

STORE ' TO LCV3

DO WHILE LCV3=' '

@ ROW( $+1,0$ SAY 'Enter A to see All of COMMENTS, $T$ to truncate to one line' GET LCV3 READ

IF UPPER(LCV3)〈〉' A' .AND.UPPER(LCV3)〈〉' $\mathrm{T}$ ' 


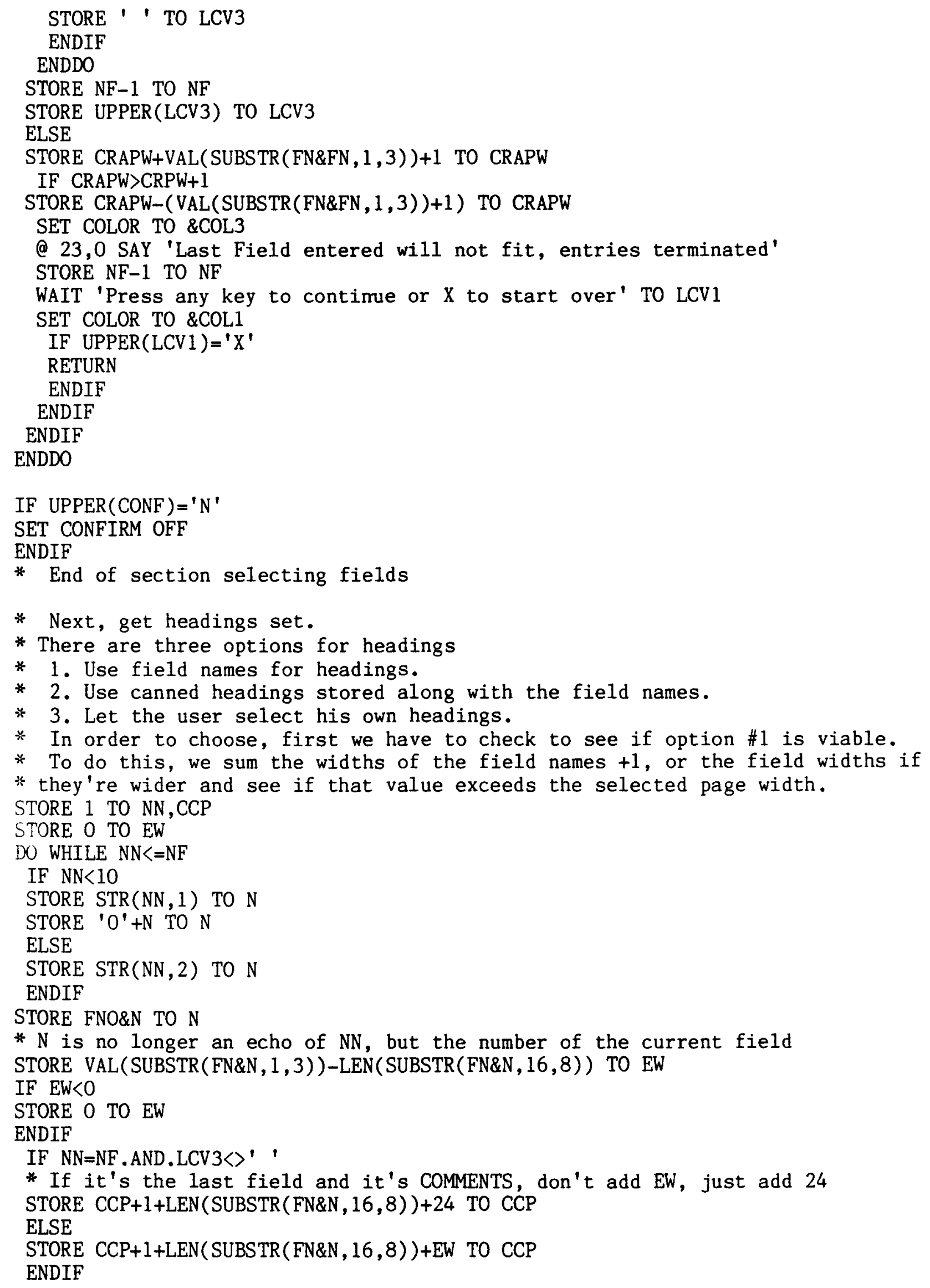


STORE NN+1 TO NN

ENDDO

STORE " TO LSI, CRDEL

IF $\mathrm{CCP} \angle \mathrm{CRPW}$

* If the field names fit, display the resulting column headings and ask the

* user if he wants to change them.

STORE .F. TO LCV1

STORE 1 TO NN,CCP

STORE 0 TO EW,EW2

STORE '" TO CH1

DO WHILE $\mathrm{NN} \angle=\mathrm{NF}$

IF $\mathrm{NN}<10$

STORE STR $(N N, 1)$ TO N

STORE ${ }^{\prime} \mathrm{O}^{\prime}+\mathrm{N}$ TO $\mathrm{N}$

ELSE

STORE STR $(N N, 2)$ TO N

ENDIF

STORE FNO\&N TO N

STORE CH1+' '+SPACE(EW2)+SUBSTR(FN\&N, 16,8) TO CH1

STORE LEN(SUBSTR(FN\&N, 16,8))-VAL(SUBSTR(FN\&N, 1,3)) TO EW

IF $E W<0$

STORE -EW TO EW2

STORE 0 TO EW

ELSE

STORE 0 TO EW2

ENDIF

STORE EW2+LEN(SUBSTR(FN\&N, 16,8)) TO CCW

* At the same time, get together the listing string, in case the user chooses

* the default headings

IF EW $>0$. AND. NN $>N F$

STORE LS1+CRDEL+SUBSTR(FN\&N, 16,8)+',"'+SPACE(EW-1)+'"' TO LS1

STORE CCP+CCW+1 TO CCP

ELSE

IF LCV3 \langle\rangle $'$ ' . AND. NN=NF

STORE LSI TO LST

STORE LS 1+CRDEL+' SUBSTR(COMMENTS, 1,(CRPW-CCP-1))' TO LS1

STORE LST+CRDEL+' COMMENTS' TO LS2

ELSE

STORE LS1+CRDEL+SUBSTR(FN\&N, 16,8) TO LS1

ENDIF

IF $\mathrm{NN}<>\mathrm{NF}$

STORE $\mathrm{CCP}+\mathrm{CCW}+1$ TO $\mathrm{CCP}$

ENDIF

ENDIF

STORE ',' TO CRDEL

STORE NN+1 TO NN

ENDDO

STORE ' TO CH2

ELSE

* If the field names don't fit, make a heading from the 'canned' column

* headings and ask the user if he wants to change them.

STORE .T. TO LCV1

STORE O TO EW,EW2, EW3

STORE 1 TO NN,CCP 


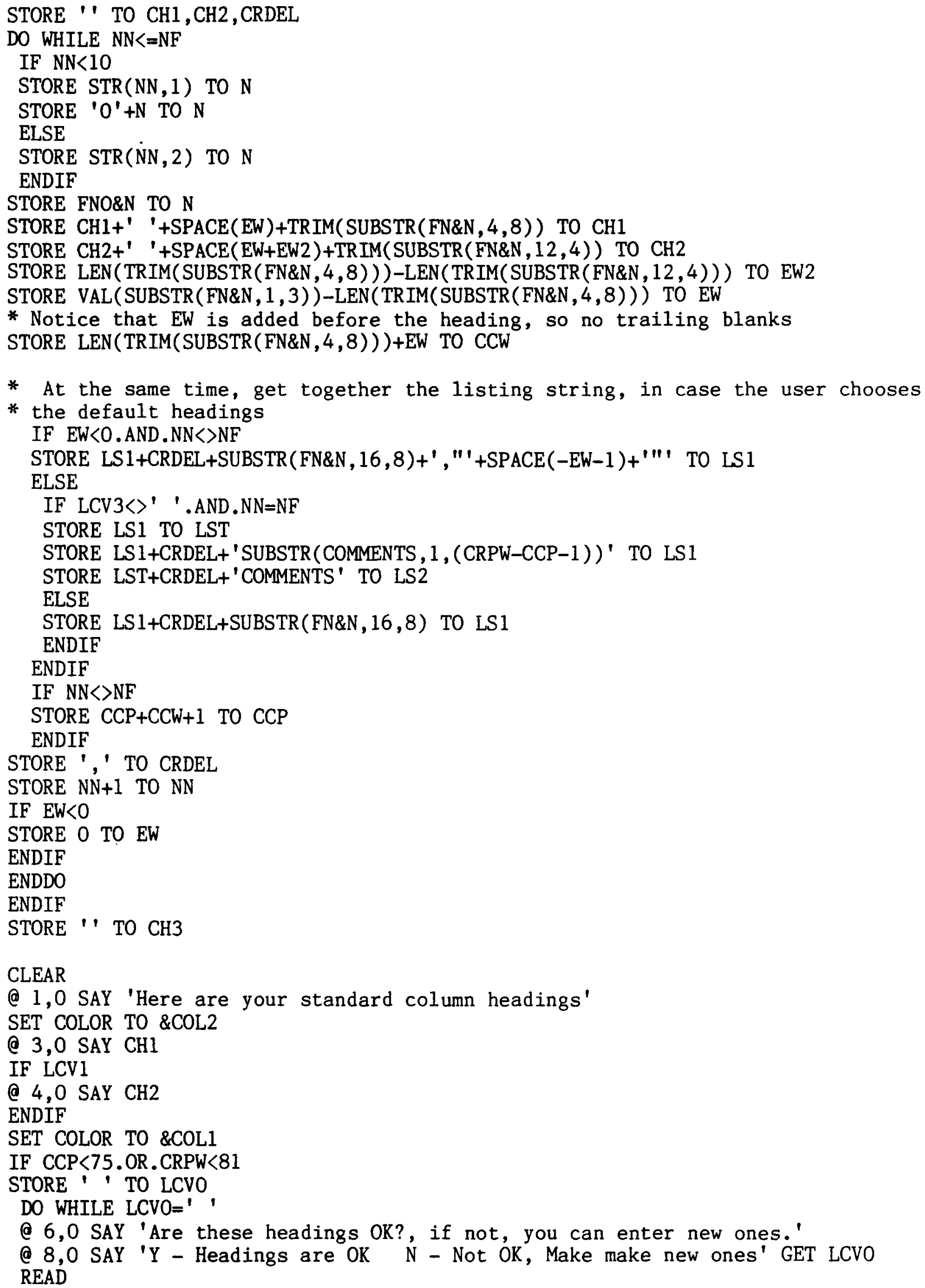


IF UPPER(LCVO) \langle\rangle$^{\prime} Y^{\prime}$. AND.UPPER(LCVO) \langle\rangle$^{\prime} N '$

STORE ' ' TO LCVO

ENDIF

ENDDO

\section{ELSE}

@ 6,0 SAY 'Your report is too wide to allow the program to display the headings'

@ 7,0 SAY 'properly on the screen, so the standard headings will be used.'

STORE ' $Y$ ' TO LCVO

ENDIF

* If the user decides to change the column headings, show him the present

* heading, its width, the maximum amount he can widen the heading without going

* off the edge of the page, and a place to type a heading up to 3 lines high.

IF UPPER (LCVO) $=$ ' $N$ '

CLEAR

SET COLOR TO \&COL2

(e 1,0 SAY 'The space shown for your heading is the widest space you can use without making'

@ 2,0 SAY 'the report too wide to fit on the page. The underlined part of the area shows'

(a 3,0 SAY 'the field width. Any spaces you use beyond the underline are subtracted from'

(a 4,0 SAY "the extra space that will be available for the next column's heading, so use"

(a) 5,0 SAY 'the extra space judiciously.'

STORE " TO CH1, CH2, CH3, LS1, CRDEL

STORE 1 TO NN,CCP

STORE '

* Figure out just how many extra spaces are available

IF LCV3=' '

STORE CRPW-CRAPW TO ESA

ELSE

STORE CRPW-(CRAPW+16) TO ESA

IF $\mathrm{ESA}<0$

STORE 0 TO ESA

ENDIF

ENDIF

DO WHILE $\mathrm{NN}<=\mathrm{NF}$

IF $\mathrm{NN}<10$

STORE STR(NN,1) TO N

STORE ' $O$ ' $+\mathrm{N}$ TO $\mathrm{N}$

ELSE

STORE STR(NN,2) TO N

ENDIF

SET COLOR TO \&COL2

@ 7,0 SAY 'Field Number Field Width'

SET COLOR TO \&COL1

@ 7,13 SAY NN PICTURE '99'

STORE FNO\&N TO FN

(a 8,2 SAY SUBSTR(FN\&FN, 16,8)+SPACE(5)

@ 8,28 SAY SUBSTR(FN\&FN, 1,3)+SPACE (2)

IF LCV3 $>$ ' '. AND. NN=NF

* If we're at the last field and it is COMMENTS

STORE CRPW-CCP-2 TO UL

STORE 'COMMENTS' +SUBSTR (LINE, 1, (UL-8)) TO HL1

STORE SUBSTR(LINE, $1, \mathrm{UL}$ ) TO HL2,HL3

ELSE

IF LCV1 
* If canned headings are being used

STORE VAL(SUBSTR(FN\&FN, 1,3))-LEN(TRIM(SUBSTR(FN\&FN, 4,8))) TO UL

IF UL $<0$

STORE ESA+UL TO ESAI

STORE $O$ TO UL

ELSE

STORE ESA TO ESA1

ENDIF

STORE TRIM(SUBSTR(FN\&FN, 4,8))+SUBSTR(LINE, 1,UL)+SPACE(ESA1) TO HL1

STORE VAL(SUBSTR(FN\&FN, 1,3))-LEN(TRIM(SUBSTR(FN\&FN, 12,4))) TO UL

IF UL $<0$

STORE ESA+UL TO ESAI

STORE 0 TO UL

ELSE

STORE ESA TO ESA1

ENDIF

STORE TRIM(SUBSTR(FN\&FN, 12,4))+SUBSTR(LINE, 1,UL)+SPACE(ESA1) TO HL2 STORE VAL(SUBSTR(FN\&FN, 1,3)) TO UL

STORE SUBSTR(LINE, 1,UL)+SPACE(ESA) TO HL3

ELSE

* If field name headings are being used

STORE VAL(SUBSTR(FN\&FN, 1,3))-LEN(TRIM(SUBSTR(FN\&FN, 16,8))) TO UL IF UL<0

STORE ESA+UL TO ESAI

STORE $O$ TO UL

ENDIF

STORE TRIM(SUBSTR(FN\&FN, 16,8))+SUBSTR(LINE, 1,UL)+SPACE(ESA1) TO HL1 STORE VAL(SUBSTR(FN\&FN, 1,3)) TO UL

STORE SUBSTR(LINE, 1,UL)+SPACE(ESA) TO HL2,HL3

ENDIF

ENDIF

SET COLOR TO \&COL2

IF $\mathrm{CCP}+\mathrm{LEN}(\mathrm{HL} 1)>78$

STORE SUBSTR(HL1,1,(78-CCP)) TO HL1

STORE SUBSTR(HL2,1,(78-CCP)) TO HL2

STORE SUBSTR(HL3,1,(78-CCP)) TO HL3

ENDIF

@ 10,CCP GET HL1

@ 11, CCP GET HL2

@ $12, \mathrm{CCP}$ GET HL3

READ

IF LEN(TRIM(HL3)) <=LEN(TRIM(HL2))

IF LEN(TRIM(HL2)) <=LEN(TRIM(HL1))

STORE LEN(TRIM(HL1)) TO CCW

ELSE

STORE LEN(TRIM(HL2)) TO CCW

ENDIF

ELSE

IF LEN(TRIM(HL3)) <=LEN(TRIM(HL1))

STORE LEN(TRIM(HL1)) TO CCW

ELSE

STORE LEN(TRTM(HL3)) TO CCW

ENDIF

ENDIF 


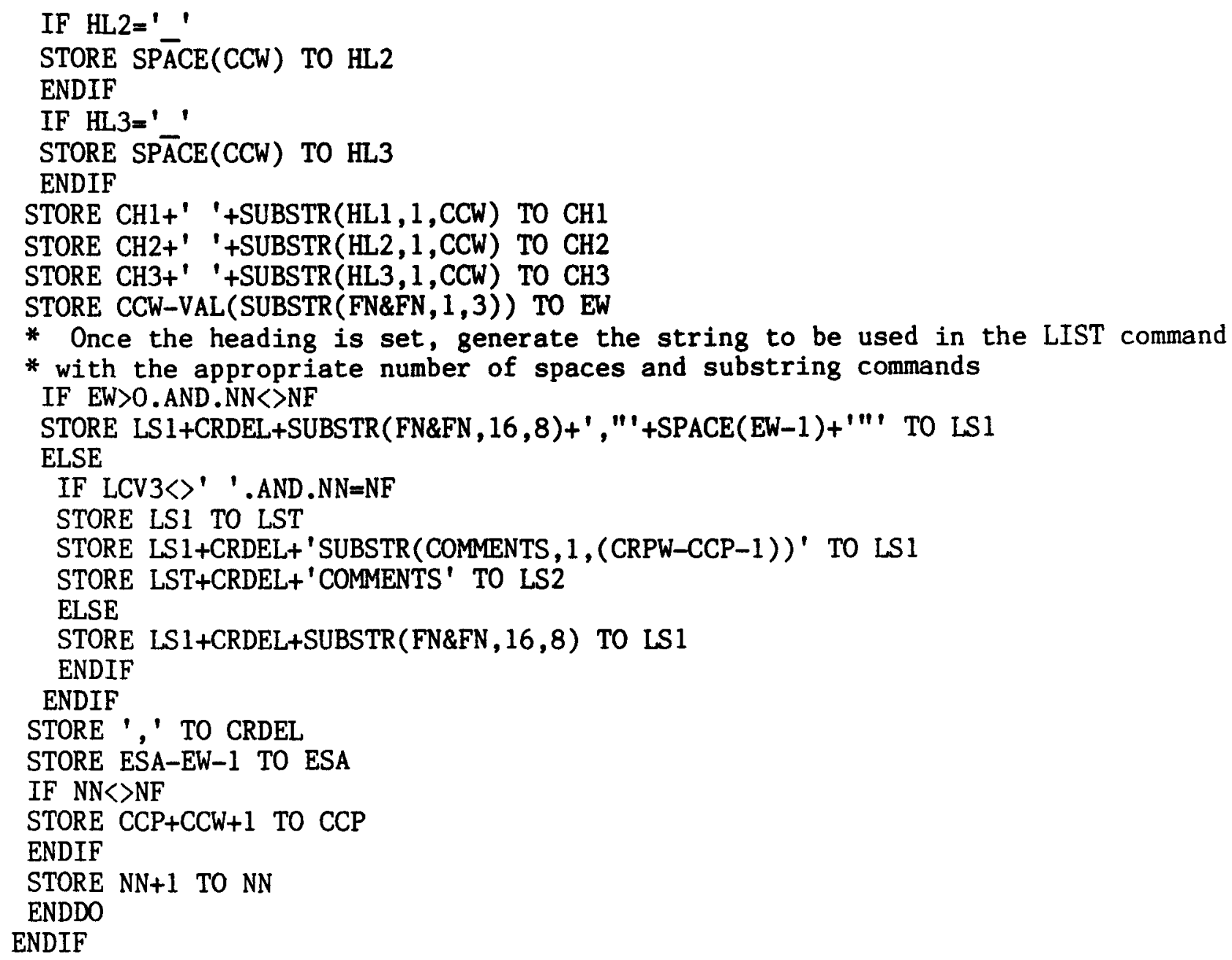

* After the list command is set, ask the user to choose between screen output * and printer output. SET COLOR TO \&COL1 


\section{ENDIF}

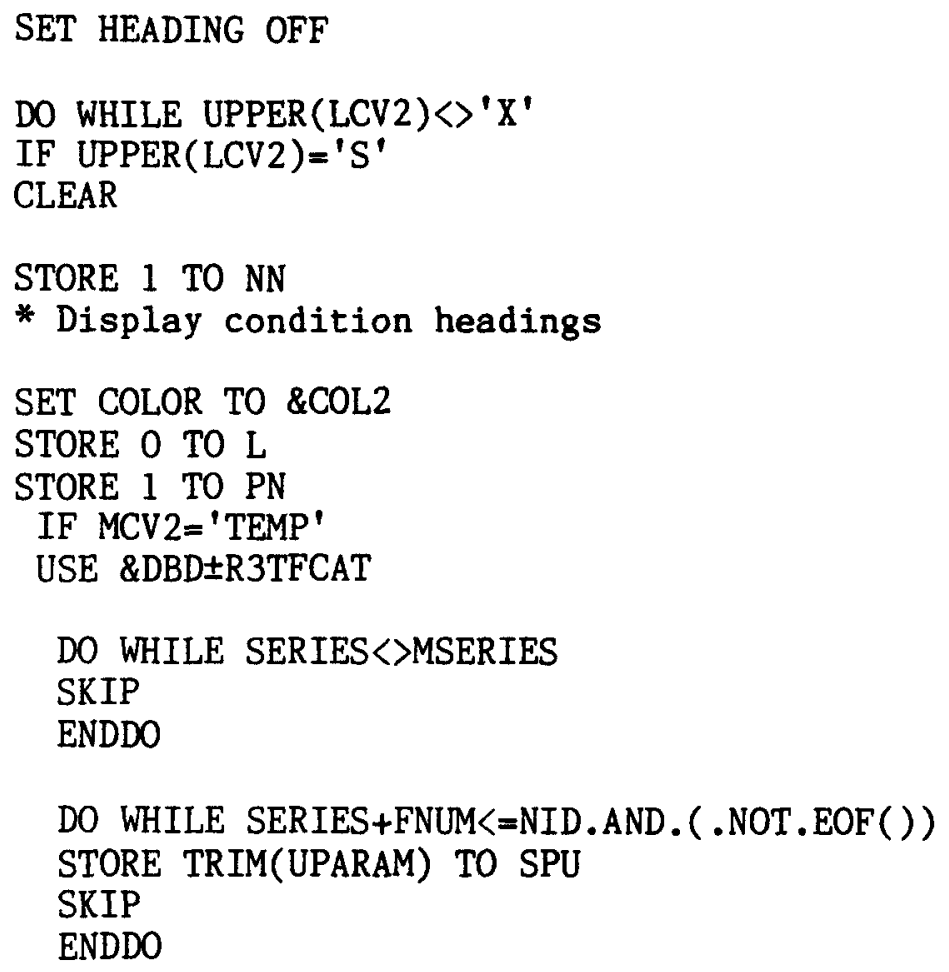

USE \&DBD $\pm R 3 T \& N I D$

ELSE

USE \&DBD \pm \&F

IF UPPER(ICV3)='S'

SET FILTER TO \&SP

GO TOP

ENDIF

ENDIF

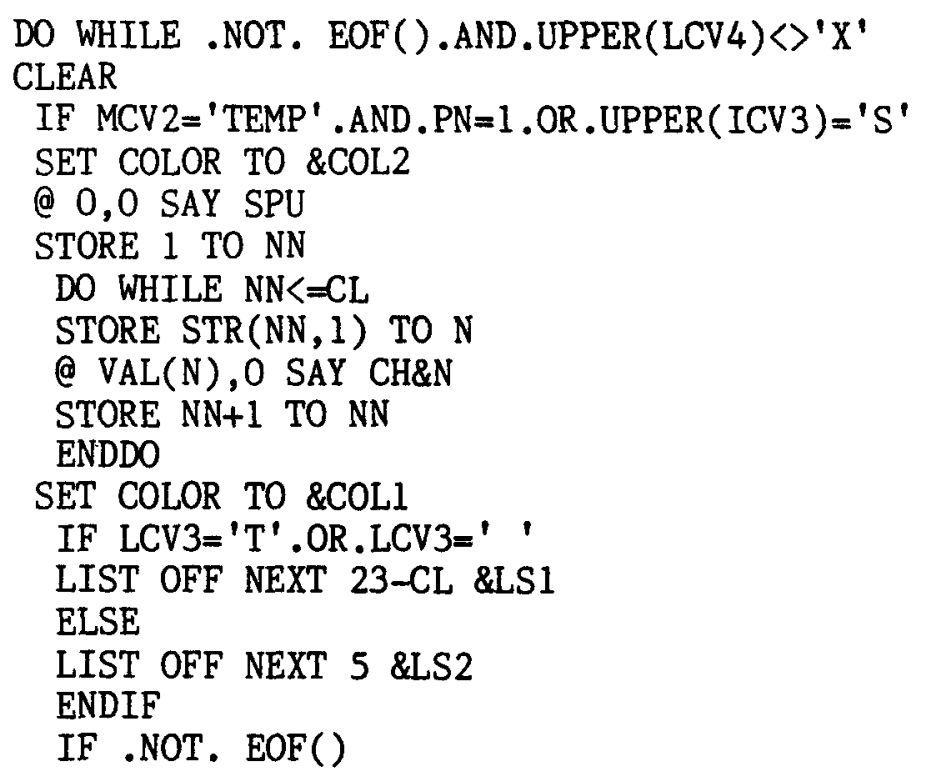




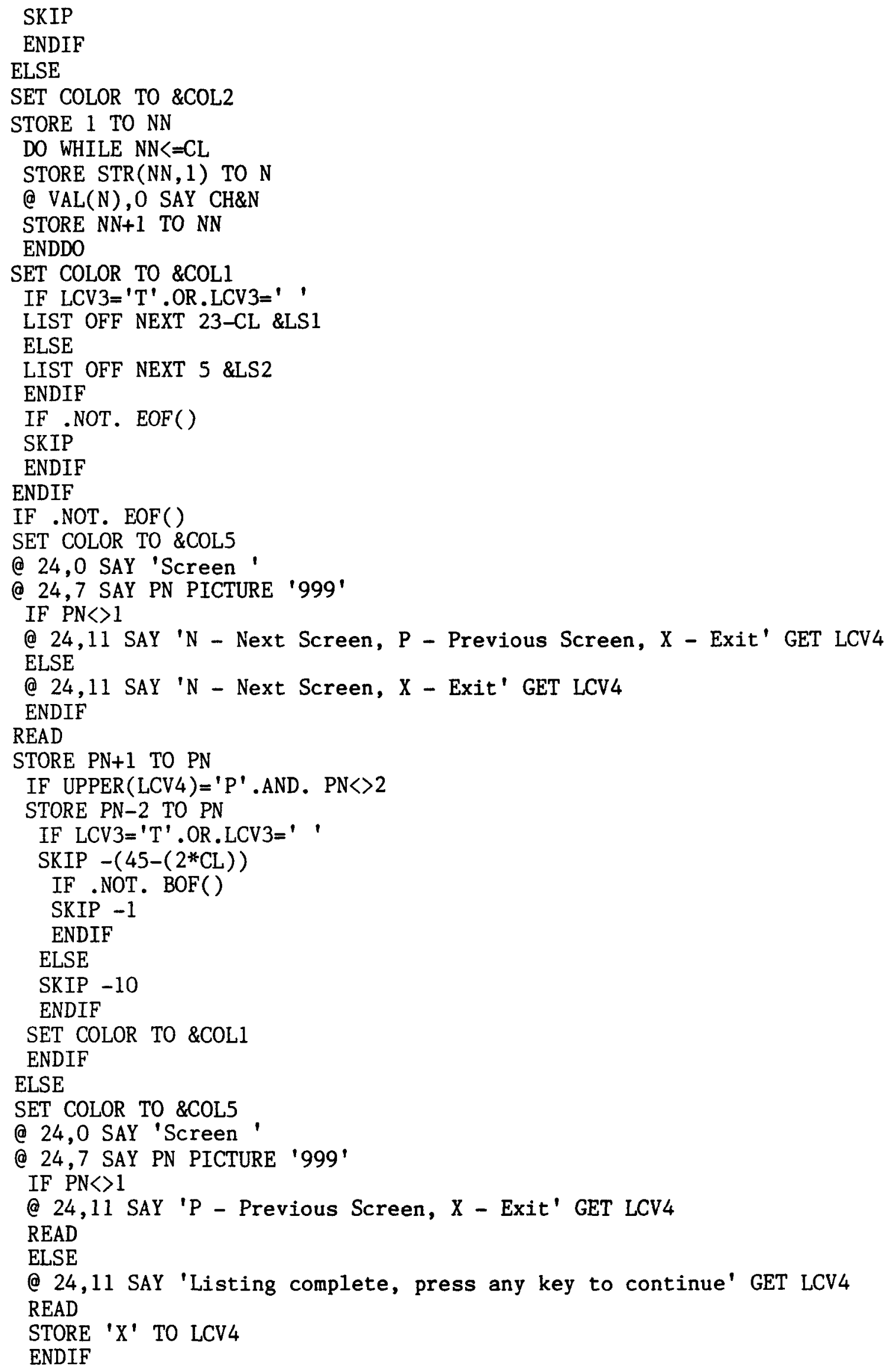




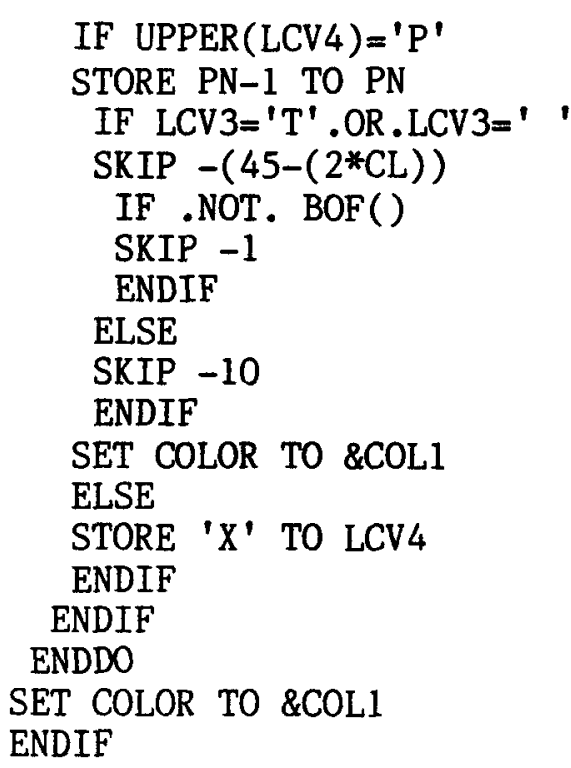

* If the user has chosen printed ouput, print the report with the selection

* parameters if it is from a search file.

IF UPPER(LCV2) =' $\mathrm{P}$ ' AND.LCV3 $\langle>$ 'A'

@ 16,0 SAY "You can type in below any notes you'd like printed in the heading" STORE SPACE(78) TO PH2

(e 17,0 GET PH2

READ

SET DEVICE TO PRINT

SET MARGIN TO 4

STORE 1 TO NN

STORE 1 TO PN

STORE ' $Y$ ' TO LCV

* Print condition headings

* PRINT FIRST HEADING

DO WHILE LCV $\langle>$ ' $X$ '

STORE 4 TO L

(e) L, 4 SAY DATE()

(d) L, 14 SAY TIME()

@ L,55 SAY "Page"

(a) L,60 SAY PN

STORE L+1 TO L

IF $\mathrm{PN}=1$

IF $\operatorname{LEN}(\operatorname{TRIM}(\mathrm{PH} 2))>0$

@ L,O SAY PH2

STORE L+1 TO L

ENDIF

IF $M C V 2=$ ' TEMP'

USE \&DBD $\pm R 3 T F C A T$

DO WHILE SERIES $<>M S E R I E S$ 


\section{SKIP}

ENDDO

DO WHILE SERIES+FNUM<=NID.AND. (.NOT.EOF( ))

@ L,O SAY TRIM(UPARAM)

STORE L+1 TO L

SKIP

ENDDO

USE \&DBD $\pm R 3 T \& N I D$

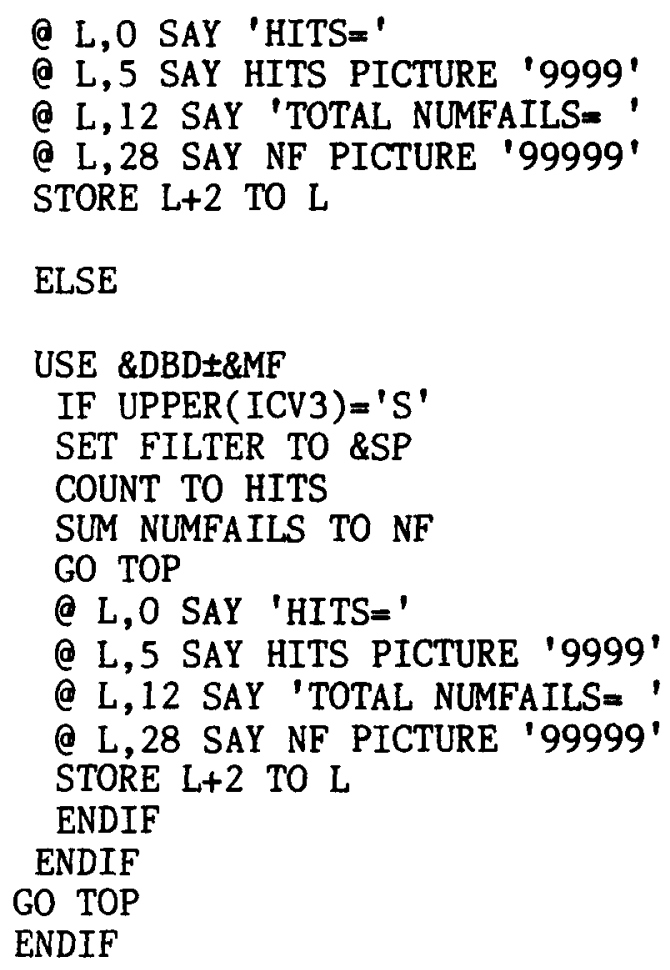

\section{(a) L,O SAY CHI}

STORE L+1 TO L

(a) L,O SAY CH2

LIST OFF NEXT 60-L \&LS1 TO PRINT

IF EOF()

STORE ' $\mathrm{X}$ ' TO LCV

ELSE

SKIP

ENDIF

STORE PN+1 TO PN

EJECT

ENDDO

SET PRINT OFF

ENDIF

IF UPPER(LCV2) $=$ ' $P$ ' .AND.UPPER(LCV3) $={ }^{\prime} A$ '

* If all of COMMENTS is being printed

(a 16,0 SAY "You can type in below any notes you'd like printed in the heading" STORE SPACE(78) TO PH2

(a 17,0 GET PH2 


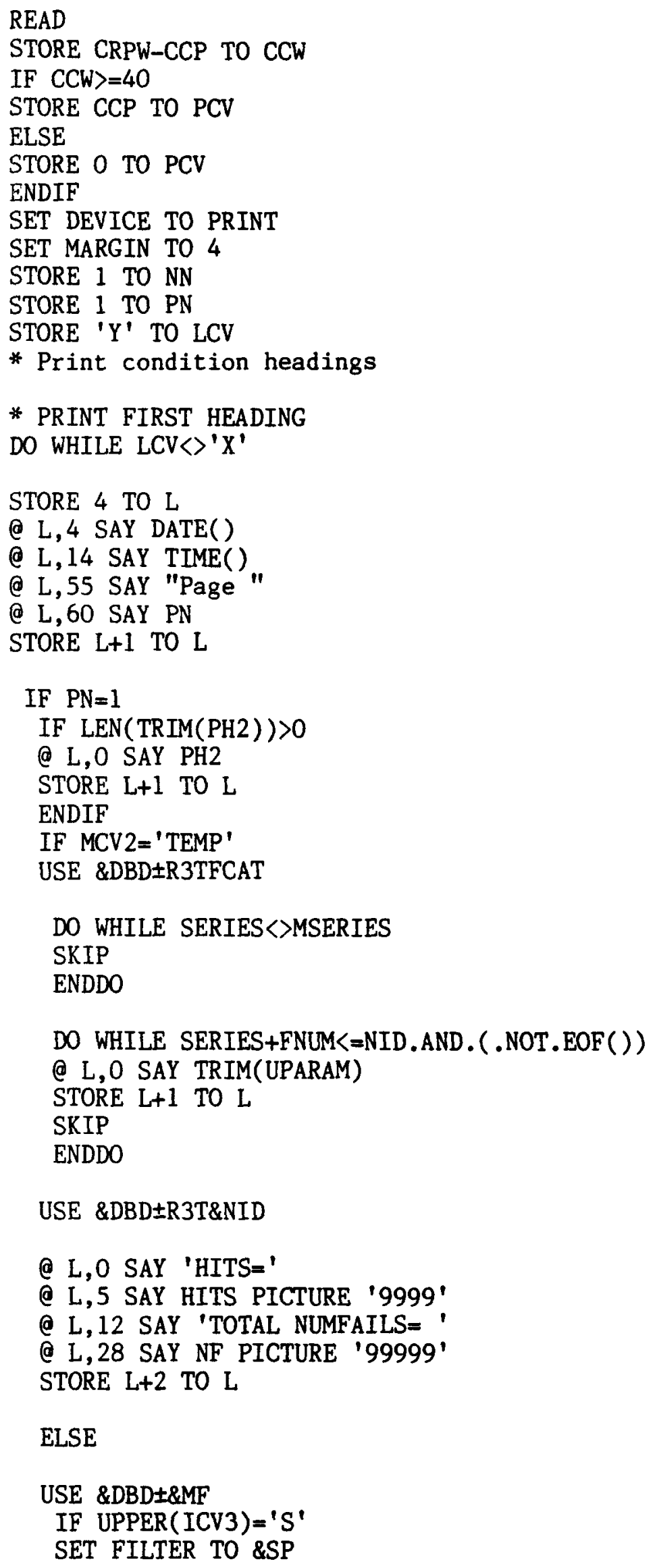

USE \&DBD $\pm R 3 T \& N I D$

(e L,O SAY 'HITS='

(a L,5 SAY HITS PICTURE '9999'

@ L,12 SAY 'TOTAL NUMFAILS='

@ I,28 SAY NF PICTURE '99999' STORE L+2 TO L

\section{ELSE}

USE \&DBD $\pm \& M F$ IF UPPER(ICV3) $=$ 'S'

SET FILTER TO \&SP 
COUNT TO HITS

SUM NUMFAILS TO NF

GO TOP

e L,O SAY 'HITS='

@ L,5 SAY HITS PICTURE '9999'

@ L, 12 SAY 'TOTAL NUMFAILS='

@ L,28 SAY NF PICTURE '99999'

STORE L+2 TO L

ENDIF

ENDIF

GO TOP

ENDIF

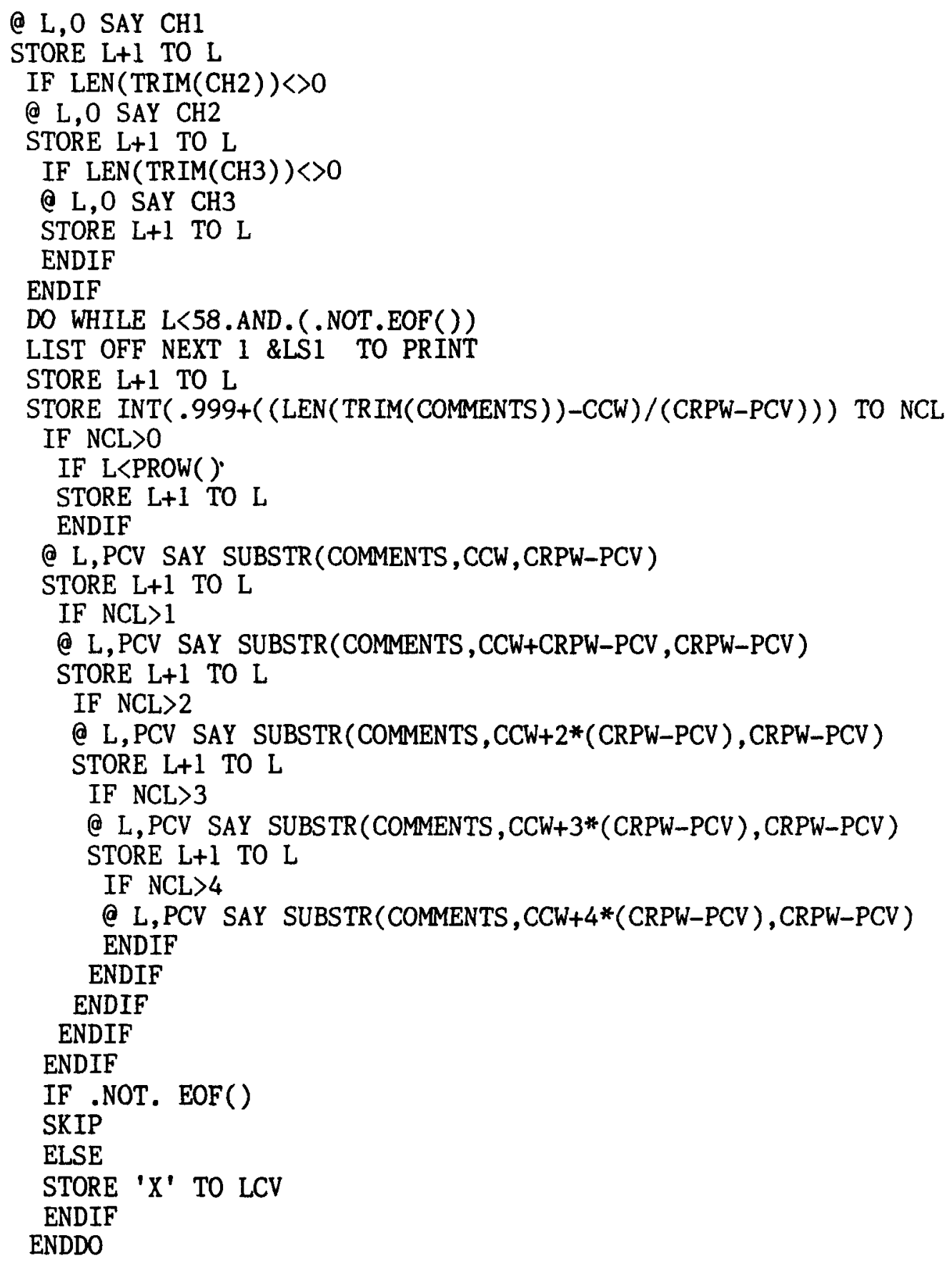


STORE PN+1 TO PN

EJECT

IF EOF()

STORE ' $\mathrm{X}$ ' TO LCV

ENDIF

ENDDO

SET PRINT OFF

ENDIF

* After the report ouput is finished, allow the user to rerun the report with

* alternate ouput, i.e. printed instead of displayed or vice versa.

SET DEVICE TO SCREEN

SET COLOR TO \&COL3

(e 24,0 SAY 'Enter $P$ to rerun Report on Printer, $S$ to rerun on Screen, $X$ to Exit' GET LCV2 READ

IF UPPER(LCV2)=' $S$ '

STORE 80 TO CRPW

ENDIF

IF UPPER (LCV2) $={ }^{\prime} \mathrm{P}$ '

(24,0 CLEAR

e 24,0 SAY 'Right margin to use for printer' GET PW

READ

STORE VAL(PW) TO CRPW

ENDIF

CLOSE DATABASES

STORE ' ' TO LCV4

SET COLOR TO \&COL1

ENDDO

IF UPPER (CONF) $=^{\prime} \mathrm{N}$ '

SET CONFIRM OFF

ENDIF

SET HEADING ON

RETURN

********* Memory variable list

* SPU Screen heading used to show parameters with temporary files

* CHl Column headings String variable

* CH2 Second line of Column heading string variable

* CH3 Third line of Column heading string variable

* LCV 0-4 Local control variables, usually string

* LCV1 Flag for default heading type, .F. for fieldnames, .T. for canned

* LCV3 Flag for Comments field,' ' if no COMMENTS, ' $T$ ' if trunc, ' $A$ ' if not

* NN Local counter, numeric

* N Local pointer, two digit string variable

* NF number of fields in custom report, numeric

* FNOOl-NF Numbers of report fields

* EW Extra Width where field is wider than field name, numeric

* EW2 Extra Width where second heading line is shorter than lst, numeric

* FN Sting indicator of Field Number

* CRPW Numeric page width

* CRAPW Actual page width filled, numeric

* ESA Extra Space Available while entering custom headings

* UL Underline length to use in custom heading enter block

* HL1-3 Lines 1 to 3 of user-entered single column headings

* CCP Current Column Position, numeric 
* CCW Current Column Width, numeric

* LS1,LS2 Listing String, used with LIST command to list out report

* CRDEL Delimiting character, normally comma, but blank for first one

* NCL Number of comment lines for printed report with all of comments

* PCV Print control variable, offset for printing all of comments, numeric

* PH2 User definable print heading 
* D18.PRG 2-21-85 KRA

* oisplays Record on sCREEN IN LER INPUT format

SET DEVICE TO SCREEN

STORE ' TO ICV2, ICV3

CLEAR

\section{IF MCV2='BASE'}

DO WHILE ICV3=' '

e 1.0 SAY 'Do you want to have all records in the database available or would you' e 2.0 SAY 'like to look only at certain records? A - All S - Selected' GET ICV3 READ

IF UPPER(ICV3) <> 'A' .AND. UPPER(ICV3) $<>$ 'S'

STORE ' TO ICV 3

ENDIF

ENDDO

IF UPPER(ICV3) $<>^{\prime} A$ '

* If THE 'SELECTED' OPTION IS CHOSEN, PRESENT MENUS LIKE REPORT PROGRAM

STORE ' I TO GCV

DO WHILE UPPER(GCV) $<>^{\prime} X T^{\prime}$

CLEAR

DO CASE

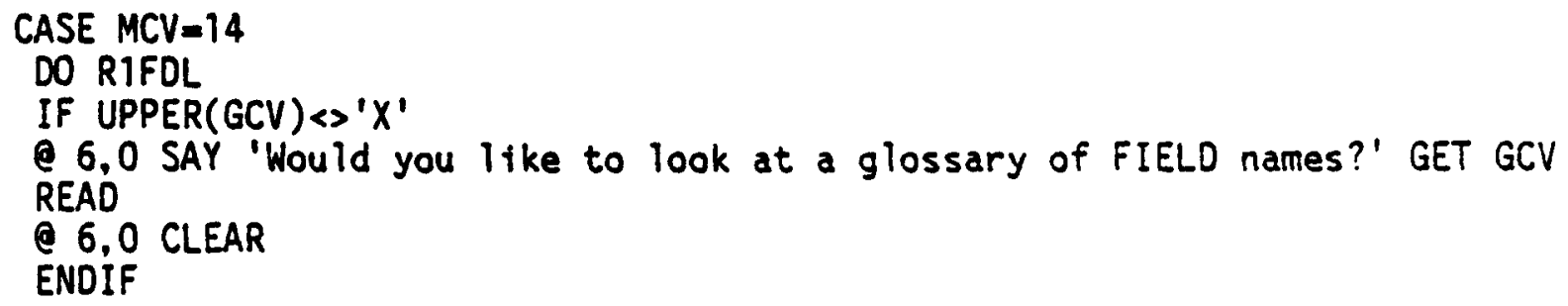




\author{
ENDIF \\ ENDIF \\ CLEAR \\ USE $80 B D \pm \& M F$ \\ IF UPPER(ICV3) ='S' \\ SET FILTER TO \&SP \\ COUNT TO HITS \\ SUM NUMFAILS TO NF \\ GO TOP \\ ENDIF
}

ELSE

USE \&DBD $\pm R 3 T \& N I D$

ENDIF

IF MCV2 $=$ 'TEMP' OR. UPPER(ICV3) $=$ 'S'

CLEAR

STORE I TO L

C L.O SAY DATE()

e L., 10 SAY TIME()

STORE $L+1$ TO $L$

IF MCV2= 'TEMP'

USE \&DBD $\pm R 3 T F C A T$

DO WHILE SERIES $\angle>M S E R I E S$

SKIP

ENDDO

DO WHILE SERIES+FNUM $<=N I D$. AND. (.NOT. EOF())

(e L, 0 SAY SUBSTR(UPARAM, 1,80 )

STORE $L+1$ TO $L$

IF LEN(TRIM(UPARAM)) $>80$

C L. 0 SAY SUBSTR(UPARAM, 81,34)

STORE $L+1$ TO $L$

ENDIF

SKIP

ENODO

e L, O SAY 'HITS='

@ L, 5 SAY HITS PICTURE ' 9999 '

e L, 12 SAY 'TOTAL NUMFAILS='

@ L. 28 SAY NF PICTURE ' $99999^{\prime}$

STORE L+2 TO L

ELSE

e L, 0 SAY SUBSTR(SPU, 1,80) 


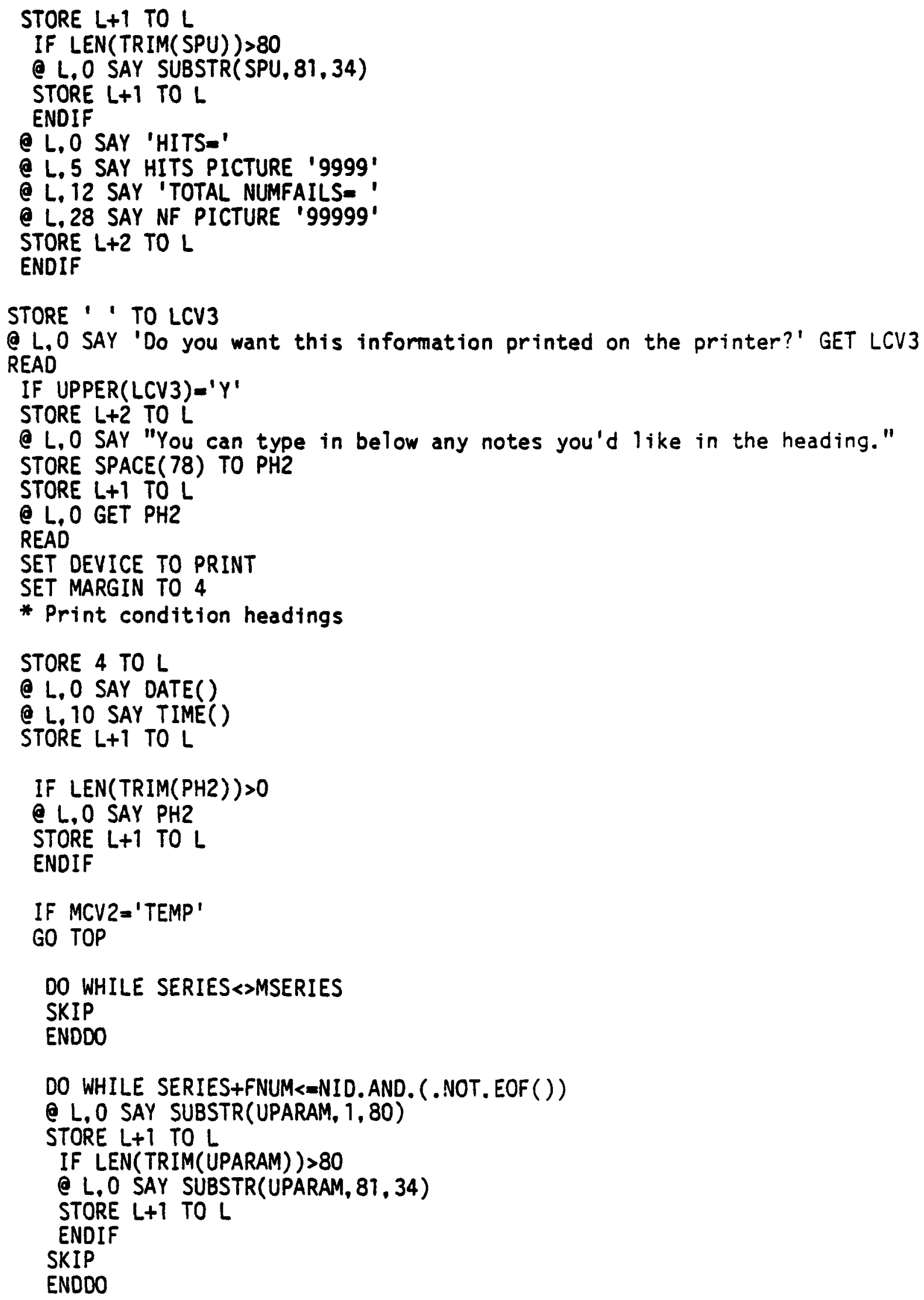




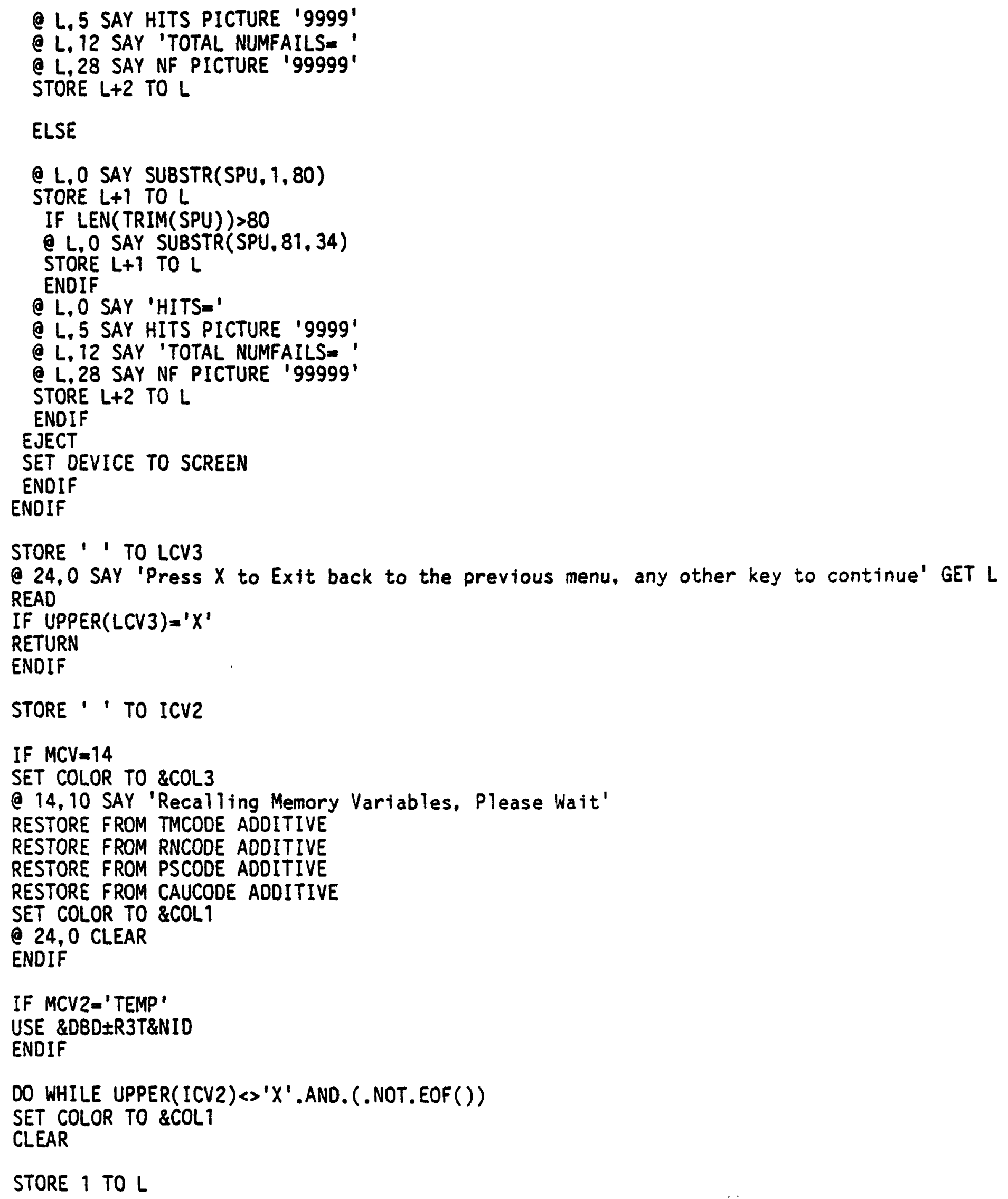


If $M C V=14$

* FULL-SCREEN display OF 14 fieldS DECODEd

STORE 2 TO L

* RECNO()

IF UPPER(ICV 3$)=$ 'S'

e L, O SAY 'Hits = '

C L, 7 SAY HITS PICTURE '9999'

e L, 13 SAY 'SUm Of NUMFAILS = '

C L, 32 SAY NF PICTURE ' 9999 '

STORE L+1 TO L

ENDIF

C L.O SAY "Identification Information for Record \#"

e L, 40 SAY RECNO()

STORE $L+1$ TO L

* Lernum

C L.2 SAY 'Database Number:'

e L. 19 SAY DATABNUM

@ L, 25 SAY "LER Number: "

@ L, 37 SAY LERNUM PICTURE "XXXXXXX"

STORE L+2 TO L

@ L, O SAY "Component Information"

STORE $L+1$ TO L

อ L.2 SAY "Type: "

* TYPEMAIN and TYPESUb1

DO CASE

CASE UPPER(TYPEMAIN) $=$ ' $V$ '

IF TYPESUB $1<>^{\prime}$ '

STORE TYPESUB 1 TO TM

C L, COL() SAY TMV\&TM

ENDIF

e L.COL()+1 SAY 'Valve'

CASE UPPER(TYPEMAIN) $=' P$ '

IF TYPESUBT $<>$ ' '

STORE TYPESUBI TO TM

@ L. COL() SAY TMP\&TM

ENDIF

e L, COL( )+1 SAY 'Penetration'

ENDCASE

STORE L+1 TO L

* ReACNAME

C L.2 SAY "Reactor Name: "

IF REACNAME $<>$ '

STORE SUBSTR(REACNAME, 1,2) TO RC

Q L, COL() SAY RN\&RC

IF RN\&RC=TRIM(RN\&RC)

e L, COL ()+1 SAY SUBSTR(REACNAME, 3,1)

ENDIF

ENDIF

* REACTYPE

e L, COL()+3 SAY "Reactor Type: " 
DO CASE

CASE UPPER(REACTYPE) $=$ ' $B$ '

e L, COL() SAY 'BWR'

CASE UPPER(REACTYPE) $=$ ' $P$ '

Q L. COL() SAY 'PWR'

CASE UPPER(REACTYPE) = ' $H$ '

C L.COL() SAY 'HTGR'

ENDCASE

STORE L+1 TO L

* CISClass

e L. 2 SAY "CIS Class"

Q L, COL () SAY CISCLASS+': '

DO CASE

CASE CISCLASS $=11$ '

e L, COL( )+2 SAY 'PWR - Large Dry Containment

CASE CISCLASS $=$ ' 2 '

e L. COL ()+2 SAY 'PWR - Subatmospheric Containment'

CASE CISCLASS $=$ ' 3 '

e L. COL()+2 SAY 'PWR - Dual (Double) Containment '

CASE CISCLASS $=$ ' 4 '

e L, COL()+2 SAY 'PWR - Ice Condenser Containment '

CASE CISCLASS $=$ ' 5 '

e L. COL( )+2 SAY 'BWR - Mark I Containment

CASE CISCLASS $=' 6$ '

e L. COL ()+2 SAY 'BWR - Mark II Containment

CASE CISCLASS $=$ ' 7 '

e L, COL ()+2 SAY 'BWR - Mark III Containment

CASE CISCLASS $=$ ' 8 '

Q L. COL ( )+2 SAY 'Other CIS

ENDCASE

STORE L+1 TO L

* SYSPRIMA

Q L, 2 SAY "Primary System involved: "

IF SYSPRIMA $<>$ ' '

STORE SYSPRIMA TO SYP

DO CASE

CASE SYP $<' 20^{\prime}$. AND. SYP $<>^{\prime} 14^{\prime}$. AND. SYP $<>^{\prime} 17^{\prime}$. AND. SYP $<>^{\prime} 11^{\prime}$. OR. SYP $=$ ' $^{\prime} 99^{\prime}$

Q L,COL() SAY PS\&SYP

CASE UPPER(REACTYPE) $=$ ' $^{\prime}$ '

@ L, COL() SAY PSB\&SYP

CASE UPPER(REACTYPE) $=$ ' $P$ '

Q L. COL() SAY PSP\&SYP

ENDCASE

ENDIF

STORE L+2 TO L

e L, O SAY "Failure Information: "

STORE L+1 TO L

* DATE

@ L.2 SAY 'Date: ' 
e L,COL() SAY DATE

* NUMFAILS

e L, COL ( )+3 SAY 'Number of Fai lures

e L.COL() SAY NUMFAILS PICTURE ' 99 '

STORE $L+1$ TO L

* MOde

Q L.2 SAY 'Failure Mode: '

DO CASE

CASE UPPER(MODE) $=$ 'A'

C L. COL() SAY 'Mode A, Leakage (failure to seal)'

CASE UPPER(MOOE) $=$ 'B'

@ L.COL() SAY 'Mode B, Failure to close within a reasonable time.' STORE L+1 TO L

e L.4 SAY 'constituting a potential failure to isolate containment.' CASE UPPER(MODE) $={ }^{\prime} \mathrm{C}$ '

e L.COL() SAY 'Mode C. Unplanned opening (failure to remain closed)' ENDCASE

STORE $L+1$ TO L

* CAUSEPRI IF L.2 SAY 'Primary Cause of Failure: '

STORE CAUSEPRI TO CP

Q L. COL() SAY CAUT\&CP

IF LEN(CAU1\&CP) $>54$

STORE L+2 TO L

ELSE

STORE $L+1$ TO L

ENDIF

ENDIF

* isOLATED

DO CASE

CASE UPPER(ISOLATED) $={ }^{\prime} Y$ '

@ L.2 SAY 'Containment was isolated'

CASE UPPER(ISOLATED) $=$ ' $N$ '

e L. 2 SAY 'Containment was not isolated'

ENDCASE

STORE L+2 TO L

* COMMENTS

@ L. O SAY "Comments: "

@ L. 11 SAY SUBSTR(COMMENTS, 1,69)

STORE L+1 TO L

Q L.2 SAY SUBSTR(COMMENTS, 70,78)

STORE $L+1$ TO $L$

อ L. 2 SAY SUBSTR(COMMENTS, 148, 78)

STORE $L+1$ TO $L$

@ L. 2 SAY SUBSTR(COMMENTS, 226, 15)

ELSE 
* full-screen display of 29 fields IF UPPER(ICV 3$)=$ 'S'

e 1.0 SAY 'Hits = '

e 1,7 SAY HITS PICTURE ' $9999^{\prime}$

e 1,13 SAY 'SUm of NUMFAILS = '

@ 1,32 SAY NF PICTURE ' $9999^{\prime}$

STORE L+1 TO L

ENDIF

e 3,0 SAY "Identification Information for Record \# "

e 3,40 SAY RECNO()

e 4,2 SAY "Data Base \#: "

e 4,15 SAY DATABNUM PICTURE "999g"

@ 4,22 SAY "LER \#: "

@ 4,29 SAY LERNUM PICTURE "XXXXXXX"

a 4,37 SAY "Revision \#:

@ 4,49 SAY REVISNUM PICTURE "XX"

อ 5,2 SAY "Accession \#: "

e 5,15 SAY ACCESNUM PICTURE " $x x x x x x "$

@ 5.23 SAY "Failure \#: "

@ 5,34 SAY ENTRYNUM PICTURE "XX"

a 7,0 SAY "Component Information"

e 8,2 SAY "Type: Main:

@ 8,14 SAY TYPEMAIN PICTURE " $X "$

a 8,17 SAY "Sub-1: "

@ 8,24 SAY TYPESUB1 PICTURE " $X$ "

@ 8,27 SAY "SUb-2:

e 8,34 SAY TYPESUB2 PICTURE " $X$ "

@ 9.2 SAY "Location:

@ 9, 12 SAY LOCATION PICTURE " $X$ "

Q 9,15 SAY "Manufacturer:

9 9.29 SAY MFG PICTURE "XXXX"

9,36 SAY "CIS Class:

9 9,47 SAY CISCLASS PICTURE " $x "$

e 10,2 SAY "Reactor: Name:

@ 10,17 SAY REACNAME PICTURE "XXX"

@ 10,22 SAY "Type:

e 10,28 SAY REACTYPE PICTURE " $X$ "

(a) 10,32 SAY "NSSS Vendor:

@ 10,45 SAY REACNSSS PICTURE " $X$ "

e 11.2 SAY "System: Primary:

@ 11,19 SAY SYSPRIMA PICTURE "XX"

C 11,24 SAY "Secondary:

@ 11,35 SAY SYSSECON PICTURE " $X X X X X "$

@ 12,2 SAY "System Designation:

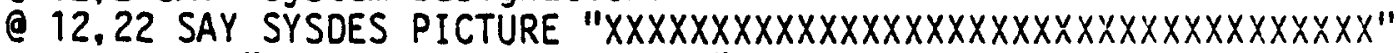

Q 14,0 SAY "Failure Information: "

e 15,2 SAY "Date: "

e 15.8 SAY DATE PICTURE "XXXXXXXXX"

อ 15,19 SAY "Power Level: "

e 15,32 SAY POWERLEV PICTURE "XXX"

@ 15,35 SAY "\% Failure Mode: "

e 15,53 SAY MODE PICTURE " $X$ "

@ 16,2 SAY "Cause: Primary: "

e 16,18 SAY CAUSEPRI PICTURE "XX" 


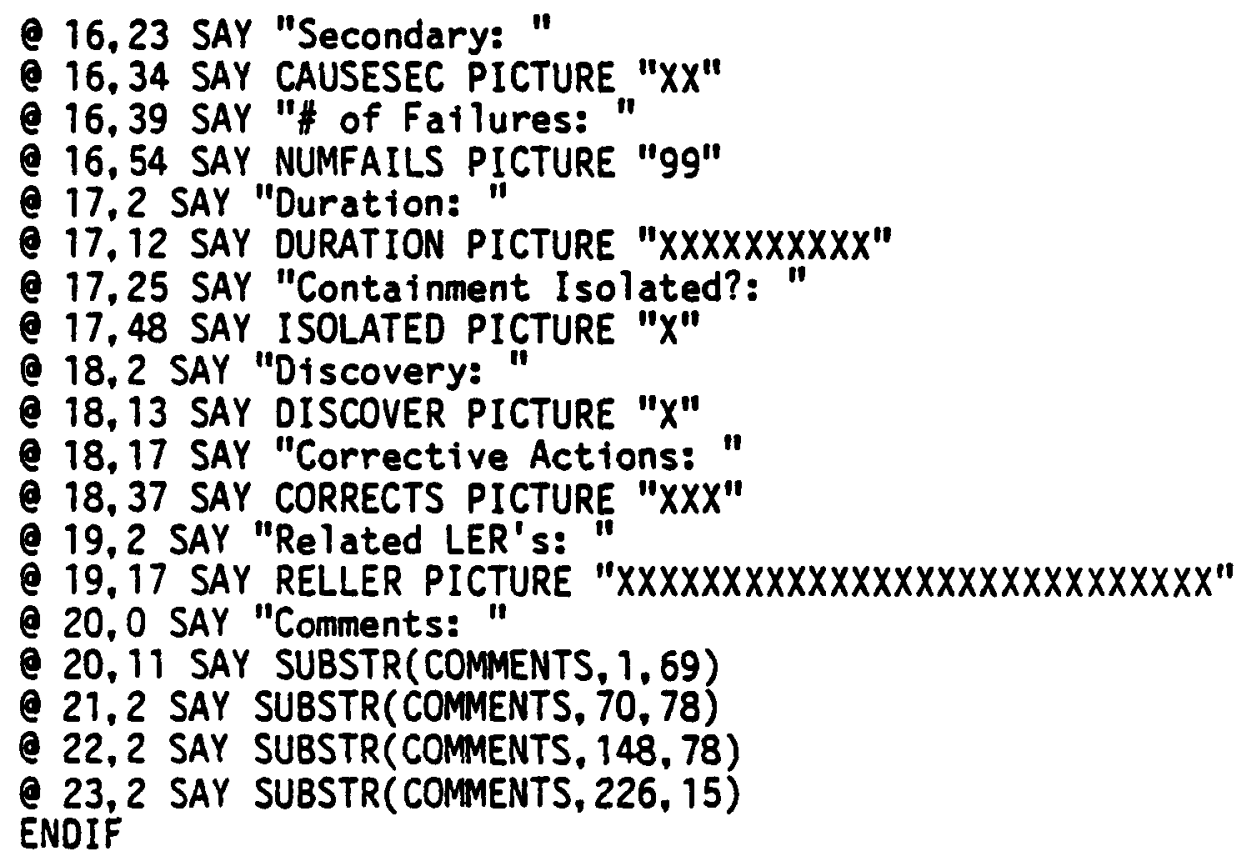

SET COLOR TO \&COL2

STORE ' ' TO ICV2

IF (UPPER(ICV3)='S'. OR.MCV2='TEMP'). AND. HITS=1

24,0 SAY 'Only one record found, press any key to return to menu.' GET ICV2 READ

STORE ' $X$ ' TO ICV 2

EXIT

ENDIF

IF MCV2 ='BASE' . AND. UPPER(ICV3) $=$ 'S'

IF .NOT.BOF().AND. (.NOT.EOF())

e 24.0 SAY 'N - Next, P - Previous, F - First, $X$ - eXit' GET ICV2

ELSE

IF $B O F()$

e 24,0 SAY ' $N$ - Next, $X$ - eXit' GET ICV2

ELSE

e 24,0 SAY ' $P$ - Previous, $F$ - First, $X$ - eXit' GET ICV 2 ENDIF

ENDIF

READ

IF UPPER(ICV2) $=$ ' $N$ '

SKIP

IF EOF()

SKIP -1

SET COLOR TO \&COL3

e 24,0 CLEAR

24,0 SAY 'Already at last record'

DO DELAY

ENDIF

ENDIF

IF UPPER(ICV2)=' $P$ '

SKIP -1

IF BOF() 
SET COLOR TO \&COL 3

@ 24,0 CLEAR

e 24,0 SAY 'Already at first record'

DO DELAY

ENDIF

ENDIF

IF UPPER(ICV2)=' $F$ '

IF RECNO() $=1$

SET COLOR TO \&COL3

e 24,0 CLEAR

C 24,0 SAY 'Already at first record'

DO DELAY

ELSE

GO TOP

ENDIF

ENDIF

IF UPPER(ICV2)=' 'L'

SKIP

IF EOF()

SKIP -1

SET COLOR TO \&COL 3

@ 24,0 CLEAR

e 24,0 SAY 'Already at last record'

DO DELAY

ELSE

GO BOTTOM

ENDIF

ENOIF

IF UPPER(ICV2) $=$ ' $X$ '

EXIT

ENDIF

\section{ELSE}

IF .NOT.BOF().AND. (.NOT.EOF())

e 24,0 SAY ' $N$ - Next, P - Previous, F - First, L - Last, S - Specify \#, X - eXit' GET ELSE

IF $B O F()$

e 24,0 SAY ' $N$ - Next, L - Last, S - Specify \#, X - eXit' GET ICV2

ELSE

e 24,0 SAY 'P - Previous, F - First, S - Specify \#, $X$ - eXit' GET ICV2 ENDIF

ENDIF

READ

IF UPPER(ICV2) $=$ ' $N$ '

SKIP

IF EOF()

SKIP -1

SET COLOR TO \&COL3

e 24,0 CLEAR

e 24,0 SAY 'Already at last record'

DO DELAY

ENDIF

ENDIF 


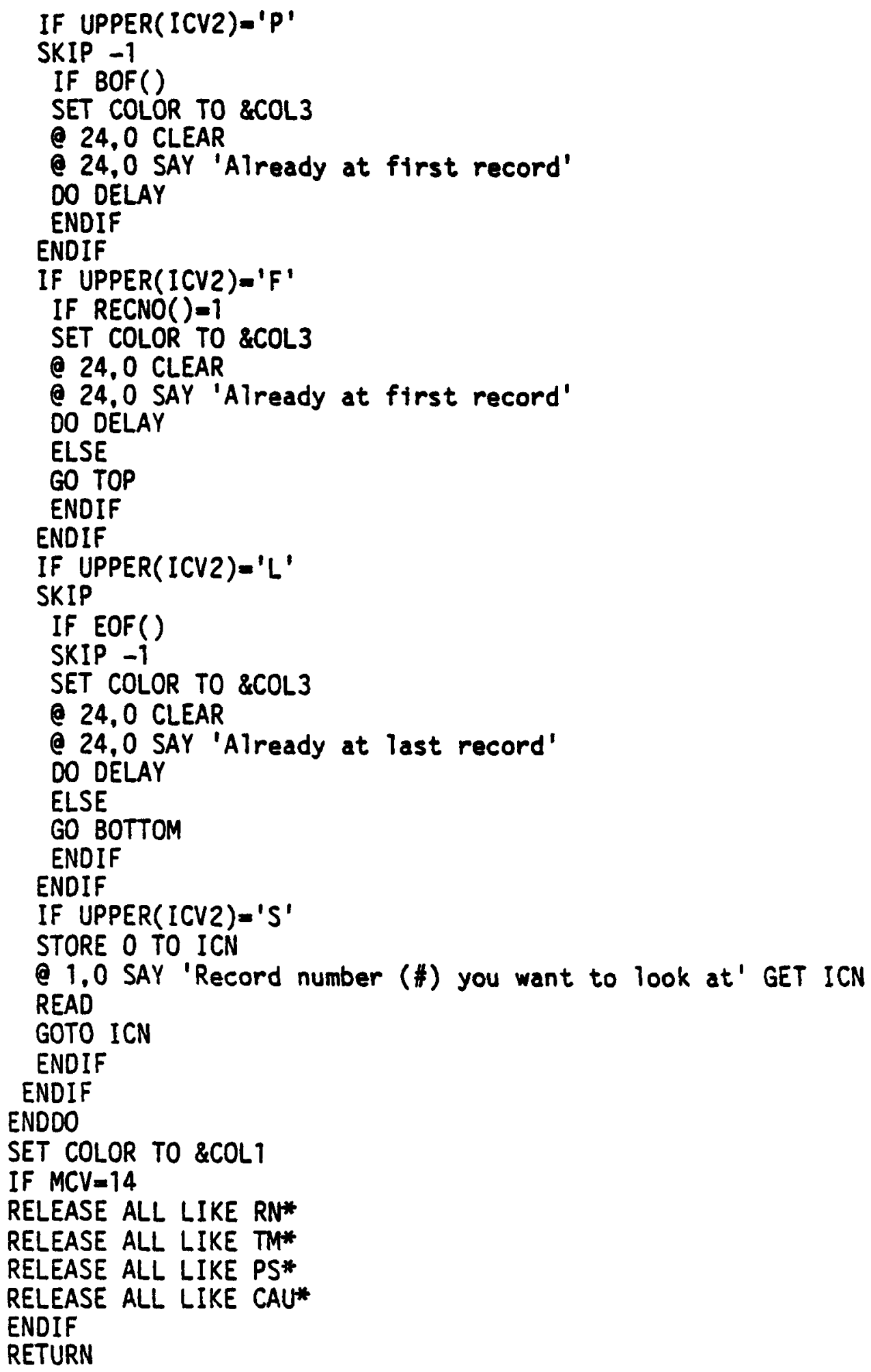


* E38.PRG 5-02-85 KRA

* EDITS RECORD(S) ON SCREEN IN LER INPUT FORMAT

PUBLIC ICV3

STORE ' ' TO ICV2, ICV 3

SET DEVICE TO SCREEN

CLEAR

SET DELETED OFF

DO WHILE ICV $3='$ '

@ 1,10 SAY 'E - Edit any record in the database'

e 2,10 SAY 'S - Select certain records to edit'

e 3,10 SAY 'A - Add new records to the database'

e 4,10 SAY ' Your Choice' GET ICV3

READ

ENDDO

IF UPPER(ICV3) $=$ ' $A$ '

APPEND BLANK

GO BOTTOM

ENDIF

IF UPPER(ICV3) $=$ 'S'

* IF THE 'SOME' OPTION IS CHOSEN, PRESENT MENUS LIKE REPORT PROGRAM

STORE 0 TO ICN2, ICN3, ICN4, ICN5, ICN6

STORE ' 'TO SPO

STORE ' $Y$ ' TO GCV

DO WHILE UPPER(GCV) \langle\rangle$^{\prime} \mathrm{X} 1^{\prime}$

CLEAR

IF $\mathrm{MCV}=14$

DO R1FDL

IF UPPER(GCV)〈〉' $X$ '

@ 6,0 SAY 'Would you like to look at a glossary of FIELD names?' GET GCV READ

@ 6,0 CLEAR

ENDIF

ELSE

DO RIFD

IF UPPER(GCV) \langle\rangle$^{\prime} X$ '

@ 8,0 SAY 'Would you like to look at a glossary of FIELD names?' GET GCV READ

(a) 8,0 CLEAR

ENDIF

ENDIF

IF UPPER(GCV) $=$ ' $X '$ ' OR .UPPER $(G C V)={ }^{\prime} N '$

STORE 'XI' TO GCV

ENDIF

IF UPPER(GCV) = ' $\mathrm{Y}$ ' 


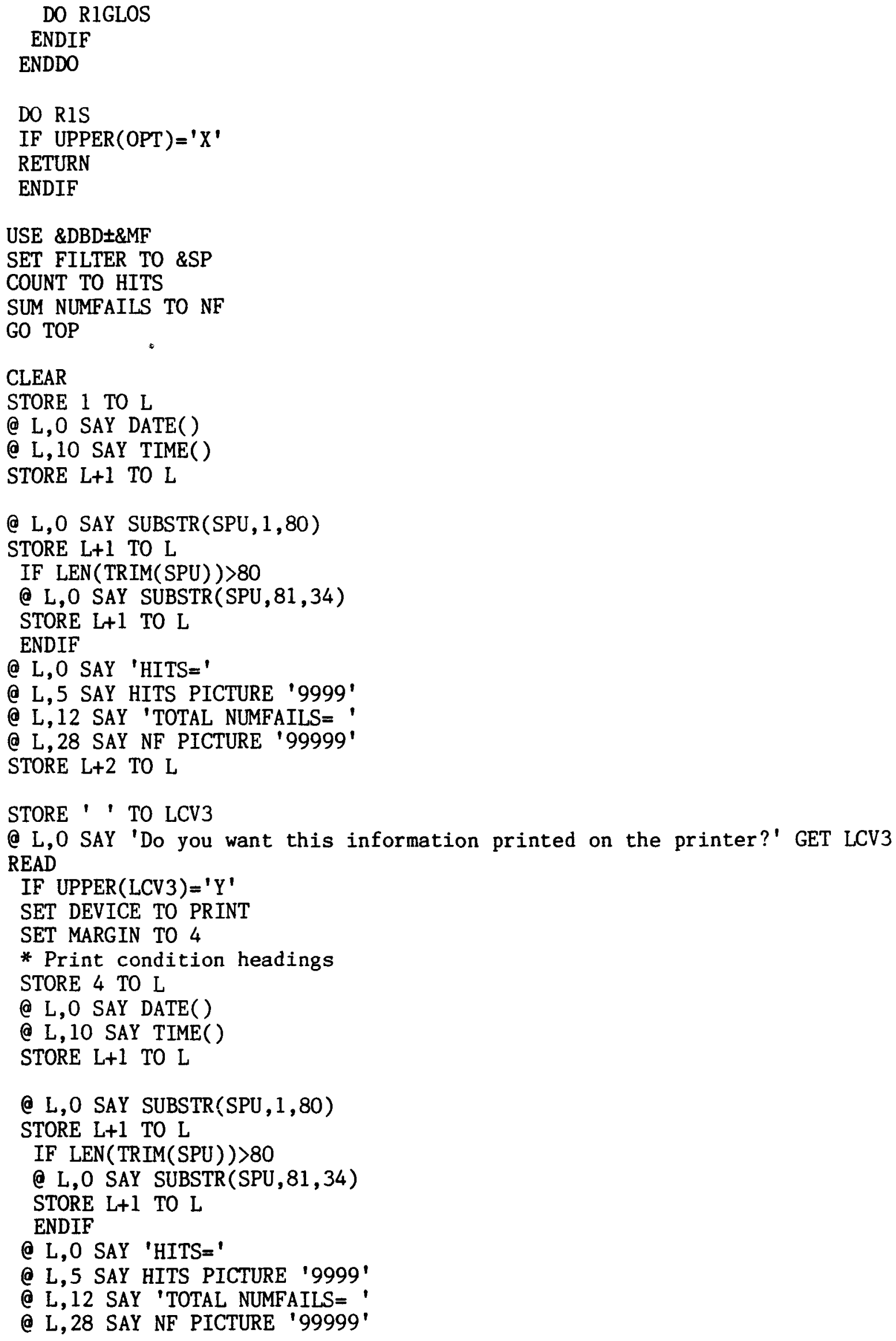


STORE L+2 TO L

- EJECT

ENDIF

SET DEVICE TO SCREEN

ELSE

USE \&DBD $\& M F$

ENDIF

STORE ' ' TO LCV3

@ 24,0 SAY 'Press $X$ to Exit back to the previous menu, any other key to continue' GET LCV3 READ

IF UPPER $($ LCV 3$)={ }^{\prime} X '$

RETURN

ENDIF

DO WHILE UPPER(ICV2) \langle\rangle$^{\prime} X^{\prime}$.AND. (.NOT.EOF( ))

SET COLOR TO \&COL1

CLEAR

STORE 1 TO L

IF DELETED( )

SET COLOR TO \&COL4

ENDIF

IF $\mathrm{MCV}=14$

* EDITS 14 FIELDS ON SCREEN

(a L,O SAY "Identification Information for Record \#"

(a L,40 SAY RECNO()

STORE L+1 TO L

@ L,2 SAY 'Database Number:'

@ L, 19 GET DATABNUM

STORE L+1 TO L

@ L,2 SAY "LER \#"

@ L,7 GET LERNUM PICTURE "XXXXXX"

STORE L+2 TO L

@ L,0 SAY "Component Information"

STORE L+1 TO L

@ L,2 SAY "Valve/Penetration"

@ L,20 GET TYPEMAIN PICTURE "X"

STORE L+1 TO L

@ L,1 SAY "Type"

@ L,20 GET TYPESUB1 PICTURE "X"

STORE L+1 TO L

@ L,2 SAY "CIS Class"

@ L, 20 GET CISCLASS PICTURE "X"

STORE L+1 TO L

@ L,2 SAY "Reactor Name"

@ L,20 GET REACNAME PICTURE "XXX"

STORE L+1 TO L

C L,2 SAY "Reactor Type"

(e L, 20 GET REACTYPE PICTURE " $X$ "

STORE L+1 TO L

@ L,2 SAY "Primary System"

@ L,20 GET SYSPRIMA PICTURE "XX" 
STORE L+2 TO L

e L,0 SAY "Failure Information"

STORE L+1 TO L

@ L,2 SAY "Date"

@ L,20 GET DATE PICTURE "XXXXXXXX"

STORE L+1 TO L

@ L,2 SAY "Failure Mode"

@ L,20 GET MODE PICTURE " $\mathrm{X}$ "

STORE L+1 TO L

a L,2 SAY "Primary Cause"

@ L,20 GET CAUSEPRI PICTURE "XX"

STORE L+1 TO L

@ L,2 SAY "\# of Failures"

@ L,20 GET NUMFAILS PICTURE "99"

STORE L+1 TO L

e L,02 SAY "Containment Iso1?"

@ $L, 20$ GET ISOLATED PICTURE " $\mathrm{X}$ "

STORE L+1 TO L

(e L,O SAY "Comments "

@ L, 9 GET COMMENTS

SET COLOR TO \&COL5

STORE L+4 TO L

@ L,O SAY 'To skip to end of record, type CTRL-C or PgDn

READ

ELSE

* EDITS ALL 29 FIELDS ON SCREEN

@ L,O SAY "Identification Information for Record \# "

@ L,40 SAY RECNO()

STORE L+1 TO L

@ L,2 SAY ."Data Base \#"

@ L,13 GET DATABNUM PICTURE "999"

@ L,22 SAY "LER \#"

@ L,27 GET LERNUM PICTURE "XXXXXX"

@ L,37 SAY "Revision \#"

@ L,47 GET REVISNUM PICTURE "XX"

STORE L+1 TO L

(a L,2 SAY "Accession \#"

@ L, 13 GET ACCESNUM PICTURE "XXXXXX"

a L,23 SAY "Failure \#"

@ L,32 GET ENTRYNUM PICTURE "XX"

STORE L+2 TO L

@ L,0 SAY "Component Information"

STORE L+1 TO L

@ L,2 SAY "Type: Main"

@ L,12 GET TYPEMAIN PICTURE " $\mathrm{X}$ "

@ L,17 SAY "Sub-1"

e L,22 GET TYPESUB1 PICTURE " $\mathrm{X}$ "

@ L,27 SAY "Sub-2"

@ L,32 GET TYPESUB2 PICTURE " $\mathrm{X}$ "

STORE L+1 TO L

@ L,2 SAY "Location"

@ L,10 GET LOCATION PICTURE " $\mathrm{X}$ "

(a L,15 SAY "Manufacturer"

@ L,27 GET MFG PICTURE "XXXX"

a L,36 SAY "CIS Class" 
@ L,45 GET CISCLASS PICTURE " $\mathrm{X}$ "

STORE L+1 TO L

@ L,2 SAY "Reactor: Name"

@ L, 15 GET REACNAME PICTURE "XXX"

@ L,22 SAY "Type"

@ L, 26 GET REACTYPE PICTURE "X"

e L,31 SAY "NSSS Vendor"

@ L,42 GET REACNSSS PICTURE " $\mathrm{X}$ "

STORE L+1 TO L

@ L,2 SAY "System: Primary"

@ L,17 GET SYSPRIMA PICTURE "XX"

C L,24 SAY "Secondary"

@ L,33 GET SYSSECON PICTURE "XXXXX"

STORE L+1 TO L

@ L,2 SAY "System Designation"

@ L,20 GET SYSDES PICTURE "XXXXXXXXXXXXXXXXXXXXXXXXXXXXXXXXXXXXXXXX"

STORE L+2 TO L

@ L,0 SAY "Failure Information"

STORE L+1 TO L

e L,2 SAY "Date"

@ L,6 GET DATE PICTURE "XXXXXXXX"

@ L,19 SAY "Power Level"

@ L,30 GET POWERLEV PICTURE "XXX"

@ L,35 SAY "\% Failure Mode"

@ L,51 GET MODE PICTURE "X"

STORE L+1 TO L

@ L,2 SAY "Cause: Primary"

@ L, 16 GET CAUSEPRI PICTURE "XX"

@ L,23 SAY "Secondary"

@ L, 32 GET CAUSESEC PICTURE "XX"

@ L,39 SAY "\# of Failures"

@ L,52 GET NUMFAILS PICTURE "99"

STORE L+1 TO L

@ L,2 SAY "Duration"

@ L,10 GET DURATION PICTURE "XXXXXXXXXX"

@ L,25 SAY "Containment Isol?"

@ L,46 GET ISOLATED PICTURE " $X$ "

STORE L+1 TO L

@ L,2 SAY "Discovery"

@ L,11 GET DISCOVER PICTURE " $\mathrm{X}$ "

@ L,17 SAY "Corrective Actions"

@ L, 35 GET CORRECTS PICTURE "XXX"

STORE L+1 TO L

@ L,2 SAY "Related LER's"

@ L,15 GET RELLER PICTURE "XXXXXXXXXXXXXXXXXXXXXXXXXXXXXX"

STORE L+1 TO L

@ L,O SAY "Comments"

@ L,9 GET COMMENTS

STORE L+4 TO L

SET COLOR TO \&COL5

@ L,O SAY 'To skip to end of record, type CTRL-C or PgDn

READ

ENDIF

IF DELETED() 
SET COLOR TO \&COL3

C L,0 SAY 'Record marked for deletion, U to Undelete, RETURN to leave as is.' GET ICV2 ' SET COLOR TO \&COL2

ENDIF

READ

IF UPPER( ICV 2$)={ }^{\prime} U$ '

RECALL

@ L,O SAY 'Record has been Undeleted

ENDIF

STORE ' ' TO ICV2

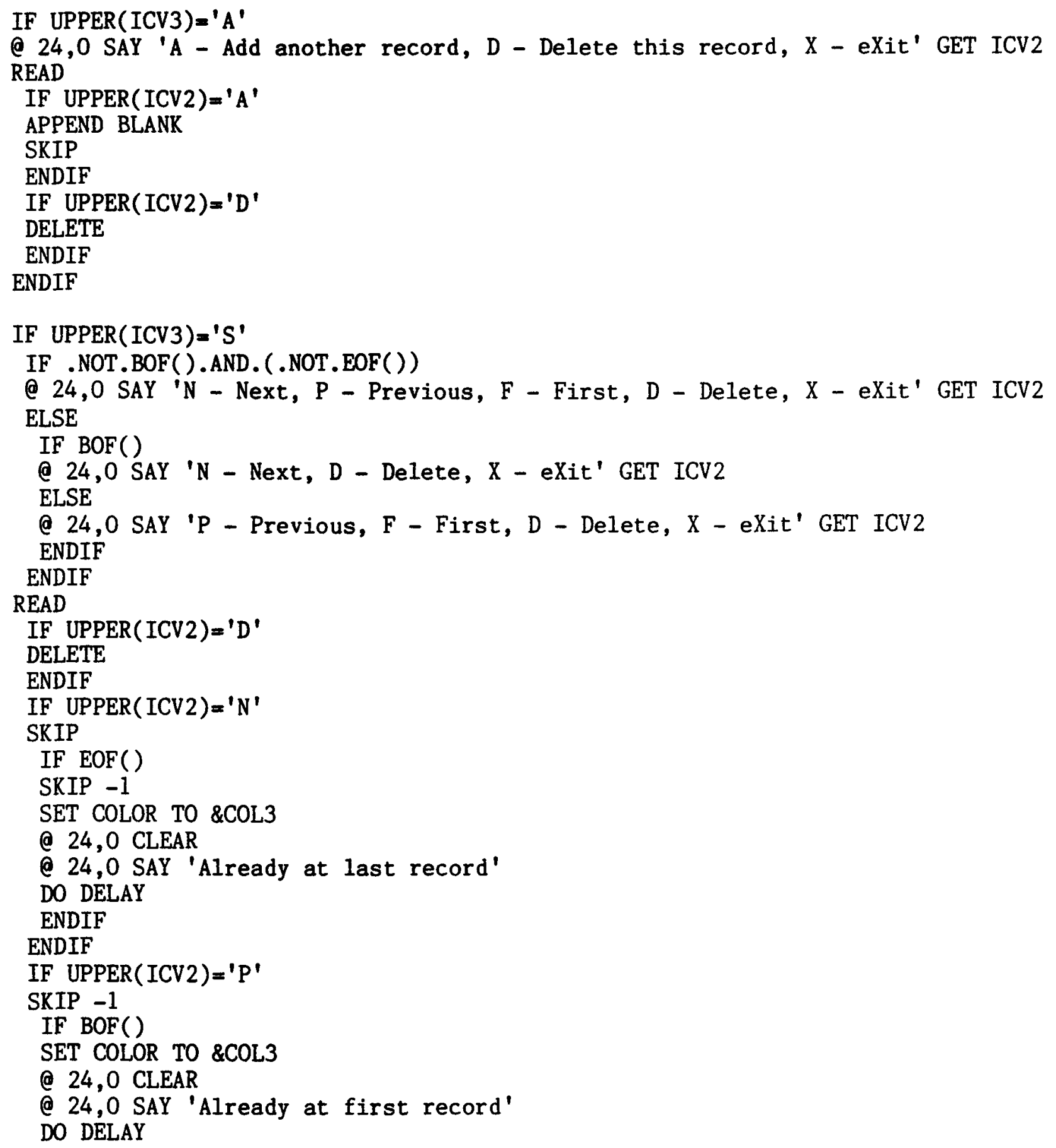


ENDIF

ENDIF

IF UPPER( ICV2) $=$ ' $F$ '

IF $\operatorname{RECNO}()=1$

SET COLOR TO \&COL3

(e) 24,0 CLEAR

@ 24,0 SAY 'Already at first record'

DO DELAY

ELSE

GO TOP

ENDIF

ENDIF

IF UPPER(ICV2) = ' $\mathrm{L}$ '

SKIP

IF $\operatorname{EOF}()$

SKIP -1

SET COLOR TO \&COL3

@ 24,0 CLEAR

@ 24,0 SAY 'Already at last record'

DO DELAY

ELSE

GO BOTTOM

ENDIF

ENDIF

IF UPPER (ICV2) ' $^{\prime}$ '

EXIT

ENDIF

ENDIF

$\operatorname{IF} \operatorname{UPPER}(\operatorname{ICV} 3)={ }^{\prime} \mathrm{E}$ '

IF .NOT.BOF( ).AND. (.NOT.EOF( ))

@ 24,0 SAY 'N Next, P Previous, F First, L Last, S Specify \#, D Delete, X eXit' GET ICV2 ELSE

IF $\mathrm{BOF}($ )

@ 24,0 SAY 'N - Next, L - Last, S - Specify \#, D - Delete, X - eXit' GET ICV2

ELSE

@ 24,0 SAY 'P - Previous, F - First, S - Specify \#, D - Delete, X - eXit' GET ICV2 ENDIF

ENDIF

READ

IF UPPER( ICV2) ' $^{\prime}$ '

DELETE

ENDIF

IF UPPER(ICV2) ' $^{\prime}$ '

SKIP

IF EOF()

SKIP -1

SET COLOR TO \&COL3

@ 24,0 CLEAR

@ 24,0 SAY 'Already at last record'

DO DELAY

ENDIF

ENDIF 


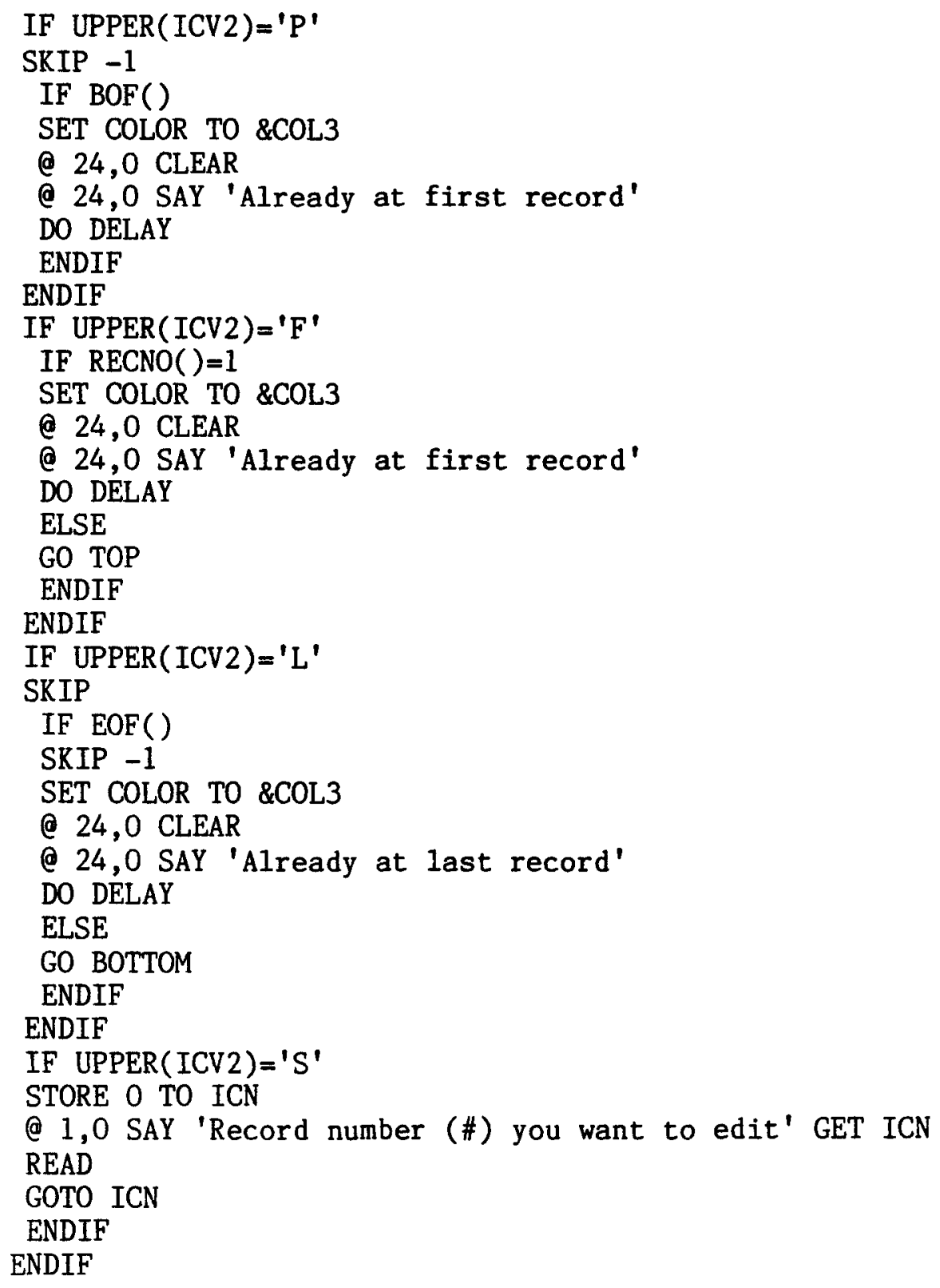


* RTPRINT. PRG 2-20-85 Ken Ames

* pRINTS ENTIRE RECORD IN LER DATA ENTRY fORMAT

* USES CONDITIONS SET BY RISEL

STORE' 'TO ICV3

CLEAR

IF MCV2 $=$ 'BASE'

DO WHILE ICV3-' '

e 1,0 SAY 'Do you want to LIST all records in the database or would you like' e 2,0 SAY 'to LIST only selected records? A - All S - Selected' GET ICV3 READ

ENDDO

IF UPPER(ICV3)='S'

* IF THE 'SELECTED' OPTION IS CHOSEN, PRESENT MENUS LIKE REPORT PROGRAM

STORE ' ' TO GCV

DO WHILE UPPER(GCV) $\angle>$ ' $X 1$ '

CLEAR

DO CASE

CASE MCV $=14$

DO RIFDL

IF UPPER(GCV) $<>$ ' $X$ '

e 6,0 SAY 'Would you like to look at a glossary of FIELD names?' GET GCV READ

Q 6.0 CLEAR

ENDIF

CASE $M C V=29$

DO RTFD

IF UPPER(GCV) $<>^{\prime} X$ '

8,0 SAY 'Would you like to look at a glossary of FIELD names?' GET GCV READ

@ 8,0 CLEAR

ENDIF

ENDCASE

IF UPPER(GCV) $=$ ' $X$ '.OR.UPPER(GCV) $=$ ' $N$ '

STORE ' $X I$ ' TO GCV

ENDIF

IF UPPER(GCV) $=$ ' $Y$ '

DO RTGLOS

ENDIF

ENDDO

DO R1S

IF UPPER(OPT) $={ }^{\prime} X$ '

RETURN

ENDIF

ENDIF 


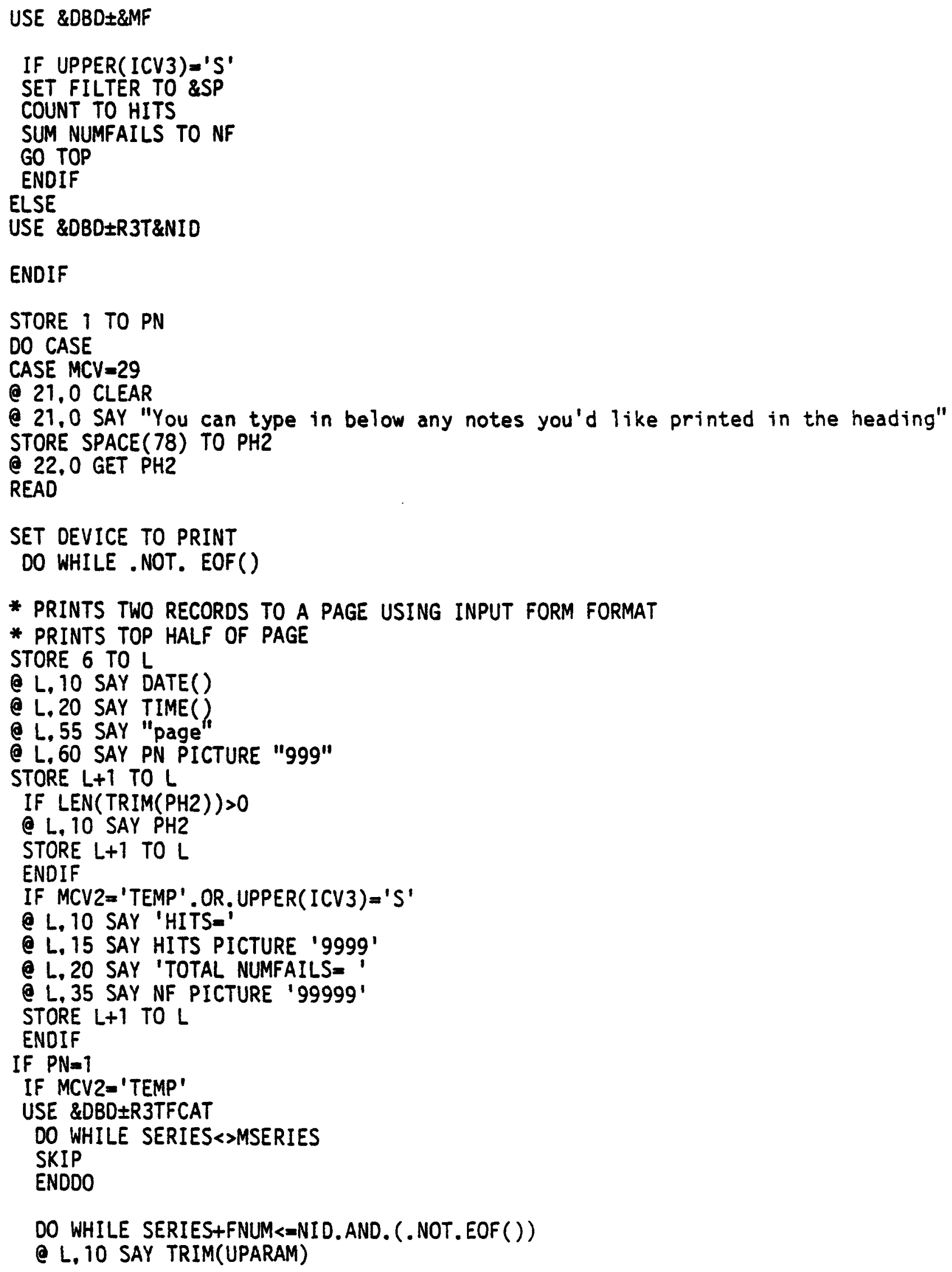


e 24.0 SAY 'Already at first record'

DO DELAY

ENDIF

ENDIF

IF UPPER(ICV2)=' $F$ '

IF RECNO() $=1$

SET COLOR TO \&COL 3

e 24,0 CLEAR

e 24,0 SAY 'Already at first record'

DO DELAY

ELSE

GO TOP

ENDIF

ENDIF

IF UPPER(ICV2) $=$ 'L'

SKIP

IF EOF()

SKIP -1

SET COLOR TO \&COL3

e 24,0 CLEAR

e 24,0 SAY 'Already at last record'

DO DELAY

ELSE

GO BOTTOM

ENDIF

ENDIF

IF UPPER(ICV2) $=$ ' $X$ '

EXIT

ENDIF

ENDIF

IF UPPER(ICV3) $=$ 'E'

IF .NOT.BOF().AND. (.NOT.EOF())

24,0 SAY ' $N$ Next, P Previous, F First, L Last, $S$ Specify \#, $D$ Delete, $X$ eXit' GET I ELSE

IF $B O F()$

@ 24,0 SAY ' $N$ - Next, L - Last, S - Specify \#, D - Delete, X - eXit' GET ICV2

ELSE

e 24.0 SAY 'P - Previous, F - First, S - Specify \#, D - Delete, X-eXit' GET ICV2 ENDIF

ENDIF

READ

IF UPPER(ICV2) $=$ ' O'

DELETE

ENDIF

IF UPPER(ICV2) $={ }^{\prime} N$ '

SKIP

IF EOF()

SKIP -1

SET COLOR TO \&COL3

e 24,0 CLEAR

e 24,0 SAY 'Already at last record'

DO DELAY 


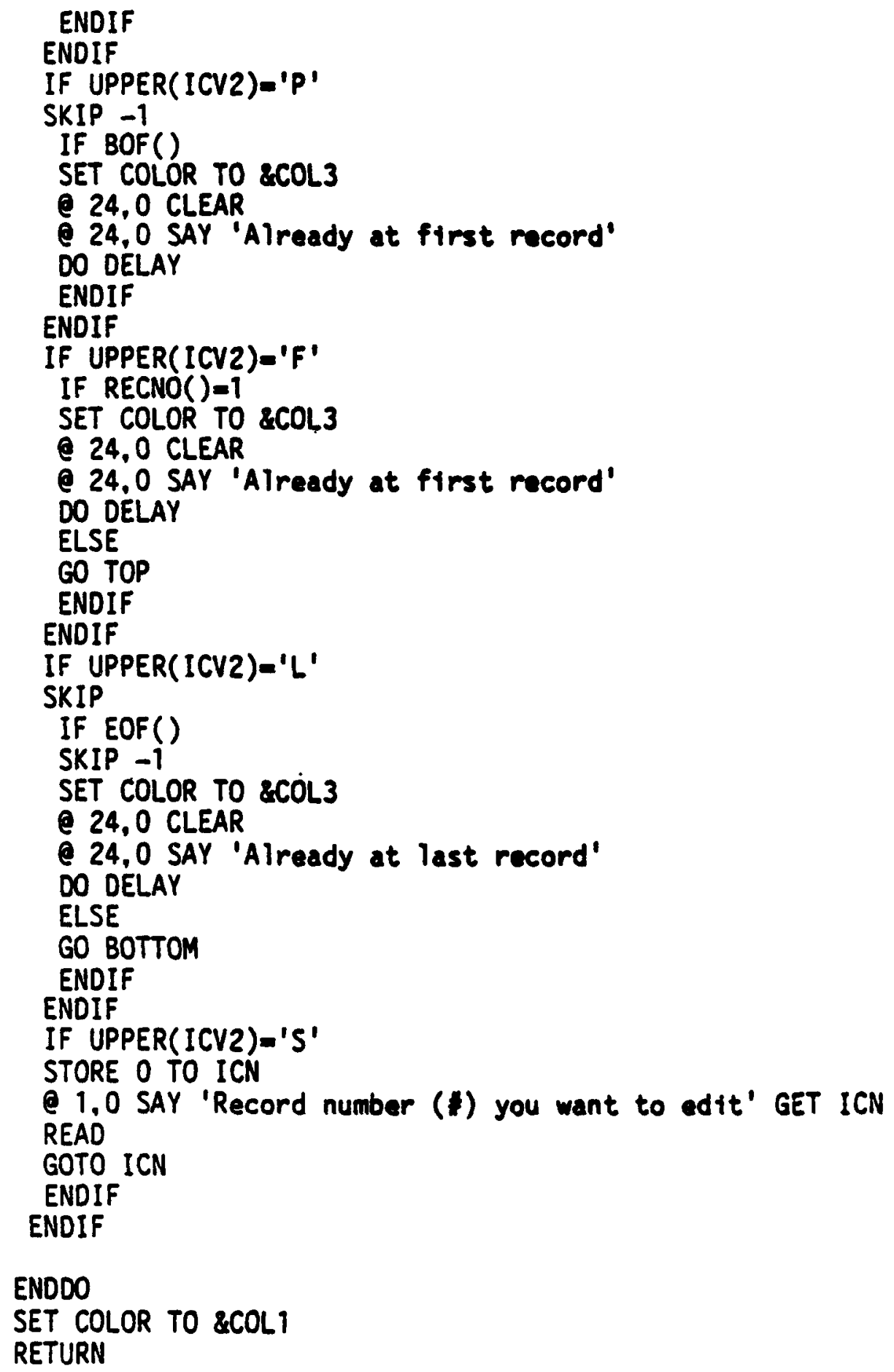


STORE $L+1$ TO L

SKIP

ENDDO

USE \&DBD $\pm R 3 T \& N I D$

\author{
ELSE \\ IF UPPER(ICV3)='S' \\ C L, 10 SAY SPU \\ STORE L+1 TO L \\ ENDIF \\ ENDIF \\ ENDIF
}

STORE L+1 TO L

e L, 10 SAY "Identification Information for Record " "

Q L, 50 SAY RECNO()

STORE L+1 TO L

C L.12 SAY "Data Base \#"

e L, 26 SAY DATABNUM PICTURE "9999"

@ L. 32 SAY "LER \#"

e L. 39 SAY LERNUM PICTURE " $X X X X X X "$

e L, 47 SAY "Revision "\#"

@ L, 59 SAY REVISNUM PICTURE "XX"

STORE $L+1$ TO L

e L. 12 SAY "Accession \#"

L. 25 SAY ACCESNUM PICTURE " $X X X X X X "$

Q L, 33 SAY "Failure "\#"

e L, 44 SAY ENTRYNUM PICTURE "XX"

STORE L+2 TO L

e L. 10 SAY "Component Information"

STORE L+1 TO L

C L. 12 SAY "Type: Main"

e L. 24 SAY TYPEMAIN PICTURE "X"

e L. 27 SAY "Sub-1"

e L. 34 SAY TYPESUB1 PICTURE " $X$ "

L, 37 SAY "Sub-2"

e L. 44 SAY TYPESUB2 PICTURE " $X$ "

STORE L+1 TO L

Q L, 12 SAY "Location"

Q L, 22 SAY LOCATION PICTURE "X"

L L, 25 SAY "Manufacturer"

Q L. 39 SAY MFG PICTURE "XXXX"

e L. 46 SAY "CIS Class"

e L. 57 SAY CISCLASS PICTURE " $X$ "

STORE L+1 TO L

e L.12 SAY "Reactor: Name"

C L, 27 SAY REACNAME PICTURE "XXX"

C L. 32 SAY "TyPe"

C L. 39 SAY REACTYPE PICTURE " $X$ "

อ L, 42 SAY "NSSS Vendor"

e L, 55 SAY REACNSSS PICTURE " $X$ "

STORE L+1 TO L

@ L. 12 SAY "System: Primary" 


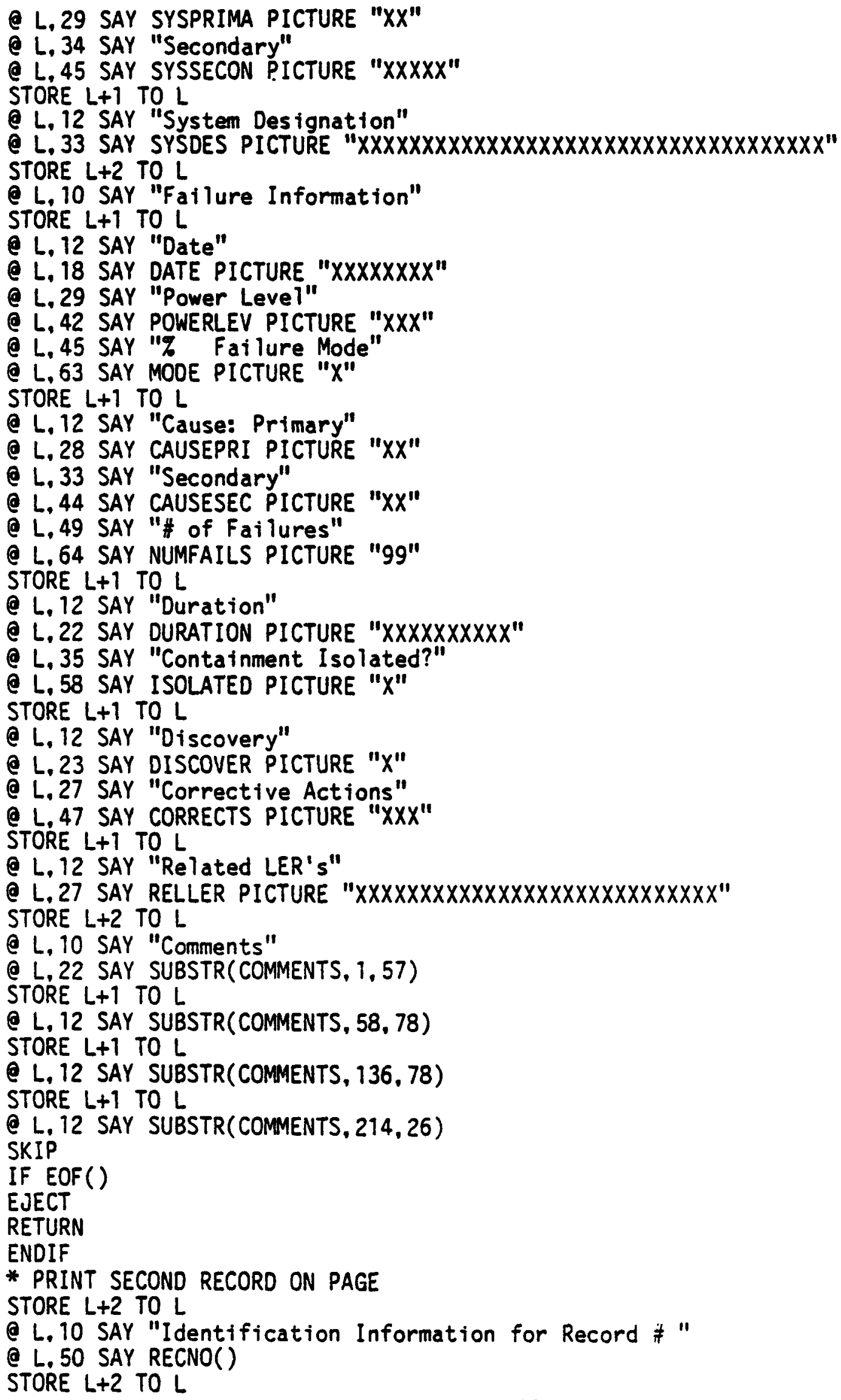




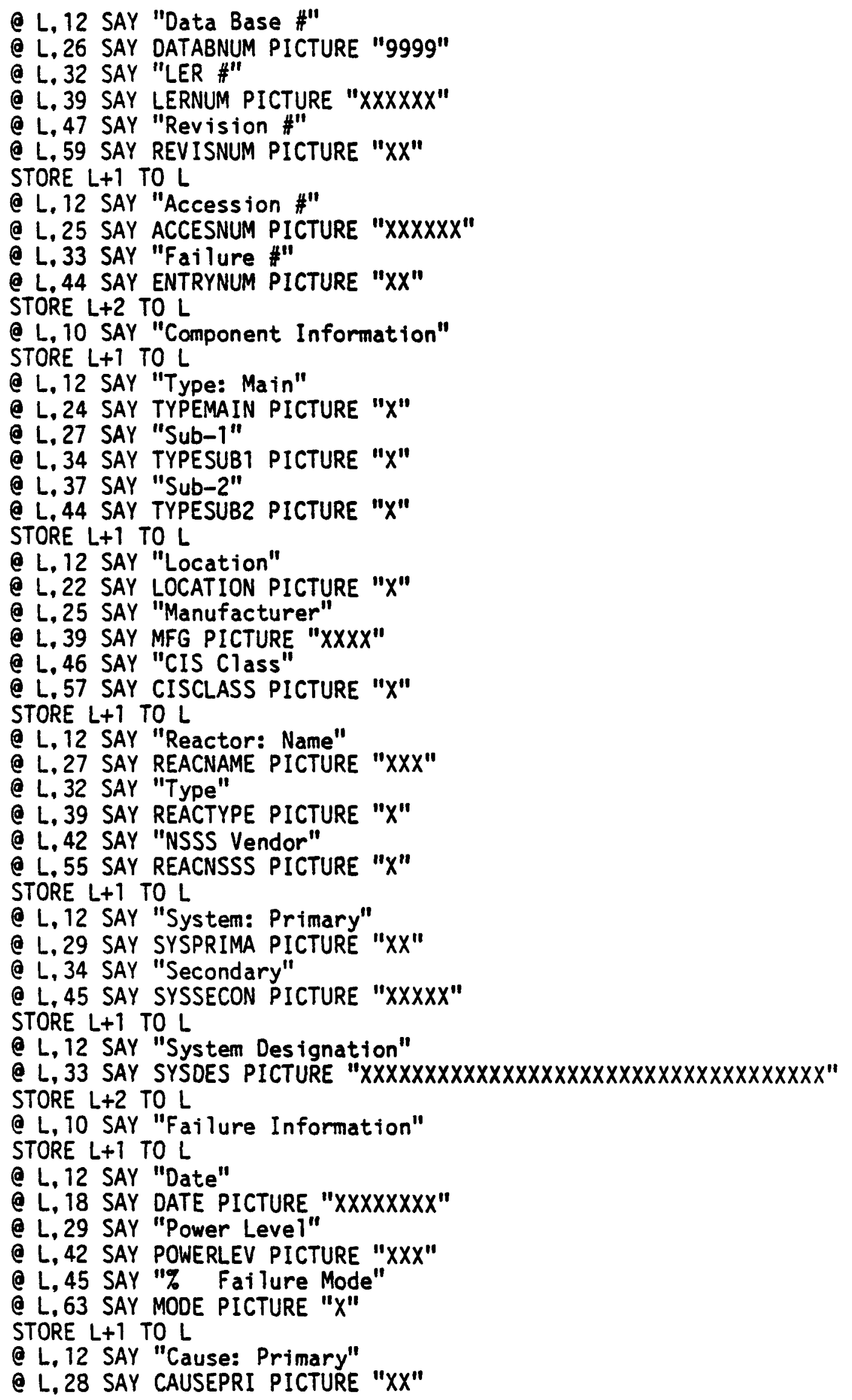




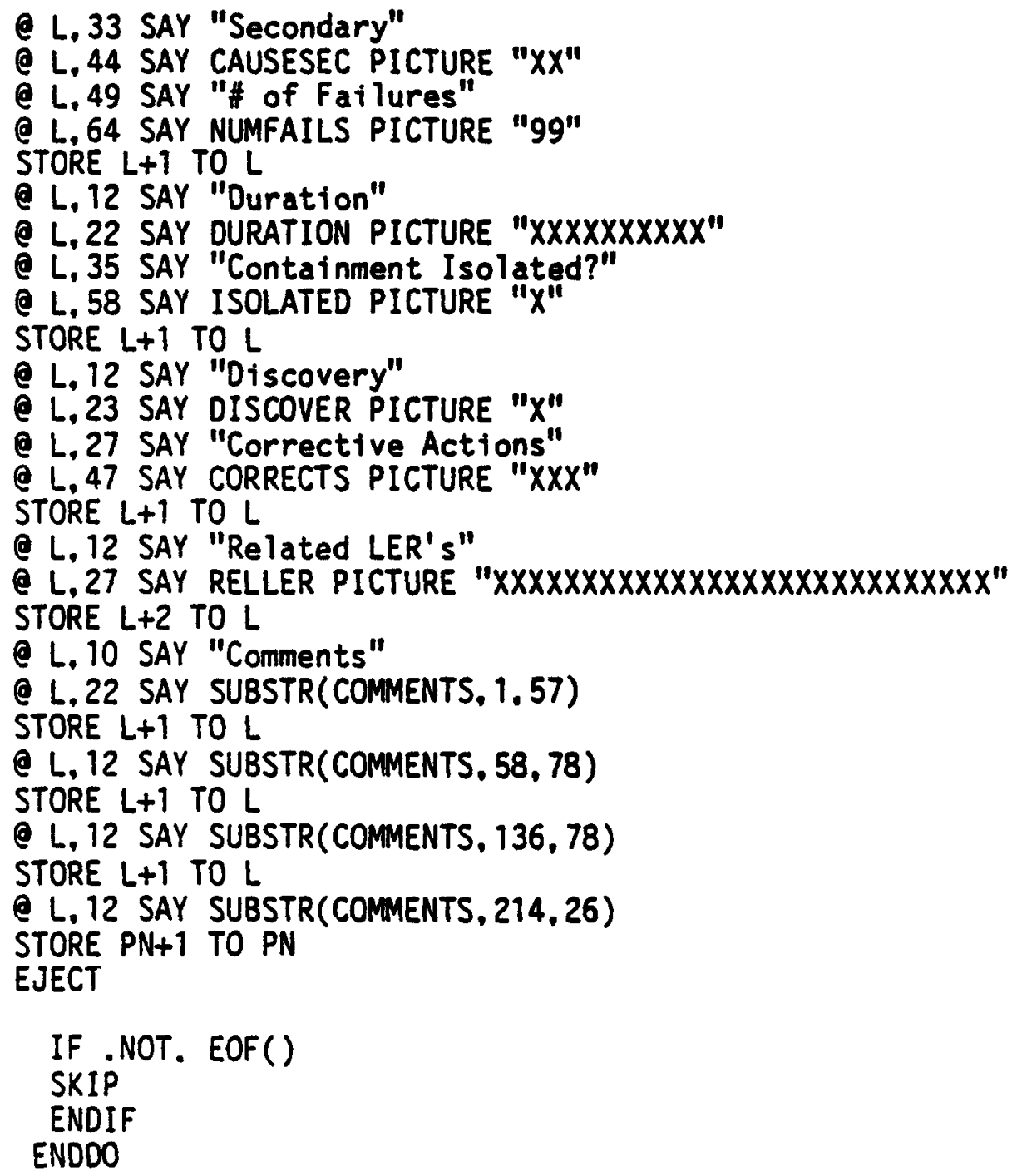




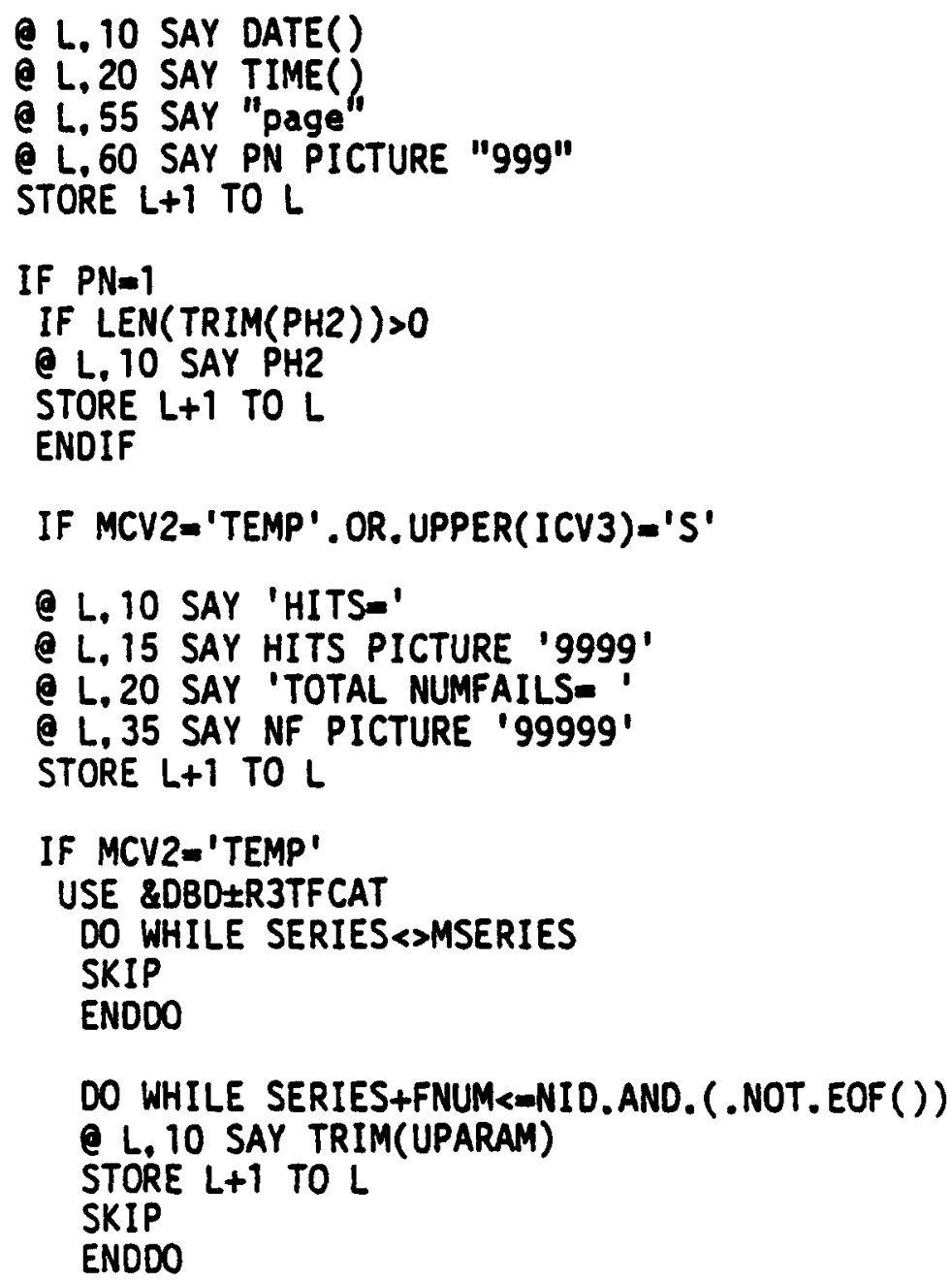

USE \&DBD $\pm R 3 T \& N I D$

ELSE

อ L. 10 SAY SPU

STORE L+1 TO L

ENDIF

ENDIF

STORE $L+1$ TO $L$

ENDIF

STORE 1 TO C

DO WHILE .NOT.EOF().AND.C<4,AND. L<44

* RECNO()

C L. 10 SAY "Identification Information for Record \#" e L. 50 SAY RECNO()

STORE L+T TO L

* LeRnum 


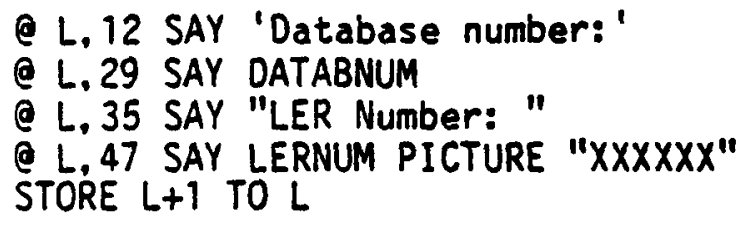




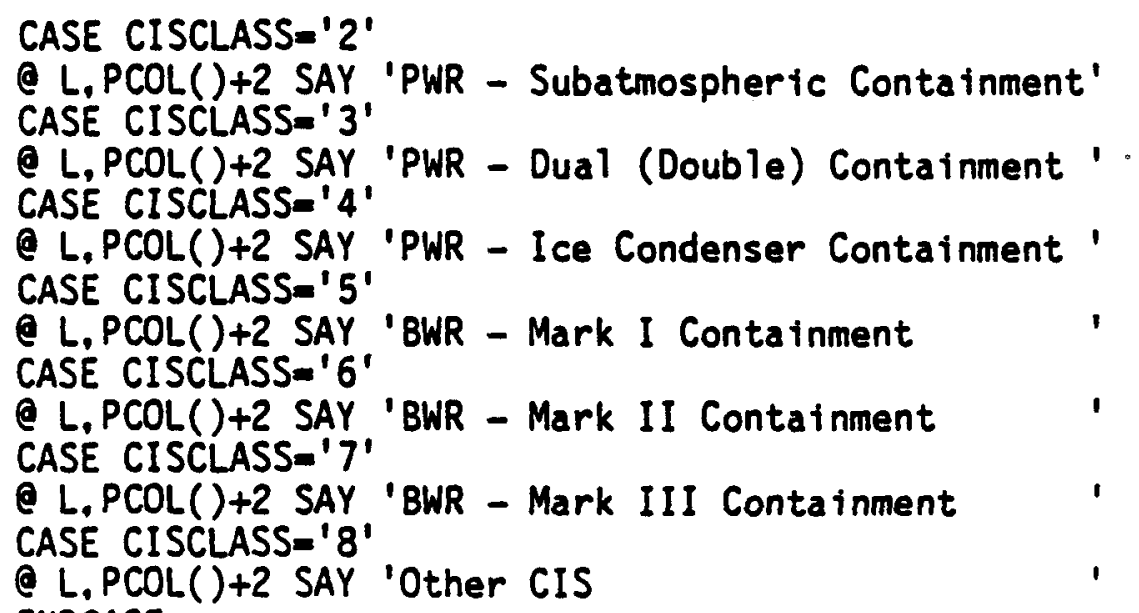




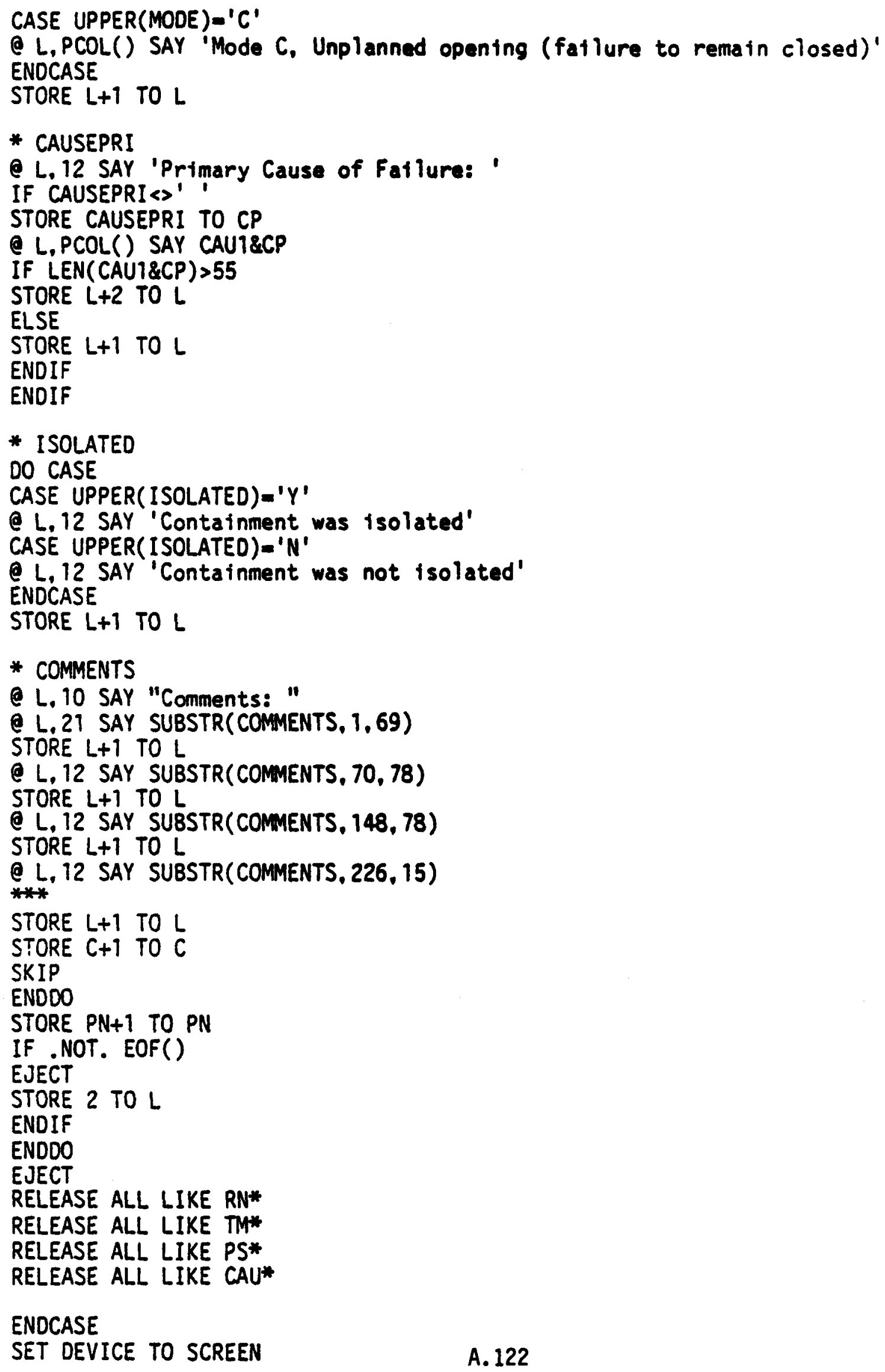


SET PRINT OFF

RETURN

A. 123 


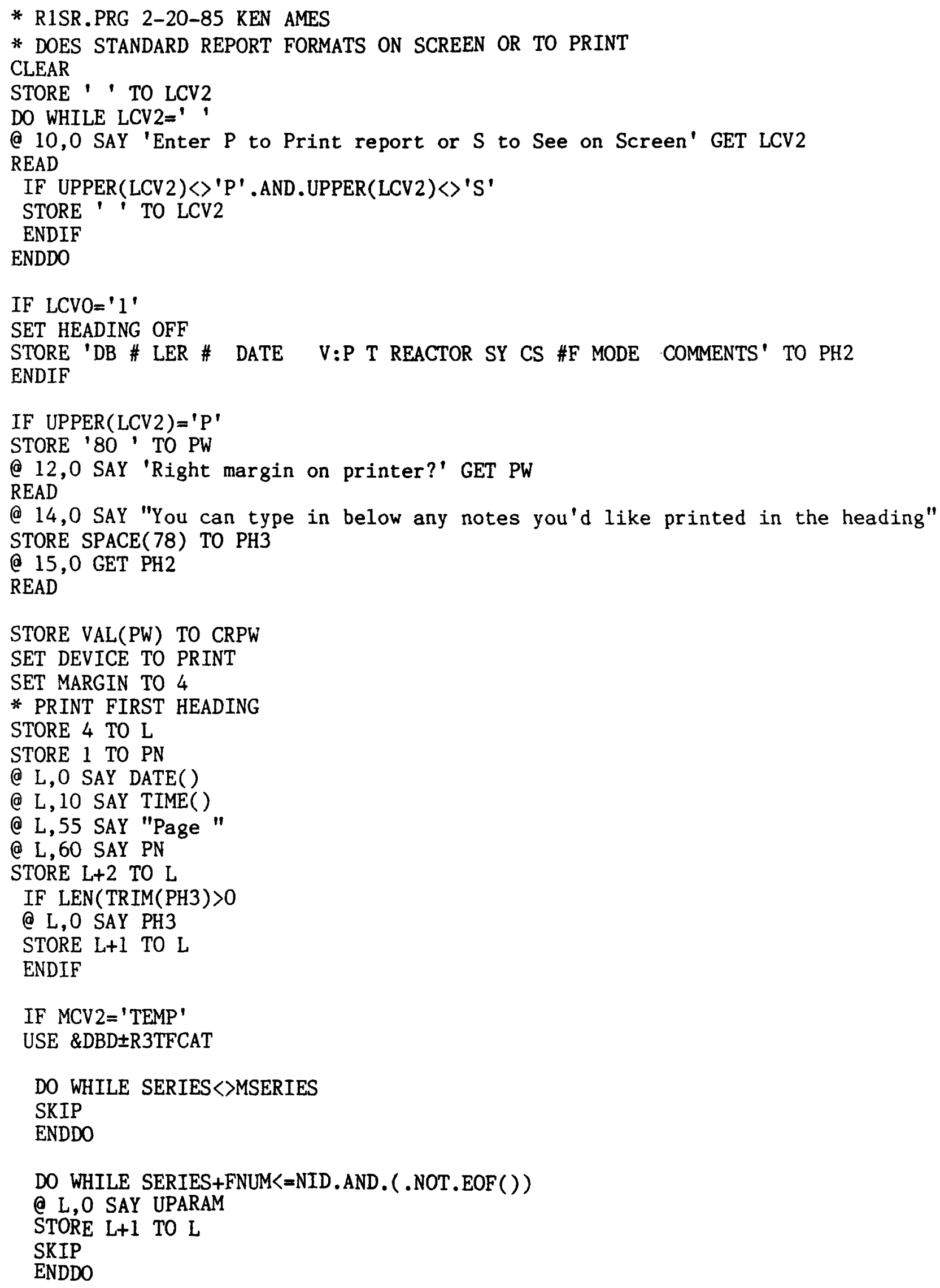




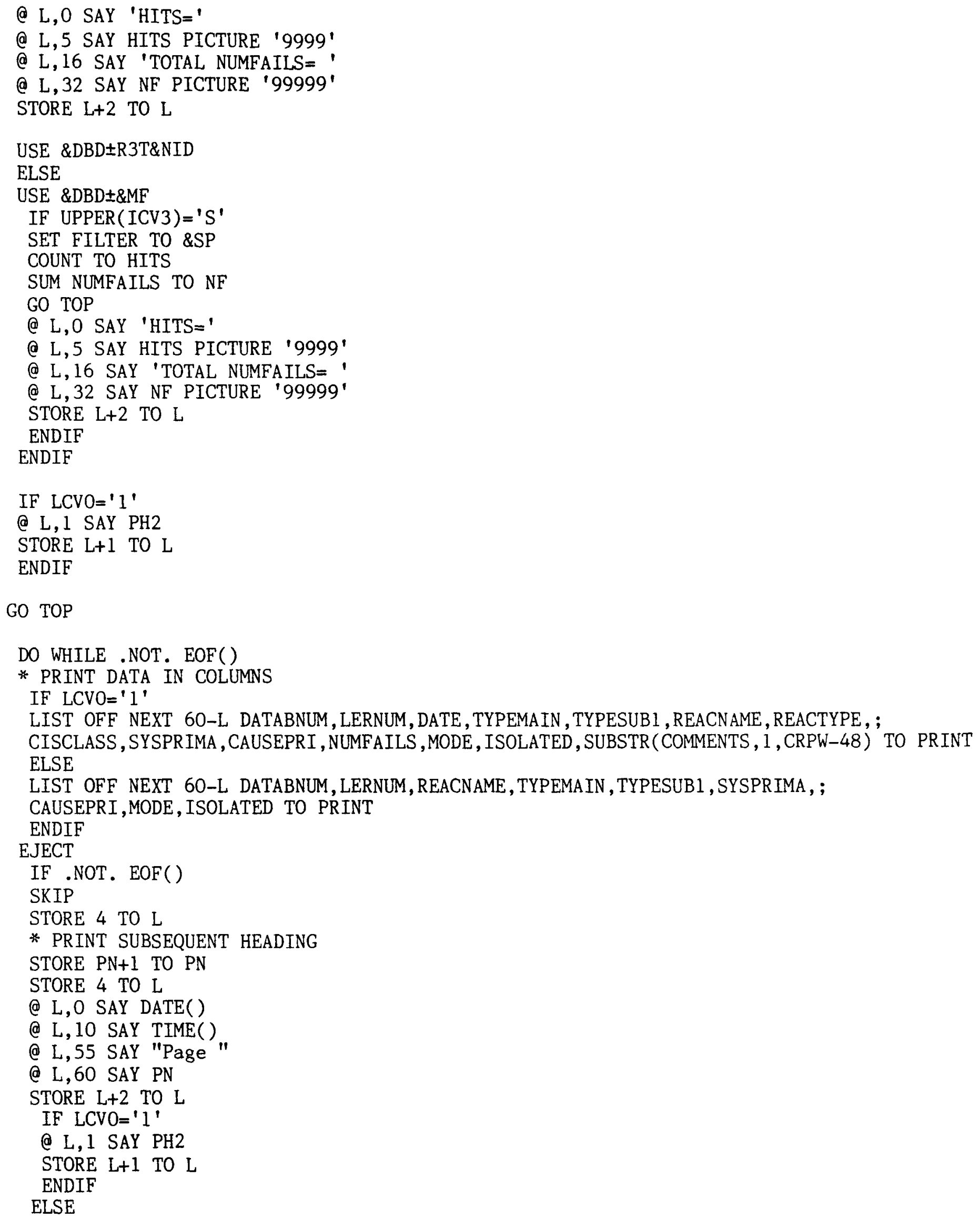


SET PRINT OFF

ENDIF

ENDDO

SET DEVICE TO SCREEN

ELSE

SET DEVICE TO SCREEN

SET COLOR TO \&COLI

CLEAR

STORE 1 TO L

SET COLOR TO \&COL2

* DISPLAY FIRST hEADING

IF MCV2= 'TEMP'

USE \&DBD $\pm R 3 T F C A T$

DO WHILE SERIES $<>M S E R I E S$

SKIP

ENDDO

DO WHILE SERIES+FNUM<=NID.AND . ( . NOT .EOF())

@ L,O SAY UPARAM

STORE L+1 TO L

SKIP

ENDDO

USE \&DBD $\pm R 3 T \& N I D$

ELSE

USE \&DBD $\pm \& M F$

IF UPPER(ICV3) =' $S$ '

SET FILTER TO \&SP

GO TOP

@ L,0 SAY SPU

STORE L+1 TO L

ENDIF

ENDIF

STORE ' ' TO LCV

STORE 1 TO PN

DO WHILE UPPER(LCV $)\langle\rangle^{\prime} X$ '

STORE ' ' TO LCV

DO WHILE .NOT. EOF( ) .AND. UPPER(LCV $)\langle\rangle^{\prime} X$ '

* display data in COLumNS

IF LCVO='1'

SET HEADING OFF

SET COLOR TO \&COL2

@ L, 1 SAY PH2

SET COLOR TO \&COL1

LIST OFF NEXT 23-L DATABNUM, LERNUM, DATE, TYPEMAIN, TYPESUB1, REACNAME, REACTYPE, ; CISCLASS, SYSPRIMA , CAUSEPRI, NUMFAILS , MODE , ISOLATED , SUBSTR(COMMENTS , 1 , 32)

ELSE 
SET COLOR TO \&COL1

LIST OFF NEXT 23-L DATABNUM, LERNUM, REACNAME, TYPEMAIN, TYPESUB1, SYSPRIMA,;

CAUSEPRI, MODE, ISOLATED

ENDIF

IF .NOT. EOF( )

SKIP

SET COLOR TO \&COL5

@ 24,0 SAY 'Screen'

@ 24,7 SAY PN PICTURE '999'

IF $\mathrm{PN}<>1$

@ 24,11 SAY 'N - Next Screen, P - Previous Screen, X - Exit' GET LCV

ELSE

(a 24,11 SAY 'N - Next Screen, X - Exit' GET LCV

ENDIF

READ

STORE PN+1 TO PN

IF UPPER (LCV $)=' P$ ' .AND. $P N<>2$

STORE PN-2 TO PN

SKIP -43

IF .NOT. BOF()

SKIP -1

ENDIF

SET COLOR TO \&COL1

ENDIF

ELSE

SET COLOR TO \&COL5

(d) 24,0 SAY 'Screen '

(e 24,7 SAY PN PICTURE '999'

IF $\mathrm{PN}<>1$

@ 24,11 SAY 'P - Previous Screen, X - Exit' GET LCV

READ

ELSE

@ 24,11 SAY 'Listing complete, press any key to continue' GET LCV

READ

STORE ' $\mathrm{X}$ ' TO LCV

ENDIF

IF UPPER(LCV) $=$ ' $P$ '

STORE PN-1 TO PN

SKIP -43

IF .NOT. BOF()

SKIP -1

ENDIF

SET COLOR TO \&COL1

ELSE

STORE ' $\mathrm{X}$ ' TO LCV

ENDIF

ENDIF

SET COLOR TO \&COL1

CLEAR

STORE 1 TO L

ENDDO

IF EOF()

STORE ' $X$ ' TO LCV

ENDIF

ENDDO 
SET HEADING ON

SET MARGIN TO 0

SET DEVICE TO SCREEN

RETURN 


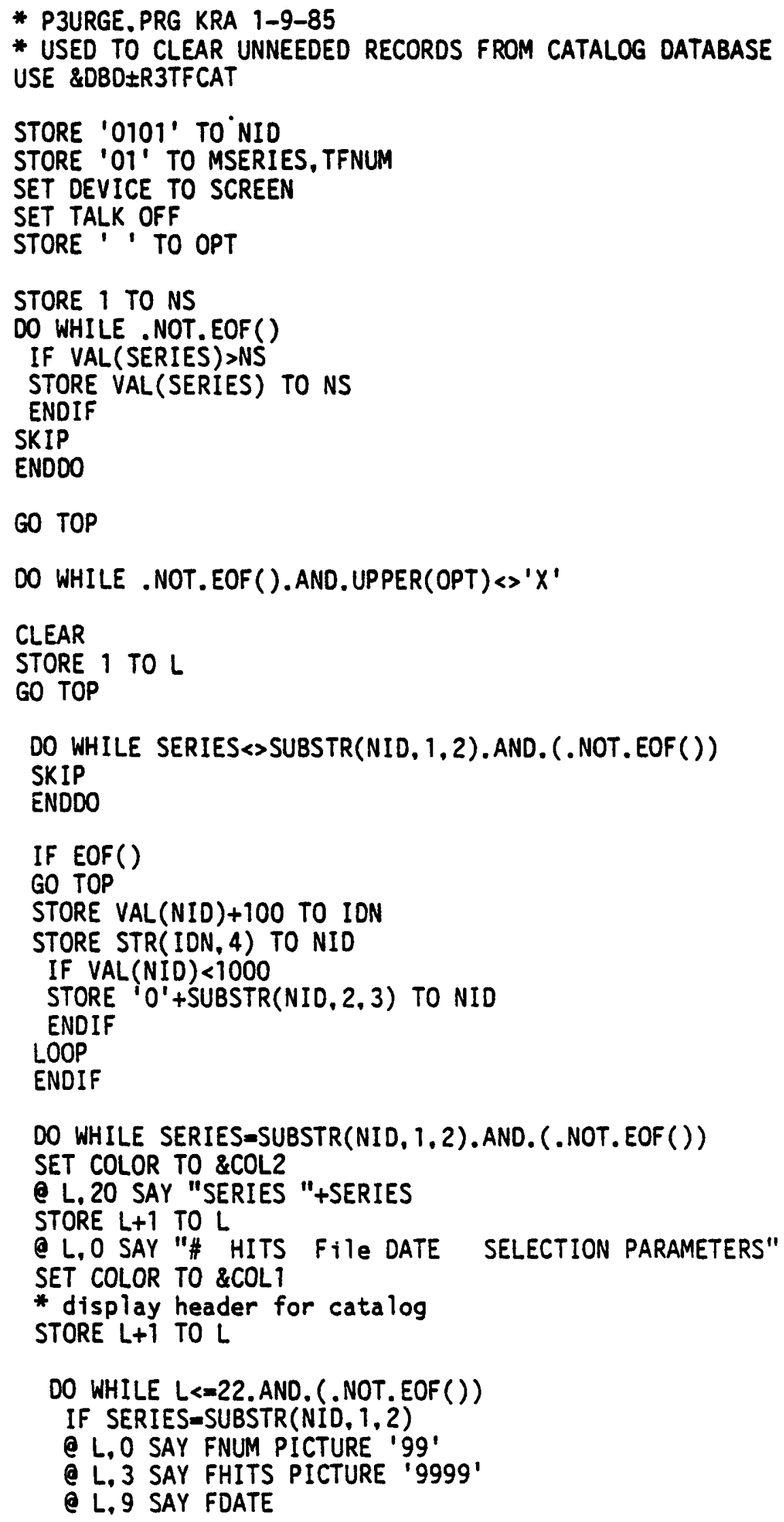




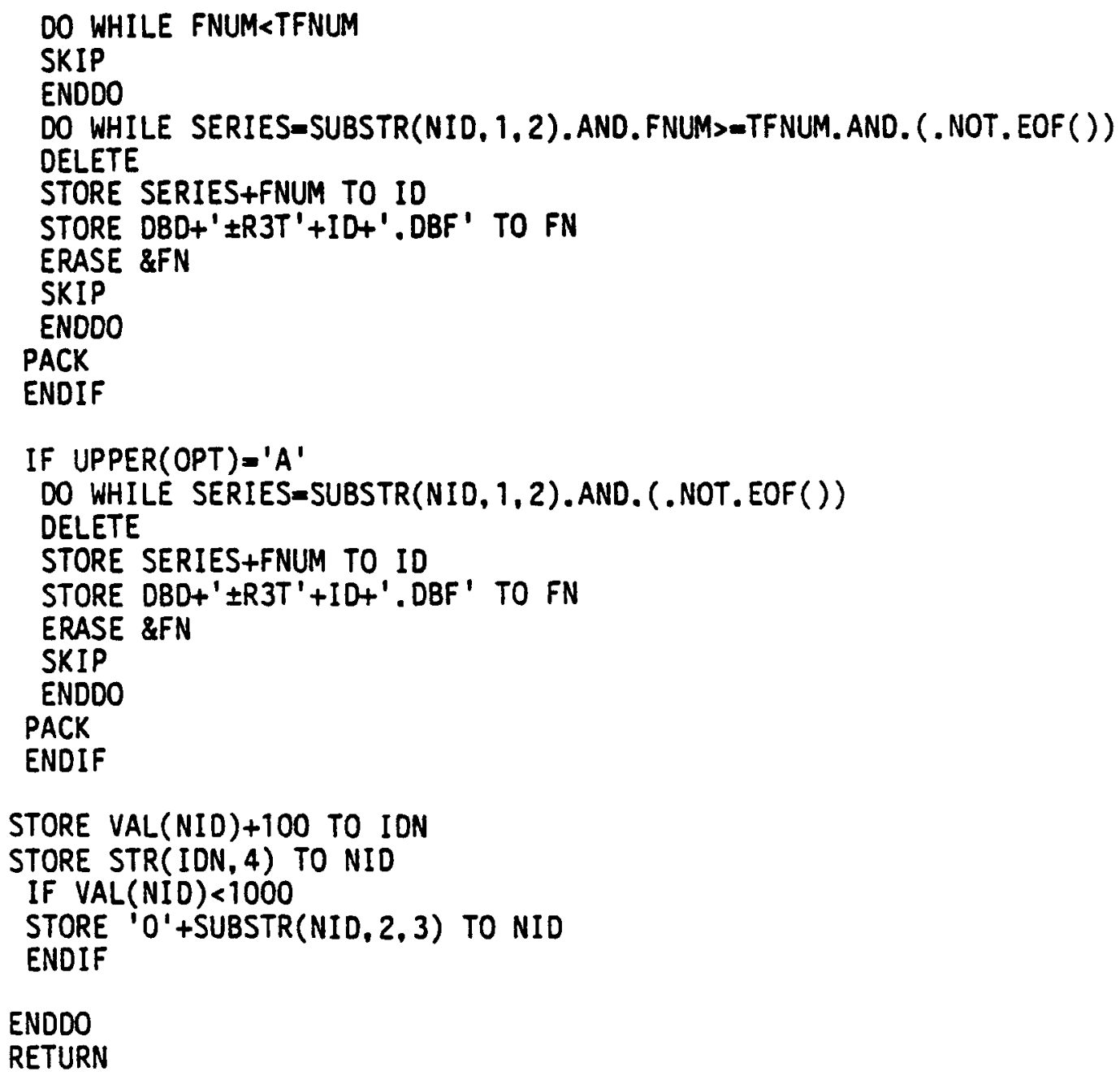


* RISET.PRG 1-17-85 KRA

CLEAR

STORE ' $N$ ' TO CONF

STORE ' $Y$ ' TO COL

STORE DBD+' 'TO DBD

e 3,0 SAY 'Type over any program default setting you want to change'

e 4,0 SAY 'Just press the RETURN for any you want unchanged'

e 6,0 SAY 'Do you want to work with all 29 fields or only 14 ' GET MCV

e 7.0 SAY 'You can have the program act as soon as you enter the commands,'

8,0 SAY 'or you can have the computer wait for a confirming RETURN'

9.0 SAY 'Do you want to confirm?' GET CONF

a 10,0 SAY 'Wt 11 you be using a color screen?' GET COL

e 11.0 SAY 'What is the designation of the disk and subdirectory (if any)'

a 12,0 SAY 'where your database files will be? ' GET OBD

e 13,0 SAY 'What is the name of your Master File? ' GET MF

TEXT

If you choose to work with only 14 fields, in the cases where the program displays entire records on the screen or outputs them to the printer, the program will decode the coded fields, such as the type of component, the name of the reactor, the name of the system which the failure occured in, and the primary cause of the failure.

ENDTEXT

IF OPT ' 'RF'

SET COLOR TO \&COL 3

e 20,0 SAY 'You must reset Master File name or drive designation before proceeding.' 21,0 SAY 'The one currentiy set, '+TRIM(DBD)+' \pm ' $+M F+'$ ', does not exist'

SET COLOR TO \&COL1

ENDIF

IF OPT $=$ 'RP'

SET COLOR TO \&COL 3

e 20,0 SAY 'You must reset drive designation before proceeding.'

e 21,0 SAY 'There is no catalog of search files on the one currently set.'

SET COLOR TO \&COL1

STORE 'RP' TO OPT

ENDIF

READ

IF UPPER(CONF) $=^{\prime} Y$ '

SET CONFIRM ON

ELSE

SET CONFIRM OFF

ENDIF

IF UPPER(COL) $=$ ' $Y$ '

STORE $' 6+/ 1,3+/ 1,1$ ' TO COL 1

STORE ' $3+/ 1,6+/ 1,1$ ' TO COL2

STORE $17+/ 4,3+11,1$ ' TO COL3

STORE $' 6 / 1,3 / 1,1 '$ TO COL 4

STORE $' 2+/ 1,6+/ 1,1$ ' TO COL5 


\section{ELSE \\ STORE ${ }^{\prime} 7+/ 0,0 / 7,0^{\prime}$ TO COL 1 STORE ' $7 / 0,0 / 7,0 '$ TO COL2 STORE ' $0 / 7,0 / 7,0$ ' TO COL 3 STORE $' 0+/ 0,7 / 0,0$ ' TO COL 4 STORE $17 / 0,0 / 7,0^{\prime}$ TO COL 5 ENDIF}

SET COLOR TO \&COL 1

STORE TRIM(DBD) TO DBD

RETURN 
* R1MI.PRG 2-5-85 KRA

* MEMORY INITIALIZING PROGRAM

STORE 'Electric motor operated (AC)' TO TMVA

STORE 'Electric motor operated (DC)' TO TMVB

STORE 'Hydraulic operated' TO TMVC

STORE 'Pneumatic diaphragm/cylinder operated' TO TMVD

STORE 'Solenoid operated (AC)' TO TMVE

STORE 'Solenoid operated (DC)' TO TMVF

STORE 'Float operated' TO TMVG

STORE 'Explosive squib operated' TO TMVH

STORE 'Mechanically operated' TO TMVJ

STORE 'Electric motor operated (unspecified)' TO TMVK

STORE 'Solenoid operated (unspecified)' TO TMVL

STORE 'Manually operated' TO TMVM

STORE 'Remotely operated' TO TMVN

STORE 'Damper' TO TMVP

STORE 'Vacuum breaker' TO TMVQ

STORE 'Relief or safety' TO TMVR

STORE 'Check' TO TMVS

STORE 'Other' TO TMVX

STORE 'Personal access' TO TMPA

STORE 'Fuel handling' TO TMPB

STORE 'Equipment access' TO TMPC

STORE 'Electrical' TO TMPD

STORE 'Instrument line' TO TMPE

STORE 'Process piping' TO TMPF

STORE 'Access (unspecified)' TO TMPG

STORE 'Other' TO TMPX

STORE 'Ark Nuc. One' TO RNAR

STORE 'Browns Ferry' TO RNBF

STORE 'Bellefonte' TO RNBL

STORE 'Big Rock Point ' TO RNBP

STORE 'Brunswick' TO RNBR

STORE 'Beaver Valley' TO RNBV

STORE 'Braidwood' TO RNBW

STORE 'Byron' TO RNBY

STORE 'Catawba' TO RNCA

STORE 'Calvert Cliffs' TO RNCC

STORE 'Clinton' TO RNCL

STORE 'Cooper Station' TO RNCO

STORE 'Commanche Peak' TO RNCP

STORE 'Crystal River' TO RNCR

STORE 'Carroll County' TO RNCT

STORE 'Callaway' TO RNCW

STORE 'Duane Arnold ' TO RNDA

STORE 'Davis-Besse' TO RNDB

STORE 'D.C. Cook' TO RNDC

STORE 'Diablo Canyon' TO RNDO

STORE 'Dresden' TO RNDR

STORE 'Enrico Fermi' TO RNEF

STORE 'E.I. Hatch' TO RNEN

STORE 'Fort Calhoun ' TO RNFC

STORE 'J.A. Fitzpatrick' TO RNFP

STORE 'Fort St. Vrain' TO RNFV 
STORE 'Grand Gulf' TO RNGG

STORE 'Humboldt Bay' TO RNHB

STORE 'Hope Creek' TO RNHC

STORE 'Haddam Neck (CT Yankee)' TO RNHN

STORE 'Indian Point' TO RNIP

STORE 'J.M. Farley' TO RNJF

STORE 'Kewaunee' TO RNKE

STORE 'LaCrosse BWR ' TO RNLB

STORE 'Limerick' TO RNLM

STORE 'LaSalle' TO RNLS

STORE 'McGuire' TO RNMG

STORE 'Millstone' TO RNMI

STORE 'Monticello ' TO RNMO

STORE 'Maine Yankee' TO RMMY

STORE 'North Anna' TO RNNA

STORE 'Nine Mile Pt.' TO RNMM

STORE 'Oyster Creek' TO RNOC

STORE 'Oconee' TO RNOE

STORE 'Palisades ' TO RNPA

STORE 'Peach Bottom' TO RNPB

STORE 'Pilgrim' TO RNPI

STORE 'Prairie Is.' TO RNPR

STORE 'Point Beach' TO RNPT

STORE 'Palo Verde' TO RNPV

STORE 'Perry' TO RNPY

STORE 'Quad Cities' TO RNQC

STORE 'River Bend' TO RNRB

STORE 'R.E. Ginna ' TO RNRG

STORE 'H.B. Robinson' TO RNRO

STORE 'Rancho Seco ' TO RNRS

STORE 'Salem' TO RNSA

STORE 'Sequoyah' TO RNSE

STORE 'Shearon Harris' TO RNSH

STORE 'St. Lucie' TO RNSL

STORE 'Shoreham ' TO RNSM

STORE 'San Onofre' TO RNSO

STORE 'Susquehanna' TO RNSS

STORE 'South Texas Project' TO RNST

STORE 'Surry' TO RNSU

STORE 'Three Mile Is.' TO RNTI

STORE 'Trojan ' TO RNTR

STORE 'Turkey Point' TO RNTU

STORE 'Vogtle' TO RNVG

STORE 'V.C. Summer' TO RNVS

STORE 'Vermont Yankee' TO RNVY

STORE 'Watts Bar' TO RNWB

STORE 'Waterford' TO RNWF

STORE 'WNP' TO RNWP

STORE 'Yankee Rowe' TO RNYR

STORE 'Zion' TO RNZI

STORE 'Zimmer' TO RNZM

STORE '01, Reactor coolant' TO PSO1

STORE '02, Main steam' TO PSO2

STORE '03, High pressure injection/recirc.' TO PSO3 
STORE '04, Low pressure injection/recirc.' TO PSO4

STORE '05, Instrument air' TO PSO5

STORE '06, Service air' TO PSO6

STORE '07, Air (unspecified)' TO PSO7

STORE 'OO, Service water' TO PS08

STORE '09, Residual heat removal' TO PSO9

STORE '10, Containment HVAC' TO PS10

STORE '12, Integrated leak rate test' TO PS12

STORE '13, Fire protection' TO PS13

STORE '15, Component cooling water' TO PS15

STORE '16, Radwaste' TO PS16

STORE '18, Main feedwater' TO PS18

STORE '19, Auxiliary feedwater' TO PS19

STORE '99, Other' TO PS99

STORE '11, Drywel1 pressure' TO PSB11

STORE '14, Drywell atmosphere' TO PSB14

STORE '17, Drywell waste gas' TO PSB17

STORE '20, Reactor core isolation cooling' TO PSB2O

STORE '21, Standby 1iquid control' TO PSB21

STORE '22, Reactor cleanup' TO PSB22

STORE '23, Drywell purge' TO PSB23

STORE '24, Drywell vent' TO PSB24

STORE '25, Drywell equipment sump' TO PSB25

STORE '26, Drywell floor sump' TO PSB26

STORE '27, Drywell sump (unspecified)' TO PSB27

STORE ' 28 , Control rod drive' TO PSB28

STORE ' 29 , Core spray' TO PSB29

STORE ' 30 , Vessel head spray' TO PSB30

STORE '31, Containment cooling' TO PSB31

STORE ' 32 , Traversing incore probe' TO PSB32

STORE '33, Torus (wetwel1) vent' TO PSB33

STORE '34, Vacuum relief' TO PSB34

STORE ' 35 , Drywell instrumentation (elec.)' TO PSB35

STORE '36, Torus (wetwel1) inst. (elec.)' TO PSB36

STORE ' 37 , Nitrogen supply' TO PSB37

STORE '38, Torus (wetwel1) purge' TO PSB38

STORE '11, Containment pressure' TO PSP11

STORE '14, Containment atmosphere' TO PSP14

STORE '17, Containment waste gas' TO PSP17

STORE '20, Pressurizer' TO PSP20

STORE '21, Safety injection' TO PSP21

STORE '22, Demineralized water' TO PSP22

STORE '23, Containment sump' TO PSP23

STORE '24, Steam generator' TO PSP24

STORE '25, Containment large - volume purge' TO PSP25

STORE ' 26 , Containment smal1 - volume purge' TO PSP26

STORE '27, Containment hydrogen purge' TO PSP27

STORE ' 28 , Containment purge (unspecified)' TO PSP28

STORE '29, Nitrogen supply' TO PSP29

STORE ' 30 , Containment spray' TO PSP30

STORE ' 31 , Chemical volume control' TO PSP31

STORE ' 32 , Refueling canal' TO PSP32

STORE ' 33 , Containment instrumentation (elec.)' TO PSP33

STORE '00, unknown' TO CAU100

STORE '01, personnel (operation)' TO CAU101 
STORE' '02, personnel (maintenance)' TO CAU102

STORE '03, personnel (testing)' TO CAU103

STORE '04, design error' TO CAU104

STORE '05, fabrication/construction/QC' TO CAU105

STORE '06, procedural discrepancy' TO CAU106

STORE '07, normal wear' TO CAU107

STORE '08, excessive wear' TO CAU108

STORE '09, corrosion' TO CAU109

STORE '10, foreign material contamination' TO CAU110

STORE ' 11 , excessive vibration' TO CAU111

STORE '12, mech. control/parts failed or out of adjustment' TO CAU112

STORE '13, seal/gasket fail/prob.' TO CAU113

STORE '14, packing fail/prob.' TO CAU114

STORE '15, bellows/boot fail/prob.' TO CAU115

STORE '16, electrical input fail/prob. (electrical power interrupt)' TO CAU116

STORE '17, bearing/bushing fail/prob.' TO CAU117

STORE '18, weld failure' TO CAU118

STORE '19, lack of 1ubrication' TO CAU119

STORE '20, electric motor operator fail/prob.' TO CAU120

STORE '21, electric solenoid fail/prob.' TO CAU121

STORE '22, leaking/ruptured diaphragm' TO CAU122

STORE '23, torque switch fail/prob.' TO CAU123

STORE '24, failure of component supply system (air supply interrupt)' TO CAU124

STORE '25, seat/disc fail/prob.' TO CAU125

STORE '26, limit switch fail/prob.' TO CAU126

STORE '27, pilot valve fail/prob.' TO CAU127

STORE '28, air solenoid fail/prob.' TO CAU128

STORE '29, solenoid (unspecified) fail/prob.' TO CAU129

STORE '30, operator (unspecified) fail/prob.' TO CAU130

STORE ' 31 , penetration sealant fail/prob.' TO CAU131

STORE ' 32 , personnel (construction)' TO CAU132

STORE '33, rupture' TO CAU133

STORE ' 34 , equalizing valve (on air lock) fail/prob.' TO CAU134

STORE '35, hydraulic operator fail/prob.' TO CAU135

SAVE ALL LIKE TM* TO TMCODE

SAVE ALL LIKE RN* TO RNCODE

SAVE ALL LIKE PS* TO PSCODE

SAVE ALL LIKE CAU* TO CAUCODE

RELEASE ALL LIKE TM*

RELEASE ALL LIKE RN*

RELEASE ALL LIKE PS*

RELEASE ALL LIKE CAU*

STORE "RECNO( )" TO FNOO

STORE "DATABNUM" TO FNO1

STORE "LERNUM" TO FNO2

STORE "REVISNUM" TO FNO3

STORE "ACCESNUM" TO FNO4

STORE "ENTRYNUM" TO FN05

STORE "TYPEMAIN" TO FNO6

STORE "TYPESUBI" TO FNO7

STORE "TYPESUB2" TO FN08

STORE "LOCATION" TO FN09

STORE "MFG" TO FN10

STORE "REACNAME" TO FN11

STORE "REACTYPE" TO FN12 
STORE "REACNSSS" TO FN13

STORE "CISCLASS" TO FN14

STORE "SYSPRIMA" TO FN15

STORE "SYSSECON" TO FN16

STORE "SYSDES" TO FN17

STORE "NUMFAILS" TO FN18

STORE "DATE" TO FN19

STORE "POWERLEV" TO FN2O

STORE "MODE" TO FN21

STORE "CAUSEPRI" TO FN22

STORE "CAUSESEC" TO FN23

STORE "DURATION" TO FN24

STORE "ISOLATED" TO FN25

STORE "DISCOVER" TO FN26

STORE "CORRECTS" TO FN27

STORE "RELLER" TO FN28

STORE "COMMENTS" TO FN29

SAVE ALL LIKE FN* TO FNCODE

RELEASE ALL LIKE FN*

STORE "RECNO()" TO FNOO

STORE "DATABNUM" TO FNO1

STORE "LERNUM" TO FNO2

STORE "TYPEMAIN" TO FN03

STORE "TYPESUBI" TO FNO4

STORE "REACNAME" TO FN05

STORE "REACTYPE" TO FNO6

STORE "CISCLASS" TO FNO7

STORE "SYSPRIMA" TO FNO8

STORE "NUMFAILS" TO FN09

STORE "DATE" TO FN10

STORE "MODE" TO FNII

STORE "CAUSEPRI" TO FN12

STORE "ISOLATED" TO FN13

STORE "COMMENTS" TO FN14

SAVE ALL LIKE FN* TO FNLCODE

RELEASE ALL LIKE FN*

RETURN 
* R3GLOSO.PRG 11-8-84 KRA

* SCREEN NUMBER 0

TEXT

GLOSSARY FOR CIS-RELATED LLER DATABASE

DATABNUM Four digit identification number assigned by PNL.

LERNUM Number assigned to the Licensee Event Report (LER) by the NRC. The first two digits are the year of the LER.

REVISNUM Some LER's are revised. This is the number of the revision. Original LER's will have a revision number of 0 .

ACCESNUM Last six digits of the accession number assigned by the NRC.

ENTRYNUM In the case where components have repeated failures, they may generate multiple LER's. For first failures, this will be 1 . 2 for second fajlures, etc.

TYPEMAIN $V$ indicates a valve failure, $P$ a penetration failure

\section{ENDTEXT}

RETURN

* r3glos1. PRg 9-18-84 KRA

* SCREEN NUMBER 1

TEXT

TYPESUB 1

For a penetration:

$A=$ personal access

$B=$ fuel handling

$C=$ equipment access

$D=$ electrical

$E=$ instrument line

$F=$ process piping

$G=$ access (unspecified)

For a valve:

$A=$ electric motor operated (AC)

$B=$ electric motor operated (DC)

$C=$ hydraulic operated

$D$ - pneumatic diaphragm/cylinder operated

$E$ = solenoid operated $(A C)$

$F=$ solenoid operated (DC)

$X=$ other

$G$ = float operated

$H=$ explosive squib operated

$J=$ mechanically operated

$K=$ electric motor operated (unspecified)

$L=$ solenoid operated (unspecified)

$M=$ manually operated

$N=$ remotely operated

$P=$ damper

$Q=$ vacuum breaker

$R=$ relief or safety

$S=$ check

$X=$ other

ENDTEXT

RETURN 
* R3GLOS2.PRG

* SCREEN NUMBER 2

(a 1,0 SAY 'TYPESUB2

(a) 2,0 SAY

a 3,0 SAY 'No designations

(a 4,0 SAY 'for penetrations

(a) 5,0 SAY

@ 6,0 SAY

a 7,0 SAY

e 8,0 SAY

c 9,0 SAY

@ 10,0 SAY '

(a) 11,0 SAY

@ 12,0 SAY

@ 13,0 SAY

(a) $14,0 \mathrm{SAY}$

(a) 15,0 SAY

@ 17,0 SAY

@ 18,0 SAY

(a) 19,0 SAY

@ 20,0 SAY

@22,0 SAY 'MFG

(a) 23,0 SAY RETURN

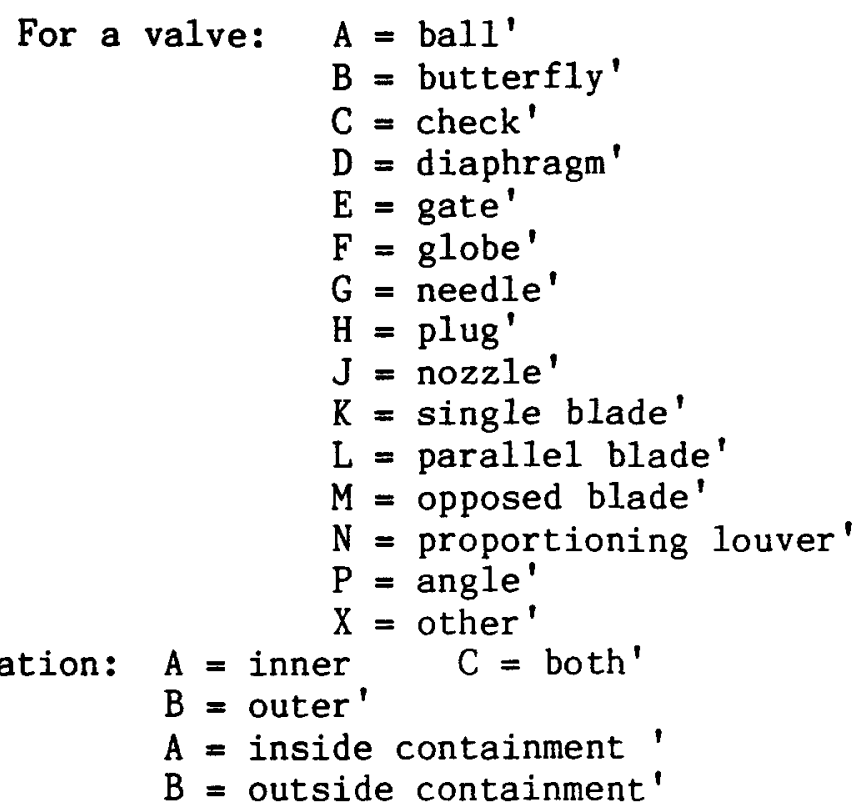

Manufacturer of the valve or penetration that failed, indicated by' the four-character identifier from Exhibit $J$ of NUREG-0161.' 
R3GLOS3.PRG 1-17-85 KRA

* SCREEN NUMBER 3

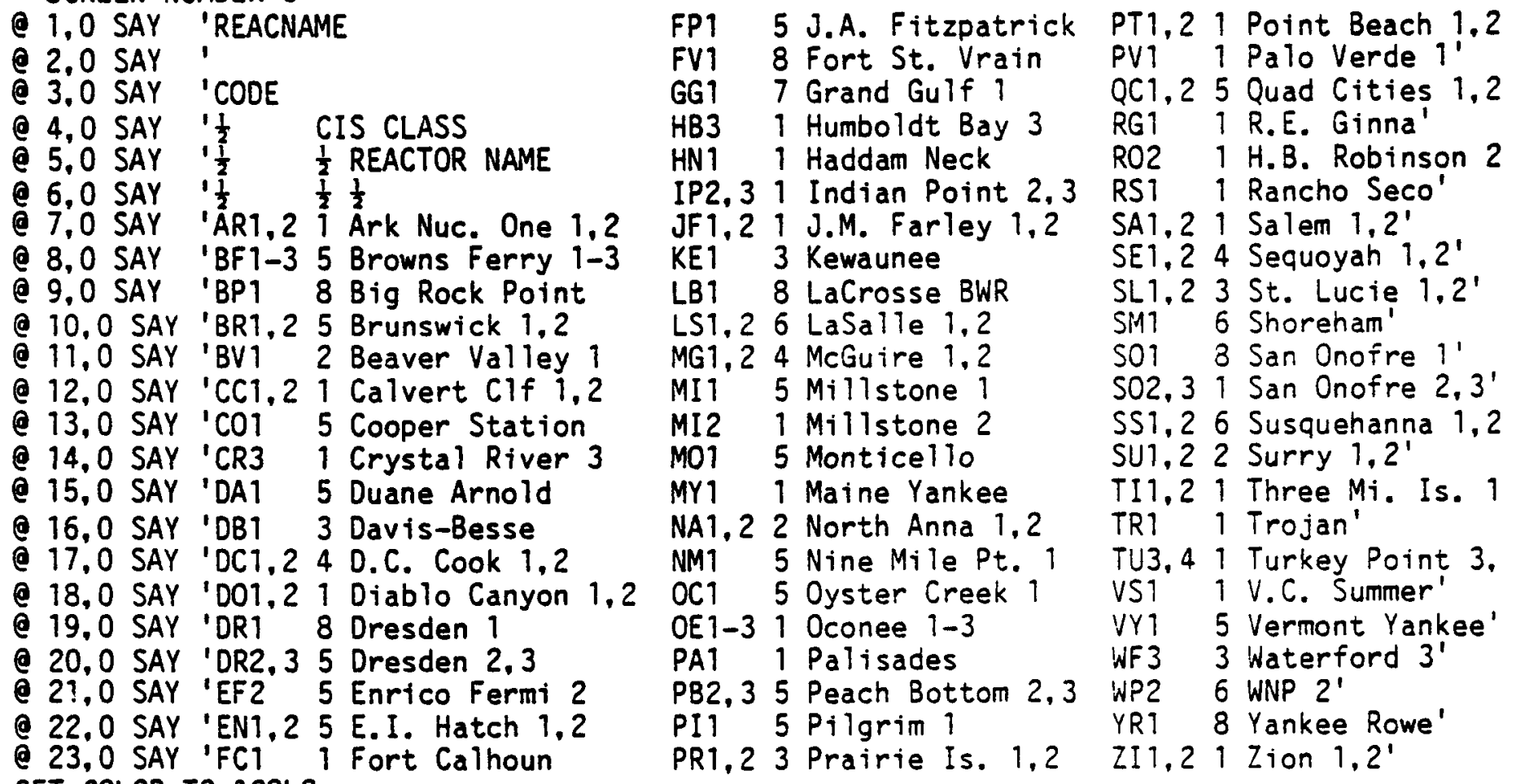

SET COLOR TO \&COL2

WAIT'1984 Current List, do you want list for newer plants? Y/N' TO GCV

SET COLOR TO \&COL1

IF UPPER(GCV) $=$ ' $Y$ '

\section{CLEAR}

Q 1.0 SAY 'REACNAME'

e 3.0 SAY

e 4,0 SAY

e 5,0 SAY

e 6,0 SAY

e 7.0 SAY

e 8.0 SAY

e 9,0 SAY

'CODE'

' $\frac{1}{2}$ CIS CLASS'

' $\frac{1}{2} \frac{1}{2}$ REACTOR NAME'

'BL1,2 Bellefonte 1,2'

'BW1,2 Braidwood 1,2'

'BY1,2 Byron 1,2'

CWT, 2

Callaway $1,2^{\prime}$

e 10,0 SAY 'CAT,2

e 11,0 SAY 'CT1,2

e 12,0 SAY 'CL1

Catawba 1,2'

Carroll County 1,2'

Clinton 11

e 13,0 SAY 'CP1, 2

e 14,0 SAY ' $\mathrm{HCT}$

Commanche Peak 1,2'

อ 15,0 SAY 'LMI, 2

Hope Creek ' '

Limerick 1,2'

e 16.0 SAY 'PY1.2

Perry 1,2'

e 17.0 SAY 'RB1

River Bend $1 '$

e 18,0 SAY 'SH1

Shearon Harris'

e 19,0 SAY 'ST1,2

S. Texas Project 1,2'

e 20,0 SAY 'VG1,2

Vogtle 1,2'

21,0 SAY 'WB1, 2

e 22,0 SAY 'WC1

Watts Bar 1,2'

e 23,0 SAY 'ZMI

Wolf Creek'

Zimmer 11

STORE ' ' TO GCV

ELSE

STORE ' ' TO GCV

RETURN

ENDIF 


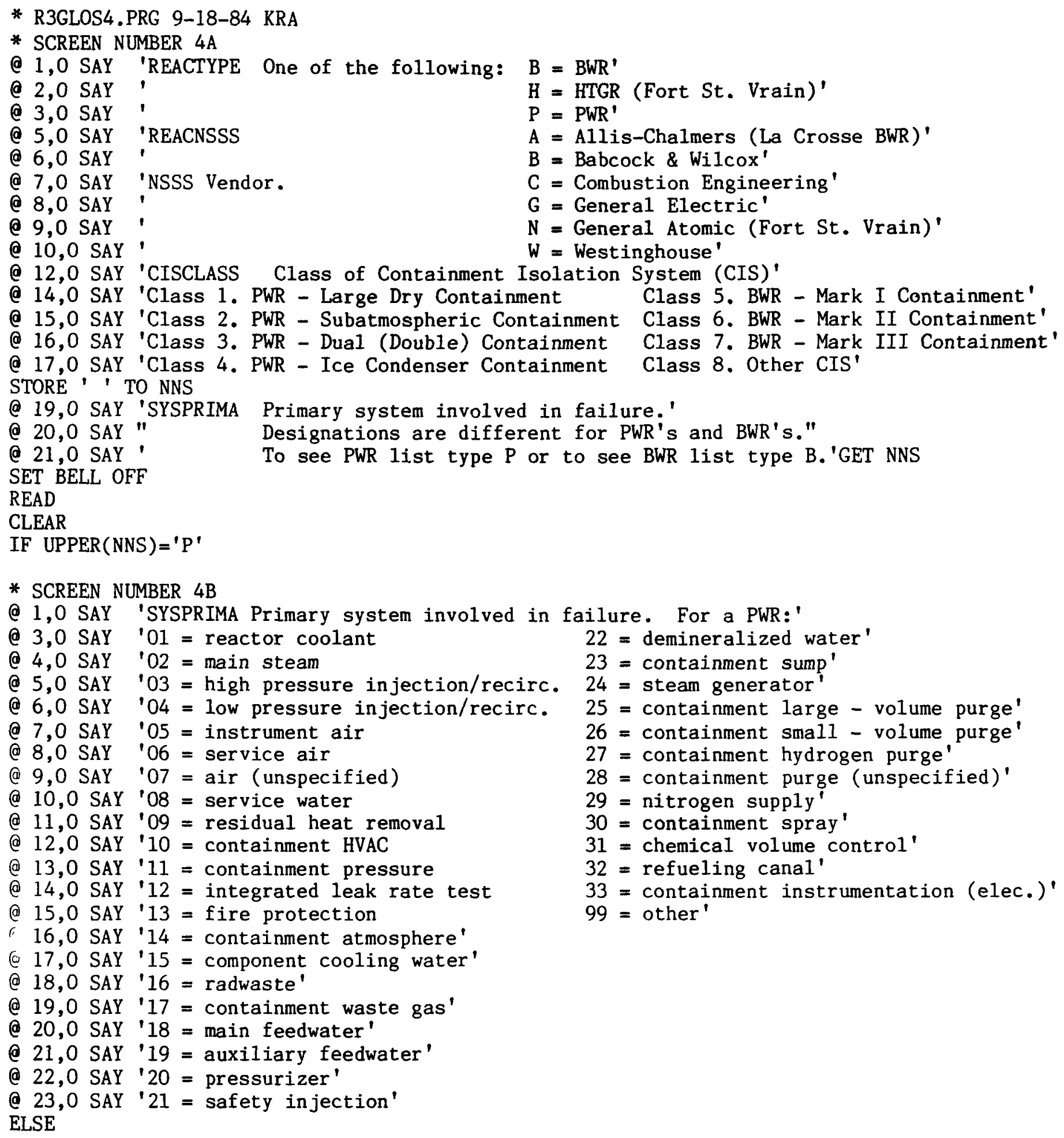


(a 6,0 SAY ' $04=$ low pressure injection/recirc.

e 7,0 SAY '05 = instrument air

e 8,0 SAY ' 06 = service air

(a 9,0 SAY ' $07=$ air (unspecified)

(a 10,0 SAY '08 = service water

(e 11,0 SAY ' 09 = residual heat removal

(a 12,0 SAY ' $10=$ containment HVAC

(a 13,0 SAY ' 11 = drywell pressure

a 14,0 SAY ' 12 = integrated leak rate test

(a $15,0 \mathrm{SAY} ' 13$ = fire protection

(a) 16,0 SAY ' 14 = drywell atmosphere

e 17,0 SAY ' 15 = component cooling water

(a) 18,0 SAY ' 16 = radwaste

(a 19,0 SAY ' 17 = drywell waste gas

(a) 20,0 SAY ' 18 = main feedwater

(a 21,0 SAY ' 19 = auxiliary feedwater'

(a 22,0 SAY ' $20=$ reactor core isolation cooling'

(a 23,0 SAY ' 21 = standby liquid control'

ENDIF

RETURN
$25=$ drywell equipment sump'

26 = drywell floor sump'

27 = drywell sump (unspecified)'

$28=$ control rod drive'

$29=$ core spray'

$30=$ vessel head spray'

31 = containment cooling'

32 = traversing incore probe'

33 = torus (wetwell) vent'

34 = vacuum relief'

$35=$ drywell instrumentation $(\text { elec. })^{\prime}$

$36=$ torus (wetwell) inst. (elec.)'

37 = nitrogen supply'

38 = torus (wetwell) purge'

99 = other 
* R3GLOS5.PRG 9-18-84 KRA

* SCREEN NUMBer 5

a 1.0 SAY 'SYSSECON The secondary system identifiers are provided to permit additional 2.0 SAY 'specification of the system.

e 4.0 SAY '01 = sample 10 = pump

5,0 SAY '02 = sensor/monitor 11 = heat exchanger

e 6.0 SAY '03 = drain

2 7,0 SAY '04 = emergency

$12=\tan k$

8,0 SAY 105 = makeup

13 = sea 1 '

e 9,0 SAY '06 = auxiliary

e 10,0 SAY ' 07 = test

e 11,0 SAY '08 = blowdown

e 12,0 SAY 'O9 = cooling'

e 15,0 SAY 'SYSDES A free field to allow additional system description as needed.'

e 17,0 SAY 'NUMFAILS Number of failures reported in the LER, 1 unless specified'

อ 18,0 SAY '"

RETURN

* R3GLOS6.PRG 1-17-85 KRA

* SCREEN NUMBER 6

a 1,0 SAY 'DATE

2,0 SAY

4.0 SAY 'POWELEV

14 - leakage control

For example, a reactor coolant'

pump seal supply line would have

the following system identifiers:

15 - recirculation

Primary $=01^{\prime}$

16 - turbine'

Secondary $=10,13 .^{\prime}$

6,0 SAY 'MODE

8.0 SAY '

e 9,0 SAY

e 10,0 SAY '

Date of failure event in six-digit code, e.g..'

830812 - August 12. 1983.'

Percent of full power of reactor when failure occurred.'

One of the following failure modes:'

$A=$ leakage (fail to seal)'

$B=$ fail to close'

$C$ = unplanned opening (fail to remain closed)'

2 13,0 SAY 'Fallure mode B refers to failures in which the component does not close'

e 14,0 SAY 'within a reasonable time limit, thereby constituting a potential failure to'

e 15,0 SAY 'isolate containment.'

21,0 SAY '

RETURN 


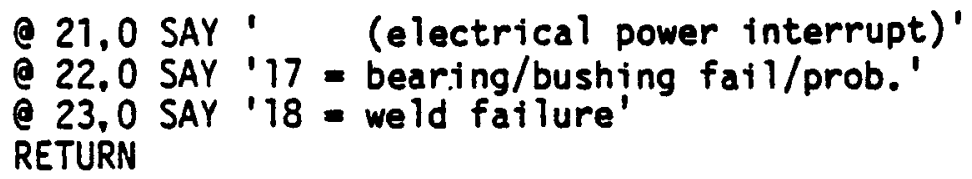

The action(s) taken to return the failed component' to service. One or two of the following: ' 


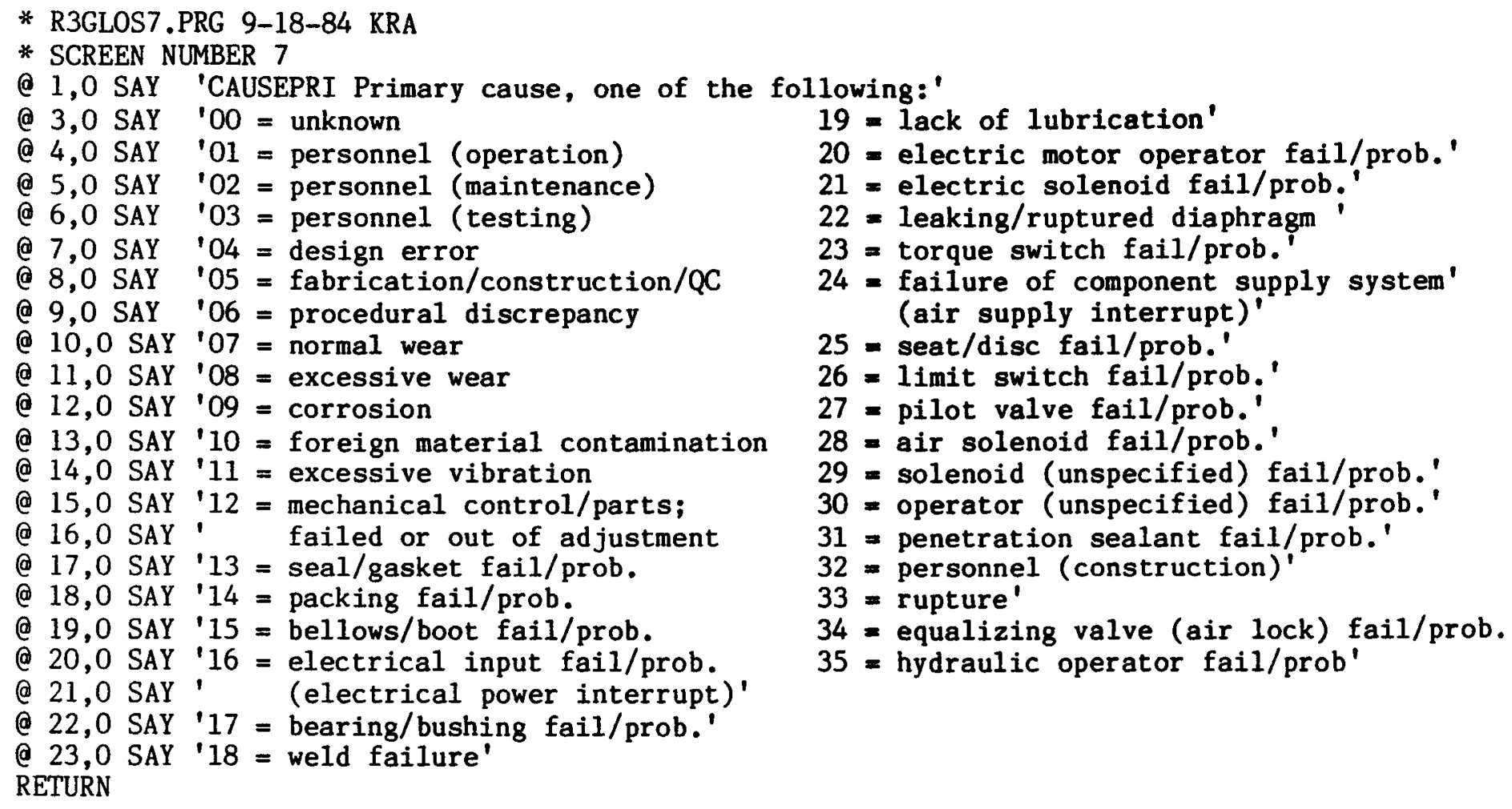


* Delay.PRG

STORE I TO $\mathrm{N}$

DO WHILE N<100

STORE $\mathrm{N}+1$ TO N

ENDDO

ENDIF

A. 147 


\section{TECHNICAL ASSISTANCE}

This program and user manual was written by Ken Ames at Battelle Pacific Northwest Laboratories. For technical help write to him at:

Battelle Northwest

Box 999

Richland, WA 99352

or phone 5093753930 (remember, this is Pacific time zone) 


\section{APPENDIX B}

STRUCTURE OF LER DATA BASE 


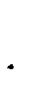




\section{APPENDIX B}

\section{STRUCTURE OF LER DATA BASE}

This appendix contalns an example of the LER coding form and corresponding instructions used to revlew the LERs; the definition of the information fields used In the computer deto base; and a IIsting of plant classes and plants included in the data base. As discussed in the main report, information was not always avallable for many of the. Information flelds. 


\section{LER COOING FORM}

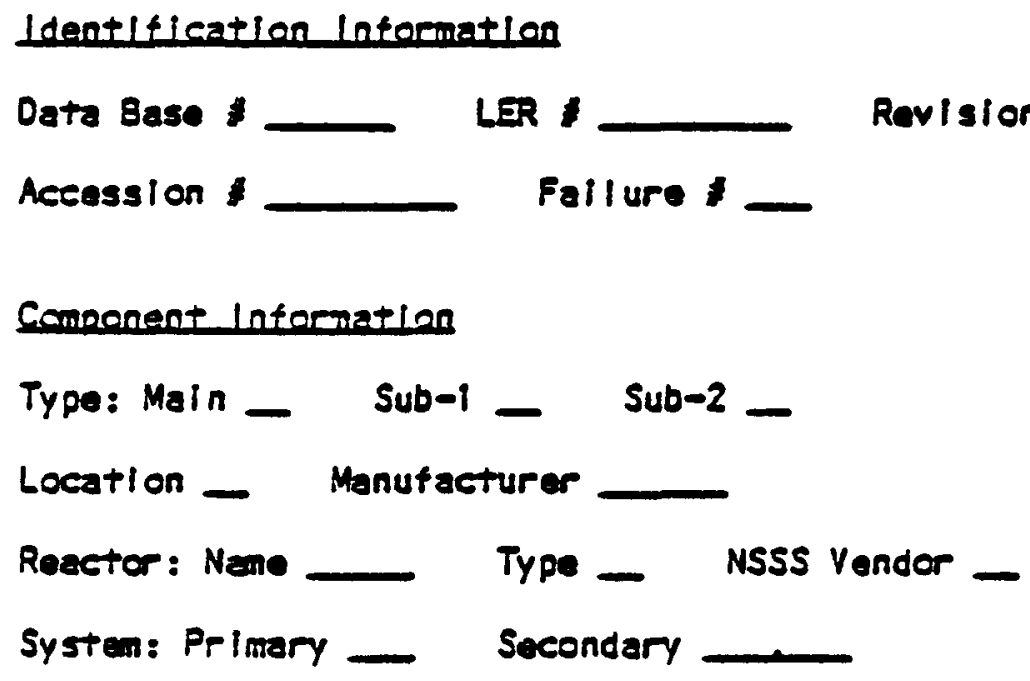

\section{Comments}




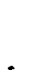


The following is a list of instructions for completing each entry in the LER Coding Form. Where no information is avallable, leave an entry blank.

Ldentification Intormation

Data Base *. Number (1-3100) listed for the NSIC data base entry.

LER f. Fiverdigit number assigned to the LER.

Revision . Number of revision to original LER (assign a zero to the original LERI.

Accession. The six digits following $00 z 0$ of the accession number (last six digits of the accession number).

Failure 3 . The number of the fallure described by the LER. This entTy enables one to provide a unique identifier to each fail $\mathrm{dre}$ descrlbed by an Individual LER since some LERs accress multiplo fallures. Always assign a $l$ as the failure number for an $L E R$ describing only one fallure.

\section{Comoonent Intormation}

Type: Main. Either a P (penetration) or V (valve).

Type: Sub-1. For a penetration:

$$
\begin{aligned}
& A=\text { personnel eccess } \\
& B=\text { fuel handling } \\
& C=\text { equi pment access } \\
& D=\text { electrical } \\
& E=\text { instrument I ine } \\
& F=\text { process piping } \\
& G=\text { access (unspecified) } \\
& X=\text { other }
\end{aligned}
$$




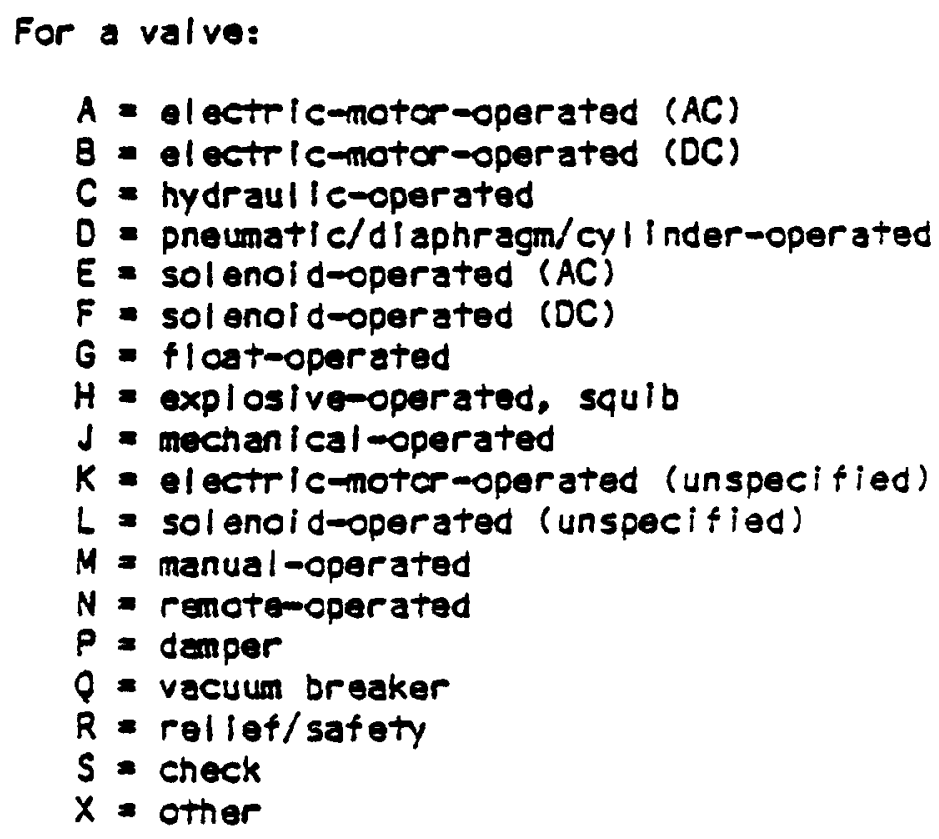

Type: Sub-2. For a penetration: no identlfiers currently anticicated.

For a valve:

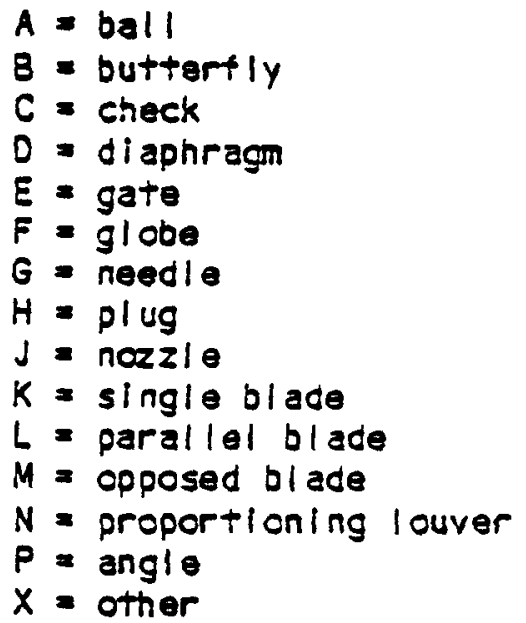

/For a valve designated in an LER solely as a diaphragn or a check valve, use the subtype-1 identifier and omit the subtyse-2 icentitier.l

Lccation. For a penetration (currently presumed apolicaole only is accesses with double doors):

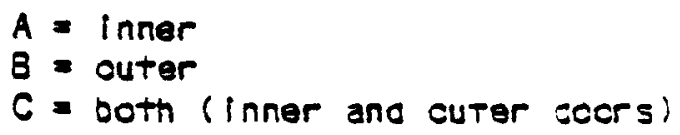

For a valve:

$A=$ inslde containment

$B$ a outside containment 
Maufacturer: The four-character Identifier fram Exhibit $\downarrow$ of NUREG-0161.

Reector: Nane. The three-character code from Table 8-1 of NUREG/CR-1730. A supplement to this table is provided at the end of these instructions which updates the table to include all reactors operating or scheduled to be operating by the end of 1984 . Also note the following updates in Table B-1:

- Arkansas Nuclear One 2 commenced operation on $3 / 26 / 80$

- North Anne 1 commenced operation on $6 / 6 / 78$

- Eduin 1. Hatch 2 commenced operation on $9 / 5 / 79$.

Reactor: Type. One of the following:

$$
\begin{aligned}
& B=\text { BWR } \\
& H=H T G R \text { (Fort St. Vrain) } \\
& P=\text { PWR }
\end{aligned}
$$

Reactor:

NSSS Vendor. One of the following:

$$
\begin{aligned}
& A=\text { Allis-Chalmers (La Crosse BWR) } \\
& 8=\text { Babcock \& Wil cox } \\
& C=\text { Combustion Engineerlng } \\
& G=\text { General ElectilC } \\
& N=\text { General Atanic (Fort St. Vrain) } \\
& W=\text { Westinghouse }
\end{aligned}
$$




\section{System:}

Primary.

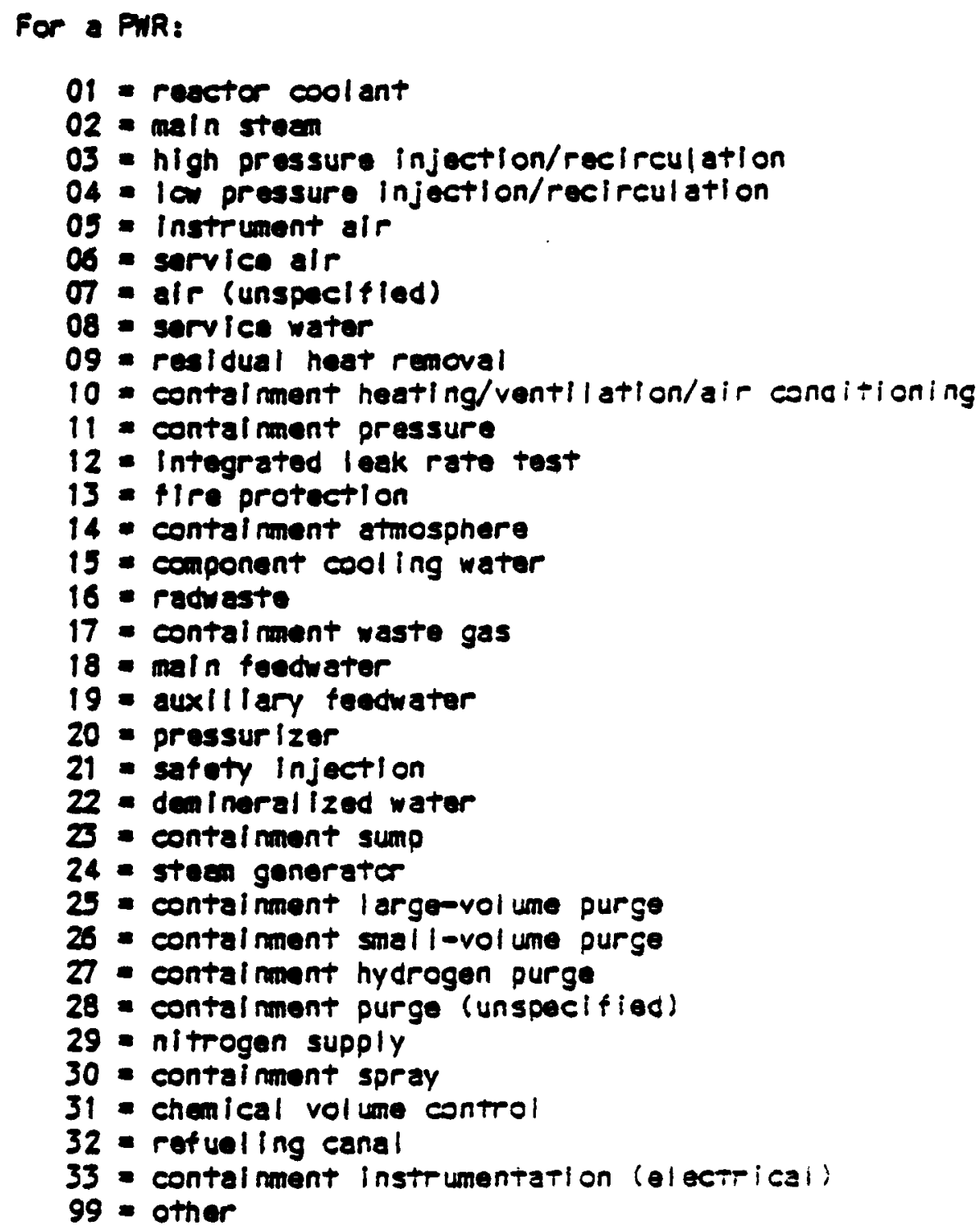

B. 8 
For a BWR:

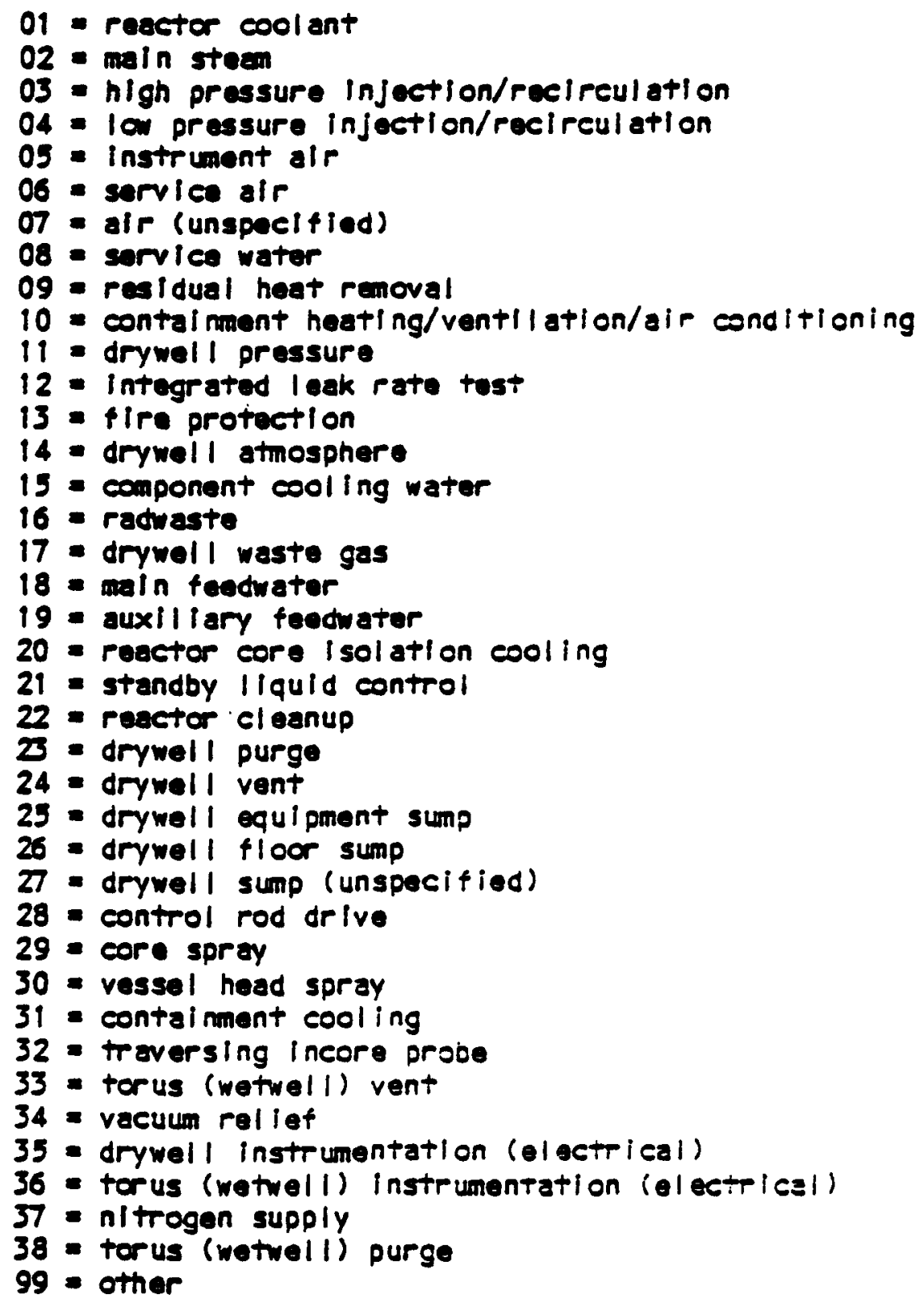


System:

Secondary. One or two of the foll lowing:

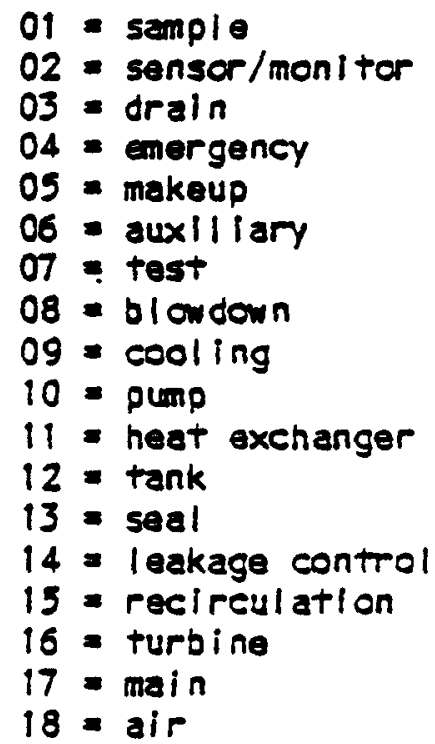

The secondary system identiflers are provided to permit adcitional specification of the system. For example, a reactor coolant pump seal supply line would have the following system icentifiers:

$$
\begin{aligned}
& \text { Primary }=01 \\
& \text { Secondary }=10,13 .
\end{aligned}
$$

The line below the system identltier entries is aravidac for aaditional system description as needed./ 


\section{Eallure Information}

Date.

Date of fallure event in six-digit code, e.g., 08/12/83= August 12, 1983.

Power Level. Percent of full power of reactor when fall ure occurred.

Fall ure Mode. One of the following:

$$
\begin{aligned}
& A=\text { leakage (fall to seal) } \\
& B=\text { fall to close } \\
& C=\text { unplanned opening (fall to remain closed) }
\end{aligned}
$$

/Fallure mode $B$ refers to fallures in which the component does not close within a reasonable time limit, thereby constituting a potential failure to isolate containment.l 
Cause:

Primary.

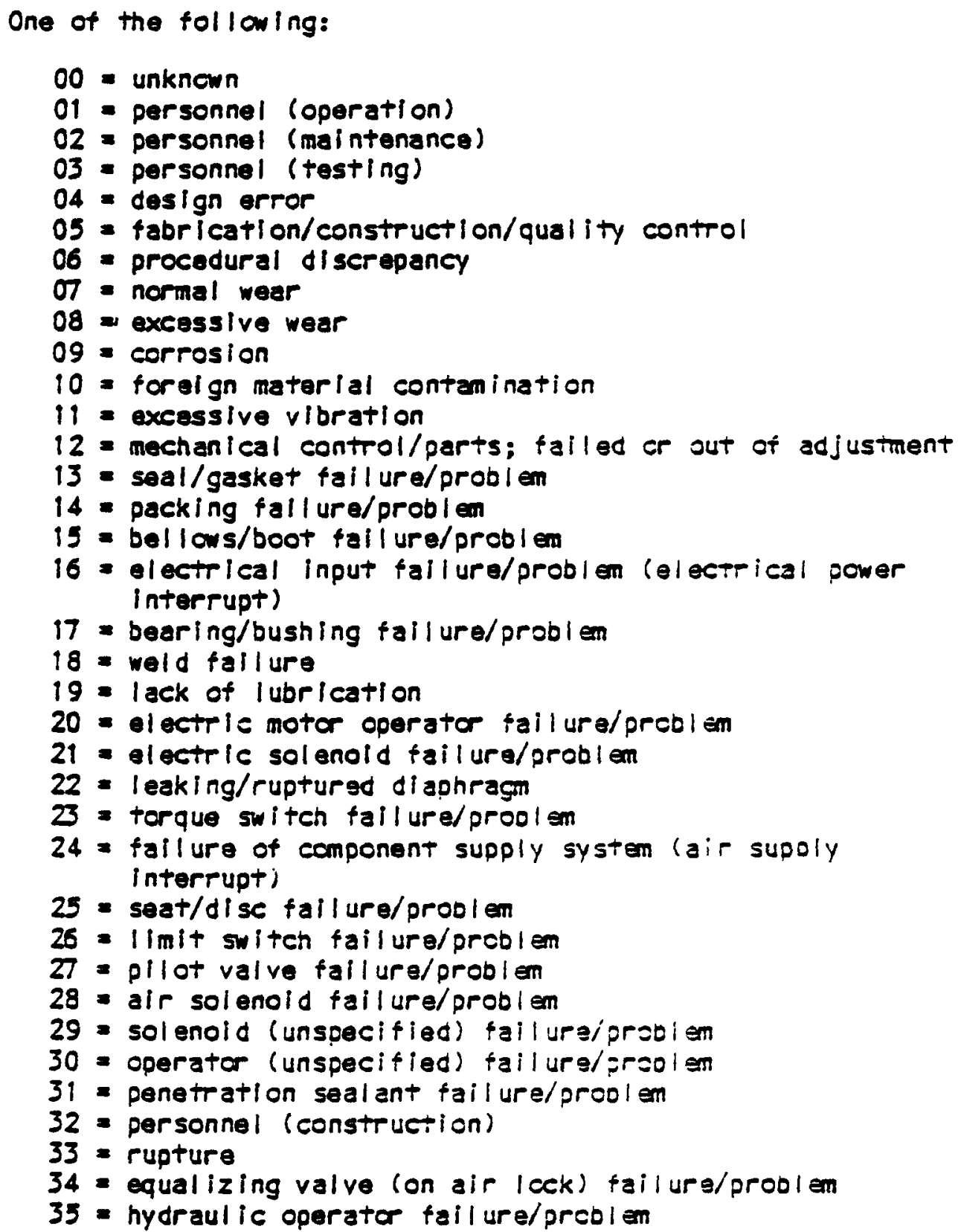

Cause:

Secondary. Use the same identlfiers as for Primary.

The following example may help to distinguisn between the primary and secondary fallure causes. Consider a damaged air l cck eccr seal resulting from personnel closing the docr wi-n excessive isrse. The primary failure cause woula be "seal/gasket failure/zrsal =m". : z); secondary cause would be "personnel (operzeticn)" i. : :.. 
Duration.

The number of days/hours/minutes during which the fail ure existed. Following the dash, enter an $A$ it the duration is known to be the actual duration. Enter an $M$ if it is an estimate of the minimum duration. If unsure, enter an $X$.

Containment I sol ated?

Despite the fallure, did contaiment remain isolated - Y = yes, $N=$ no?

Discovery.

When was the fallure discovered? One of the fallowing.

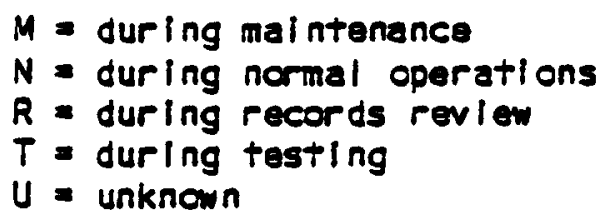

Corrective Actions.

The action(s) taken to return the falled cemponent to service. One or two of the following:

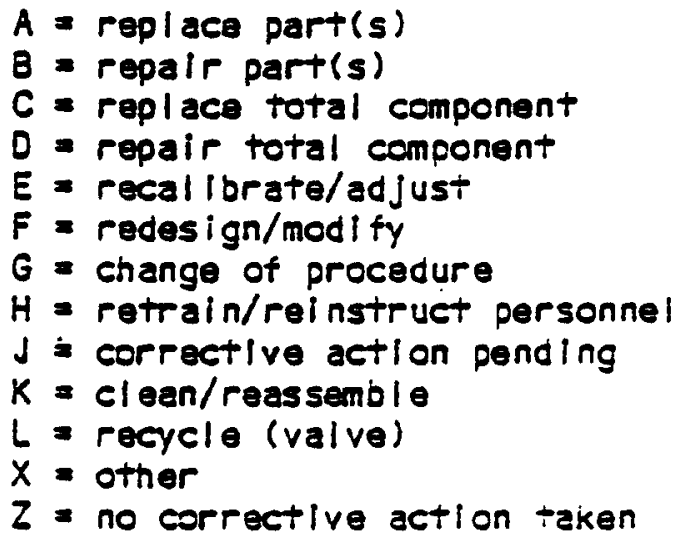

Related LERs. Other LERs designated as being related to the failure iso not include rovisions of the LER being ravieweo).

\section{Comments}

Include additional information as well as expanding en previcusly escec information in this section. Typical information mignt be an axoanced description of the component (e.g., valve size) or the failure (e.g., Jrand name of defective penetration sealant). Leakage rates recorted snouls se incluced here. Any unlque aspects of the LER should be menticnec. 
The computer data base (COB) contalns 29 intormation flelds corresponding to the 27 infcrmation fields listed on each LER Coding Form, plus two acditional information flelds. Twenty-eight of the 29 fields in the CCB have labels beginning with the letters 1, C, or F followed by a colon. These letters indicate the type of information contained in the field and correspond to the fields on the LER Coding Form as follows:

$$
\begin{aligned}
& I=\text { Identification Information } \\
& C=\text { Component Information } \\
& F=\text { Fall ure information }
\end{aligned}
$$

Fol lowing the colon in each CCB label is a name wnich more specifically characterizes the field. These names also correspond to the ileld names on the LER Coding Form. There are two exceptions, which are discussed lator when gach field is examined individually. The last field in the CDB is "Conments" and corresponds to the "Comments" field on the LER Coding Form. Three of the 29 CDB fielo labels have ":F" following the name. This indicates that the tiele contains information in a freestyle format, i.e., uncoded.

Each of the 29 flelds in the cos is examined individually as follows.

COB FIELD
LER CODING FORM
SIELD NAME

01 1:DATABNUM Data Base \#

02 I:LERNUM LER \$

03 I:REYISNUM Revision

04 I:ACCESNUM RCCession

\author{
PEMARKS \\ Enter 4 digits (use areceding \\ zeros where needed to cemoletely \\ fill fielo, e.g., enter Jata Ease \\ $\$ 38$ as Coj8) \\ Enter E eigits with sasi :-) \\ between first 2 anc last $j$ (e..., \\ $83-005$ ) \\ Enter 2 digits luse prececing zero \\ where needed to comoletely illi \\ tield, e.g., enter Revision \#2 as \\ 02) \\ Enter 5 jigits luse preceding \\ zeros where needec to comoletely \\ flll tield, e.g., enter nicsession \\ \# 98707 as 098797 ;
}




\begin{tabular}{|c|c|c|c|}
\hline \multicolumn{2}{|c|}{$\begin{array}{r}\text { CDE FIELD } \\
+\quad \text { NAMEE } \\
\end{array}$} & \multirow{2}{*}{$\begin{array}{l}\text { LER COOING FORM } \\
\text { EIELO NAME } \\
\text { FalluFe }\end{array}$} & \multirow[b]{2}{*}{ 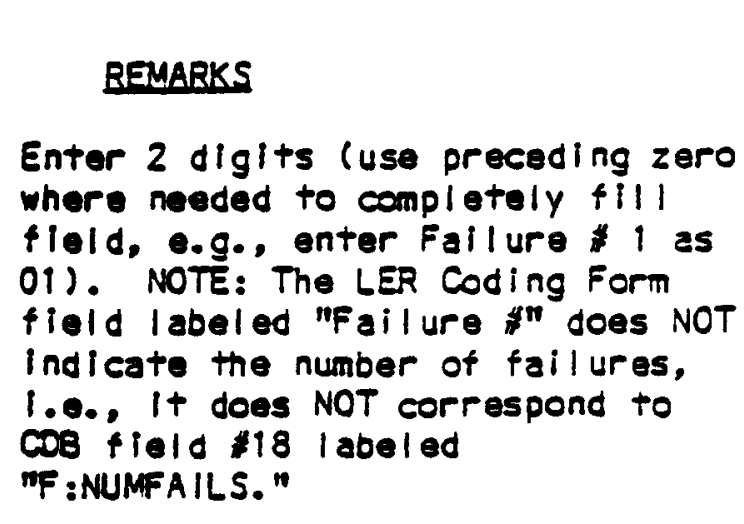 } \\
\hline 05 & 1:ENTRYNUM & & \\
\hline 06 & C:TYPEMAIN & Type: Main & Entor 1 letter \\
\hline 07 & C:TYPESUBI & Typo: Sub-1 & Enter 1 letter \\
\hline 08 & C:TYPESUB2 & Type: Sub-2 & Enter 1 letter \\
\hline 09 & C:LOCATION & Location & Enter 1 letter \\
\hline 10 & C:MANUFACT & Manufacturer & $\begin{array}{l}\text { Enter } 4 \text { characters (1 letter } \\
\text { foll loved by } 3 \text { digits) }\end{array}$ \\
\hline 11 & C:REACNAME & Resctor: Neme & $\begin{array}{l}\text { Enter } 3 \text { eharacters ( } 2 \text { letters } \\
\text { foll lawed by } 1 \text { digit) }\end{array}$ \\
\hline 12 & C:REACTYFE & Reector: Type & Enter i latter \\
\hline 13 & C:REACNSSS & Reactor: NSSS Vendor & Enter 1 letrer \\
\hline 14 & C:CISCLASS & - & 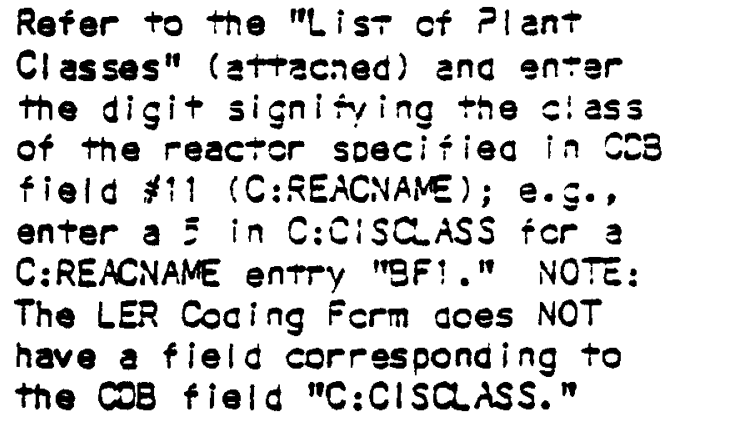 \\
\hline 15 & C:SYSFRIMA & System: PrImary & $\begin{array}{l}\text { Enter } 2 \text { digits (use preceding zero } \\
\text { where neeceo to comoletaly t:ll } \\
\text { fleld, e.g., enter System:=-imary } \\
\text { in as } 07 \text { ) }\end{array}$ \\
\hline
\end{tabular}


\begin{tabular}{c} 
CDB FIELD \\
iNAME \\
\hline
\end{tabular}

16 C:SYSSECON

17 C:SYSDES:F

18 F:NUMFAILS
LER CODING FORM EIELDINAME

System: Secondary

System (tree-fleld descr (ption)

\section{REMARKS}

Enter 1 or 2 pairs of digits, separated by a comma if 2 pairs are entered (no comma for just 1 pair). NOTE: With in each pair, use preceding zero where needed to completely fill that pair's fleld, e.g., enter System: Secondary \#8 as 08; System: Secondary $\# 12,7$ as $12,07)$.

Enter $\leq 36$ characters from freefleld description (underlined on LER coding Form immediately below System fields), using approprlate abbrevlations where needed (See list of abbrevlations following this table)

Enter 2 diglts (use preceding zero where needed to completely fill fleld, e.g., enter 3 fallures as 03). NOTE: The LER Coding Form does NOT have a fleld corresponding to the CDB fleld "F : NUMFAILS." Normally, 01 should be entered in this field (representing 1 fall ure). However, some LER Coding Forms indicate multiple fallures, usually as a clrcled item toward the upper right, e.g., "6 valves" circled in the upper right. For such an item, enter the circled number in CDB fleld "F: NUMFAILS," e.g., 06 . 
$\begin{array}{r}\text { COB FIELO } \\ + \text { NAME } \\ \hline\end{array}$

19 F:DATE

20 F:POWERLEY

21 F :MOOE

22 F:CAUSEPRI

23 F:CAUSESEC

24 F:DURATION
LER COOING FORM EIELD NAME

Dato

Power Level (s)

Fall ure Mode

Cause: Primary

Cause: Secondary

Duration

Discovery

Corrective Actions
25 F:ISQATED Contaimment Isol ated? Enter I letter

BEMARKS

Enter 8 characters ( 3 palrs of digits separated by slashes $[/]$ ). NOTE: With in each peir, use preceding zero where needed to completely fill that pair's field, -.g.. enter Date $1 / 6 / 83$ as 01/06/83.

Enter 3 digits luse preceding zero where needed to comoletely fill fleld, e.g., enter Power Level 95: as 095). NOTE: The s symbol should NOT be entered.

Enter 1 digit

Enter 2 digits (use preceding zero where needed to completely fill fleld, e.g., enter Cause:Primary $\$ 5$ as 05)

Enter 2 digits (use preceding zero where needed to cempletsiy fill

fleld, e.g., enter Cause: Secondary 3 as 03)

Enter 10 characters ( 3 pairs of digits, separated by sl asnes $[/]$, followed by a desn $[-]$ enc a letter). NOTE: ithin each pair of digits, use prececing zero where neeced to comoietsly till that pair's fiele, a.g., enter Curation $0 / \Sigma / i \equiv-i, 1$ as $00 / 05 / i \equiv-u$.

26 F:DISCOVER

27 F:CORRECTS

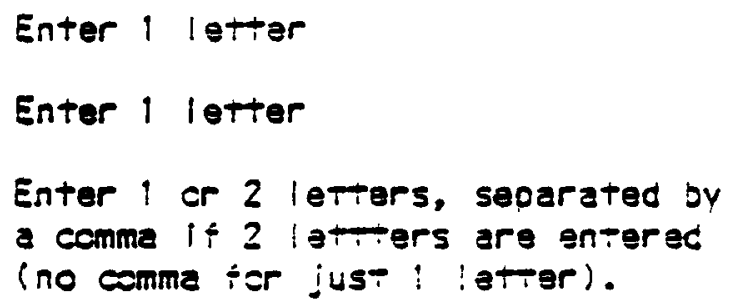
a comme if 2 (etTers are enterac (no comme ior just ! lattor). 
$\begin{array}{r}\text { COB FIELD } \\ +\quad \text { NAME } \\ \hline\end{array}$

28 F:RELER:F

29 COMMENTS:F
LER CODING FORM EIELD NAME

Rel ated LERS

$($ tree-tield)

Comments (freem field)

\section{REMARKS}

Enter $\leq 28$ characters from free field

Enter $\leq 240$ characters from iree fleld, using appropriate abbreviations where needed ( See llst of abbreviations following this table)

\section{WIST OE AEEREY IATIONS}

$V$ a vaive

IV - isolation valve

$A L=$ air lock

PAL = personnel air lock

il = fall/tallure

lk = leak/l eakage

$\&$ and

**NOTE: Use other common abbreviations as appropriate. 


\section{LIST OF PLANT CLASSES}

Class 1. PWR - Large Dry Containment

Class 2. PrR - Subatmospheric Containment

Class 3. PWR - Dual (Double) Contel nment

Class 4. PWR - lee Condenser Contalmment

Class 3. BWR - Mark I Containment

Class 6. BWR - Mark II Containnent

Class 7. BWR - Mark 111 Contal mment

Class 8. Other 
PLANT

Arkansas Nuclear One I

Arkansas Nucleer One 2

Browns Ferry 1

Browns Ferry 2

Browns Ferry 3

Big Rock Point

Brunsw lak $?$

Brunswick 2

Beaver Valloy 1

Calvert Clitts I

Calvert Clitts 2

Cooper Station

Crystal River 3

Duane Arnold

Dav/s-besse 1
CODE

AR1

AR2

BF 1

BF2

BF3

BP1

BRI

BR2

BVI

$\infty 1$

$\infty 22$

$\infty 1$

023

DA1

DB1
gASS

1

1

5

5

5

a

5

5

2

1

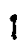

5

\section{1}

5

3 
PLANT

D. C. Cook 1

D. C. Cook 2

Diablo Canyon 1

Diablo Canyon 2

Oresden 1

Dresden 2

Dresden 3

Enrlco Fermi 2

E. 1. Hateh 1

E. 1. Haten 2

Fort Cal houn

J. A. Fitzpatrick

Fort St. Viraln

Grand Gult I

Humbol dt Bay 3

Haddan Neck (CT Yankee)

Indian Point 2

Indian Point 3

J. M. Farley 1

d. M. Farley 2

Kewaunee

LaCrosse 8WR

Lasal le 1

Lasal le 2

Mcsulre 1

Mcsuire 2
CODE

DC1

DC2

Dor

D02

DR1

DR2

DR3

EF2

EN1

EN2

FCI

FP1

FV1

GQ1

HB3

HN1

IP2

IP3

JF?

JF2

KEI

LI

LSI

LS2

MGI

MG2
5

3

8

CLASS

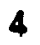

4

1

1

8

5

5

5

5

5

1

5

8

7

1

1

1

1

1

6

5 


\begin{tabular}{|c|c|c|}
\hline RLANT & CODE & QLASS \\
\hline Millstone I & MII & 5 \\
\hline Mll I stone 2 & $M 12$ & 1 \\
\hline Monticel lo & MOI & 5 \\
\hline Maine Yankee & $M T$ & 1 \\
\hline North Anna 1 & NA1 & 2 \\
\hline North Anna 2 & NA2 & 2 \\
\hline Nine Mile Point I & NM1 & 5 \\
\hline Oyster Creek I & $\mathrm{OCl}$ & 5 \\
\hline Oconee 1 & OEI & 1 \\
\hline Oconee 2 & 052 & 1 \\
\hline Oconee 3 & $0 \mathbf{3}$ & 1 \\
\hline Pal i sades & PA1 & 1 \\
\hline Peach Bottan 2 & PB2 & 5 \\
\hline Peach Botton 3 & FB3 & 5 \\
\hline Pilgrim i & $P \| 1$ & 5 \\
\hline Prairie Island 1 & PRI & 3 \\
\hline Pralrie Island 2 & PRZ & 3 \\
\hline Point Beach 1 & FTI & 1 \\
\hline Polnt Beach 2 & FT2 & 1 \\
\hline Palo Verde I & PYI & 1 \\
\hline Qued Citles 1 & QCi & 5 \\
\hline Quad Cities 2 & QC2 & 5 \\
\hline R. E. Ginna & $R_{G 1}$ & 1 \\
\hline H. B. Robinson 2 & $\mathrm{RO2}$ & 1 \\
\hline Rancho Seco & RSI & $i$ \\
\hline Salen 1 & SAI & $:$ \\
\hline
\end{tabular}




\begin{tabular}{|c|c|c|}
\hline ELANI & CODE & GAS: \\
\hline Sal en 2 & SA2 & 1 \\
\hline Sequoyan 1 & SEI & 4 \\
\hline Sequoyah 2 & SE2 & 4 \\
\hline St. Lucle 1 & $\boldsymbol{s i}$ & 3 \\
\hline St. Lucle 2 & 52 & 3 \\
\hline Shorenan & SM1 & 6 \\
\hline San Onofre 1 & s01 & 8 \\
\hline San Onofre 2 & 502 & 1 \\
\hline San Onotre 3 & 503 & 1 \\
\hline Susquehanna I & SSi & 6 \\
\hline Susquehanna 2 & SS2 & 6 \\
\hline Surry 1 & su1 & 2 \\
\hline Surry 2 & su2 & 2 \\
\hline Three Mile Island I & $T 11$ & 1 \\
\hline Three Mile Island 2 & $T 12$ & 1 \\
\hline Trojan & TRI & $i$ \\
\hline Turkey Point 3 & $\pi 3$ & 1 \\
\hline Turkey Point 4 & $\pi 4$ & 1 \\
\hline V. C. Summer 1 & vsi & 1 \\
\hline Vermont Yankee & VY1 & 5 \\
\hline Waterford 3 & WF3 & 3 \\
\hline WNP 2 & WPZ & 6 \\
\hline Yankee Rowe & YRI & 8 \\
\hline Zion 1 & 211 & $\mathrm{i}$ \\
\hline Zion 2 & 212 & ? \\
\hline
\end{tabular}


APPENDIX C

LISTING OF PENETRATIONS AND YALYES 


\section{APPENDIX C}

\section{LUSTING OF PENETRATIONS AND YALYES}

This appendix provides a listing of containment penetrations and valves for

Peach Bottom 2 and St. Lucle 2. This listing supports the example analysis in Section 7.0. 
Standard Listing of Peach Bottom 2 Penetrations for RACISP

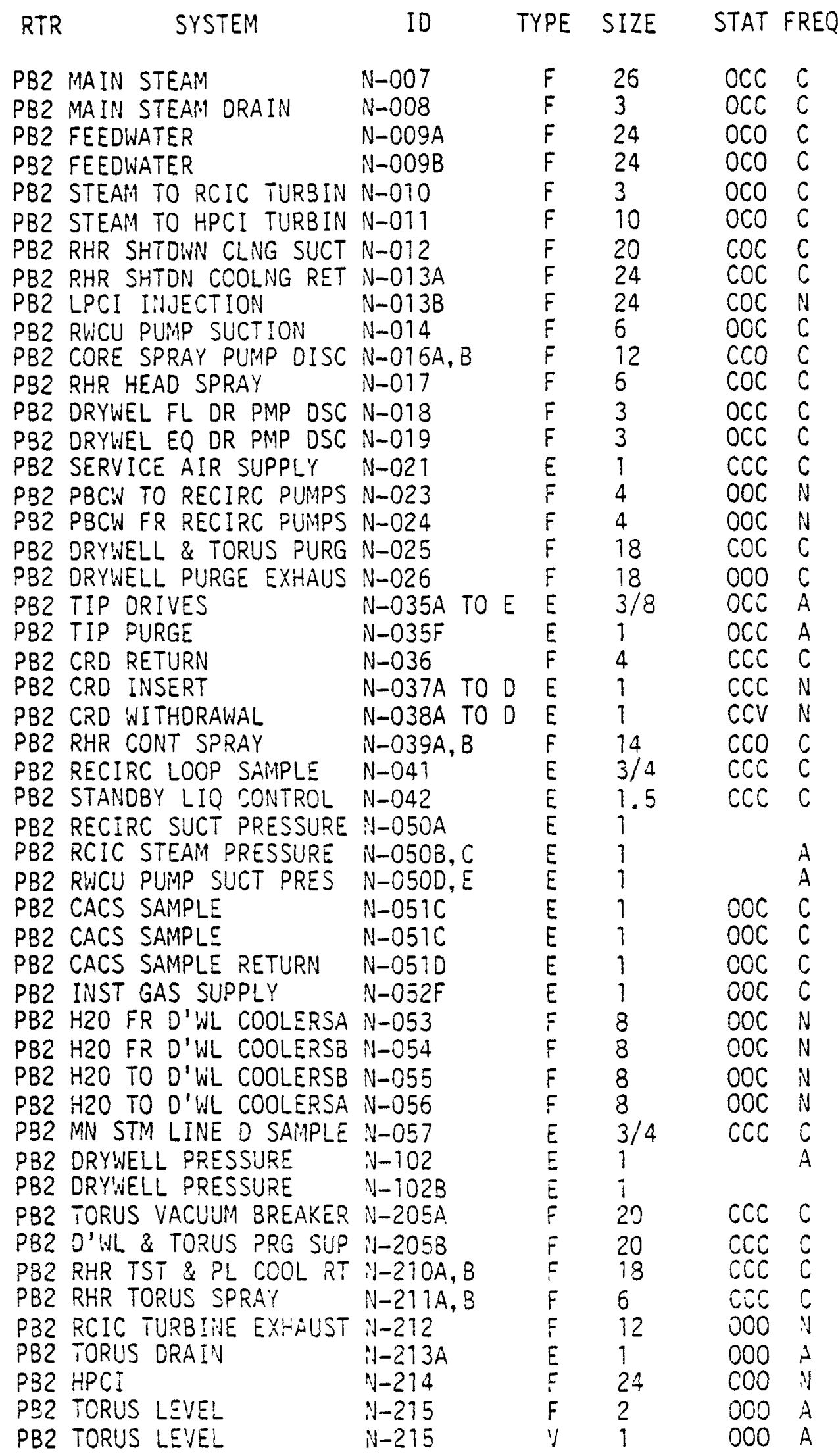


Standard Listing of Peach Bottom 2 Penetrations for RACISP

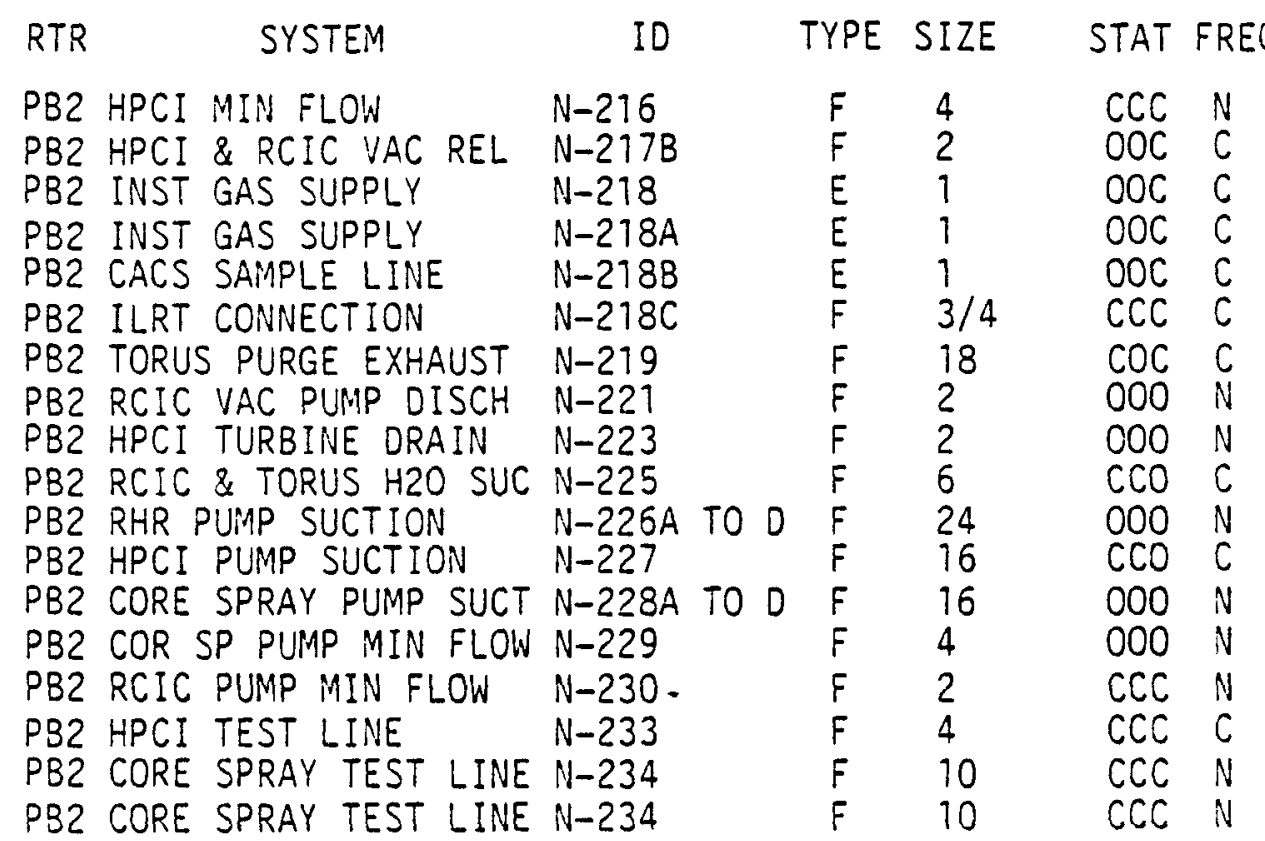


Standard Listing of Peach Bottom 2 Valves for RACISP

\begin{tabular}{|c|c|c|c|c|c|c|c|c|}
\hline RTR & SYSTEM & ID & YPE & $O P$ & SIZE & STAT & FREQ & STANDARD \\
\hline 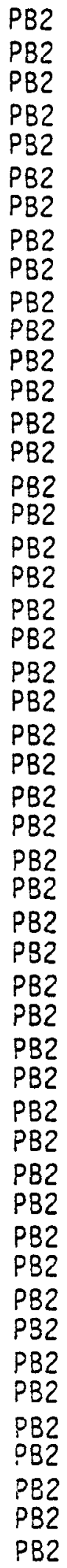 & 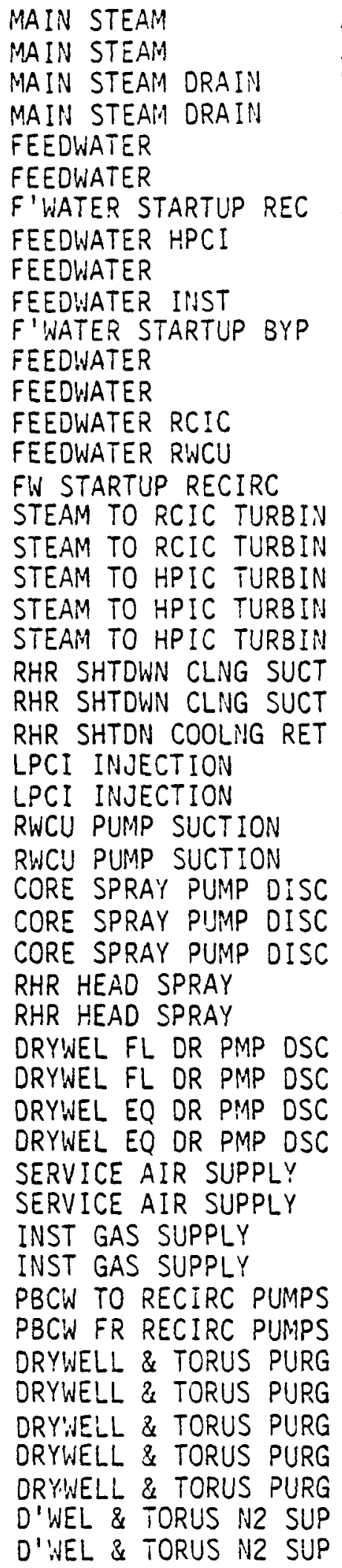 & 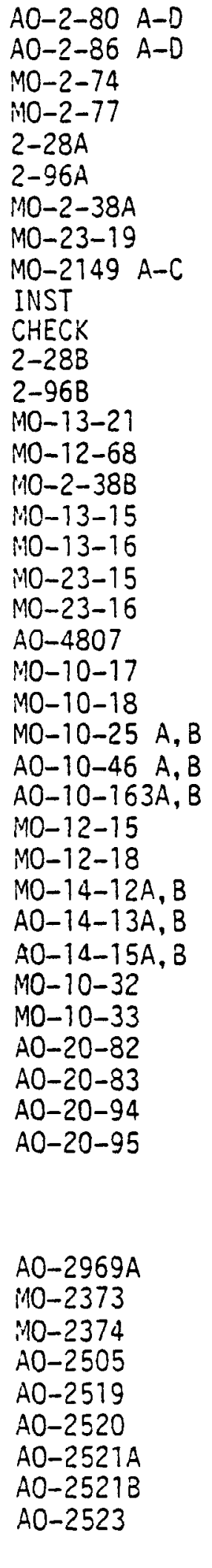 & $\begin{array}{l}F \\
F \\
E \\
E \\
C \\
C \\
E \\
E \\
E \\
F \\
C \\
C \\
C \\
E \\
F \\
E \\
E \\
F \\
E \\
E \\
E \\
E \\
E \\
E \\
C \\
D \\
F \\
F \\
E \\
C \\
D \\
E \\
E \\
D \\
D \\
D \\
D \\
F \\
F \\
C \\
D \\
E \\
E \\
B \\
B \\
B \\
D \\
D\end{array}$ & 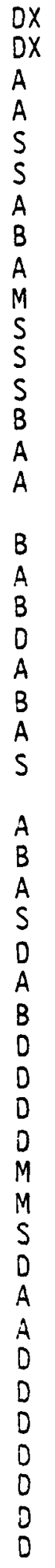 & $\begin{array}{l}26 \\
26 \\
3 \\
3 \\
24 \\
24 \\
24 \\
24 \\
24 \\
1 \\
24 \\
24 \\
24 \\
24 \\
24 \\
24 \\
3 \\
3 \\
10 \\
10 \\
10 \\
20 \\
20 \\
24 \\
24 \\
24 \\
6 \\
6 \\
12 \\
12 \\
12 \\
6 \\
6 \\
3 \\
3 \\
3 \\
3 \\
1 \\
1 \\
1 \\
1 \\
4 \\
4 \\
18 \\
20 \\
20 \\
20 \\
20 \\
20 \\
20\end{array}$ & $\begin{array}{l}O C C \\
O C C \\
C O C \\
C O C \\
O C O \\
O C C \\
C C C \\
C C O \\
O O C \\
O O O \\
C C C \\
O C O \\
O C C \\
C C O \\
O O C \\
C C C \\
O C O \\
O C O \\
O C O \\
O C O \\
O C O \\
C O C \\
C O C \\
C O C \\
C O C \\
C C C \\
O O C \\
O O C \\
C C O \\
C C O \\
C C C \\
C O C \\
C O C \\
O C C \\
O C C \\
O C C \\
O C C \\
C C C \\
C C C \\
O O C \\
O O C \\
O O C \\
O C C \\
C O C \\
C C C \\
C O C \\
C O C \\
C O C \\
C C C \\
C C C\end{array}$ & $\begin{array}{l}C \\
C \\
C \\
C \\
C \\
C \\
C \\
C \\
C \\
C \\
C\end{array}$ & \\
\hline
\end{tabular}


Standard Listing of Peach Bottom 2 Valves for RACISP

RTR SYSTEM ID TYPE OP SIZE STAT FREQ STANDARD

\begin{tabular}{|c|c|c|c|c|c|c|}
\hline PB2 & D'WEL \& TORUS VAC RL & $\mathrm{AO}-2502 \mathrm{~A}$ & 8 & 0 & 20 & $\mathrm{CCC}$ \\
\hline PB2 & D'WEL \& TORUS VAC RL & $9-26 A$ & $x$ & $S$ & 20 & $\mathrm{CCC}$ \\
\hline PB2 & D'WEL \& TORUS PRESS & INST & $F$ & $M$ & 20 & 000 \\
\hline PB2 & O'WEL \& TORUS N2 SUP & & C & $S$ & 20 & $\mathrm{CCC}$ \\
\hline PB2 & O'WEL PURGE EXH CAD & $A 0-2509$ & 0 & $D$ & 18 & 000 \\
\hline PB2 & D'WEL PURGE EXH CAD & $A O-2510$ & 0 & $D$ & 18 & $\mathrm{CCO}$ \\
\hline PB2 & D'WEL EXHAUST PURGE & $A 0-2506$ & $B$ & 0 & 18 & $\mathrm{COC}$ \\
\hline$P B$ & D'WEL EXHAUST PURGE & $\operatorname{coc} 2507$ & $B$ & D & 18 & 000 \\
\hline 10 & D'WEL EXH INST GAS & $A 0-4235$ & 0 & $D$ & 18 & OOC \\
\hline PB2 & D'WEL EXH INST GAS & SV -8100 & $x$ & $E$ & 18 & $\mathrm{OOC}$ \\
\hline$B 2$ & D'WEL EXH CACS SAMPL & $S V-2671$ & $x$ & $\bar{E}$ & 18 & OOC \\
\hline PB2 & D'WEL EXH CACS SAMPL & $S V-2978$ & $x$ & $\bar{F}$ & 18 & $\mathrm{CCO}$ \\
\hline PB2 & D'WEL EXH CAO SAMPLE & $S V-4960 B$ & $x$ & $E$ & 18 & $\mathrm{CCC}$ \\
\hline PB2 & D'WEL EXH CAO SAMPLE & SV $-4961 B$ & $x$ & $E$ & 18 & $\mathrm{CCO}$ \\
\hline PB2 & DW EXH RAD GAS SAMPL & $S V-4966 B$ & $x$ & $E$ & 18 & $\mathrm{CCO}$ \\
\hline PB2 & DW EXH RAO GAS SAMPL & SV-8101 & $x$ & $E$ & 18 & $\mathrm{CCO}$ \\
\hline PB? & DW EXH PURG PRESSURE & INST & $F$ & $M$ & 18 & 000 \\
\hline$P R$ & TIP DRIVES & & $A$ & $E$ & $3 / 8$ & OCC \\
\hline & TIP DRIVES & & $x$ & $H$ & $3 / 8$ & OOC \\
\hline PB & TIP PURGE & & C & $S$ & 1 & OCC \\
\hline PB & TIP PURGE & $7-113$ & $x$ & $E$ & 1 & $\operatorname{CCC}$ \\
\hline$P B$ & CRD RETURN & $3-113$ & C & $S$ & 4 & $\mathrm{CCC}$ \\
\hline & CRD RETURN & $3-110$ & C & $S$ & 4 & $\mathrm{CCC}$ \\
\hline$P B$ & CRD INSERT & & $\mathrm{C}$ & $S$ & 1 & $\mathrm{CCC}$ \\
\hline PB & CRD WITHDRAWAL & & $x$ & $E D$ & 1 & $\mathrm{CCC}$ \\
\hline PB & CRD WITHDRAWAL & & $E$ & $E D$ & 1 & $\mathrm{CCC}$ \\
\hline$P B$ & CRD WITHDRAWAL & $C V 3-32 \quad A, B$ & $F$ & 0 & 1 & OOC \\
\hline PB & CRO WITHDRAWAL & cV $3-33$ & $F$ & $D$ & 1 & $\mathrm{OOC}$ \\
\hline PB & CRD WITHORAWAL & $C V 3-35$ A, 3 & $F$ & $\bar{D}$ & 1 & $\mathrm{OOC}$ \\
\hline PB & CRD WITHDRAWAL & CV $3-36$ & $F$ & $\overline{0}$ & 1 & $\mathrm{OOC}$ \\
\hline PB & RHR CONT SPRAY RHR & $M O-10-31 \quad A, B$ & $E$ & $A$ & 14 & $\mathrm{CCO}$ \\
\hline PB & RHR CONT SPRAY RHR & $M O-10-26$ A, B & $\bar{E}$ & $A$ & 14 & $\mathrm{CCO}$ \\
\hline R & RHR CONT SPRAY CAD & SV -4948 A, B & $x$ & $E$ & 14 & $\mathrm{CCO}$ \\
\hline PB & RHR CONT SPRAY CAD & SV $-4949 \mathrm{~A}, \mathrm{~B}$ & $x$ & $\bar{E}$ & 14 & $\mathrm{CCO}$ \\
\hline$P B$ & RHR CONT SPRAY CAD & & C & $S$ & 14 & $\mathrm{CCO}$ \\
\hline D & RECIRC LOOP SAMPLE & $A O-2-39$ & D & $D$ & $3 / 4$ & $\mathrm{CCC}$ \\
\hline PB & RECIRC LOOP SAMPLE & $A O-2-40$ & D & $D$ & $3 / 4$ & $\operatorname{CCC}$ \\
\hline$P B$ & STANDBY LIQ CONTROL & $11-16$ & C & $S$ & 1.5 & $\mathrm{CCC}$ \\
\hline & STANOBY LIQ CONTROL & $11-17$ & C & $S$ & 1.5 & $\mathrm{CCC}$ \\
\hline 0 & DRYWELL PRESSURE & $10-53 \mathrm{~A}, \mathrm{C}$ & $F$ & $M$ & 1 & \\
\hline 0 & DRYWELL PRESSURE & $10-60$ A,C & $F$ & $M$ & 1 & \\
\hline$P B$ & RECIROC SUCT PRESSUR & $305 A$ & $F$ & $M$ & 1 & \\
\hline & RCIC STEAM PRESSURE & & $F$ & $M$ & 1 & \\
\hline$P B$ & RCIC STEAM PRESSURE & $54 A, B$ & $F$ & $M$ & $i$ & \\
\hline & RWCU PUMP SUCT PRES & $125 \mathrm{~A}, \mathrm{~B}$ & $x$ & & 1 & \\
\hline PB & RWCU PUMP SUCT PRES & $6 \mathrm{~A}, \mathrm{~B}$ & $x$ & & 1 & \\
\hline & CACS SAMPLE & $S V-2671 E, D$ & $x$ & $E$ & 1 & $00 \mathrm{C}$ \\
\hline PB & CACS SAMPLE & SV-2978 E,D & $x$ & $F$ & 1 & $00 \mathrm{C}$ \\
\hline PBC & CACS SAMPLE & SV $-2671 C$ & $\mathrm{~s}$ & $E$ & 1 & $\mathrm{OOC}$ \\
\hline D & SAMPLE & $S V-26780$ & a & $E$ & 1 & $\operatorname{COC}$ \\
\hline
\end{tabular}


Standard Listing of Peach Bottom 2 Valves for RACISP

\begin{tabular}{|c|c|c|c|c|c|c|}
\hline SYSTEM & ID & TYPE & OP SIZE & STAT & FREQ & STANDARD \\
\hline 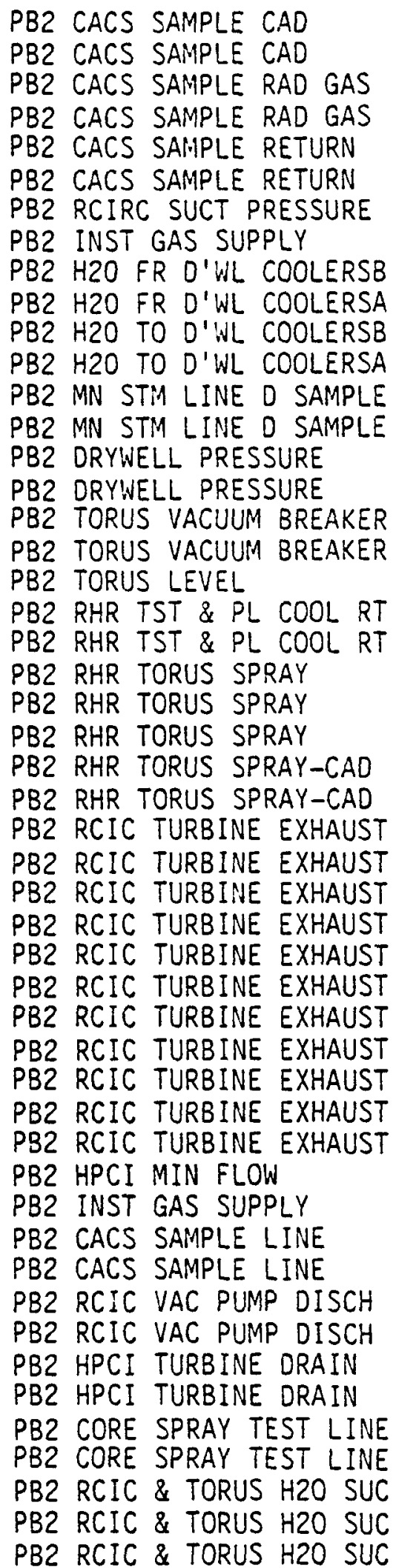 & 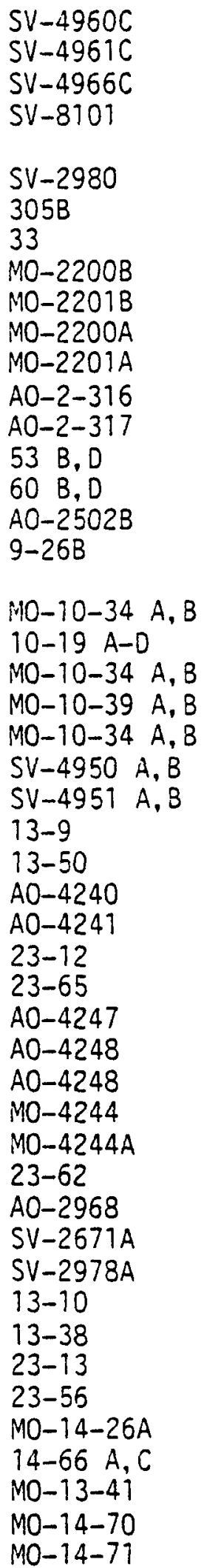 & $\begin{array}{l}X \\
X \\
X \\
X \\
C \\
X \\
X \\
C \\
E \\
E \\
E \\
E \\
D \\
D \\
F \\
F \\
D \\
X \\
F \\
B C \\
C \\
B \\
B \\
B \\
B E \\
X \\
X \\
C \\
C \\
C \\
D \\
D \\
C \\
C \\
D \\
D \\
D \\
E \\
E \\
C \\
D \\
X \\
X \\
C \\
C \\
C \\
C \\
F \\
C \\
E \\
E \\
E\end{array}$ & 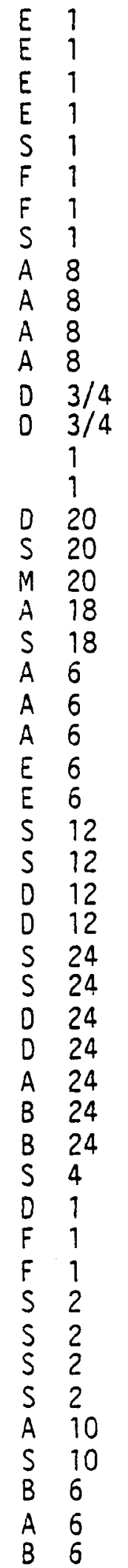 & $\begin{array}{l}C C C \\
C C C \\
000 \\
C C C \\
C O D \\
C C C \\
C C C \\
C C C \\
C C O \\
C C O \\
000 \\
000 \\
000 \\
000 \\
000 \\
000 \\
000 \\
000 \\
000 \\
00 C \\
00 C \\
C C C \\
00 C \\
00 C \\
00 C \\
000 \\
C C D \\
000 \\
C C D \\
C C C \\
C C C \\
C C D \\
C C C \\
C C C\end{array}$ & $\begin{array}{l}C \\
C \\
C \\
C \\
C \\
C \\
C \\
C \\
N \\
N \\
N \\
N \\
C \\
C \\
A \\
C \\
C \\
A \\
C \\
N \\
C \\
C \\
C \\
C \\
C \\
N \\
N \\
N \\
N \\
N \\
N \\
N \\
N \\
N \\
N \\
N \\
N \\
C \\
C \\
C \\
N \\
C \\
N \\
C \\
N \\
N \\
C \\
C \\
C\end{array}$ & \\
\hline
\end{tabular}




\section{Standard Listing of Peach Bottom 2 Valves for RACISP}

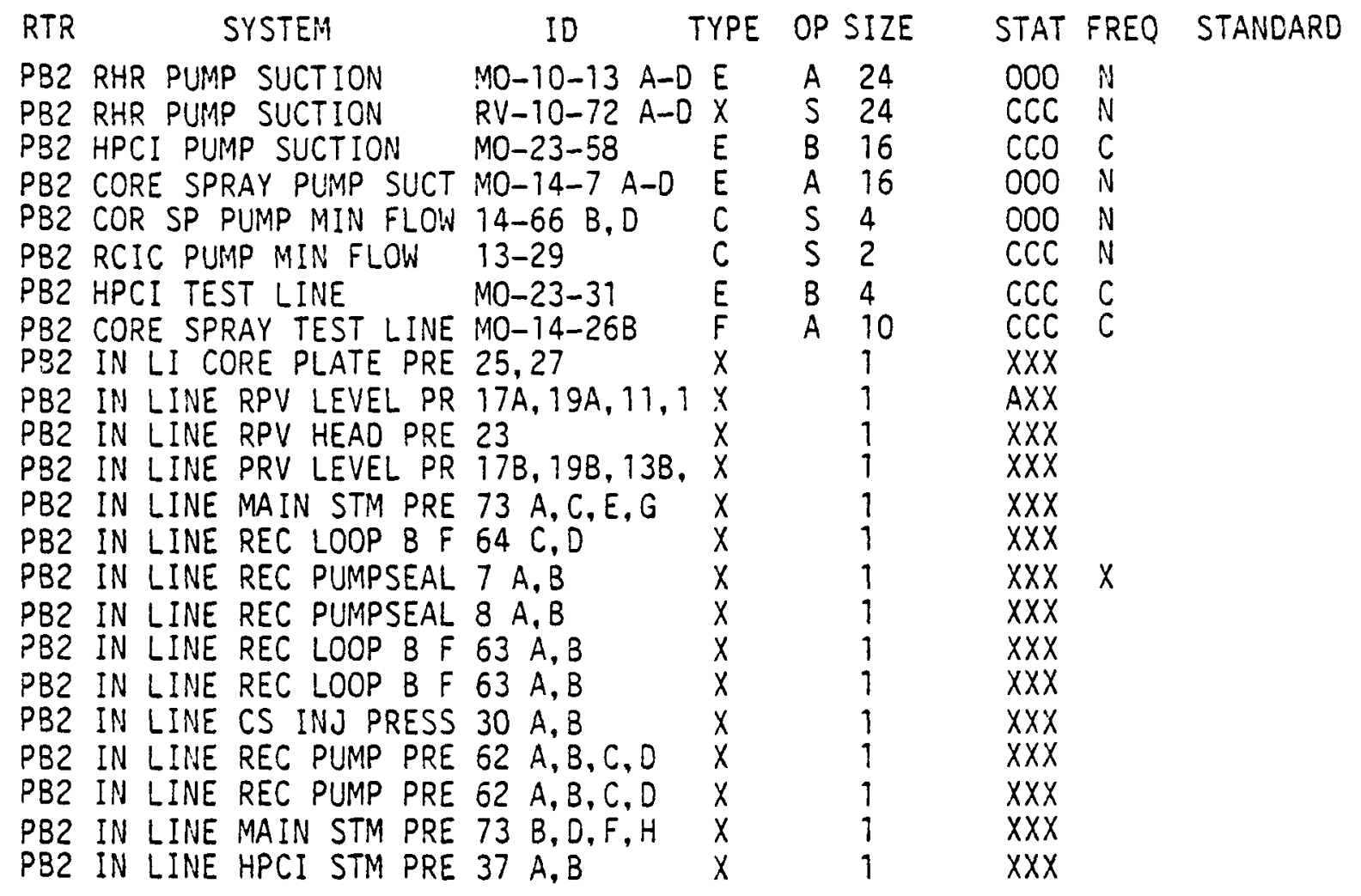


Standard Listing of St. Lucie 2 Penetrations for RACISP

\begin{tabular}{|c|c|c|c|c|c|c|c|}
\hline RTR & SYSTEM & ID & TYPE & SIZE & STAT & FREQ & STANDARD \\
\hline SL2 & MAIN STEAM & $13411=23$ & $F$ & 34 & OCE & 5 & Goc57 \\
\hline SL2 & MAIN STEAM & $134 M 529$ & $F$ & 34 & OCE & $B$ & 60057 \\
\hline SL2 & FEEDUAATEF & $I 20 \quad E F 1+$ & $\mathrm{F}$ & 20 & oce & $\mathrm{E}$ & G0E57 \\
\hline SL 2 & FEEDU:ATER & I 20 BFI: & $F$ & 20 & OCC & B & 60057 \\
\hline SL2 & ELOWOIININ & 1282 & $\mathrm{~F}$ & 2 & acc & E & Gecs7 \\
\hline SL2 & BLOWDOLIN & I $2 B 1$ & $\mathrm{~F}$ & 2 & Dec & $\mathrm{E}$ & 190057 \\
\hline SL2 & FRIM HZO SUPPLY & I2 PMAl & $F$ & 2 & ECO & $E$ & GDCSE \\
\hline SL2 & STATION AIR SUPPLY & $12 \sin 2$ & $x$ & 2 & cov & c & G0056 \\
\hline$L 2$ & INSTRU AIR SUIFELY & $\operatorname{I} 2 \operatorname{IA} 14$ & $x$ & 2 & Dec & E & B0056 \\
\hline L2 & HEC CONT PUIRGE & & $x$ & 48 & $\operatorname{coc}$ & $\mathrm{c}$ & G0050 \\
\hline $5 \mathrm{~L} 2$ & N2 SUPFLY & I IWMZ26 & $\mathrm{F}$ & 1 & 000 & $E$ & G005.5 \\
\hline SL2 & N2 SUPPLY & I 1WMBS1 & $\mathrm{F}$ & 1 & Doc & & GDCS6 \\
\hline SLZ & CCW RTN FAN COOLEP & I 85043 & $F$ & 8 & 000 & & G0LS7 \\
\hline L2 & ECW SUJFPLY COOLEF & 130039 & $\mathrm{~F}$ & 8 & & & \\
\hline L 2 & COW RETUFN COOLEF & Iscctt & $F$ & 3 & & & \\
\hline SL2 & ECW SUPPLY CODLER & $\operatorname{IBC}=40$ & $F$ & 8 & & & \\
\hline SL2 & COW RETURN BDOLER & $1900+1$ & $F$ & 3 & & & \\
\hline SL2 & COW SUFPLY COOLER & I 30037 & $\mathrm{~F}$ & 8 & & & \\
\hline SL2 & ECW RETIIFN COOLER & 150042 & $F$ & $\xi$ & & & \\
\hline SLZ & CCW SUPPLY COOLER & 160038 & $F$ & 3 & & & \\
\hline SL2 & HZO SUIFFLY FILP & $1 \operatorname{ecc} 138$ & $F$ & 8 & 000 & $E$ & G0056 \\
\hline SL2 & H2O RETURN RCP & 1300158 & $F$ & 8 & act & $c$ & BCES.6 \\
\hline SL2 & FUEL TFANNS TUEE & $I \leq c 01 \leqslant 8$ & 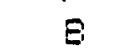 & 30 & & $\varepsilon$ & \\
\hline SL2 & LETDOWN LINE & $13 \mathrm{CH} 103$ & $F$ & 2 & $\triangle C E$ & c. & 60055 \\
\hline LL & CHAREITIG LINE & I $2 \mathrm{CH} 10 \%$ & $\mathrm{~F}$ & 2 & 000 & & 601655 \\
\hline SL2 & SAMPLING HOT LEG & $13 / 355635$ & $x$ & 3,8 & DEC & $\Xi$ & 60055 \\
\hline$S L 2$ & SAMPLING FFESS STM & 13,855633 & x & $3 / \theta$ & ace & $E$ & G0055 \\
\hline SL2 & BLOLUOOINN & $11 / 2 \mathrm{BB} 1$ & $F$ & 1,2 & & E & 60057 \\
\hline SL2 & CONT WENT HEADER & I $11, N M 2 Z 3$ & $\because$ & 2 & ouc & C & EDESS \\
\hline SL2 & CONT SUMP SUCTION & $124 \quad 084$ & $\mathrm{~F}$ & 24 & EEO & & GOC50 \\
\hline SL2 & CONT SIMP SULTION & 124085 & $\mathrm{~F}$ & 24 & cro & & 50056 \\
\hline SL2 & CONT SPRAY & 110 CS1 & $\mathrm{F}$ & 10 & 000 & & $G 0050$ \\
\hline SL2 & CONT SFRAY & $110 \quad \operatorname{cs} 13$ & $F$ & 10 & Eco & & EDES: \\
\hline SLZ & CONT SPRAY & I12 Cs18 & $F$ & 12 & cot & & 60056 \\
\hline SL2 & CONT SFRAY & 1120519 & $F$ & 12 & ED & & B0050 \\
\hline SL2 & SI LOOP $2 A 2$ & $15 S I 113$ & $\mathrm{~F}$ & 3 & 000 & & GOC55 \\
\hline SL2 & EI LQUF 2A1 & $I \angle S I 113$ & $\mathrm{~F}$ & $\leq$ & [a] & & 6005 \\
\hline SLZ & SI LOOP 2BI & $165 I 111$ & $\mathrm{~F}$ & 6 & 000 & & 60055 \\
\hline SL2 & SI LDOP ZEZ & $I 051110$ & $F$ & g & E00 & & BOES5 \\
\hline SLZ & SHTDWN CODLING & 11051362 & $F$ & 10 & COC & & GnCSE \\
\hline$S L Z$ & SI TANNK TEST & $1251+79$ & $\%$ & 2 & EES & $c$ & ELES5 \\
\hline SL2 & DONT SLMP PUMP OISCH & $13 C 503$ & $F$ & 3 & CEO & & GDLES \\
\hline SLZ & REAE OFAIN FUHA EUICT & I 引N10 & $\mathrm{F}$ & & gev & & GOEE: \\
\hline SL2 & FICP CONTRL BLEED DFF & $13 / 4 C H 1=9$ & $\mathrm{~F}$ & 3,4 & aE, & & GOESE \\
\hline 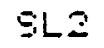 & REFUEL CAU PURIF IN & $I \subseteq 0552$ & $\Xi$ & 3 & ECE & $E$ & GOESO \\
\hline SL2 & REFIUEL CAU FUPIF DUT & I 30556 & $\bar{z}$ & 3 & ELE & E & G0050 \\
\hline$E L Z$ & HE EAMFLING & $13 / \operatorname{MS} 12$ & $x$ & $3 / 5$ & {$[1,0$} & $E$ & 60055 \\
\hline SL2 & BLOWDULNN & $11 / 2 \quad 882$ & $F$ & 12 & & $B$ & \\
\hline SLz & SFARE & & ৫ & & & & \\
\hline & H2 SAMFLING & $13 / 8 M S 14$ & $x$ & $\exists / 8$ & 1100 & $E$ & 60056 \\
\hline
\end{tabular}




\section{Standard Listing of St. Lucie 2 Penetrations for RACISP}

\begin{tabular}{|c|c|c|c|c|c|c|c|}
\hline RTP & SYSTEM & ID & TYFE & SILE & STAT & FPEQ & STANCARD \\
\hline ELZ & CONT, ANINUL FFESE DIF & & $x$ & & & $A$ & $8: G-11$ \\
\hline SL2 & INTTEG LEAK FATE TEST & & $x$ & & $\operatorname{cec}$ & ᄃ & Gors. \\
\hline $5 L 2$ & EONT, ANNHUL OIFF FFES & & Y & & & $A$ & $8 E-1.11$ \\
\hline SL2 & INTEG LEHHH FATE TEST & ISITE1 & $x$ & 3 & $\operatorname{coc}$ & c & GDESS \\
\hline SL2 & SFAFE & & $x$ & & & & \\
\hline SLZ & HES PURGE INLET & I 5043 & $x$ & $\Xi$ & 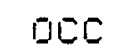 & & 60056 \\
\hline SL2 & H\&Y FUREE BUTLET & $1 \Xi 5,8$ & $x$ & 3 & UICL & & EOLD \\
\hline SL2 & SPAPE & & $x$ & & & & \\
\hline SL2 & HESU EONT PIIRGE & & $x$ & $4 \Xi$ & CuC & & G[C5: \\
\hline SL2 & SHIJODWN EOOLING & 11031363 & $F$ & 10 & $\operatorname{coc}$ & & 60055 \\
\hline SLI & HEU WACULIM FELIEF & & $x$ & 24 & $\operatorname{cov}$ & & GDC56 \\
\hline SL2 & HOT LEG 2A INJECTION & 1351179 & $F$ & 3 & $\operatorname{ccc}$ & & BDC55 \\
\hline$\Xi L Z$ & HOT LES ZE INJECTION & I $\leqq I 1 \Xi 1$ & $\mathbf{F}$ & 3 & CEL & & EOEES \\
\hline SLZ & SFARE & & $x$ & & & & \\
\hline SLZ & EFAFE & & 3 & & & & \\
\hline SL2 & ELELTFI L & & 0 & & 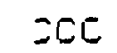 & $B$ & \\
\hline SLZ & CONETFHITIGN HATEH & & $E$ & ZEFT & EEE & $E$ & \\
\hline SL2 & INTERIGR PERS ACLESB & & A & $5 !$ & EUC & z & \\
\hline SL & ELECTFILAL & & 0 & & LEL & $\equiv$ & \\
\hline SL2 & EXTERIDP PERS ACZESE & & $\dot{A}$ & 51 & CUE & B & \\
\hline SLZ & EMEREENIER AIF AELESS & & $<$ & & {$[1,0$} & $\varepsilon$ & \\
\hline SLZ & LOCK TEST & & $x$ & & ECC & $B$ & \\
\hline SL 2 & ELECTFICAL & & 0 & & ECE & $\Xi$ & \\
\hline SL2 & ESCAFE LQCK (INT) & & $A$ & 59 & こ片 & $B$ & \\
\hline SL2 & ELECTFI ERIL & & 0 & & ECE & $\Xi$ & \\
\hline SLZ & ESLAPE LOLK ' EKT) & & A & & EUE & $E$ & \\
\hline$S L 2$ & ELECTRILAL & & 0 & & Ect & 8 & \\
\hline SL2 & TEST PENETRATI CNS & & $x$ & & $\operatorname{cco}$ & $\bar{E}$ & \\
\hline$S L Z$ & EMERG AIF FLANGE & & $x$ & & 0.15 & $E$ & \\
\hline SL2 & MAINTNEANIEE HATCH & & $\mathrm{G}$ & & CUE & e & \\
\hline
\end{tabular}


Standard Listing of St. Lucie 2 Valves for RACISP

\begin{tabular}{|c|c|c|c|c|c|c|c|c|}
\hline RTR & SYSTEM & ID & TYPE & $O P$ & SIIE & STAT & FREQ & STANDAF \\
\hline SLZ & MSI'J & IHEVOE1A & $F$ & 0 & 34 & $\operatorname{Dec}$ & $E$ & GDE5: \\
\hline 2 & MSIU & IMUOS1A & $E$ & $A M$ & 3 & $\operatorname{ccc}$ & ¿ & G0C5T \\
\hline$a$ & MSIU & IMUOS1E & E & $A M$ & 3 & CCC & C & G[C57 \\
\hline & MSIU & I HCVD $81 \mathrm{~B}$ & $F$ & D & 34 & $\triangle C C$ & $\mathrm{C}$ & GDC57 \\
\hline & AUK FEEDWATER & IMU079 & $F$ & $\hat{A M}$ & 4 & 000 & $E$ & G01557 \\
\hline & HUXX FEECWHTER & IMUOB12 & $E$ & $B M$ & 4 & 000 & E & GDC57 \\
\hline & STM GEN EL GINGIILN & IFCU233 & E & $D M$ & 2 & $\mathbb{Z I C L}$ & $E$ & 60557 \\
\hline & PRIM MAKELUP MATER & IHCU151 & $F$ & $D M$ & 2 & CEC & $C$ & GOC5O \\
\hline & FRIM MALEUIP I,NATER & $1 \cup 151347$ & E & 5 & 2 & & c & GOLSE \\
\hline & STATION AIR & IU18947 & $F$ & & 2 & EEv & c & GOCSIS \\
\hline & STATIGN AIR & $I \cup 1 S 747 F$ & $F$ & & 2 & & $E$ & GDC56 \\
\hline & INSTRIMMENT AIR & IHCU181 & $F$ & D & 2 & OCC & c & G0CSO \\
\hline & INSTFIIMENT AIF: & $1 \cup 1895 ?$ & $\varepsilon$ & & 2 & & E & G0L56 \\
\hline & CONT PUJPEE EX FAUST & IFCU256 & $B$ & $D M$ & 48 & ECC & $E$ & EDESS \\
\hline & EONT FUFGE E:'HAUST & IFC'V5 & $E$ & $O M$ & +8 & ELE & E & GOCES \\
\hline & CONT PUPGE EXHKUST & IFCU $\geq 54$ & $B$ & $O M$ & 48 & $\operatorname{ccc}$ & $\varepsilon$ & GoC5s \\
\hline & CONT FIIFIEE SUFFLY & IFQU251 & 8 & {$[M$} & $+E$ & EEE & $E$ & $5[15-5$ \\
\hline & CORIT PLIRGE SUPPLY & IFCU252 & 8 & $\mathrm{OM}$ & 48 & ECE & $E$ & GDESD \\
\hline & CINT PIJEGE GUFPLY & IFIU253 & 8 & $O M$ & 45 & CEL & C & GOCS: \\
\hline & NZ SUPFLY TO SI TANK & V6741 & $F$ & DM & 1 & DOE & $\varepsilon$ & SDCSE \\
\hline & NZ SUPPLY TO SI THNK & V0792 & C & 5 & 1 & & $\tau$ & GDE5.5 \\
\hline-2 & FAN CODL H2O RETUIRN & $1 M U 1410$ & 8 & $\hat{A M}$ & 3 & 000 & & BDE57 \\
\hline & FAN EODL HZO SIIPPLY & $\operatorname{IMU} 149$ & B & $A M$ & $\Xi$ & 000 & & BDES7 \\
\hline & RCP COOL HZO SIJPPLY & I HCU1 4 ? & B & $D M$ & $\Xi$ & DCE & E & $6005 \mathrm{~s}$ \\
\hline & REF EOOL HEO SUPPLY & IHCW' 41 & B & $D M$ & 8 & Bet & E & BOSE: \\
\hline & RCP COOL HZO PETUPN & I HCU1 to & 8 & CM & 8 & OEL & 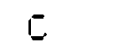 & 605.5.5 \\
\hline-2 & RCP EOUL H2O FETIIFN & IHEN142 & E & LM & $\theta$ & ace & $\Xi$ & $6[1556$ \\
\hline & CWCS LETDUWN $)$ & IV 2515 & $F$ & $D M$ & 2 & $D C C$ & C & GOESE \\
\hline & CUCS (LETDOWN) & 112522 & $F$ & OHA & 2 & OE: & 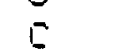 & G0LE5 \\
\hline & CUCS (CHARGING) & I'/24 $\leq 2$ & c & $S$ & 2 & & & 5.5 \\
\hline & CUCS (CHAFEING) & 142523 & $F$ & 0 & $\overline{2}$ & 000 & & GDCS5 \\
\hline & SI TANK SAMPLE & ISEOS1A & $\mathbf{F}$ & $D M$ & $3 ; 8$ & CEL & $E$ & G0155 \\
\hline & SI TANIK SAMPLE & ISEOSIE & $F$ & CM & $3 / 8$ & CE: & C & GOCES \\
\hline & RCS HOT LEG SAMPLE & 11,5200 & $F$ & CM & $3 / \Xi$ & $\mathrm{occ}$ & $E$ & 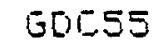 \\
\hline & RCS HOT LEG SAMFLE & Iบ520 & $F$ & OM & $3 / 8$ & $\operatorname{OCC}$ & $\Xi$ & $19005=$ \\
\hline 2 & PRESS SURGE GAMPLE & 115204 & $F$ & {$[M$} & $3 / 8$ & $\operatorname{coc}$ & $c$ & 55 \\
\hline & PRESS SUFGE E'RSTEM & IV 5201 & $F$ & {$[M$} & $3<8$ & ESC & $\Xi$ & ECESE \\
\hline & PRESS STM SAMFLE & 11,15205 & $F$ & CMI & $3 \cdot 6$ & BI: & E & BOES5 \\
\hline & FRESS STM SAMFLE & $19.520=$ & $F$ & DNA & $3 / 8$ & are & $E$ & E[1ESE \\
\hline & STM GEN BLEN SAMPLE & IFCU:37 & $F$ & CM & $1 \%$ & DEt & $E$ & G0E5: \\
\hline & CONT VENT HEAOER & $140-13$ & [] & {$[p+1$} & 1 & 000 & $E$ & GLILSS \\
\hline & EONT VENT HEAOER & 110650 & 0 & $U M$ & $!$ & acic & 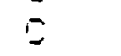 & GUC5: \\
\hline & CONT SUMP SULTIONI & IM1⿴囗十丁-口 & $E$ & Al1 & 24 & 100 & & BOCSE \\
\hline & EDNT SPFIAY & IFCNOTIA & $\Xi$ & $O M$ & $: 0$ & ELO & $\overline{-}$ & BOCE \\
\hline & ECNIT EFFAY & 110.71553 & $E$ & $\vdots$ & $: 0$ & & & g[1ES0 \\
\hline & SAFETY INJECTIIN & IHCW & $F$ & & $=$ & 000 & & GCES5 \\
\hline 2 & SHFETY INJECTIIN & I HLUラڤ25 & $F$ & & $=$ & 600 & & $6[1555$ \\
\hline 2 & SAFETY IN.JECTION & I HCU.3635 & $F$ & & $=$ & 500 & & BLCES \\
\hline & EAFETY INIEETION & IHCUES45 & $F$ & & $=$ & 500 & & 60155 \\
\hline & SAFETY IN.JECTION & IHCV 5010 & $\mathrm{~F}$ & & 5 & DOD & & EDTSE \\
\hline
\end{tabular}


Standard Listing of St. Lucie 2 Valves for RACISP

\begin{tabular}{|c|c|c|c|c|c|c|c|c|}
\hline RTR & SYSTEM & 10 & TYPE & OP & SIZE & STAT & FREQ & STANOARO \\
\hline SL2 & EAFETY IMUELTION & I HCUSEZ & $F$ & & 0 & EDOC & & 60055 \\
\hline SL2 & SAFETY INJECTIUN & IHCV3636 & $F$ & & b & $c 00$ & & GDCSS \\
\hline$S L 2$ & EAFETY INIEETION & IHCU3646 & $F$ & & 0 & $\mathrm{COO}$ & & GOCS5 \\
\hline SL2 & EAFETY INJELTION & IHCUSE1? & $F$ & & s & 000 & & GDC55 \\
\hline SL2 & EAFETY IN.JECTION & I HCl.3027 & $F$ & & s & E[10 & & GDE55 \\
\hline SL2 & EAFETY INJEDTI IN & I HEU3637 & $F$ & & 6 & $\mathrm{COO}$ & & GDCS5 \\
\hline SL2 & EAFETY INUECTIDN & IHCUE 547 & $F$ & & $s$ & E[I] & & 500.55 \\
\hline SL2 & SAFET' INJEETI IN & 143258 & $c$ & & 6 & & & G0C55 \\
\hline SL2 & EAFET， IMUIECTI UN & IU325. & C & & 6 & & & GOCS5 \\
\hline SL2 & EAFETY IN.JEETIDN & IV3250 & C & & 0 & & & GDC55 \\
\hline SLZ & EAFETY IN.IECTICH & {$[1,3261$} & C & & 6 & & & G0C55 \\
\hline LL2 & SHUTODUN CODLING & 113005 & $E$ & & 10 & $\mathrm{COC}$ & & GDC5S \\
\hline SL2 & SHLITOEWN COOLING & $1 \sqrt{1} 6551$ & $\bar{E}$ & & 10 & cor & & GDC55 \\
\hline SL2 & SIT TEST LINE & ISE032A & $F$ & $F M$ & 2 & ECE & $E$ & GDCE5 \\
\hline SL2 & EIT TEST LINE & 11,3463 & E & & 2 & CEL & $E$ & 60055 \\
\hline SLZ & REHUITY SUMP DISCHAR & ILCUDフ11A & $F$ & CM & 3 & ELC & $E$ & G0C56 \\
\hline GL2 & FEAUTY SUMF OISCHAF & ILENUT11E & $F$ & {$[M$} & $\Xi$ & EEC & E & 60050 \\
\hline SL2 & REDT PIJMF SUETIDHI & IU6341 & 0 & $\mathrm{OM}$ & 3 & $\triangle C^{1}$ & $E$ & GDE56 \\
\hline SL2 & FCOT FIMAF SUCTIEN & 106342 & 0 & $O M$ & 3 & orv & $E$ & GDC56 \\
\hline SL2 & RCF ETFL BLEEDDFF & I 62524 & $F$ & $D M$ & 3,4 & Øட゙ல & $E$ & G0C55 \\
\hline SL2 & RLP ETFL ELEEEUGF & $1 \cup 2505$ & $F$ & DM & $3 / 4$ & GLU & C & 60L55 \\
\hline SLZ & FLUID INIST LINE & EXEES FLOUN & $E$ & $s$ & 3,5 & & & $R G-11$ \\
\hline SLZ & FUEL FDOL ELEANHIJF-I & $1107(1 \leq 07)$ & $E$ & $M$ & 3 & $\operatorname{ccc}$ & $E$ & GLILES \\
\hline SL2 & FUEL FOCL CLESNNIIP-I & IUD? $1 \leq 00)$ & $\bar{E}$ & $M$ & 3 & CEE & $\tau$ & GOES: \\
\hline SL2 & FUEL FOOL ELEANUF-D & IUด7:1=00 & $E$ & $M$ & 3 & SEL & $E$ & GECEO \\
\hline SL2 & FUEL PDOL CLEANIIP-E & $1107(1600)$ & $E$ & $M$ & 3 & $\cos$ & $\mathrm{C}$ & G0056 \\
\hline SLZ & HZ EMMPLE LINES EILIT & IFSEZTS & $F$ & $E M$ & $3: 3$ & EUE & $\Xi$ & G0105.5 \\
\hline SL2 & Hב SAMPLE LINES DIUT & IFSE2715 & E & $E M$ & $3 / 8$ & CUC & $E$ & BLICS.S \\
\hline SL2 & FLUID INST LINE & EXEES FLOW & $c$ & $\Xi$ & $3 / 8$ & CEU & & $F E-! 1$ \\
\hline SL2 & H2 SAMPLE LINES-I & $I V 27(1342)$ & c & & 3,3 & UEV & $E$ & G0C5: \\
\hline SL2 & H2 SAMFLE LINES-I & IFSE:P10 & $\Xi$ & $E+1$ & $3 / 3$ & EEE & $E$ & 60056 \\
\hline SL2 & CONT PFESSURE & ISEOPSE & $\vec{F}$ & $O M$ & $3 / 3$ & 000 & & $R G-11$ \\
\hline SL2 & CENT RAD MONITORING & IFCUZ\& 1 & $F$ & $C M$ & 1 & QICE & c & BDESG \\
\hline SL2 & CONT RAD MINITORIMIG & IFCU2S2 & $F$ & DNT & 1 & $\operatorname{DCC}$ & $c$ & 6005 \\
\hline SL2 & CONT RAD MONIITERING & IFCI263 & $F$ & [M-1 & 1 & UEL & $E$ & BDES: \\
\hline SL2 & CONT RAD MDNITORIMG & IFCU204 & $F$ & $O M$ & 1 & DCE & $E$ & QELE: \\
\hline SL2 & EONT FAD MONITOFIMIE & IFCU2SE & $F$ & $D M$ & 1 & OCC & $E$ & 50I5 \\
\hline SL2 & ECNT RAD MONITEFINB & IFCU 250 & $F$ & {$[11$} & 1 & DEE & $E$ & EE5 \\
\hline Eᄂこ & ILRT & $1400(1=25)$ & $F$ & $M$ & 1 & ECL & $E$ & $G[5=$ \\
\hline SL2 & ILFT & {$[1000(1325)$} & $F$ & $M$ & 1 & cos & $E$ & GOES: \\
\hline$S L Z$ & ILET & I $100(1322)$ & $F$ & $M$ & 39 & EEE & $E$ & $B D E 50$ \\
\hline SLZ & I LRT & I $100(1 \geqslant 22)$ & $F$ & $M$ & $3: 3$ & QEE & $E$ & $65=5$ \\
\hline$E L=$ & ILRT & 1000012 & $E$ & $i$ & $\xi$ & CEL & $\bar{L}$ & 351150 \\
\hline SLZ & EONT PRESS INST & $I \Xi E O>S A$ & $F$ & $F M$ & 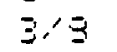 & 000 & & $F G-1.11$ \\
\hline & H2 PUFEE MAKELIP-I & IFEUニSこら & $\Xi$ & 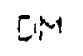 & $\xi$ & DE & C & $B[E 50$ \\
\hline SLZ & HZ PURGE MAKEUP-I & 11,2525 & $=$ & $\Xi$ & $\Xi$ & OCD & E & GOCE \\
\hline & HZ FUREE MAKEUF-ES & IFEU $=5=0$ & $\varepsilon$ & 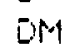 & $\xi$ & GCE & $E$ & GDESS \\
\hline & HZ PUFGE MIREEUF-EX & IFCUลSZ: & $E$ & [M & $\beta$ & OCE & 5 & BOESD \\
\hline SLS & EDNT PFESS INST & IEEOTEE & $=$ & Fi1 & 2.9 & 000 & & $F E-1.11$ \\
\hline$S L 2$ & CONT VAC PELIEF & I1) 2520 & C & $\Xi$ & 24 & EEC & $E$ & GOCE \\
\hline
\end{tabular}


Standard Listing of St. Lucie 2 Valves for RACISP

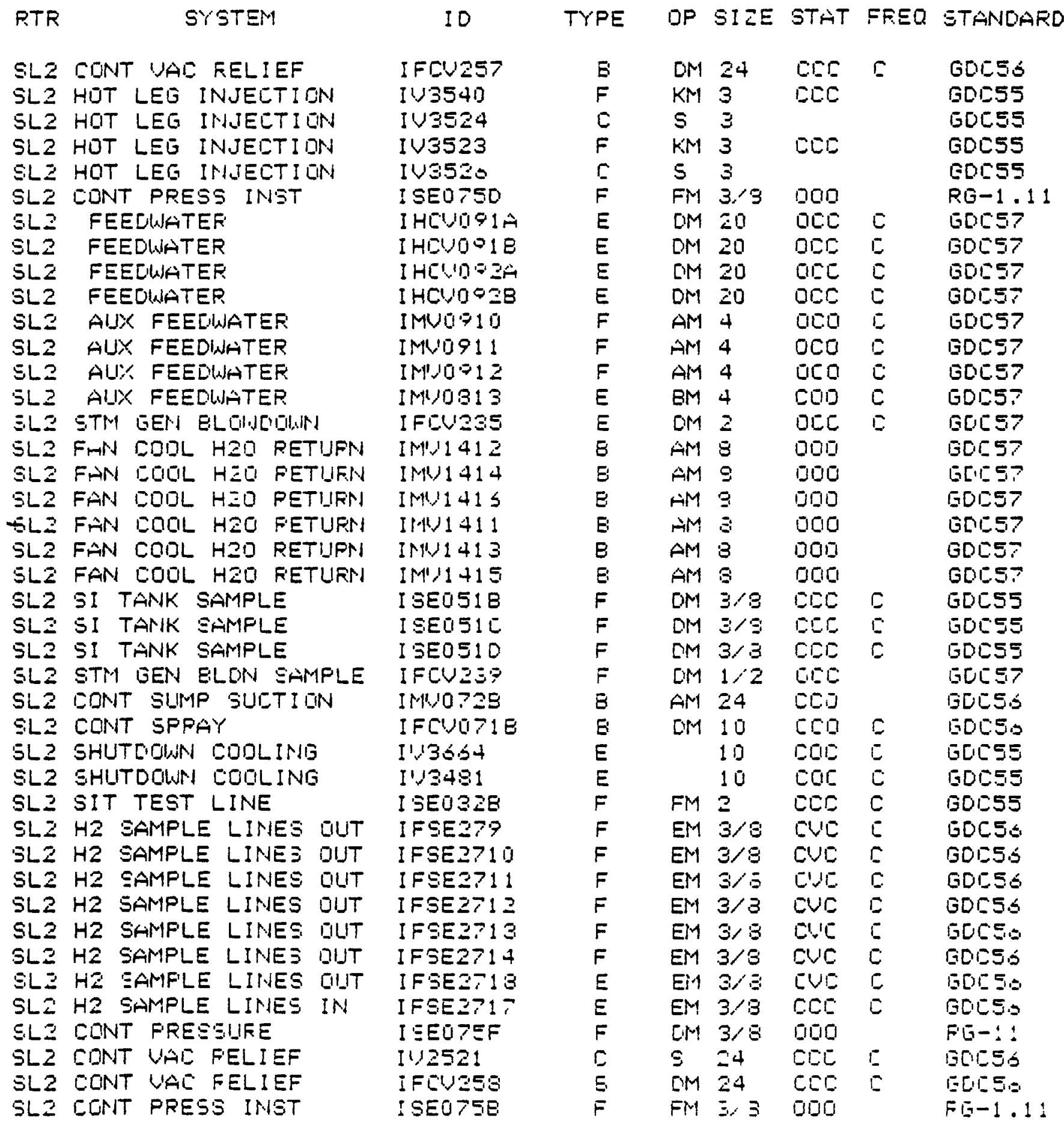


No. of

Copies

OFFSITE

U.S. Nuclear Regulatory Commission

Division of Technical Information and Document Control

7920 Norfolk Avenue

Bethesda, MD 20014

25 Y. Huang

Division of System Interaction

Office of Nuclear Reactor Regulation

U.S. Nuclear Regulatory Commission

7920 Norfolk Avenue

Bethesda, MD 20014

T. Bridges

Idaho National Engineering Laboratory

EG\&G Idaho, Inc.

P.0. Box 1625

Idaho Falls, ID 83415

A. S. Benjamin

Sandia National Laboratory

P.0. Box 5800

Aibuquerque, NM 87185

C. V. Subramanian

Sandia National Laboratory

P.0. Box 5800

Albuquerque, NM 87185
No. of

Copies

M. B. Weinstein

American Nuclear Insurers

The Exchange, Suite 245

270 Farmington Avenue

Farmington, CT 06032

R. H. Gallucci

C $-E$ Power Systems

Combustion Engineering, Inc.

1000 Prospect Hill Road

P.0. Box 500

Windsor, CT 06095

40 ONSITE

V. R. Ames

S. H. Bian

C. A. Counts

M. R. Garnich

C. H. Henager

J. C. Lavender

M. A. Mclean

P. J. Pelto

R. E. Rhoads

R. J. Shippell

M. T. Smith

Publishing Coordination (2)

Technical Information (5) 


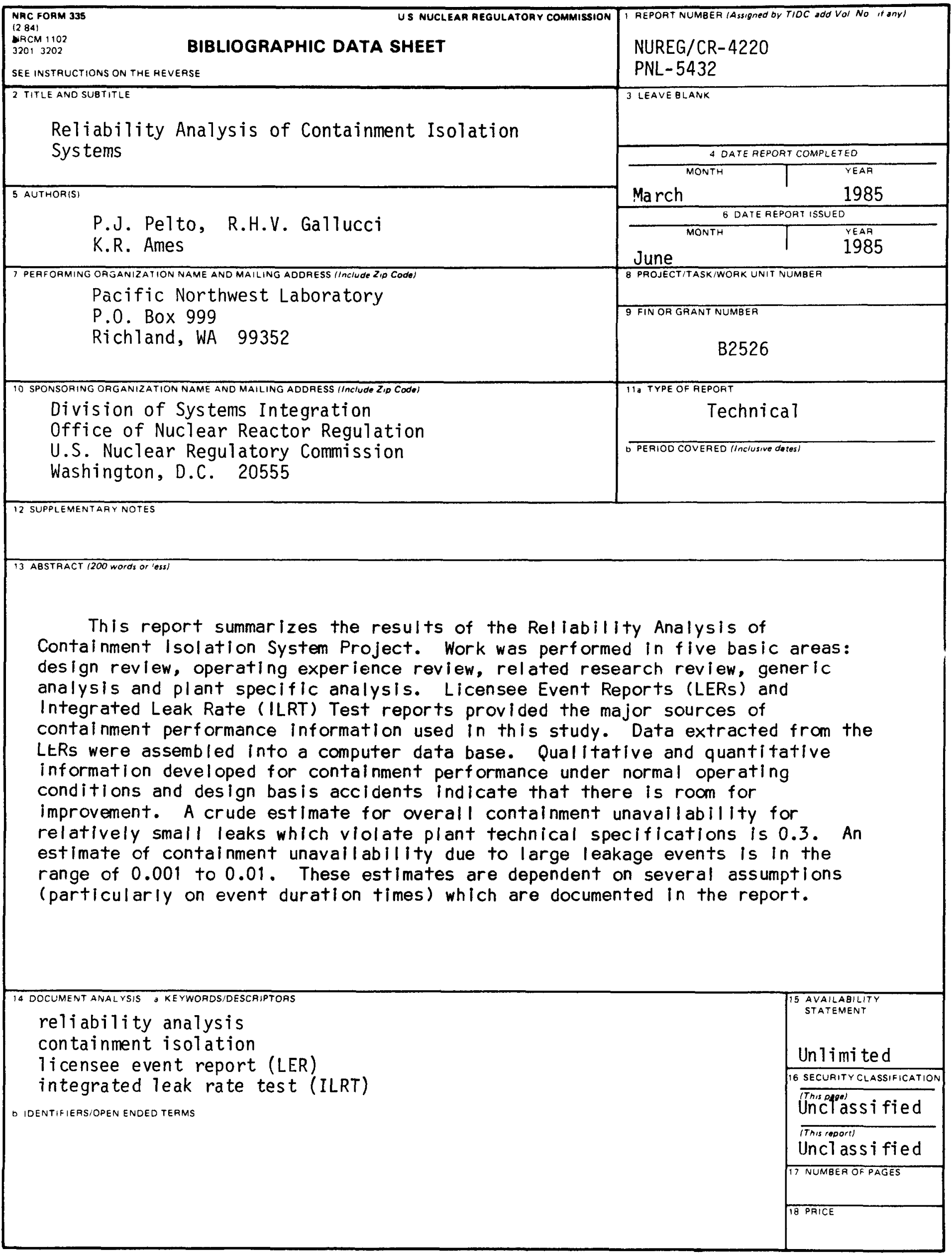

